\title{
Severity of disease in critically ill patients: Inflammatory parameters and clinical condition
}

Citation for published version (APA):

Froon, A. H. (1999). Severity of disease in critically ill patients: Inflammatory parameters and clinical condition. [Doctoral Thesis, Maastricht University]. Universitaire Pers Maastricht. https://doi.org/10.26481/dis.19990910af

Document status and date:

Published: 01/01/1999

DOI:

10.26481/dis.19990910af

Document Version:

Publisher's PDF, also known as Version of record

\section{Please check the document version of this publication:}

- A submitted manuscript is the version of the article upon submission and before peer-review. There can be important differences between the submitted version and the official published version of record.

People interested in the research are advised to contact the author for the final version of the publication, or visit the DOI to the publisher's website.

- The final author version and the galley proof are versions of the publication after peer review.

- The final published version features the final layout of the paper including the volume, issue and page numbers.

Link to publication

\footnotetext{
General rights rights.

- You may freely distribute the URL identifying the publication in the public portal. please follow below link for the End User Agreement:

www.umlib.nl/taverne-license

Take down policy

If you believe that this document breaches copyright please contact us at:

repository@maastrichtuniversity.nl

providing details and we will investigate your claim.
}

Copyright and moral rights for the publications made accessible in the public portal are retained by the authors and/or other copyright owners and it is a condition of accessing publications that users recognise and abide by the legal requirements associated with these

- Users may download and print one copy of any publication from the public portal for the purpose of private study or research.

- You may not further distribute the material or use it for any profit-making activity or commercial gain

If the publication is distributed under the terms of Article $25 \mathrm{fa}$ of the Dutch Copyright Act, indicated by the "Taverne" license above, 
Severity of disease in critically ill patients: inflammatory parameters and clinical condition 
(C) A.H.M. Froon, Maastricht 1999

Druk: Datawyse/ Universitaire Pers Maastricht 


\title{
Severity of disease in critically ill patients: inflammatory parameters and clinical condition
}

\author{
Proefschrift
}

ter verkrijging van de graad van doctor aan de Universiteit Maastricht, op gezag van de Rector Magnificus, Prof.dr. A.C. Nieuwenhuijzen Kruseman, volgens het besluit van het College van Decanen, in het openbaar te verdedigen op vrijdag 10 september 1999 om 14.00 uur

door

Albertus Hermanus Maria Froon geboren te Utrecht, 12 februari 1963 


\section{Promotores}

Prof.dr. P.B. Soeters

Dr. C.J. van der Linden

\section{Co-promotores}

Dr. W.A. Buurman

Dr. J.W.M. Greve

Beoordelingscommissie

Prof.dr. H.F.P. Hillen (voorzitter)

Prof.dr. H.J. ten Duis (Rijksuniversiteit Groningen)

Dr. S. van der Geest

Prof.dr. L.G. Thijs (Universiteit van Amsterdam)

Prof.dr. E.F.M. Wouters 
aan mijn moeder in herinnering aan mijn vader 


$\begin{array}{ll}\text { ABBREVIATIONS } \\ \text { BPI } & \begin{array}{l}\text { bactericidal/ permeability-increasing protein } \\ \text { cluster of differentiation }\end{array} \\ \text { CD } & \begin{array}{l}\text { enzyme linked immunosorbent assay } \\ \text { ELISA }\end{array} \\ \text { HDL } & \text { high density lipoprotein } \\ \text { ICAM } & \text { intercellular adhesion molecule } \\ \text { IL } & \text { interleukin } \\ \text { kD } & \text { kilodalton } \\ \text { LBP } & \text { LPS binding protein } \\ \text { LPS } & \text { lipopolysaccharide } \\ \text { mAb } & \text { monoclonal antibody } \\ \text { PAF } & \text { platelet-activating factor } \\ \text { PMN } & \text { polymorphonuclear leukocytes } \\ \text { R } & \text { receptor } \\ \text { r } & \text { recombinant } \\ \text { S } & \text { soluble } \\ \text { TNF } & \text { tumor necrosis factor }\end{array}$




\section{CONTENTS}

chapter 1

General Introduction

1. Inflammatory response and definitions

2. Inflammation and intensive care medicine 10

3. Severity of disease: scoring systems 11

3.1 the Acute Physiology and Chronic Health Evaluation 11

3.2 the Grading of Sepsis score $\quad 12$

4. Severity of disease: mediators of inflammation 13

$\begin{array}{lll}4.1 & \text { Lipopolysaccharides } & 15\end{array}$

4.2 Bactericidal/ permeability-increasing protein $\quad 16$

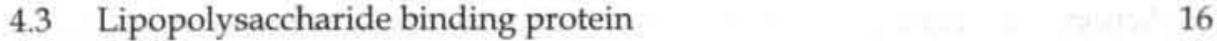

$\begin{array}{lll}4.4 \mathrm{CD} 14 & 17\end{array}$

$\begin{array}{lll}4.5 & \text { Tumor necrosis factor } & 18\end{array}$

$\begin{array}{lll}4.6 & \text { Soluble TNF receptors } & 20\end{array}$

$\begin{array}{lll}4.7 & \text { Interleukin-6 } & 21\end{array}$

4.8 Interleukin-8 22

4.9 Adhesion molecules $\quad 23$

4.9.1 E-selectin 24

4.9.2 Intercellular adhesion molecule 25

4.10 Platelet-activating factor 26

5. Introduction to and discussion of the studies 28

5.1 Registration of ICU patients 28

$\begin{array}{ll}5.2 \text { The studies } & 29\end{array}$

6. References 35

chapter $2 \quad 53$

The ICU patient population

chapter 3

Increased plasma levels of soluble tumor necrosis factor receptors in sepsis syndrome: correlation with plasma creatinine

chapter 4

Increased concentrations of cytokines and adhesion molecules in patients after repair of abdominal aortic aneurysm

chapter 5

LPS toxicity regulating proteins in bacteremia 
Treatment with the platelet-activating factor antagonist TCV-309 in patients with severe systemic inflammatory response syndrome. A prospective, multicenter, double-blind, randomized phase II trial

chapter 7

The systemic inflammatory response in the development of ventilatorassociated pneumonia

chapter 8

Prediction of clinical severity and outcome of ventilator-associated pneumonia. Comparison of simplified acute physiology score with systemic inflammatory mediators

Summary

Samenvatting

Appendix

Nawoord

Curriculum vitae 
CHAPTER 1

GENERAL INTRODUCTION 


\section{INFLAMMATORY RESPONSE AND DEFINITIONS}

Infection, tissue injury and ischemia can initiate a wide range of physiological changes that are executed by the host to survive these events. This process is known as inflammation. It is initiated at the site of infection or trauma in an effort to prevent ongoing tissue damage, isolate and destroy infectious agents and activate the repair processes that are necessary to return to normal function. Inflammation includes the release of mediators that mobilize responses of all major systems of the body (1).

The clinical presentation of an inflammatory response ranges from relatively benign to a severe and devastating illness characterized by failure of multiple organ systems. Many definitions were proposed to describe the variety in clinical presentation of inflammation. Initially, the inflammatory response accompanying bacteremia was defined as sepsis. Later, it was recognized that noninfectious diseases such as trauma, pancreatitis or large burns, can cause similar inflammatory responses (2-9). These observations resulted in new definitions proposed by The American College of Chest Physicians/ Society of Critical Care Medicine, as there are: systemic inflammatory response syndrome (SIRS), sepsis, severe sepsis, septic shock, and multiple organ dysfunction syndrome (MODS) (10) (for definitions see Appendix). Although several pathways in the pathophysiology of MODS are revealed, it remains unclear why SIRS sometimes deteriorates resulting in organ and tissue damage leading to MODS. The development of MODS in patients with SIRS is associated with additional mortality, and mortality increases with the number of organs failing. Single organ failure is responsible for $16-40 \%$ mortality whereas 4 or more failing organs are associated with $88-100 \%$ mortality $(2,6,11-13)$. In surgical ICUs the incidence of MODS varies between $8-42 \%$ and is responsible for a mortality rate up to $80 \%$ in all surgical ICU patients $(12,14-16)$.

\section{INFLAMMATION AND INTENSIVE CARE MEDICINE}

In the past decades medicine has undergone dramatic changes. The introduction of antibiotics and improvement of their antibacterial activity, was an important step in the battle against sepsis. In addition, close observation of patients is increasingly complemented by complex interventions. When SIRS is complicated by organ dysfunction, organ function can be (temporarily) supported (respiratory failure) or artificially replaced (renal failure). Subsequently, modern medicine results in an increase in complexity of illness as well as in an increasing number of severely ill patients kept longer alive.

This kind of patients often requires a multi-disciplinary treatment, and much of this care is concentrated on Intensive Care Units (ICUs). Costs and benefits are a topic of increasing importance. Intensive care medicine is a major consumer of hospital budgets, and the demand for care often exceeds available resources. The explosive 
growth in the quantity and quality of life support measures, coupled with the need to utilize available resources more efficiently, urges for the identification of patients who really benefit from ICU admission. The benefit of intensive care medicine, usually expressed in terms of survival, seems unpredictable in individual cases, although mortality rates are associated with the diagnosis on admission ranging from $1 \%$ to $66 \%$ (17). A major topic in this is to differentiate between patients who are likely to survive as a result of intensive care and those who will not survive despite this care. However, at present it is not possible to reliably predict which patient with SIRS will develop MODS and die subsequently.

\section{SEVERITY OF DISEASE: SCORING SYSTEMS}

Scoring systems, developed to measure severity of disease, are widely used to plan therapeutic strategies, to assess their efficacy and to predict the risk of fatal outcome. For example, the TNM (tumor, node, metastasis) classification for solid tumors is commonly used to plan appropriate therapy, as well as to provide an estimation of response to therapy and chance of survival. The same objective was the basis for the development of scoring systems in critically ill patients. Over the past 15 years, several scoring systems have been developed to measure severity of illness and to predict hospital death. Besides scoring systems, plasma levels of endotoxin and inflammatory mediators are reported to reflect severity of disease. The presence of systemic inflammation, resulting in derangement of whole body physiology, is accompanied by changes in plasma levels of inflammatory mediators. For some mediators these changes are associated with fatal outcome. However, measuring severity of disease and predicting mortality, either by scoring systems or plasma parameters, is generally considered suitable for patient populations but not for decision making in the care of the individual critically ill patient.

The scoring systems have evolved from simple identification of risk categories (shock vs. non-shock, gram-positive vs. gram-negative, bacteremic vs. non-bacteremic) to the development of relatively complex scoring systems such as the 'Acute Physiology and Chronic Health Evaluation' (APACHE) (17-19). Currently, scoring systems are predominantly used to stratify patient populations to evaluate therapeutic strategies.

\subsection{Acute Physiology and Chronic Health Evaluation (APACHE)}

The APACHE II severity of disease classification was presented by Knaus et al. in 1985, as a simplification of the APACHE I score $(17,18)$. The basis for the development of the APACHE score was the hypothesis that the severity of acute disease can be measured by quantifying the degree of abnormality of multiple physiologic variables. APACHE 
II was based on a nationwide study including 5815 ICU admissions. This study proposed APACHE II as a tool to stratify a wide variety of ICU patients and to compare ICU populations with respect to efficacy of therapeutic strategies and mortality rates.

The APACHE II score consists of the Acute Physiology Score (APS), the Chronic Health Evaluation, and Age Points (Table see Appendix). The APS includes 12 physiologic variables calculated during the first 24 hours of ICU admission. The most deranged values observed in this period are used for calculation of the APS. A weight ranging from $0-4$ is assigned to each variable. The Glasgow Coma Score (GCS) contributes to the APS by subtracting 15 minus actual GCS. A history of severe organ system insufficiency or a compromised immune system is known to significantly reduce the probability to survive acute illness. Therefore, the Chronic Health Evaluation is incorporated in APACHE II. Nonoperative and emergency surgery admissions have a substantially higher risk for death from their prior organ system insufficiency than elective surgical admissions. Therefore, the chronic health points assigned, depend on operative state. Age reflects diminished physiologic reserve, and is therefore incorporated into APACHE II. Age is divided into five categories with matching Age Points. The sum of the APS, Age Points, and Chronic Health Points forms the APACHE II score. Mortality is associated with the one principal reason for ICU admission. In order to predict death rates, a patient has to be assigned to a specific diagnostic category. A regression equation was developed to compute predicted death rates using APACHE II score, surgical state, and diagnostic category weight.

APACHE II was used in numerous studies and found, although not consistently, to be useful in predicting mortality (20-25).

\subsection{The Grading of Sepsis score}

After the introduction of APACHE I, Elebute and Stoner proposed the Grading of Sepsis score as a less complicated system to assess severity of sepsis (26). The authors developed the score driven by the statement that measuring severity of sepsis is a prerequisite for studying septic patients in detail and to interpret studies on this subject. Clinical features of the septic state were scored under four headings: local effects of infection, pyrexia, secondary effects of sepsis and laboratory data (Table see Appendix). The score considers data that are usually readily available. To each variable a weight ranging from 0-6 is assigned, and the total provides a number which indicates the severity of sepsis and which varies with patient's clinical condition in time. The score was developed using data obtained in 15 patients. Five out of 15 patients had a score exceeding 20 with a mortality rate of $80 \%$, whereas 10 patients had a score of less than 20 with a mortality rate of $10 \%$.

The authors recommended a validation of these data in a larger group of patients. In the years following its publication, the Grading of Sepsis score was validated in 
several studies considering patients with a variety of infections $(27,28)$. However, the Grading of Sepsis score has its limitations. The score failed to predict mortality in a study on intravenous administration of IgG in patients with scores of 20 or more (29). Similarly, the Grading of Sepsis score failed to predict mortality in septic shock patients (24). The failure to predict mortality in these studies may be explained by the inclusion criteria used. Extremely ill patients were included with sepsis scores exceeding 20. Elebute and Stoner observed $80 \%$ mortality in such patient categories. The predictive value of score systems may be lost when only subgroups with extreme scores are considered.

In an attempt to improve the accuracy of mortality prediction, modifications of the Sepsis Score were proposed. These modifications included data on plasma levels of acute-phase proteins. The modification improved predictive value up to $87 \%-100 \%$ (27, 28). The Grading of Sepsis score has only been validated for patients with sepsis, whereas APACHE II is considered suitable to predict mortality in a wide variety of diseases.

\section{SEVERITY OF DISEASE: MEDIATORS OF INFLAMMATION}

Activation of mononuclear phagocytes (including monocytes, Kupffer cells, and peritoneal, pulmonary and other macrophages), one of the earliest cellular responses, is considered to play a central role in inflammation. Probably one of the most investigated pathways of mononuclear phagocyte activation is the pathway induced by endotoxin (lipopolysaccharide=LPS). Endotoxins (Fig. 1), cell wall components of gram-negative bacteria, are capable to initiate a severe inflammatory response known as gram-negative septic shock. LPS can stimulate mononuclear phagocytes (30) by binding to a LPS-receptor called CD14 (31). The interaction between LPS with the LPSreceptor is modulated by an acute phase protein named LPS binding protein (LBP) and the neutrophil product bactericidal/ permeability-increasing protein (BPI). LBP enhances LPS induced mononuclear phagocyte activation, whereas BPI does the opposite (32).

Mononuclear phagocyte activation is associated with the release of a variety of inflammatory mediators including cytokines (33-37), arachidonic acid metabolites (38, 39 ), lysosomal enzymes (40), and oxygen free radicals (40-42). Cytokines are polypeptide cell regulators produced by cells of the immune system as well as by a number of other cell types. The cytokines released by activated mononuclear phagocytes unfold their widespread activity by binding to cell-bound receptors. Some cytokine receptors are, beside cell-bound, also present in plasma in a soluble form (i.e. soluble (s) TNF receptors). These soluble receptors function, at least in part, opposite to the same but membrane-bound receptors. For example, binding of TNF to sTNF-R prevents TNF from binding and activating cell-bound TNF-R at the same time (43). 


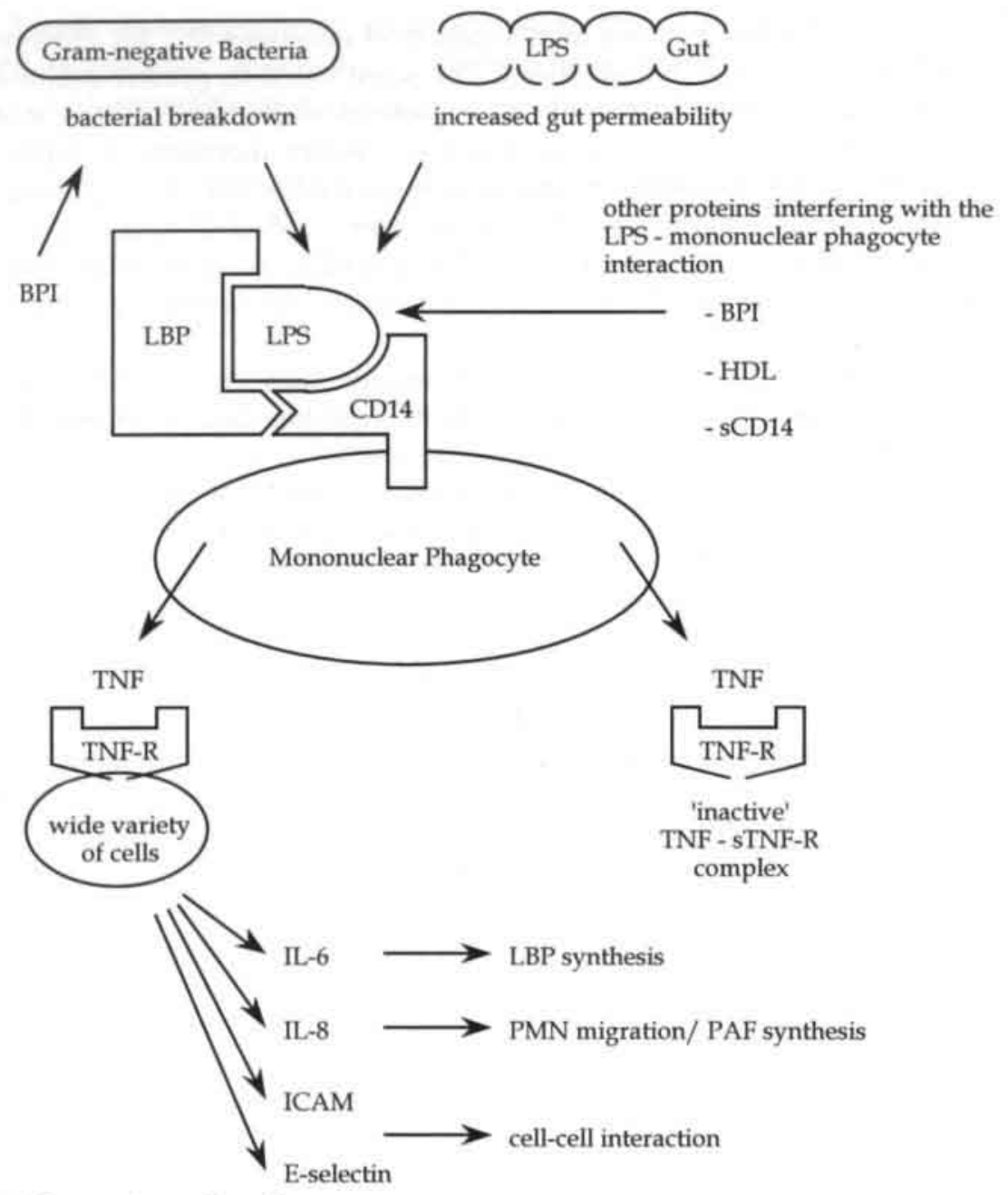

Figure 1: Inflammation and mediators

Besides mononuclear phagocytes, neutrophils are a key element in inflammation. Their role has been extensively described in infectious diseases (sepsis syndrome) as well as in ischemia/ reperfusion injury (for reviews see $(42,44)$ ). Activated neutrophils adhere to and migrate across the endothelium. Both, neutrophils and endothelial cells play an active role in this process. Adhesion molecules expressed on endothelial cells facilitate the adhesion of leukocytes. In addition, endothelial cells mediate neutrophil infiltration by the release of arachidonic acid metabolites, nitric oxide, endothelin, platelet-activating factor, complement, and cytokines (44-46). During migration of 
leukocytes through the endothelial layer they cause local destruction by releasing free radicals, proteolytic enzymes (collagenase, elastase, cathepsin G), and peroxidases (44, 47). Sequestration of activated neutrophils may also occur in organs which were not primarily affected. This process is considered to be an important factor in the development of multiple organ dysfunction $(42,48)$.

A cascade of inflammatory mediators implicates an extensive mechanism. To give a clear overview, some limitations have to be made. In this thesis, mediators are studied that are considered to play a major role in the pathophysiology of multiple organ dysfunction syndrome. Their involvement has been demonstrated in numerous intervention studies. These mediators are discussed, wherever possible, chronologically following the exposure to probably one of the most important initiators of MODS i.e. LPS.

\subsection{Lipopolysaccharides (LPS)}

Endotoxin has been described since the mid-19th century, and since the 1920s endotoxin has been the subject of intensive investigation. Endotoxins are lipopolysaccharide (LPS) constituents of the outer membrane of gram-negative bacteria. The LPS molecule consists of three regions. The outermost $\mathrm{O}$-antigen polysaccharide region is unique to each particular strain of gram-negative bacteria. The core polysaccharide region is similar among many strains of gram-negative bacteria. This core region couples the $\mathrm{O}$-antigen polysaccharide to the highly conserved lipid $\mathrm{A}$ region. The biological structures of lipid A from different gram-negative microorganisms are similar. lipid A represents that portion of the LPS molecule that is responsible for many if not all of the pathophysiologic sequelae observed in gramnegative sepsis (49). At the moment endotoxins are considered to be one of the principal initiators of the systemic inflammatory response syndrome (SIRS).

LPS activates mononuclear phagocytes to produce inflammatory mediators, such as tumor necrosis factor (TNF) (50), and interleukin-1 (51), which are responsible for many of the clinical features of endotoxemia $(52,53)$. In addition, endotoxins have been implicated as a causal factor in complement activation $(54,55)$, activation of the coagulation system $(56,57)$, and generation of vasoactive kinins.

During gram-negative bacterial breakdown LPS is released and may enter the circulation resulting in endotoxemia (58). LPS is believed to be the initiator of the clinical manifestations of gram-negative sepsis (59-61). Interestingly, endotoxemia was also reported in critically ill patients without a gram-negative infection $(62,63)$. In these patients, endotoxin is probably absorbed from the gut as a result of failure of the gut mucosal barrier (64-66).

The immune system has a high sensitivity for LPS, and local infections are usually adequately resolved. In the response to LPS many proteins are involved such as CD14, LBP, BPI, high-density lipoproteins (HDL) $(67,68)$, and specific antibodies directed 
against LPS. The interaction of LPS with lipoproteins, mediated by LPS binding protein, results in reduced bioactivity of LPS $(67,68)$, and an enhanced LPS clearance (69-71).

The antibodies produced upon LPS exposure are directed against the O-antigen and are therefore strain specific (72). Much effort was invested to develop and to isolate proteins that bind and inactivate LPS $(60,61,73-76)$. These anti-LPS proteins have been proven to be beneficial in animals, but predominantly by pre-treatment i.e. before the 'septic insult'. In humans, the treatment of gram-negative sepsis with antiendotoxins is still controversial $(60,74)$.

\subsection{Bactericidal/ permeability-increasing protein (BPI)}

Bactericidal/ permeability-increasing protein, is considered to play an important role in regulating LPS effects during endotoxemia (75-79). BPI is a $55 \mathrm{kD}$ cationic protein stored in azurophilic granules (80), and expressed on the cell surface of polymorphonuclear leukocytes (PMN) $(81,82)$. The cytotoxicity of BPI is specifically directed against gram-negative bacteria (83). Binding of BPI to LPS in the cell wall of gram-negative bacteria induces membrane alterations and finally bacterial death by increasing membrane permeability (84).

Besides being bactericidal, BPI was demonstrated to inhibit LPS-induced phagocyte activation $(81,85-90)$. This may explain why exogenous BPI was found to be protective against metabolic alterations, organ damage, and death in experimental animal studies on gram-negative infection (75-79). In a preliminary study on the administration of BPI in meningococcal sepsis, the observed mortality was lower than predicted mortality by the Glasgow meningococcal prognostic septicemia score (91).

Activation of PMN induces release of a part of their BPI content in vitro $(80,81)$. This was confirmed by studies which showed large quantities of BPI in several body fluids during infection $(92,93)$, whereas in plasma of healthy volunteers BPI was not detectable (92). In human subjects, increased plasma BPI levels were detected in critically ill and in healthy volunteers after LPS administration (94-96). The rise in BPI levels appears to be independent from the cytokine tumor necrosis factor (TNF) (97). Interestingly, aspecific inflammatory responses, as elicited for example by hemodialysis, were also reported to induce a temporary BPI increase (98).

\subsection{Lipopolysaccharide binding protein (LBP)}

Lipopolysaccharide binding protein (LBP) is a $60 \mathrm{kD}$ acute phase protein with a striking homology in its DNA sequence when compared to BPI. Despite this homology, LBP appears to function in an opposite fashion to BPI $(99,100)$. LBP facilitates binding of LPS to the LPS-receptor CD14, whereas BPI prevents this interaction $(31,88,101,102)$. 
Specifically in the presence of low LPS concentrations LBP was demonstrated to enhance LPS induced cell activation $(88,101,103,104)$. LBP is an important but not essential factor in the cellular response to LPS (105). It was recently demonstrated that LBP deficient mice did respond to LPS by the release of TNF-alpha, suggesting an LBPindependent mechanism for LPS induced mononuclear phagocyte activation.

LBP/ LPS complexes stimulate the production of TNF by monocytes and macrophages $(99,101)$. Recently it was reported, however, that LBP also neutralizes LPS effects by transferring LPS to high-density lipoproteins $(106,107)$. This may explain the attenuation of LPS effects in humans with experimental endotoxemia following the administration of HDL (108). On the other hand, increased LBP levels as demonstrated in animals after LPS administration (109) may, as in vitro, antagonize BPI effects and enhance LPS toxicity $(88,103,110)$. Similarly, enhanced LBP levels in patients with gram-negative infections or after LPS administration in volunteers, are expected to increase LPS effects (94). Since LBP and BPI have a pronounced and opposite function in modulating LPS effects, both proteins have to be considered when gram-negative infections are analyzed.

\section{$4.4 \mathrm{CD} 14$}

CD14 is a receptor for the LPS/ LBP complex $(101,111)$. It is expressed on the membrane of monocytes and macrophages $(112,113)$. Binding of the LPS/ LBP complex to CD14 results in the release of TNF by these cells. Interestingly, the expression of CD14 on monocytes is upregulated by LPS, which suggests a positive feedback mechanism (114).

The membrane associated CD14, 53 to $55 \mathrm{kD}$ in molecular weight, can be shed from the cell surface $(115,116)$, resulting in a soluble CD14 (sCD14) with a molecular weight of $48-50 \mathrm{kD}$ (117). The shedding of CD14 from the monocyte cell surface is, among other agents, induced by LPS (117), whereas glucocorticoids suppress both the expression and release of CD14 (118). The role of sCD14, normally present in plasma, seems to be twofold in modulating LPS toxicity. For CD14 negative cells such as endothelial and epithelial cells, sCD14 has been shown to strongly enhance LPS-induced cell activation (119-123). The binding of LPS and LBP to SCD14 is a prerequisite for the interaction between SCD14 and non-myeloid cells (124).

For CD14 positive cells SCD14 has been demonstrated to neutralize LPS effects by competing with cell bound CD14 (120). In addition, for CD14 positive cells the shedding of CD14 is considered to function as an efficient regulatory mechanism to blunt the response to LPS and prevent excessive production of TNF (117).

In a limited number of publications SCD14 levels were reported to be increased in polytraumatized and severely burned patients, and levels were related to severity of injury and clinical signs of sepsis $(125,126)$. The role for CD14 in the pathophysiology 
of sepsis is further supported by the protective effects against endotoxin-induced shock in primates as a result of anti-CD14 antibodies (127).

\subsection{Tumor necrosis factor (TNF)}

The cytokine tumor necrosis factor (TNF) is a trimeric polypeptide consisting of subunits of $17 \mathrm{kD}$, which bind non-covalently to form the active cytokine $(128,129)$. Early research demonstrated that murine macrophages stimulated with LPS, produced a serum factor which causes hemorrhagic necrosis of experimental sarcomas in mice. This factor was called 'tumor necrosis factor' (37). Another line of research was focussed on an endogenous humoral mediator, cachectin, responsible for cachexia accompanying chronic infection $(130,131)$. Later, TNF was found to be identical to Cachectin as demonstrated, for example, by direct comparison of biological activities (132-134).

TNF is one of the monocyte and macrophage mediators produced in reaction to stimulation with LPS products (135-137). The central role of the macrophage in TNF production was confirmed in a study on mice that are unresponsive to lipopolysaccharide. Macrophages activated with endotoxin were shown to produce a factor (TNF) that, when injected into endotoxin resistant mice, resulted in weight loss, anorexia and dead (131). In addition, transfer of lymphoreticular cells derived from LPS sensitive mice restores reactivity for LPS in endotoxin resistant mice (30). Besides being synthesized by macrophages, TNF is also produced by other cells of the immune system such as lymphocytes (138), natural killer cells (139), and neutrophils (140). LPS is a major stimulus for TNF release, as demonstrated in baboons (141) and in humans (142). But, there are more stimuli involved in TNF release. Parasites (143) as well as yeasts (144) induce the release of TNF. Non-infectious stimuli as trauma and hemorrhagic shock enhanced the release of TNF in an experimental animal model (145). In addition, hypoxia in an in vitro model increased TNF production by human macrophages (146) and hemorrhage enhanced production of TNF by mice Kupffer cells (147).

The role of TNF in the inflammatory response is diverse. Macrophages, stimulated by TNF, release cytotoxic products as hydrogen peroxide (148), and augment killing of parasites and viruses (149-153). In addition, TNF stimulates neutrophils to enhance phagocytic and cytotoxic activities $(154,155)$, degranulation (156), and release of oxygen radicals $(156,157)$. The adhesion, aggregation, and migration of neutrophils through the endothelium is enhanced as a result of TNF induced CD11b/ CD18 activation on neutrophils $(158,159)$. Furthermore, TNF induces additional release of eicosanoids $(160,161)$, and PAF (162).

TNF has a beneficial role in the defence against infections. In an animal model of experimental peritonitis (induced by cecal ligation and puncture), passive 
immunization against TNF was demonstrated to enhance mortality (163). In line with that study was the observation that antibodies directed against TNF enhance plasmodium parasitemia (164). It was also found that TNF inhibited multiplication of malarial parasites in experimental infection (165), and protected against lethal bacterial (166), and leishmaniasis infections (167).

Although TNF is crucial in the defence against infections, TNF is undoubtedly involved in the metabolic and hemodynamic alterations seen in endotoxemia $(131,168$ 170). Evidence for the involvement of TNF in the pathophysiology of sepsis was obtained in studies of acute exposure to TNF. For example, TNF administration as therapy for cancer in humans was accompanied by sepsis like symptoms (170), and shock and tissue injury was observed after TNF administration in animals $(52,171)$. Overproduction of TNF is considered to be devastating. The production of TNF, therefore, has to to be regulated strictly. Several regulatory mechanisms are involved to control TNF production. The endocrine system modulates TNF response via the pituitary-adrenal axis. In the absence of endogenous steroids TNF release is enhanced (172), whereas glucocorticosteroids suppress TNF release (173). Various inflammatory mediators were demonstrated to enhance TNF release, such as IL-1 and interferongamma (174). In contrast, IL-10, present in large amounts during SIRS (175-178), diminished TNF release in vitro (177). In addition, IL-10 reduces TNF release and protects against the lethality of endotoxin in a murine model of septic shock (179). In a murine model of pneumonia induced by intranasal inoculation with Streptococcus pneumoniae IL-10 similarly decreased lung concentrations of TNF, whereas antibodies directed against IL-10 increased lung levels of TNF (180). Similar data were obtained after a sublethal dose of LPS in baboons (181), and during experimental endotoxemia in humans (182). TNF production is also suppressed by PAF-antagonists as was shown in mice challenged with LPS (183). Differences in genetic control (184), as evidenced by different TNF genotypes (185), result in interindividual differences in TNF secretory ability. A polymorphism in the promoter region of the TNF-alpha gene is associated with differences in the secretion of TNF. For example, the TNF2 allele is associated with higher constitutive and inducible levels of TNF secretion and associated with higher mortality in children with meningococcal infection compared to the TNF1 allele (186).

The involvement of TNF in the pathophysiology of SIRS is supported by reports on enhanced TNF plasma levels in patients with severe infections (187-189); high plasma TNF levels were associated with organ failure and death (190-192). The prognostic value of TNF concentrations in inflammation, however, is still controversial. Some authors found a positive correlation between plasma TNF levels and mortality in sepsis and meningitis $(187,188,190,193)$, whereas others could not confirm these data $(23,194)$. The inconsistency in TNF data can be explained by the short half life of TNF. As a result, TNF is only present in plasma in short intervals during sepsis syndrome as 
was shown in meningococcal sepsis (195), and in studies with experimentally induced endotoxemia in animals and humans $(142,168)$.

The important role for TNF in the pathophysiology of SIRS is underscored by the beneficial effects of TNF antibodies in animal models. Pre-treatment with TNF antibodies protects mice against LPS induced shock and the lethal effects of endotoxin (196). In addition, pre-treatment with TNF antibodies protects against organ failure and mortality in baboons with E. coli induced sepsis (197), and against organ damage from experimental sepsis (135). Other types of TNF antagonists have been developed i.e. TNF antagonist composed of TNF receptors. These tumor necrosis factor receptor immunoadhesins protects against endotoxin induced lethality in mice (198).

In contrast to animal data, TNF antagonists failed to be protective in humans (23, 199). Clinical course in patients is influenced by, among other factors, underlying disease and age. This may explain the discrepancy between experimental and patient data concerning concerning TNF antagonists. Differences in timing of TNF antagonist administration are considered essential. Whereas in experimental models TNF antagonists are infused before, or shortly after sepsis is induced, patients are included in studies hours or days after the septic insult. As a result, the inflammatory cascade may already be triggered to such an extent, that an attempt to block the TNF overshoot is not beneficial anymore.

\subsection{Soluble TNF receptors (sTNF-R)}

TNF receptors were first discovered in urine of febrile patients as proteins exhibiting TNF inhibitory activity. (200). Later, urine and plasma of patients on chronic hemodialysis were demonstrated to contain large amounts of TNF-R (43). TNF receptors are present on practically all analyzed cells (201-205). Two types of the highaffinity TNF receptor have been identified (206) with a molecular weight of $55 \mathrm{kD}$ and $75 \mathrm{kD}$, respectively. Soluble TNF-R are derived by proteolytic cleavage of the extracellular part of the TNF cell surface receptor from activated target cells (207). Increased shedding of cell surface receptors is associated with increased levels in plasma or cell culture medium. In vitro, hypoxia was demonstrated to increase sTNF-R concentrations (146). LPS administration in mice (208) and in humans $(209,210)$ resulted in increased plasma sTNF-R levels. Similarly, in cancer patients plasma sTNF$R$ levels increased as a result of TNF infusion (211). In addition, sTNF- $R$ levels were found to be increased in critically ill patients (209), and a positive correlation with mortality was observed in meningococcemia (212).

Plasma concentrations of sTNF-R likely depend on TNF-R shedding. In general, plasma concentrations are influenced by production as well as clearance. In animal experiments a central role for the kidney in the clearance of both TNF-R and TNF/ TNF-R complexes in mice was demonstrated (208). This is in line with the increased sTNF receptor levels in patients with chronic renal failure (43). In addition, in patients 
with chronic renal failure sTNF-R levels were positively correlated with different degrees of chronic renal failure (213), suggesting that the kidney is involved in sTNF-R clearance in humans.

The role of soluble TNF-R in disease has not been resolved at the moment. The shedding of the TNF receptors may function as a protective mechanism against the harmful effects of TNF. Loss of TNF cell surface receptors may lead to a decreased responsiveness of the cell to TNF. In addition, sTNF-R were demonstrated to bind TNF with high affinity, and inhibit the biological activity of TNF $(43,214,215)$. Therefore, sTNF-R are thought to be involved in the physiological control of the cytokine response during infectious disease (212). On the other hand, sTNF-R may augment TNF activity since biologically inactive complexes of sTNF-R and TNF may serve as a 'slow release reservoir' of biologically active TNF (216).

The protective effect of sTNF-R in infectious disease has been demonstrated in several studies and data are comparable with those on anti-TNF antibodies. Recombinant sTNF-R protected mice from LPS induced lethality (217), and sTNF-R protected against mortality due to E. coli in baboons (218-220). In addition, a TNF-R IgG chimera, constructed to enhance TNF-R half life and its affinity for TNF, was demonstrated to antagonize TNF in vitro, and to prevent against LPS induced lethality in mice (198).

\subsection{Interleukin-6 (IL-6)}

Interleukin-6 (IL-6) is a $21 \mathrm{kD}$ glycoprotein produced by many cell types including lymphocytes (221), fibroblasts (222), endothelial cells (223), monocytes (35), and macrophages (36) (for review see (224)). IL-6 is involved in the modulation of inflammatory reactions, and in the induction of acute-phase proteins in the liver (225). This inflammatory response consists of fever, leukocytosis, tachycardia, catabolism, and alterations in the production of acute-phase proteins by the liver (226-228). Furthermore, IL-6 can provoke neutrophil degranulation in vivo $(33,229)$, suppress the production of TNF and IL-1 beta in vitro (230), activate the coagulation system (231), and modulate hematopoiesis (232).

Recently, IL-6 was demonstrated to contribute to host defense against pneumococcal pneumonia (233). Studies on IL-6 administration and IL-6 blockade offered additional insight in its role in inflammation. In an experimental animal model the infusion of IL-6 did not result in hemodynamic alterations as seen in sepsis, suggesting that IL-6 does not have a primary role in the pathophysiology of sepsis (234). IL-6 blockade has not resulted in consistent benefit. In a murine model anti-IL-6 antibodies and IL- 6 receptor antibodies offered some protection against lethal doses of TNF, but this protection was abrogated by higher TNF doses (235). In addition, in chimpanzees treated with endotoxin, anti-IL-6 antibodies did not affect TNF and IL-8 
levels, neutrophil count and degranulation, whereas activation of coagulation was attenuated (236).

In the production of IL-6, TNF was found to be an intermediate. In baboons challenged with LPS, a peak in plasma IL-6 levels was preceded by a peak in TNF levels $(218,237)$. Later, these results were confirmed in healthy humans after LPS injection (238). The increase in plasma IL-6 levels after TNF administration in healthy humans further supported the involvement of TNF in regulating the IL-6 response (236). Even more evidence was obtained in two experimental studies in which the IL-6 response was inhibited by pre-treatment with anti-TNF antibodies (239-241). IL-1, a stimulus in TNF synthesis (174), was found to synergize with TNF to increase IL-6 production as was shown in a mice model (239). In line with this observation was the attenuated IL-6 response following interleukin-1 receptor blockade in E. coli induced septic shock in baboons (242).

Several other experimental models were associated with IL-6 release. Hemorrhage was shown to increase TNF and IL-6 production by mice Kupffer cells (147), and hemorrhagic shock in an animal model resulted in increased TNF and IL-6 plasma levels (145).

Various diseases are associated with increased IL-6 production and increased plasma levels of IL-6. In patients suffering from infectious diseases, IL-6 levels appeared to predict the presence of bacteremia (243), and increased levels were associated with severity of disease and mortality (191, 195, 243-251). Enhanced IL-6 levels were also observed in the absence of infection as in trauma patients (252), and after surgery $(253,254)$. Plasma levels correlated with the extent of surgery and with a complicated postoperative course.

Considering reports on IL-6, IL-6 appears to play an important role in the regulation of the acute phase response in infectious as well as in non-infectious diseases. In contrast to TNF, IL-6 does not seem to be responsible for the derangement of body physiology as observed in SIRS. Interestingly, IL-6 was found to correlate more closely with severity of disease and outcome compared to TNF. Apparently, clinical value of inflammatory mediators depends on other factors rather than on its role in the pathophysiology of disease.

\subsection{Interleukin-8 (IL-8)}

IL-8 is a $8-10 \mathrm{kD}$ C-X-C chemokine, and is an important member of the cytokine family whose primary functions include neutrophil activation, induction of degranulation and chemotaxis $(33,229,255-262)$. IL-8 is produced by a variety of cells including monocytes (256), alveolar macrophages (263, 264), neutrophils (265), lymphocytes (266), epithelial cells (267), endothelial cells (257), and dermal fibroblasts (268). 
Studies regarding IL-8 administration and blockade further unraveled the function of IL-8 in the pathophysiology of inflammation. IL-8 administered intradermally in humans induces a time dependent perivascular neutrophil influx (269). Interestingly, intravenous injection of IL-8 in baboons gave no hemodynamic abnormalities, no TNF, IL-1 beta, and IL-6 production, and no significant neutrophilic tissue inflammation or injury (218). The role of IL-8 in neutrophil activation, and chemotaxis is supported by the protective effect of anti-IL- 8 antibodies in a rabbit ischemia-reperfusion lung injury model (270).

Several stimuli are associated with IL-8 production. IL-1 induces IL-8 production in an in vitro model with human endothelial cells (271). Administration of IL-1 and LPS in baboons resulted in a rise of IL-8, simultaneously with IL-6, following a rise in TNF plasma levels (272). Similarly, injection of either LPS or TNF in humans was followed by increased IL-8 levels, and kinetics followed those of IL-6 $(238,273,274)$. This sequence of events suggests that, in analogy to IL-6, TNF is the main stimulus for $\mathrm{IL}-8$ production in sepsis. This is further confirmed by the reduced IL-8 release in endotoxemic baboons when pre-treated with anti-TNF antibodies (275). Significant release of IL-8 was also observed in a 'non-infectious' model. Monocytes exposed to anoxia-hyperoxia were demonstrated to release IL-8, suggesting that IL-8 may be involved in the ischemia-reperfusion injury in vivo (276).

In several infectious as well as non-infectious diseases, enhanced IL-8 concentrations were observed, indicating a role for IL- 8 in their pathophysiology. The detection of IL-8 in bronchial secretions was associated with the presence of nosocomial pneumonia in a mixed intensive care population (277). Enhanced IL-8 levels in bronchoalveolar lavage (BAL) fluid were associated with the development of ARDS in patients at risk $(278,279)$, suggesting that $I L-8$ is important in mediating organ dysfunction including ARDS following sepsis. In addition, in the BAL fluid of patients suffering from adult respiratory distress syndrome (ARDS) IL-8 was found to be present, correlating with BAL neutrophil count, and with mortality in ARDS patients $(280,281)$. In human sepsis, IL-8 was detectable in plasma and levels were found to correlate with outcome $(191,233,282,283)$.

In summary, the reported studies indicate that the function of IL-8 in inflammation is the recruitment, and activation of neutrophils at specific sites. This neutrophil sequestration and activation is considered to be responsible for tissue injury as observed in organ failure.

\subsection{Adhesion molecules}

Neutrophil adhesion to the vessel wall and migration into reperfused tissue is mediated by chemotactic proteins such as IL- 8 and adhesion molecules expressed on 
leukocytes and endothelial cells (284-287). Three major families of adhesion receptors participating in leukocyte interaction with endothelium have been defined:

1) integrin (lymphocyte function-associated antigen-1=LFA-1/ membrane attack complex-1=Mac-1),

2) immuno-globulin-related (ICAM), and

3) selectin molecules (E-selectin).

The leukocyte integrins, dimer molecules composed of an alpha and a beta chain, are involved in many cell-cell and cell-substrate interactions (for review (288)). Three integrins all sharing the same beta chain, are expressed on neutrophils. CD11a/ CD18 (LFA-1) as well as CD11b/ CD18 (Mac-1) bind to the immunoglobulin related molecule ICAM-1 (CD54) on endothelium and leukocytes, whereas CD11c/ CD18 has no clear function in adhesion $(287,289)$. The immunoglobulin related molecule ICAM-1 was the first cell surface protein identified mediating leukocyte-leukocyte and leukocyteendothelium interaction. In contrast to immunoglobulin-related molecules and integrins, selectins have only been found on circulating cells (P-selectin and L-selectin) and the endothelium (E-selectin).

\subsubsection{E-selectin}

Selectins are the most recently recognized class of adhesion molecules. E-selectin was discovered as an endothelial activation antigen, inducible by inflammatory mediators in vitro on cultured human vascular endothelial cells (290) and in vivo on endothelial cells at sites of inflammation (291). Later, E-selectin (ELAM, E-selectin or CD62E) was identified as an inducible endothelial-leukocyte adhesion molecule, synthesized and expressed by endothelial cells following stimulation with LPS or TNF and IL-1 in vitro $(286,292,293)$. E-selectin expression in an in vitro model on human endothelial cells peaked at 3-6 hours after stimulation with LPS, TNF and IL-1, respectively, and declined to basal levels in 24-48 hours (294).

Following in vitro activation endothelium was found to release E-selectin (294296). As a result, soluble E-selectin is detectable in plasma (296-298). In vitro, the quantity of adhesion molecules released by cells correlates directly with expression of adhesion molecules on the cell surface (294), indicating that plasma concentrations of circulating adhesion molecules may reflect inflammatory state in vivo $(294,296,298)$. In contrast to other parameters of endothelial activation (trombomodulin, endothelin, von Willebrand factor), sE-selectin is a specific parameter for endothelial activation.

The interaction between E-selectin and fucosylated Sialyl Lewis x (CD15s) (299, 300) promotes adhesion of neutrophils, monocytes, and a sub-population of lymphocytes to endothelium $(286,301-303)$. E-selectin induced neutrophil rolling is recognized as an early step in neutrophil-endothelium interaction. Maximal rolling is 
observed after 2-6 hours of endothelial cell activation with LPS, TNF, or IL-1 beta ( 304 , 305).

The involvement of E-selectin in inflammation was further demonstrated in several experimental animal studies. A rat model of immune complex-induced lung injury revealed a striking upregulation of E-selectin expression in the lung vasculature, and anti-E-selectin antibodies markedly reduced vascular injury related to greatly diminished recruitment of neutrophils (306). In addition, in a primate model of extrinsic asthma, blocking E-selectin diminished neutrophil influx associated with late phase airway obstruction.

Greatly increased tissue expression of E-selectin was found in patients with SIRS as a result of peritonitis (307) and in E. coli and LPS challenged baboons $(308,309)$. In addition, plasma levels of sE-selectin were increased twenty-fold in patients with complicated sepsis. High sE-selectin levels or persistent elevation were correlated with increased mortality (296). Others reported increased sE-selectin levels in patients with SIRS to be associated with the presence of organ dysfunction and death (310).

In infectious as well as non-infectious diseases enhanced plasma levels of sEselectin were found. (i.e. diabetes mellitus, polyarteritis nodosa, scleroderma, systemic lupus erythemathosus, malaria). Overall, no correlation with disease activity was found.

The exact role of sE-selectin in inflammation is unknown. However, sE-selectin is suggested to play a role in modulating inflammatory reactions. In an in vitro model recombinant sE-selectin was demonstrated to inhibit leukocyte adhesion (311). The impact of enhanced sE-selectin levels in disease still has to be resolved.

\subsubsection{Intercellular adhesion molecule 1 (ICAM-1)}

ICAM-1 is expressed on endothelial cells and on mononuclear leukocytes, but not on neutrophils, and participates in adhesive reactions of multiple cell types $(287,312)$. On most cells surface expression of ICAM-1 is low, but can be enhanced in a few hours by various stimuli including several cytokines $(313,314)$. ICAM-1 binds to LFA-1 expressed on endothelium and all leukocytes (287) and to Mac-1 expressed on leukocytes $(287,289)$.

The role of ICAM-1 in neutrophil adhesion is demonstrated by numerous experimental studies in which the interaction between ICAM-1 and its ligands was studied. Blocking ICAM-1 ligand interaction protected against cardiac ischemiareperfusion injury in cats (315), reduced organ injury caused by hemorrhagic shock (316) and protected against lung injury after pulmonary ischemia and reperfusion in rabbits (317), and reduced organ injury and improved survival following hemorrhagic 
shock in rabbits and in rhesus monkeys (318). In addition, antibodies blocking the interaction between ICAM-1 and its ligand prevented glomerular injury in rats with experimental glomerular nefritis (319). Furthermore, antibodies against ICAM-1 were effective in prevention and treatment of acute renal allograft rejection in Cynomolgus monkeys (320).

Soluble ICAM (sICAM), first demonstrated in human serum $(297,321)$, contains most of the extracellular part of membrane bound ICAM (297). Endothelial cells as well as peripheral blood mononuclear cells were demonstrated to release ICAM-1 in vitro upon stimulation with LPS, TNF, or IL-1 $(294,295)$. Release of functional adhesion molecules may influence adhesion in two different ways. Release of ICAM-1 from the cell surface is expected to diminish adhesive capacity of this particular cell. In addition, sICAM, demonstrated to retain its ability to bind its ligand LFA-1, may subsequently inhibit leukocyte-leukocyte and leukocyte-endothelium adhesion by competition (297).

Increased ICAM-1 levels were reported in several diseases. In SIRS increased sICAM-1 levels were found, but no correlation with severity of disease was reported (310). In inflammation, infection, and in cancer ICAM-1 levels were increased up to 2-5 times normal (321-323). In analogy to sE-selectin, sICAM levels may provide information on activation of leukocytes and endothelium, and are therefore of interest to monitor in relation to severity of disease.

\subsection{Platelet-activating factor (PAF)}

PAF is a natural occurring lipid derived from the phospholipid components of cell membranes. Several lines of evidence emphasized the role of PAF in the pathophysiology of endotoxemia and sepsis $(169,324-330)$. PAF is released by, among other cells, mononuclear phagocytes, macrophages, neutrophils, platelets, and endothelial cells in response to various stimuli $(331,332)$. Its role in inflammation includes the activation of neutrophil functions directly and by priming neutrophils for subsequent activation by other agonistic stimuli $(163,326,333,334)$. In addition, platelet aggregation during inflammation was demonstrated to be, at least partially, induced by PAF $(335,336)$.

PAF is strongly related to the cytokine network: TNF, IL-1, and IL-8 stimulate PAF production $(162,337,338)$ whereas, in turn, PAF is able to trigger these cytokines ( 331 , 339-343), suggesting a positive feedback loop.

The role of PAF in inflammation is supported by animal studies regarding the role of PAF and PAF-antagonists in endotoxemia. PAF was demonstrated to prime for LPS induced lung injury in a rat model. The PAF enhanced TNF synthesis was proposed responsible for this observation (344). In addition, the administration of PAF resulted 
in pathological changes that closely resemble those found in sepsis: hypotension, cardiodepression, bronchoconstriction, margination and activation of leukocytes, pulmonary injury and vascular leakage, trombocytopenia, and leukopenia (325-327, $333,334,345,346)$.

Additional information on the role of PAF in inflammation was obtained by studies on PAF antagonists. PAF antagonists were demonstrated to inhibit several inflammatory pathways in animal models of endotoxemia. Administration of a PAF antagonist in experimental endotoxemia reduced TNF plasma levels in animals (332, $347,348)$. PAF antagonists were also reported to attenuate the metabolic effects of endotoxin in an animal model (349). The beneficial role of PAF antagonists in disease was demonstrated by the attenuation of hemodynamic effects following LPS administration $(328,347,350)$, and notably of PAF induced hypotension $(347,351,352)$. In addition, PAF antagonists reduce lung injury $(328,353)$, the manifestation of DIC $(324,345)$ as well as that of MOF $(324)$ in animal models of endotoxemia. Finally, PAF antagonists reduced endotoxin $(328,347,348,352,353)$, and PAF induced mortality $(347,351,354)$ in experimental animal models.

The observed increased plasma levels of PAF in animal and in human sepsis further supports the involvement of PAF in the pathophysiology of inflammation, sepsis and organ failure $(328,329,355-357)$. These data suggest that treatment with PAF-antagonists, like in experimental animal studies, may be beneficial in human sepsis. 


\section{INTRODUCTION TO AND DISCUSSION OF THE STUDIES}

The aim of this thesis is to elucidate the role of inflammatory mediators and scoring systems in assessing severity of disease in critically ill patients. Measuring severity of disease is essential to evaluate instituted therapies, and may be helpful, however still controversial, in decision making to start or to discontinue intensive care treatment. Initially, severity of disease was measured using clinical and laboratory data, and more recently by severity of disease scoring systems.

In vitro, stimulus and inflammatory response are closely related. We therefore hypothesized that plasma parameters of the inflammatory response reflect severity of the event initiating this response (i.e. infection, ischemia). In the last decade the clinical value of inflammatory mediators present in plasma of patients has been recognized. In this thesis, plasma inflammatory mediators were studied in patients with infectious and noninfectious disease. Kinetics of these mediators were analyzed in relation to severity of disease and outcome.

The first category of patients studied were patients suffering from infectious diseases. Infections are responsible for a substantial number of patients with a deteriorating clinical state leading to ICU admission. On the other hand, infections related to hospitalization (nosocomial infections) contribute to additional morbidity and mortality during ICU stay. The second category of patients studied included patients suffering from hemorrhagic shock. Hemorrhagic shock is associated with an extensive inflammatory response and subsequently the development of complications such as multiple organ dysfunction and death.

The prognostic value of inflammatory mediators in critical care medicine was studied using an ICU patient database. This database was used to select patients fulfilling the inclusion criteria as stated in each study. In addition this database served as a source for patient details.

\subsection{Registration of ICU patients}

The studies described in this thesis are all based on data derived from an ICU database. This database was developed as a source for ICU related research. To analyze the ICU patient population, demographic data, prior health status, ICU admission diagnosis, operative status, length of ICU stay, and outcome were recorded.

Secondly, therapeutic and diagnostic interventions were studied. In intensive care medicine the use of diagnostic and therapeutic invasive devices is indispensable. However, the use of these invasive devices is unmistakably related to (infectious) complications associated with additional morbidity and sometimes death. Therefore, the registration included bacterial cultures, the use of agents to decontaminate the digestive tract, antibiotics, and the presence of invasive catheters. 
Thirdly, the registration included clinical and laboratory data as part of severity of disease scoring systems. Severity of disease was assessed by APACHE II score which is, despite the introduction of APACHE III, still one the most frequently used scores in intensive care medicine to stratify patient populations and to predict mortality. Furthermore, the Grading of Sepsis score was recorded. In order to calculate APACHE II score, the Grading of Sepsis score and organ function, hematology, blood chemistry, blood gases, and vital signs were registered on a daily basis.

Finally, to study the clinical value of inflammatory mediators, daily plasma samples were collected from each patient. The samples were stored at $-70^{\circ} \mathrm{C}$ until use for several analytical purposes as described elsewhere. Data were collected on admission, the first 24 hours of intensive care, and subsequently every day of the ICU stay. The prospectively registered data provided up to date information concerning ICU utilization and performance, and served as a database for ICU specific research.

\subsubsection{The studies}

The studies performed are described in chapters 2-8. Data on observed mortality versus predicted mortality (APACHE II) in critically ill patients are discussed in chapter 2 . Studies addressing the correlation between inflammatory mediators and severity of disease are the subject of chapter 3-5. In chapter 6 data are presented considering a phase II study on the administration of a platelet-activating factor (PAF) antagonist in patients with severe sepsis. The development of pneumonia in mechanically ventilated ICU patients and the associated inflammatory response are reported in chapters 7 and 8 .

\section{2 .2}

The results regarding the clinical value of severity of disease scoring systems are reported in chapter 2. Intensive care medicine is a major consumer of hospital budget. The identification of patients who really benefit from ICU admission may be helpful to manage available resources more efficiently. Predicting mortality by scoring systems is therefore a topic of increasing interest. Two scoring systems were evaluated: APACHE II (17) and the Grading of Sepsis score (26). APACHE II was used in numerous studies and found, although not consistently, to be useful in predicting mortality (20-25). In addition, the Grading of Sepsis score was validated in several studies considering patients with a variety of infections $(27,28)$.

The results demonstrate that APACHE II scores were strongly correlated with hospital mortality. Even in septic patients APACHE II scores were significantly correlated with outcome whereas, interestingly, the Grading of Sepsis score failed to discriminate between survivors and nonsurvivors. APACHE II is proposed to stratify acutely ill patients. However, discrepancies between observed and APACHE II predicted death rates in specific diagnostic categories ranged from $-62.1 \%$ to $+118.2 \%$. 
APACHE II is not useful in decision making with respect to the individual patient. If one intends to use the scoring system for other purposes, one needs to evaluate critically its limitations.

\section{2 .3}

TNF was compared with TNF-R as parameters of the severity of the sepsis syndrome in chapter 3. TNF is generally considered to play a central role in the pathogenesis of sepsis. Plasma levels of TNF are, although not consistently, reported to correlate with the clinical severity of sepsis and outcome. The inconsistency in TNF data can, at least in part, be explained by the short half life of TNF. TNF induced proteins with slower kinetics compared to TNF may reflect the short-lived TNF peaks. Soluble TNF receptors appear to meet these requirements. Both the $55 \mathrm{kD}$ and the $75 \mathrm{kD}$ receptor are up-regulated as well as shedded from the cell surface by TNF exposure, leading to increased levels of sTNF-R in plasma.

The study described demonstrates that, in contrast to TNF, increased sTNF-R levels $(55 \mathrm{kD})$ were significantly correlated with mortality. These data are in line with the literature regarding sTNF-R levels. Increased soluble TNF receptor levels have been reported in critically ill patients, and a positive correlation with mortality was found $(209,210,212,358-361)$.

Plasma levels of sTNF-R may reflect temporary TNF peaks, other lines of evidence suggested that sTNF-R kinetics are substantially influenced by renal TNF-R clearance. In patients with renal failure enhanced levels of sTNF-R levels were found $(43,213$, 362 ) and the kidney was demonstrated to play a central role in sTNF-R clearance in mice (363). Therefore, we additionally analyzed sTNF-R levels in relation to renal function as assessed by plasma creatinine levels. Plasma levels of the $55 \mathrm{kD}$ as well as the $75 \mathrm{kD}$ sTNF-R correlated significantly with creatinine values in sepsis syndrome patients. The significant correlation between sTNF-R levels and creatinine levels indicate that increased sTNF receptor levels in sepsis syndrome may merely be the result of renal failure complicating sepsis, and are likewise correlated with mortality.

In other studies regarding the prognostic value of sTNF-R in inflammatory diseases, data concerning renal function are usually not reported $(209,210,212,358$ 361). It is therefore difficult to differentiate whether enhanced sTNF-R levels reflect high TNF peaks or impaired sTNF-R clearance. Subsequently, the clinical value of monitoring sTNF-R levels is limited.

In conclusion, whereas STNF-R administration in experimental models of SIRS has a beneficial effect on mortality, enhanced sTNF-R levels resulting from renal failure are associated with poor outcome in SIRS.

\section{2 .4}

In chapter 4 the inflammatory response resulting from hemorrhagic shock was studied in relation to clinical outcome. Patients with hemorrhagic shock complicating acute abdominal aortic aneurysm (AAA) repair were studied and compared to those without 
shock. In experimental animal models hemorrhagic shock and ischemia induces an inflammatory response characterized by increased concentrations of cytokines such as TNF and IL-6 in plasma (145), neutrophil activation and extravasation mediated by chemotactic proteins such as IL-8 as well as by adhesion molecules expressed on leukocytes and endothelial cells (284-287, 364, 365). Enhanced expression and activation of adhesion molecules appeared to be reflected by increased plasma levels of soluble adhesion molecules as demonstrated in vitro (294).

The results demonstrate that shock complicating AAA repair and fatal outcome is significantly associated with enhanced plasma IL-6 and sICAM-1 levels. In addition, hemorrhagic shock, but not outcome, is correlated with enhanced IL-8 levels in AAA patients. Surgical trauma, as assessed by operation time, was similar in patients with and without hemorrhagic shock, respectively. Therefore, hemorrhagic shock seems to be responsible for the differences observed.

Endotoxin may be a significant stimulus in the shock induced inflammatory response. Hemorrhagic shock leads to regional hypoxia (366), bacterial translocation, and transient endotoxemia $(367,368)$. Endotoxemia may also be involved in the enhanced ICAM-1 expression and release in AAA patients with shock. Furthermore, ischemia and reperfusion are associated with oxygen-radical production which additionally induces ICAM-1 expression.

Shedding of cell surface adhesion molecules may serve as a regulatory mechanism to prevent against excessive neutrophil adhesion and sequestration as in the pathophysiology of MODS. The presence of high concentration of soluble adhesion molecules may have a similar effect. Soluble adhesion molecules may compete with cell bound adhesion molecules for the interaction with their ligands. Ischemia and reperfusion injury can be ameliorated by agents blocking the ICAM-1 ligand interaction as demonstrated in several animal studies (315-319). Monitoring plasma levels of inflammatory mediators such as IL-6 and sICAM-1 in AAA patients may be useful to identify those patients which are prone for a complicated postoperative course due to hemorrhagic shock. Additional research is required to determine whether these 'high risk patients' benefit by blocking ICAM-1 ligand interaction.

\section{2 .5}

In chapter 5 proteins modulating the toxicity of LPS were studied in patients with gram-negative bacteremia in relation to clinical course. LPS, a component of the gramnegative bacterial cell wall, is considered to be responsible for the symptoms of gramnegative sepsis. The toxicity of LPS, is modified by proteins such as BPI, LBP, and soluble CD14. BPI is specifically cytotoxic for gram-negative bacteria and inhibits LPSinduced phagocyte activation. LPS binding protein (LBP) appears to function in an opposing fashion to BPI. LBP facilitates binding of LPS to the LPS-receptor CD14, whereas BPI prevents this interaction. The role of $\mathrm{sCD} 14$, the soluble form of the LPSreceptor CD14, in modulating LPS toxicity seems to be twofold dependent on the presence of cell surface CD14 on the target cell. 
The data presented show that BPI and LBP levels were significantly higher in bacteremic patients compared to healthy controls. Interestingly, these proteins, specifically directed against LPS, were similarly increased in patients with gramnegative and gram-positive bacteremia. This suggest that both proteins are also released upon neutrophil activating components of gram-positive bacteremia. Another explanation may be the presence of significant amounts of LPS in the circulation during gram-positive bacteremia as a result of LPS absorption from the gut due to increased gut permeability as seen in critically ill patients.

BPI, released by blood neutrophils, is a protein with a short half life. As a result, plasma levels were hypothesized to dependent on blood neutrophil count. Therefore BPI/ neutrophil ratio, as a parameter of neutrophil activation, was analyzed. In patients suffering from sepsis syndrome BPI/ neutrophil ratio as well as LBP levels were significantly higher compared to patients without sepsis syndrome. In addition, high BPI/ neutrophil values were associated with fatal outcome. BPI/ neutrophil ratio apparently reflects neutrophil activation which is associated with severity of disease in patients suffering from bacteremia.

LPS is extremely toxic for humans, and an adequate response towards LPS is of vital interest. In the protection against LPS the direct release of BPI seems essential. Although LBP is present in plasma of healthy individuals, additional LBP release by the liver requires the production of $\mathrm{IL}-6$ as an intermediate. It is unknown at the moment whether the ratio of plasma BPI and LBP levels is a significant factor in the clinical course of gram-negative infections. In the present study, only a tendency was observed towards higher LBP/ BPI values in nonsurvivors of gram-negative bacteremia.

Recently, exogenous BPI was found to protect against LPS induced metabolic alterations, organ damage, and death $(75-79,91)$. It is unknown at the moment whether plasma BPI levels are useful to select those patients who may benefit from exogenous BPI administration.

\section{2 .6}

In chapter 6 a phase II study is described on the administration of a PAF-antagonist in patients with severe sepsis. PAF is involved in the pathophysiology of sepsis as demonstrated in studies on the administration of PAF and its antagonists, respectively $(325-327,333,334,345,346)$. Administration of PAF antagonists resulted in reduced TNF plasma levels $(332,347,348)$, attenuated hemodynamic effects $(328,347,350-352)$, reduced lung injury $(328,353)$, diminished manifestations of MOF $(324)$, and reduced mortality $(328,347,348,352,353)$.

The safety and efficacy of the platelet-activating factor antagonist TCV-309 in the treatment of systemic inflammatory response syndrome was studied in a prospective randomized, double-blind, placebo-controlled study. In total 29 patients were treated with $1.0 \mathrm{mg} / \mathrm{kg}$ TCV-309 twice daily during 7 days or with placebo. Adverse events, 
day 28 and day 56 mortality, multi-organ failure scores and the inflammatory mediators TNF, IL-6, IL-8, and soluble E-selectin were measured.

There was no difference in number and severity of adverse events between TCV309 and placebo-treated patients. Day 28 and day 56 mortality was similar in both groups (day 56: 7/ 12 TCV-309 vs. 9/ 16 placebo, NS). Pulmonary (day 28 values) and hematological (day 7 values) failure scores improved significantly in TCV-309-treated patients $(\mathrm{P}<.05)$. There were no differences in plasma levels of the inflammatory mediators between TCV-309 and placebo-treated patients.

The inflammatory cascade is complex and many drugs have been developed to interfere with the cascade at various levels. Although pre-treatment with many of these drugs has been proven to be successful in animal studies, most of them failed in patients in which the inflammatory cascade is already triggered. Only retrospective analysis demonstrated some drugs to be beneficial in subgroups. In the present study treatment with TCV-309 appears to be safe in patients with systemic inflammatory response syndrome and to improve organ failure significantly. However, in line with previous studies regarding intervention with the inflammatory cascade in SIRS patients, no effect on mortality was observed.

Furthermore, although PAF is strongly related to the cytokine network, no differences were observed in plasma TNF, IL-6, IL-8, and E-selectin levels between the TCV-309 and placebo-treated patients. This can be explained by the heterogeneity of the patients studied. The period between the onset of infectious disease and inclusion in the study was not restricted by the inclusion criteria. In addition, some patients were included in the study after surgery, an event interfering with plasma levels of several inflammatory mediators.

Interestingly, the improvement in pulmonary and hematological failure after treatment with TCV-309 compared to placebo can be explained by extrapolation of experimental data. Experimental studies did show the involvement of PAF in lung and hematologic dysfunction $(324,327,328,333,344,345,353)$. In contrast to TNF antagonists, PAF antagonists act more distal in the inflammatory cascade and may therefore be more useful in the treatment of SIRS.

\section{2 .7}

The development of pneumonia in mechanically ventilated ICU patients and the associated inflammatory response is reported in chapters 7-8. Ventilator associated pneumonia (VAP) is the most frequent occurring infection among mechanically ventilated patients and is associated with additional morbidity and mortality. At the moment, there are no variables that can predict clinical course and outcome of VAP.

IL-6 has been identified previously as a reliable parameter for severity of inflammation in several diseases. In addition, IL-8 concentrations in bronchial secretions are associated with the presence of nosocomial pneumonia (277). Therefore the predictive value of IL- 6 and IL-8 plasma levels was studied in patients developing 
VAP. The patients were compared to controls that were matched on duration of mechanical ventilation and another 6 variables.

The development of VAP was not associated with increased IL-6 or IL-8 levels. However, in VAP patients with severe sepsis or septic shock $(n=10)$, IL-6 and IL-8 levels were significantly higher compared to corresponding controls. In addition, high levels of IL-6 and IL-8 were associated with high mortality. Mortality in VAP accompanied by sepsis was $60 \%$ versus $20 \%$ in their matched controls $(\mathrm{P}=.06)$. Mortality rates in cases with uncomplicated VAP and their matched controls were comparable.

Measuring IL-6 and IL-8 in a mixed ICU patient population was found not to be useful as a diagnostic tool to identify VAP. The clinical picture of VAP is heterogeneous. VAP may present as a devastating infection accompanied by severe sepsis or septic shock, with elevated levels of IL-6 and IL-8, and an increased mortality rate. On the other hand, VAP patients may have a rather uncomplicated disease, without an obvious inflammatory response or increased mortality.

\section{2 .8}

In chapter 8 , proteins reflecting neutrophil activation and proteins involved in neutrophil migration and adhesion were studied in a mixed patient population developing VAP. These proteins included BPI, and the circulating adhesion molecules ICAM-1 and E-selectin. Data were compared with the predictive value of easily available severity of disease scoring systems such as the Simplified Acute Physiology Score (SAPS), and APACHE II scores. VAP was diagnosed on quantitative cultures of samples obtained by bronchoscopic techniques. Plasma levels were measured on days $4,-2,0$ and +2 , relative to diagnosis. In addition, correlations between the systemic levels of these mediators and the clinical severity of infection (VAP whether or not accompanied with severe sepsis or septic shock) and patient outcome (mortality at day 10 after diagnosis) were studied.

Increasing values of SAPS II scores and rising systemic levels of inflammatory mediators were only found in patients in whom the development of VAP was accompanied with severe sepsis or septic shock. Systemic levels of the inflammatory mediators studied did not predict clinical severity or patient outcome better than daily SAPS II scores. SAPS II score of the day of infection predicted patient outcome better than the APACHE II score on the day of admission.

The heterogenity of the clinical presentation of VAP is obvious. In uncomplicated VAP, SAPS II scores as well as plasma levels of the inflammatory mediators tested remained rather stable. Only in patients with VAP accompanied with sepsis, elevated SAPS II values and plasma levels of inflammatory mediators were correlated with outcome. Subsequently, the readily available clinical scoring system SAPS II is at least a suitable predictor for severity of disease and outcome in VAP patients when compared to plasma levels of the inflammatory mediators tested. 


\section{REFERENCES}

1. Baumann H, Gauldie J. The acute phase response. Immunol Today $1994,15: 74-80$

2. Goris RJ, Te Boekhorst TP, Nuytinck JK, et al. Multiple-organ failure. Generalized autodestructive inflammation? Arch Surg 1985;120:1109-15

3. Aronson MD, Bor DH. Blood cultures. Ann Intern Med 1987;106:246-53

4. Sibbald WJ, Marshall J, Christou N, et al. "Sepsis"--clarity of existing terminology ... or more confusion? Crit Care Med 1991;19:996-8

5. Marshall J, Sweeney D. Microbial infection and the septic response in critical surgical illness. Sepsis, not infection, determines outcome. Arch Surg 1990;125:17-22

6. Faist $\mathrm{E}$, Baue AE, Dittmer $\mathrm{H}$, et al. Multiple organ failure in polytrauma patients. J Trauma $1983 ; 23: 775-87$

7. Marshall Jr WG, Dimick AR. The natural history of major burns with multiple subsystem failure. J Trauma 1983;23:102-5

8. Henao FJ, Daes JE, Dennis RJ. Risk factors for multiorgan failure: a case-control study. J Trauma 1991;31:74-80

9. Allardyce DB. Incidence of necrotizing pancreatitis and factors related to mortality. Am J Surg 1987; 154:295-9

10. Bone RC, Balk RA, Cerra FB, et al. Definitions for sepsis and organ failure and guidelines for the use of innovative therapies in sepsis. The ACCP/ SCCM Consensus Conference Committee. American College of Chest Physicians/ Society of Critical Care Medicine. Chest 1992;101:1644-55

11. Tran DD, Groeneveld AB, Van der Meulen J, et al. Age, chronic disease, sepsis, organ system failure, and mortality in a medical intensive care unit. Crit Care Med 1990;18:474-9

12. Knaus WA, Draper EA, Wagner DP, et al. Prognosis in acute organ-system failure. Ann Surg 1985;202:685-93

13. Rauss A, Knaus WA, Patois E, et al. Prognosis for recovery from multiple organ system failure: the accuracy of objective estimates of chances for survival. The French Multicentric Group of ICU Research. Med Decis Making 1990;10:155-62

14. Regel G, Grotz M, Weltner T, et al. Pattern of organ failure following severe trauma. World J Surg 1996;20:422-9

15. Deitch EA. Multiple organ failure. Pathophysiology and potential future therapy. Ann Surg 1992;216:117-34

16. Fry DE, Pearlstein L, Fulton RL, et al. Multiple system organ failure. The role of uncontrolled infection. Arch Surg 1980;115:136-40

17. Knaus WA, Draper EA, Wagner DP, et al. APACHE II: a severity of disease classification system. Crit Care Med 1985;13:818-29

18. Knaus WA, Zimmerman JE, Wagner DP, et al. APACHE-acute physiology and chronic health evaluation: a physiologically based classification system. Crit Care Med 1981;9:591-7

19. Knaus WA, Wagner DP, Draper EA, et al. The APACHE III prognostic system. Risk prediction of hospital mortality for critically ill hospitalized adults. Chest 1991;100:1619-36

20. Dellinger EP. Use of scoring systems to assess patients with surgical sepsis. Surg Clin North Am 1988;68:123-45

21. Lemeshow S, Teres D, Avrunin JS, et al. A comparison of methods to predict mortality of intensive care unit patients. Crit Care Med 1987;15:715-22

22. Fagon JY, Chastre J, Novara A, et al. Characterization of intensive care unit patients using a model based on the presence or absence of organ dysfunctions and/ or infection: the ODIN model. Intensive Care Med 1993;19:137-44 
23. Fisher Jr CJ, Opal SM, Dhainaut JF, et al. Influence of an anti-tumor necrosis factor monoclonal antibody on cytokine levels in patients with sepsis. The CB0006 Sepsis Syndrome Study Group. Crit Care Med 1993,21:318-27

24. Arregui LM, Moyes DG, Lipman J, et al. Comparison of disease severity scoring systems in septic shock. Crit Care Med 1991;19:1165-71

25. Brown PE, McClave SA, Hoy NW, et al. The Acute Physiology and Chronic Health Evaluation II classification system is a valid marker for physiologic stress in the critically ill patient. Crit Care Med 1993;21:363-7

26. Elebute EA, Stoner HB. The grading of sepsis. Br J Surg 1983;70:29-31

27. Dionigi R, Dominioni L, Jemos V, et al. Sepsis score and complement factor B for monitoring severely septic surgical patients and for predicting their survival. Eur Surg Res 1985;17:269-80

28. Dominioni L, Dionigi $\mathrm{R}$, Zanello $\mathrm{M}$, et al. Sepsis score and acute-phase protein response as predictors of outcome in septic surgical patients. Arch Surg 1987;122:141-6

29. Dominioni L, Dionigi R, Zanello M, et al. Effects of high-dose IgG on survival of surgical patients with sepsis scores of 20 or greater. Arch Surg 1991;126:236-40

30. Michalek SM, Moore RN, McGhee JR, et al. The primary role of lymphoreticular cells in the mediation of host responses to bacterial endotoxim. J Infect Dis 1980;141:55-63

31. Hailman E, Lichenstein HS, Wurfel MM, et al. Lipopolysaccharide (LPS)-binding protein accelerates the binding of LPS to CD14. J Exp Med 1994;179:269-77

32. Glauser MP, Zanetti G, Baumgartner JD, et al. Septic shock: pathogenesis. Lancet 1991;338:732-6

33. Baggiolini M, Walz A, Kunkel SL. Neutrophil-activating peptide-1/ interleukin 8, a novel cytokine that activates neutrophils. J Clin Invest 1989;84:1045-9

34. Oppenheim JJ, Zachariae CO, Mukaida N, et al. Properties of the novel proinflammatory supergene "intercrine" cytokine family. Annu Rev Immunol 1991;9:617-48

35. Aarden LA, De Groot ER, Schaap OL, et al. Production of hybridoma growth factor by human monocytes. Eur J Immunol 1987;17:1411-6

36. Coulie PG, Cayphas S, Vink A, et al. Interleukin-HP1-related hybridoma and plasmacytoma growth factors induced by lipopolysaccharide in vivo. Eur J Immunol 1987;17:1217-20

37. Carswell EA, Old LJ, Kassel RL, et al. An endotoxin-induced serum factor that causes necrosis of tumors. Proc Natl Acad Sci U S A 1975;72:3666-70

38. Fletcher JR, Ramwell PW, Herman CM. Prostaglandins and the hemodynamic course of endotoxin shock. J Surg Res 1976;20:589-594

39. Dinarello CA, Cannon JG, Mancilla J, et al. Interleukin-6 as an endogenous pyrogen: induction of prostaglandin E2 in brain but not in peripheral blood mononuclear cells. Brain Res 1991;562:199-206

40. Smedly LA, Tonnesen MG, Sandhaus RA, et al. Neutrophil-mediated injury to endothelial cells. Enhancement by endotoxin and essential role of neutrophil elastase. J Clin Invest 1986;77:1233-43

41. Goode HF, Webster NR. Free radicals and antioxidants in sepsis. Crit Care Med 1993;21:1770-6

42. Weiss SJ. Tissue destruction by neutrophils. N Engl J Med 1989;320:365-76

43. Peetre $\mathrm{C}$, Thysell $\mathrm{H}$, Grubb A, et al. A tumor necrosis factor binding protein is present in human biological fluids. Eur J Haematol 1988;41:414-9

44. Welbourn CR, Goldman G, Paterson IS, et al. Pathophysiology of ischaemia reperfusion injury: central role of the neutrophil. Br J Surg 1991;78:651-5

45. Lindsay TF, Hill J, Ortiz F, et al. Blockade of complement activation prevents local and pulmonary albumin leak after lower torso ischemia-reperfusion. Ann Surg 1992;216:677-83

46. Bassenge E. Clinical relevance of endothelium-derived relaxing factor (EDRF). Br J Clin Pharmacol 1992;34:37S-42S

47. Windsor AC, Mullen PG, Fowler AA, et al. Role of the neutrophil in adult respiratory distress syndrome. Br J Surg 1993;80:10-7 
48. Malech HL, Gallin JI. Current concepts: immunology. Neutrophils in human diseases. N Engl J Med 1987:317:687-94

49. Morrison DC, Ryan JL. Endotoxins and disease mechanisms. Annu Rev Med 1987;38:417-32

50. Beutler B, Cerami A. Cachectin: more than a tumor necrosis factor. N Engl J Med 1987;316:379-85

51. Dinarello CA. Interleukin-1. Rev Infect Dis 1984;6:51-95

52. Tracey KJ, Beutler B, Lowry SF, et al. Shock and tissue injury induced by recombinant human cachectin. Science $1986 ; 234: 470-4$

53. Akira S, Hirano T, Taga T, et al. Biology of multifunctional cytokines: IL 6 and related molecules (IL 1 and TNF). Faseb J 1990;4:2860-7

54. Morrison DC, Kline LF. Activation of the classical and properdin pathways of complement by bacterial lipopolysaccharides (LPS). J Immunol 1977;118:362-8

55. Vukajlovich SW, Hoffman J, Morrison DC. Activation of human serum complement by bacterial lipopolysaccharides: structural requirements for antibody independent activation of the classical and alternative pathways. Mol Immunol 1987;24:319-31

56. Levy GA, Schwartz BS, Curtiss LK, et al. Regulatory roles of $\mathrm{T}$ mu and $\mathrm{T}$ gamma cells in the collaborative cellular initiation of the extrinsic coagulation pathway by bacterial lipopolysaccharide. J Clin Invest 1985;76:548-55

57. Kalter ES, Van Dijk WC, Timmerman A, et al. Activation of purified human plasma prekallikrein triggered by cell wall fractions of Escherichia coli and Staphylococcus aureus. J Infect Dis 1983;148:682-91

58. Shenep Л, Mogan KA. Kinetics of endotoxin release during antibiotic therapy for experimental gram-negative bacterial sepsis. J Infect Dis 1984;150:380-8

59. Van Deventer SJ, Buller HR, Ten Cate JW, et al. Endotoxaemia: an early predictor of septicaemia in febrile patients. Lancet 1988;1:605-9

60. Ziegler EJ, McCutchan JA, Fierer J, et al. Treatment of gram-negative bacteremia and shock with human antiserum to a mutant Escherichia coli. N Engl J Med 1982;307:1225-30

61. Baumgartner JD, Glauser MP, McCutchan JA, et al. Prevention of gram-negative shock and death in surgical patients by antibody to endotoxin core glycolipid. Lancet 1985;2:59-63

62. Rush Jr BF, Sori AJ, Murphy TF, et al. Endotoxemia and bacteremia during hemorrhagic shock. The link between trauma and sepsis? Ann Surg 1988;207:549-54

63. Boom SJ, Reidy J, Ramsay G. Endotoxemia in severe staphylococcal infection. Surg Res Comm 1992;12:25-31

64. Ryan CM, Yarmush ML, Burke JF, et al. Increased gut permeability early after burns correlates with the extent of burn injury. Crit Care Med 1992;20:1508-12

65. Sori AJ, Rush Jr BF, Lysz TW, et al. The gut as source of sepsis after hemorrhagic shock. Am J Surg 1988;155:187-92

66. Herndon DN, Zeigler ST. Bacterial translocation after thermal injury. Crit Care Med 1993;21:S50-4

67. Ulevitch RJ, Johnston AR. The modification of biophysical and endotoxic properties of bacterial lipopolysaccharides by serum. J Clin Invest 1978;62:1313-24

68. Liao W, Floren $\mathrm{CH}$. Hyperlipidemic response to endotoxin-a part of the host-defence mechanism. Scand J Infect Dis 1993;25:675-82

69. 'Harris HW, Grunfeld C, Feingold KR, et al. Chylomicrons alter the fate of endotoxin, decreasing tumor necrosis factor release and preventing death. J Clin Invest 1993;91:1028-34

70. Mathison JC, Ulevitch RJ. The clearance, tissue distribution, and cellular localization of intravenously injected lipopolysaccharide in rabbits. J Immunol 1979;123:2133-43

71. Munford RS, Dietschy JM. Effects of specific antibodies, hormones, and lipoproteins on bacterial lipopolysaccharides injected into the rat. J Infect Dis 1985;152:177-84

72. Kirkland TN, Ziegler EJ. An immunoprotective monoclonal antibody to lipopolysaccharide. J Immunol 1984;132:2590-2 
73. Teng NN, Kaplan HS, Hebert JM, et al. Protection against gram-negative bacteremia and endotoxemia with human monoclonal IgM antibodies. Proc Natl Acad Sci U S A 1985;82:1790-4

74. Ziegler EJ, Fisher Jr CJ, Sprung CL, et al. Treatment of gram-negative bacteremia and septic shock with HA-1A human monoclonal antibody against endotoxin. A randomized, double-blind, placebocontrolled trial. The HA-1A Sepsis Study Group. N Engl J Med 1991;324:429-36

75. Fisher Jr CJ, Marra MN, Palardy JE, et al. Human neutrophil bactericidal/ permeability-increasing protein reduces mortality rate from endotoxin challenge: a placebo-controlled study. Crit Care Med 1994;22:553-8

76. Kelly CJ, Cech AC, Argenteanu M, et al. Role of bactericidal permeability-increasing protein in the treatment of gram-negative pneumonia. Surgery 1993;114:140-6

77. Kohn FR, Ammons WS, Horwitz A, et al. Protective effect of a recombinant amino-terminal fragment of bactericidal/ permeability-increasing protein in experimental endotoxemia. J Infect Dis 1993;168:1307-10

78. Lin Y, Kohn FR, Kung AH, et al. Protective effect of a recombinant fragment of bactericidal/ permeability increasing protein against carbohydrate dyshomeostasis and tumor necrosis factoralpha elevation in rat endotoxemia. Biochem Pharmacol 1994;47:1553-9

79. Ammons WS, Kung AH. Recombinant amino terminal fragment of bactericidal/ permeabilityincreasing protein prevents hemodynamic responses to endotoxin. Circ Shock 1993;41:176-84

80. Weiss J, Olsson I. Cellular and subcellular localization of the bactericidal/ permeability-increasing protein of neutrophils. Blood 1987;69:652-9

81. Marra MN, Wilde CG, Collins MS, et al. The role of bactericidal/ permeability-increasing protein as a natural inhibitor of bacterial endotoxin. J Immunol 1992;148:532-7

82. Weersink AJ, Van Kessel KP, Van den Tol ME, et al. Human granulocytes express a 55-kDa lipopolysaccharide-binding protein on the cell surface that is identical to the bactericidal/ permeability-increasing protein. J Immunol 1993;150:253-63

83. Gazzano-Santoro H, Parent JB, Grinna L, et al. High-affinity binding of the bactericidal/ permeability-increasing protein and a recombinant amino-terminal fragment to the lipid $\mathrm{A}$ region of lipopolysaccharide. Infect Immun 1992;60:4754-61

84. Weiss J, Elsbach P, Olsson I, et al, Purification and characterization of a potent bactericidal and membrane active protein from the granules of human polymorphonuclear leukocytes. J Biol Chem $1978 ; 253: 2664-72$

85. Marra MN, Wilde CG, Griffith JE, et al. Bactericidal/ permeability-increasing protein has endotoxin-neutralizing activity. J Immunol 1990;144:662-6

86. Ooi CE, Weiss J, Doerfler ME, et al. Endotoxin-neutralizing properties of the $25 \mathrm{kD} \mathrm{N}$-terminal fragment and a newly isolated $30 \mathrm{kD}$ C-terminal fragment of the $55-60 \mathrm{kD}$ bactericidal/ permeability-increasing protein of human neutrophils. J Exp Med 1991;174:649-55

87. Weiss J, Elsbach P, Shu C, et al. Human bactericidal/ permeability-increasing protein and a recombinant $\mathrm{NH} 2$-terminal fragment cause killing of serum-resistant gram-negative bacteria in whole blood and inhibit tumor necrosis factor release induced by the bacteria. J Clin Invest 1992;90:1122-30

88. Dentener MA, Von Asmuth EJ, Francot GJ, et al. Antagonistic effects of lipopolysaccharide binding protein and bactericidal/ permeability-increasing protein on lipopolysaccharide-induced cytokine release by mononuclear phagocytes. Competition for binding to lipopolysaccharide. J Immunol 1993;151:4258-65

89. Corradin SB, Heumann D, Gallay P, et al. Bactericidal/ permeability-increasing protein inhibits induction of macrophage nitric oxide production by lipopolysaccharide. J Infect Dis 1994;169:105-11

90. Meszaros K, Parent JB, Gazzano-Santoro $\mathrm{H}$, et al. A recombinant amino terminal fragment of bactericidal/ permeability-increasing protein inhibits the induction of leukocyte responses by LPS. J Leukoc Biol 1993;54:558-63 
91. Giroir BP, Quint PA, Barton P, et al. Preliminary evaluation of recombinant amino-terminal fragment of human bactericidal/ permeability-increasing protein in children with severe meningococcal sepsis. Lancet 1997;350:1439-43

92. Dentener MA, Francot GJ, Smit FT, et al. Presence of bactericidal/ permeability-increasing protein in disease: detection by ELISA. J Infect Dis 1995;171:739-43

93. Opal SM, Palardy JE, Marra MN, et al. Relative concentrations of endotoxin-binding proteins in body fluids during infection. Lancet 1994;344:429-31

94. Calvano SE, Thompson WA, Marra MN, et al. Changes in polymorphonuclear leukocyte surface and plasma bactericidal/ permeability-increasing protein and plasma lipopolysaccharide binding protein during endotoxemia or sepsis. Arch Surg 1994;129:220-6

95. Wong HR, Doughty LA, Wedel $\mathrm{N}$, et al. Plasma bactericidal/ permeability-increasing protein concentrations in critically ill children with the sepsis syndrome. Pediatr Infect Dis J 1995;14:1087-91

96. Pereira BJ, Sundaram S, Snodgrass B, et al. Plasma lipopolysaccharide binding protein and bactericidal/ permeability increasing factor in CRF and HD patients. J Am Soc Nephrol 1996;7:47987

97. Von der Mohlen MA, Van der Poll T, Jansen J, et al. Release of bactericidal/ permeabilityincreasing protein in experimental endotoxemia and clinical sepsis. Role of tumor necrosis factor. J Immunol 1996;156:4969-73

98. Schindler R, Marra MN, McKelligon BM, et al. Plasma levels of bactericidal/ permeabilityincreasing protein (BPI) and lipopolysaccharide-binding protein (LBP) during hemodialysis. Clin Nephrol 1993;40:346-51

99. Schumann RR, Leong SR, Flaggs GW, et al. Structure and function of lipopolysaccharide binding protein. Science 1990;249:1429-31

100. Gray PW, Flaggs G, Leong SR, et al. Cloning of the cDNA of a human neutrophil bactericidal protein. Structural and functional correlations. J Biol Chem 1989;264:9505-9

101. Wright SD, Ramos RA, Tobias PS, et al. CD14, a receptor for complexes of lipopolysaccharide (LPS) and LPS binding protein. Science 1990;249:1431-3

102. Tobias PS, Soldau K, Ulevitch RJ. Isolation of a lipopolysaccharide-binding acute phase reactant from rabbit serum. J Exp Med 1986;164:777-93

103. Heumann D, Gallay P, Barras C, et al. Control of lipopolysaccharide (LPS) binding and LPSinduced tumor necrosis factor secretion in human peripheral blood monocytes. J Immunol 1992;148:3505-12

104. Mathison JC, Tobias PS, Wolfson E, et al. Plasma lipopolysaccharide (LPS)-binding protein. A key component in macrophage recognition of gram-negative LPS. J Immunol 1992;149:200-6

105. Wurfel MM, Monks BG, Ingalls RR, et al. Targeted deletion of the lipopolysaccharide (LPS)-binding protein gene leads to profound suppression of LPS responses ex vivo, whereas in vivo responses remain intact. J Exp Med 1997;186:2051-6

106. Wurfel MM, Kunitake ST, Lichenstein H, et al. Lipopolysaccharide (LPS)-binding protein is carried on lipoproteins and acts as a cofactor in the neutralization of LPS. J Exp Med 1994;180:1025-35

107. Massamiri T, Tobias PS, Curtiss LK. Structural determinants for the interaction of lipopolysaccharide binding protein with purified high density lipoproteins: role of apolipoprotein A-I. J Lipid Res 1997;38:516-25

108. Pajkrt D, Doran JE, Koster F, et al. Antiinflammatory effects of reconstituted high-density lipoprotein during human endotoxemia. J Exp Med 1996;184:1601-8

109. Geller DA, Kispert PH, Su GL, et al. Induction of hepatocyte lipopolysaccharide binding protein in models of sepsis and the acute-phase response. Arch Surg 1993;128:22-7

110. Gazzano-Santoro H, Meszaros K, Birr C, et al. Competition between rBPI23, a recombinant fragment of bactericidal/ permeability-increasing protein, and lipopolysaccharide (LPS)-binding protein for binding to LPS and gram-negative bacteria. Infect Immun 1994;62:1185-91 
111. Tobias PS, Soldau K, Kline L, et al. Cross-linking of lipopolysaccharide (LPS) to CD14 on THP-1 cells mediated by LPS-binding protein. J Immunol 1993;150:3011-21

112. Todd 3d RF, Nadler LM, Schlossman SF. Antigens on human monocytes identified by monoclonal antibodies. J Immunol 1981;126:1435-42

113. Goyert SM, Ferrero EM, Seremetis SV, et al. Biochemistry and expression of myelomonocytic antigens. J Immunol 1986;137:3909-14

114. Marchant A, Duchow J, Delville JP, et al. Lipopolysaccharide induces up-regulation of CD14 molecule on monocytes in human whole blood. Eur J Immunol 1992;22:1663-5

115. Haziot A, Tsuberi BZ, Goyert SM. Neutrophil CD14: biochemical properties and role in the secretion of tumor necrosis factor-alpha in response to lipopolysaccharide. J Immunol 1993;150:5556-65

116. Maliszewski CR, Ball ED, Graziano RF, et al. Isolation and characterization of My23, a myeloid cellderived antigen reactive with the monoclonal antibody AML-2-23. J Immunol 1985;135:1929-36

117. Bazil V, Strominger JL. Shedding as a mechanism of down-modulation of CD14 on stimulated human monocytes. J Immunol 1991;147:1567-74

118. Nockher WA, Scherberich JE. Expression and release of the monocyte lipopolysaccharide receptor antigen CD14 are suppressed by glucocorticoids in vivo and in vitro. J Immunol 1997;158:1345-52

119. Pugin J, Schurer-Maly CC, Leturcq D, et al. Lipopolysaccharide activation of human endothelial and epithelial cells is mediated by lipopolysaccharide-binding protein and soluble CD14. Proc Natl Acad Sci U S A 1993;90:2744-8

120. Haziot A, Rong GW, Silver J, et al. Recombinant soluble CD14 mediates the activation of endothelial cells by lipopolysaccharide. J Immunol 1993;151:1500-7

121. Frey EA, Miller DS, Jahr TG, et al. Soluble CD14 participates in the response of cells to lipopolysaccharide. J Exp Med 1992;176:1665-71

122. Von Asmuth EJ, Dentener MA, Bazil V, et al. Anti-CD14 antibodies reduce responses of cultured human endothelial cells to endotoxin. Immunology 1993;80:78-83

123. Hailman E, Vasselon T, Kelley M, et al. Stimulation of macrophages and neutrophils by complexes of lipopolysaccharide and soluble CD14. J Immunol 1996;156:4384-90

124. Tapping RI, Tobias PS. Cellular binding of soluble CD14 requires lipopolysaccharide (LPS) and LPS-binding protein. J Biol Chem 1997;272:23157-64

125. Kruger C, Schutt C, Obertacke U, et al. Serum CD14 levels in polytraumatized and severely burned patients. Clin Exp Immunol 1991;85:297-301

126. Landmann R, Reber AM, Sansano S, et al. Function of soluble CD14 in serum from patients with septic shock. J Infect Dis 1996;173:661-8

127. Leturcq DJ, Moriarty AM, Talbott G, et al. Antibodies against CD14 protect primates from endotoxin-induced shock. J Clin Invest 1996;98:1533-8

128. Davis JM, Narachi MA, Alton NK, et al. Structure of human tumor necrosis factor alpha derived from recombinant DNA. Biochemistry 1987;26:1322-6

129. Smith RA, Baglioni C. The active form of tumor necrosis factor is a trimer. J Biol Chem 1987;262:6951-4

130. Beutler B, Mahoney J, Le Trang N, et al. Purification of cachectin, a lipoprotein lipase-suppressing hormone secreted by endotoxin-induced RAW 264.7 cells. J Exp Med 1985;161:984-95

131. Cerami A, Ikeda Y, Le Trang N, et al. Weight loss associated with an endotoxin-induced mediator from peritoneal macrophages: the role of cachectin (tumor necrosis factor). Immunol Lett 1985;11:173-7

132. Beutler B, Greenwald D, Hulmes JD, et al. Identity of tumour necrosis factor and the macrophagesecreted factor cachectin. Nature 1985;316:552-4

133. Pennica D, Nedwin GE, Hayflick JS, et al. Human tumour necrosis factor: precursor structure, expression and homology to lymphotoxin. Nature 1984;312:724-9 
134. Caput D, Beutler B, Hartog K, et al. Identification of a common nucleotide sequence in the 3'untranslated region of mRNA molecules specifying inflammatory mediators. Proc Natl Acad Sci U S A $1986 ; 83: 1670-4$

135. Mathison JC, Wolfson E, Ulevitch RJ. Participation of tumor necrosis factor in the mediation of gram negative bacterial lipopolysaccharide-induced injury in rabbits. J Clin Invest 1988;81:1925-37

136. Matthews N. Tumour-necrosis factor from the rabbit. II. Production by monocytes. Br J Cancer 1978; $38: 310-5$

137. Mannel DN, Moore RN, Mergenhagen SE. Macrophages as a source of tumoricidal activity (tumornecrotizing factor). Infect Immun 1980;30:523-30

138. Cuturi MC, Murphy M, Costa-Giomi MP, et al. Independent regulation of tumor necrosis factor and lymphotoxin production by human peripheral blood lymphocytes. J Exp Med 1987;165:1581-94

139. Wright SC, Bonavida B. Studies on the mechanism of natural killer cell-mediated cytotoxicity. VII. functional comparison of human natural killer cytotoxic factors with recombinant lymphotoxin and tumor necrosis factor. J Immunol 1987;138:1791-8

140. Djeu JY, Serbousek D, Blanchard DK. Release of tumor necrosis factor by human polymorphonuclear leukocytes. Blood 1990;76:1405-9

141. Hesse DG, Tracey KJ, Fong Y, et al. Cytokine appearance in human endotoxemia and primate bacteremia. Surg Gynecol Obstet 1988;166:147-53

142. Michie HR, Manogue KR, Spriggs DR, et al. Detection of circulating tumor necrosis factor after endotoxin administration. N Engl J Med 1988;318:1481-6

143. Ferrante A, Staugas RE, Rowan-Kelly B, et al. Production of tumor necrosis factors alpha and beta by human mononuclear leukocytes stimulated with mitogens, bacteria, and malarial parasites. Infect Immun 1990;58:3996-4003

144. Djeu JY, Blanchard DK, Richards AL, et al. Tumor necrosis factor induction by Candida albicans from human natural killer cells and monocytes. J Immunol 1988;141:4047-52

145. Ayala A, Wang P, Ba ZF, et al. Differential alterations in plasma IL-6 and TNF levels after trauma and hemorrhage. Am J Physiol 1991;260:R167-71

146. Scannell G, Waxman K, Kaml GJ, et al. Hypoxia induces a human macrophage cell line to release tumor necrosis factor-alpha and its soluble receptors in vitro. J Surg Res 1993;54:281-5

147. Ayala A, Perrin MM, Ertel W, et al. Differential effects of hemorrhage on Kupffer cells: decreased antigen presentation despite increased inflammatory cytokine (IL-1, IL-6 and TNF) release. Cytokine 1992;4:66-75

148. Hoffman M, Weinberg JB. Tumor necrosis factor-alpha induces increased hydrogen peroxide production and Fc receptor expression, but not increased Ia antigen expression by peritoneal macrophages. J Leukoc Biol 1987;42:704-7

149. Liew FY, Parkinson C, Millott S, et al. Tumour necrosis factor (TNF alpha) in leishmaniasis. I. TNF alpha mediates host protection against cutaneous leishmaniasis. Immunology 1990;69:570-3

150. Wirth JJ, Kierszenbaum F. Recombinant tumor necrosis factor enhances macrophage destruction of Trypanosoma cruzi in the presence of bacterial endotoxin. J Immunol 1988;141:286-8

151. Esparza I, Mannel D, Ruppel A, et al. Interferon gamma and lymphotoxin or tumor necrosis factor act synergistically to induce macrophage killing of tumor cells and schistosomula of Schistosoma mansoni. J Exp Med 1987; 166:589-94

152. Mestan J, Digel W, Mittnacht S, et al. Antiviral effects of recombinant tumour necrosis factor in vitro. Nature 1986;323:816-9

153. Wong GH, Goeddel DV. Tumour necrosis factors alpha and beta inhibit virus replication and synergize with interferons. Nature 1986;323:819-22

154. Shalaby MR, Aggarwal BB, Rinderknecht E, et al. Activation of human polymorphonuclear neutrophil functions by interferon-gamma and tumor necrosis factors. J Immunol 1985;135:2069-73 
155. Djeu JY, Blanchard DK, Halkias D, et al. Growth inhibition of Candida albicans by human polymorphonuclear neutrophils: activation by interferon-gamma and tumor necrosis factor. J Immunol 1986;137:2980-4

156. Klebanoff SJ, Vadas MA, Harlan JM, et al. Stimulation of neutrophils by tumor necrosis factor. J Immunol 1986;136:4220-5

157. Tsujimoto M, Yokota S, Vilcek J, et al. Tumor necrosis factor provokes superoxide anion generation from neutrophils. Biochem Biophys Res Commun 1986;137:1094-100

158. Arnaout MA. Structure and function of the leukocyte adhesion molecules CD11/ CD18. Blood 1990;75:1037-50

159. Berger M, Wetzler EM, Wallis RS. Tumor necrosis factor is the major monocyte product that increases complement receptor expression on mature human neutrophils. Blood 1988;71:151-8

160. Bachwich PR, Chensue SW, Larrick JW, et al. Tumor necrosis factor stimulates interleukin-1 and prostaglandin E2 production in resting macrophages. Biochem Biophys Res Commun 1986;136:94101

161. Endo H, Akahoshi T, Kashiwazaki S. Additive effects of IL-1 and TNF on induction of prostacyclin synthesis in human vascular endothelial cells. Biochem Biophys Res Commun 1988;156:1007-14

162. Camussi G, Bussolino F, Salvidio G, et al. Tumor necrosis factor/ cachectin stimulates peritoneal macrophages, polymorphonuclear neutrophils, and vascular endothelial cells to synthesize and release platelet-activating factor. J Exp Med 1987;166:1390-404

163. Echtenacher B, Falk W, Mannel DN, et al. Requirement of endogenous tumor necrosis factor/ cachectin for recovery from experimental peritonitis. J Immunol 1990;145:3762-6

164. Neifer S, Kremsner PG, Bienzle U. Application of anti-TNF to Plasmodium vinckei-infected mice is followed by an increase of parasitaemia. Acta Trop 1989;46:273-5

165. Taverne J, Tavernier J, Fiers W, et al. Recombinant tumour necrosis factor inhibits malaria parasites in vivo but not in vitro. Clin Exp Immunol 1987;67:1-4

166. Cross AS, Sadoff JC, Kelly N, et al. Pretreatment with recombinant murine tumor necrosis factor alpha/ cachectin and murine interleukin 1 alpha protects mice from lethal bacterial infection. J Exp Med 1989;169:2021-7

167. Titus RG, Sherry B, Cerami A. Tumor necrosis factor plays a protective role in experimental murine cutaneous leishmaniasis. J Exp Med 1989;170:2097-104

168. Suffredini AF, Fromm RE, Parker MM, et al. The cardiovascular response of normal humans to the administration of endotoxin. N Engl J Med 1989;321:280-7

169. Giroir BP. Mediators of septic shock: new approaches for interrupting the endogenous inflammatory cascade. Crit Care Med 1993;21:780-9

170. Chapman PB, Lester TJ, Casper ES, et al. Clinical pharmacology of recombinant human tumor necrosis factor in patients with advanced cancer. J Clin Oncol 1987;5:1942-51

171. Tracey KJ, Lowry SF, Fahey 3d TJ, et al. Cachectin/ tumor necrosis factor induces lethal shock and stress hormone responses in the dog. Surg Gynecol Obstet 1987;164:415-22

172. Zuckerman SH, Shellhaas J, Butler LD. Differential regulation of lipopolysaccharide-induced interleukin 1 and tumor necrosis factor synthesis: effects of endogenous and exogenous glucocorticoids and the role of the pituitary-adrenal axis. Eur J Immunol 1989;19:301-5

173. Beutler B, Krochin N, Milsark IW, et al. Control of cachectin (tumor necrosis factor) synthesis: mechanisms of endotoxin resistance. Science 1986;232:977-80

174. Philip R, Epstein LB. Tumour necrosis factor as immunomodulator and mediator of monocyte cytotoxicity induced by itself, gamma-interferon and interleukin-1. Nature 1986;323:86-9

175. Derkx B, Marchant A, Goldman M, et al. High levels of interleukin-10 during the initial phase of fulminant meningococcal septic shock. J Infect Dis 1995;171:229-32

176. Gomez-Jimenez J, Martin MC, Sauri R, et al. Interleukin-10 and the monocyte/ macrophageinduced inflammatory response in septic shock. J Infect Dis 1995;171:472-5 
177. Marchant A, Deviere J, Byl B, et al. Interleukin-10 production during septicaemia. Lancet 1994:343:707-8

178. Van Deuren M, Van der Ven-Jongekrijg J, Bartelink AK, et al. Correlation between proinflammatory cytokines and antiinflammatory mediators and the severity of disease in meningococcal infections. J Infect Dis 1995;172:433-9

179. Gerard C, Bruyns C, Marchant A, et al. Interleukin 10 reduces the release of tumor necrosis factor and prevents lethality in experimental endotoxemia. J Exp Med 1993;177:547-50

180. Van der Poll T, Marchant A, Keogh CV, et al. Interleukin-10 impairs host defense in murine pneumococcal pneumonia. J Infect Dis 1996;174:994-1000

181. Van der Poll T, Jansen PM, Montegut WJ, et al. Effects of IL-10 on systemic inflammatory responses during sublethal primate endotoxemia. J Immunol 1997;158:1971-5

182. Pajkrt D, Camoglio L, Tiel-van Buul MC, et al. Attenuation of proinflammatory response by recombinant human $\Pi-10$ in human endotoxemia: effect of timing of recombinant human $I L-10$ administration. J Immunol 1997;158:3971-7

183. Ferguson-Chanowitz KM, Katocs Jr AS, Pickett WC, et al. Platelet-activating factor or a plateletactivating factor antagonist decreases tumor necrosis factor-alpha in the plasma of mice treated with endotoxin. J Infect Dis 1990;162:1081-6

184. Molvig J, Baek L, Christensen P, et al. Endotoxin-stimulated human monocyte secretion of interleukin 1, tumour necrosis factor alpha, and prostaglandin E2 shows stable interindividual differences. Scand J Immunol 1988;27:705-16

185. Pociot F, Briant L, Jongeneel CV, et al. Association of tumor necrosis factor (TNF) and class II major histocompatibility complex alleles with the secretion of TNF-alpha and TNF-beta by human mononuclear cells: a possible link to insulin-dependent diabetes mellitus. Eur J Immunol 1993;23:224-31

186. Nadel S, Newport MJ, Booy R, et al. Variation in the tumor necrosis factor-alpha gene promoter region may be associated with death from meningococcal disease. J Infect Dis 1996;174:878-80

187. Debets JM, Kampmeijer R, Van der Linden MP, et al. Plasma tumor necrosis factor and mortality in critically ill septic patients. Crit Care Med 1989;17:489-94

188. Damas P, Reuter A, Gysen P, et al. Tumor necrosis factor and interleukin-1 serum levels during severe sepsis in humans. Crit Care Med 1989;17:975-8

189. Girardin E, Grau GE, Dayer JM, et al. Tumor necrosis factor and interleukin-1 in the serum of children with severe infectious purpura. N Engl J Med 1988;319:397-400

190. Marks JD, Marks CB, Luce JM, et al. Plasma tumor necrosis factor in patients with septic shock. Mortality rate, incidence of adult respiratory distress syndrome, and effects of methylprednisolone administration. Am Rev Respir Dis 1990;141:94-7

191. Damas P, Canivet JL, De Groote D, et al. Sepsis and serum cytokine concentrations. Crit Care Med 1997; 25:405-12

192. Friedland JS, Porter JC, Daryanani S, et al. Plasma proinflammatory cytokine concentrations, Acute Physiology and Chronic Health Evaluation (APACHE) III scores and survival in patients in an intensive care unit. Crit Care Med 1996;24:1775-81

193. Waage A, Halstensen A, Espevik T. Association between tumour necrosis factor in serum and fatal outcome in patients with meningococcal disease. Lancet 1987;1:355-7

194. Hamilton G, Hofbauer S, Hamilton B. Endotoxin, TNF-alpha, interleukin-6 and parameters of the cellular immune system in patients with intraabdominal sepsis. Scand J Infect Dis 1992;24:361-8

195. Waage A, Brandtzaeg P, Halstensen A, et al. The complex pattern of cytokines in serum from patients with meningococcal septic shock. Association between interleukin 6, interleukin 1, and fatal outcome. J Exp Med 1989;169:333-8

196. Beutler B, Milsark IW, Cerami AC. Passive immunization against cachectin/ tumor necrosis factor protects mice from lethal effect of endotoxin. Science 1985;229:869-71 
197. Tracey KJ, Fong Y, Hesse DG, et al. Anti-cachectin/ TNF monoclonal antibodies prevent septic shock during lethal bacteraemia. Nature 1987;330:662-4

198. Ashkenazi A, Marsters SA, Capon DJ, et al. Protection against endotoxic shock by a tumor necrosis factor receptor immunoadhesin. Proc Natl Acad Sci U S A 1991;88:10535-9

199. Reinhart K, Wiegand-Lohnert C, Grimminger F, et al. Assessment of the safety and efficacy of the monoclonal anti-tumor necrosis factor antibody-fragment, MAK 195F, in patients with sepsis and septic shock: a multicenter, randomized, placebo-controlled, dose-ranging study. Crit Care Med $1996 ; 24: 733-42$

200. Seckinger P, Isaaz S, Dayer JM. A human inhibitor of tumor necrosis factor alpha. J Exp Med 1988;167:1511-6

201. Aggarwal BB, Eessalu TE, Hass PE. Characterization of receptors for human tumour necrosis factor and their regulation by gamma-interferon. Nature 1985;318:665-7

202. Hahn BH, Gonda MA, Shaw GM, et al. Genomic diversity of the acquired immune deficiency syndrome virus HTLV-III: different viruses exhibit greatest divergence in their envelope genes. Proc Natl Acad Sci US A 1985;82:4813-7

203. Scheurich P, Ucer U, Kronke M, et al. Quantification and characterization of high-affinity membrane receptors for tumor necrosis factor on human leukemic cell lines $\square$. Int J Cancer 1986;38:127-33

204. Hohmann HP, Remy R, Brockhaus M, et al. Two different cell types have different major receptors for human tumor necrosis factor (TNF alpha). J Biol Chem 1989;264:14927-34

205. Munker R, DiPersio J, Koeffler HP. Tumor necrosis factor: receptors on hematopoietic cells. Blood $1987 ; 70: 1730-4$

206. Brockhaus M, Schoenfeld HJ. Schlaeger EJ, et al. Identification of two types of tumor necrosis factor receptors on human cell lines by monoclonal antibodies. Proc Natl Acad Sci U S A 1990;87:3127-31

207. Porteu F, Nathan C. Shedding of tumor necrosis factor receptors by activated human neutrophils. J Exp Med 1990;172:599-607

208. Bemelmans MH, Gouma DJ, Buurman WA. LPS-induced sTNF-receptor release in vivo in a murine model. Investigation of the role of tumor necrosis factor, IL-1, leukemia inhibiting factor, and IFNgamma. J Immunol 1993;151:5554-62

209. Van Zee KJ, Kohno T, Fischer E, et al. Tumor necrosis factor soluble receptors circulate during experimental and clinical inflammation and can protect against excessive tumor necrosis factor alpha in vitro and in vivo. Proc Natl Acad Sci U S A 1992;89:4845-9

210. Spinas GA, Keller U, Brockhaus M. Release of soluble receptors for tumor necrosis factor (TNF) in relation to circulating TNF during experimental endotoxinemia. J Clin Invest 1992;90:533-6

211. Lantz M, Malik S, Slevin ML, et al. Infusion of tumor necrosis factor (TNF) causes an increase in circulating TNF-binding protein in humans. Cytokine 1990;2:402-6

212. Girardin E, Roux-Lombard P, Grau GE, et al. Imbalance between tumour necrosis factor-alpha and soluble TNF receptor concentrations in severe meningococcaemia. The J5 Study Group. Immunology 1992;76:20-3

213. Brockhaus M, Bar Khayim Y, Gurwicz S, et al. Plasma tumor necrosis factor soluble receptors in chronic renal failure. Kidney Int 1992;42:663-7

214. Lantz M, Gullberg U, Nilsson E, et al. Characterization in vitro of a human tumor necrosis factorbinding protein. A soluble form of a tumor necrosis factor receptor. J Clin Invest 1990;86:1396-42

215. Porteu F, Brockhaus M, Wallach D, et al. Human neutrophil elastase releases a ligand-binding fragment from the 75-kDa tumor necrosis factor (TNF) receptor. Comparison with the proteolytic activity responsible for shedding of TNF receptors from stimulated neutrophils. J Biol Chem 1991;266:18846-53

216. Aderka D, Engelmann H, Maor Y, et al. Stabilization of the bioactivity of tumor necrosis factor by its soluble receptors. J Exp Med 1992;175:323-9 
217. Lesslauer W, Tabuchi H, Gentz R, et al. Recombinant soluble tumor necrosis factor receptor proteins protect mice from lipopolysaccharide-induced lethality. Eur J Immunol 1991;21:2883-6

218. Van Zee KJ, Fischer E, Hawes AS, et al. Effects of intravenous IL-8 administration in nonhuman primates. J Immunol 1992;148:1746-52

219. Van Zee KJ, Moldawer LL, Oldenburg HS, et al. Protection against lethal Escherichia coli bacteremia in baboons (Papio anubis) by pretreatment with a 55-kDa TNF receptor (CD120a)-Ig fusion protein, Ro 45-2081. J Immunol 1996;156:2221-30

220. Van der Poll T, Jansen PM, Van Zee KJ, et al. Pretreatment with a 55-kDa tumor necrosis factor receptor-immunoglobulin fusion protein attenuates activation of coagulation, but not of fibrinolysis, during lethal bacteremia in baboons. J Infect Dis 1997;176:296-9

221. Van Snick J, Cayphas S, Vink A, et al. Purification and NH2-terminal amino acid sequence of a Tcell-derived lymphokine with growth factor activity for B-cell hybridomas. Proc Natl Acad Sci U S A 1986;83:9679-83

222. Van Damme J, Cayphas S, Opdenakker G, et al. Interleukin 1 and poly ( $\mathrm{rI}$ ).poly (rC) induce production of a hybridoma growth factor by human fibroblasts. Eur J Immunol 1987;17:1-7

223. Sironi M, Breviario F, Proserpio P, et al. IL-1 stimulates IL-6 production in endothelial cells. J Immunol 1989;142:549-53

224. Bauer J, Herrmann F. Interleukin-6 in clinical medicine. Ann Hematol 1991;62:203-10

225. Kushner I, Ganapathi M, Schultz D. The acute phase response is mediated by heterogeneous mechanisms. Ann N Y Acad Sci 1989;557:19-29

226. Baumann H, Gauldie J. Regulation of hepatic acute phase plasma protein genes by hepatocyte stimulating factors and other mediators of inflammation. Mol Biol Med 1990;7:147-59

227. Steel DM, Whitehead AS. The major acute phase reactants: C-reactive protein, serum amyloid P component and serum amyloid A protein. Immunol Today 1994;15:81-8

228. Kopf M, Baumann H, Freer G, et al. Impaired immune and acute-phase responses in interleukin-6deficient mice. Nature 1994;368:339-42

229. Borish L, Rosenbaum R, Albury L, et al. Activation of neutrophils by recombinant interleukin 6 . Cell Immunol 1989;121:280-9

230. Schindler R, Mancilla J, Endres S, et al. Correlations and interactions in the production of interleukin-6 (IL-6), IL-1, and tumor necrosis factor (TNF) in human blood mononuclear cells: IL-6 suppresses IL-1 and TNF. Blood 1990;75:40-7

231. Van der Poll T, Levi M, Hack CE, et al. Elimination of interleukin 6 attenuates coagulation activation in experimental endotoxemia in chimpanzees. J Exp Med 1994;179:1253-9

232. Borden EC, Chin P. Interleukin-6: a cytokine with potential diagnostic and therapeutic roles. J Lab Clin Med 1994;123:824-9

233. Van der Poll T, Keogh CV, Guirao X, et al. Interleukin-6 gene-deficient mice show impaired defense against pneumococcal pneumonia. J Infect Dis 1997;176:439-44

234. Preiser JC, Schmartz D, Van der Linden P, et al. Interleukin-6 administration has no acute hemodynamic or hematologic effect in the dog. Cytokine 1991;3:1-4

235. Libert C, Vink A, Coulie P, et al. Limited involvement of interleukin-6 in the pathogenesis of lethal septic shock as revealed by the effect of monoclonal antibodies against interleukin- 6 or its receptor in various murine models. Eur J Immunol 1992;22:2625-30

236. Van der Poll T, Van Deventer SJ, Hack CE, et al. Effects on leukocytes after injection of tumor necrosis factor into healthy humans. Blood 1992;79:693-8

237. Creasey AA, Stevens P, Kenney J, et al. Endotoxin and cytokine profile in plasma of baboons challenged with lethal and sublethal Escherichia coli. Circ Shock 1991;33:84-91

238. Kuhns DB, Alvord WG, Gallin JI. Increased circulating cytokines, cytokine antagonists, and Eselectin after intravenous administration of endotoxin in humans. J Infect Dis 1995;171:145-52 
239. Shalaby MR, Waage A, Aarden LA, et al. Endotoxin, tumor necrosis factor-alpha and interleukin 1 induce interleukin 6 production in vivo. Clin Immunol Immunopathol 1989;53:488-98

240. Fong Y, Lowry SF. Tumor necrosis factor in the pathophysiology of infection and sepsis. Clin Immunol Immunopathol 1990;55:157-70

241. Fong Y, Tracey KJ, Moldawer LL, et al. Antibodies to cachectin/ tumor necrosis factor reduce interleukin 1 beta and interleukin 6 appearance during lethal bacteremia. J Exp Med 1989;170:162733

242. Fischer E, Marano MA, Van Zee KJ, et al. Interleukin-1 receptor blockade improves survival and hemodynamic performance in Escherichia coli septic shock, but fails to alter host responses to sublethal endotoxemia. J Clin Invest 1992;89:1551-7

243. Moscovitz H, Shofer F, Mignott H, et al. Plasma cytokine determinations in emergency department patients as a predictor of bacteremia and infectious disease severity. Crit Care Med 1994:22:1102-7

244. Dofferhoff AS, Bom VJ, De Vries-Hospers HG, et al. Patterns of cytokines, plasma endotoxin, plasminogen activator inhibitor, and acute-phase proteins during the treatment of severe sepsis in humans. Crit Care Med 1992;20:185-92

245. Damas P, Ledoux D, Nys M, et al. Cytokine serum level during severe sepsis in human IL-6 as a marker of severity. Ann Surg 1992;215:356-62

246. Calandra T, Gerain J, Heumann D, et al. High circulating levels of interleukin- 6 in patients with septic shock: evolution during sepsis, prognostic value, and interplay with other cytokines. The Swiss-Dutch J5 Immunoglobulin Study Group. Am J Med 1991;91:23-9

247. Casey LC, Balk RA, Bone RC. Plasma cytokine and endotoxin levels correlate with survival in patients with the sepsis syndrome. Ann Intern Med 1993;119:771-8

248. Endo S, Inada K, Inoue Y, et al. Two types of septic shock classified by the plasma levels of cytokines and endotoxin. Circ Shock 1992;38:264-74

249. Goldie AS, Fearon KC, Ross JA, et al. Natural cytokine antagonists and endogenous antiendotoxin core antibodies in sepsis syndrome. The Sepsis Intervention Group. Jama 1995;274:172-7

250. Sullivan JS, Kilpatrick L, Costarino Jr AT, et al. Correlation of plasma cytokine elevations with mortality rate in children with sepsis. J Pediatr 1992;120:510-5

251. Hack CE, De Groot ER, Felt-Bersma RJ, et al. Increased plasma levels of interleukin-6 in sepsis. Blood 1989;74:1704-10

252. Ertel W, Faist E, Nestle C, et al. Kinetics of interleukin- 2 and interleukin- 6 synthesis following major mechanical trauma. J Surg Res 1990;48:622-8

253. Cruickshank AM, Fraser WD, Burns HJ, et al. Response of serum interleukin-6 in patients undergoing elective surgery of varying severity. Clin Sci Colch 1990;79:161-5

254. Baigrie RJ, Lamont PM, Kwiatkowski D, et al. Systemic cytokine response after major surgery. Br J Surg 1992;79:757-60

255. Larsen CG, Anderson AO, Appella E, et al. The neutrophil-activating protein (NAP-1) is also chemotactic for T lymphocytes. Science 1989;243:1464-6

256. Yoshimura T, Matsushima K, Oppenheim JJ, et al. Neutrophil chemotactic factor produced by lipopolysaccharide (LPS)-stimulated human blood mononuclear leukocytes: partial characterization and separation from interleukin 1 (IL 1). J Immunol 1987;139:788-93

257. Strieter RM, Kunkel SL, Showell HJ, et al. Endothelial cell gene expression of a neutrophil chemotactic factor by TNF-alpha, LPS, and IL-1 beta. Science 1989;243:1 167-9

258. Peveri P, Walz A, Dewald B, et al. A novel neutrophil-activating factor produced by human mononuclear phagocytes. J Exp Med 1988;167:1547-59

259. Matsushima K, Morishita K, Yoshimura T, et al. Molecular cloning of a human monocyte-derived neutrophil chemotactic factor (MDNCF) and the induction of MDNCF mRNA by interleukin 1 and tumor necrosis factor. J Exp Med 1988;167:1883-93 
260. Schroder JM, Mrowietz U, Morita E, et al. Purification and partial biochemical characterization of a human monocyte-derived, neutrophil-activating peptide that lacks interleukin 1 activity. J Immunol 1987;139:3474-83

261. Rampart M, Van Damme J, Zonnekeyn L, et al. Granulocyte chemotactic protein/ interleukin-8 induces plasma leakage and neutrophil accumulation in rabbit skin. Am J Pathol 1989;135:21-5

262. Gimbrone Jr MA, Obin MS, Brock AF, et al. Endothelial interleukin-8: a novel inhibitor of leukocyte-endothelial interactions. Science 1989;246:1601-3

263. Strieter RM, Chensue SW, Standiford TJ, et al. Disparate gene expression of chemotactic cytokines by human mononuclear phagocytes. Biochem Biophys Res Commun 1990;166:886-91

264. Kunkel SL, Standiford T, Kasahara K, et al. Interleukin-8 (IL-8): the major neutrophil chemotactic factor in the lung. Exp Lung Res 1991;17:17-23

265. Strieter RM, Kasahara K, Allen R, et al. Human neutrophils exhibit disparate chemotactic factor gene expression. Biochem Biophys Res Commun 1990;173:725-30

266. Gregory H, Young J, Schroder JM, et al. Structure determination of a human lymphocyte derived neutrophil activating peptide (LYNAP). Biochem Biophys Res Commun 1988;151:883-90

267. Standiford TJ, Kunkel SL, Basha MA, et al. Interleukin- 8 gene expression by a pulmonary epithelial cell line. A model for cytokine networks in the lung. J Clin Invest 1990;86:1945-53

268. Mielke V, Bauman JG, Sticherling M, et al. Detection of neutrophil-activating peptide NAP/ IL-8 and NAP/ IL-8 mRNA in human recombinant IL-1 alpha- and human recombinant tumor necrosis factor-alpha-stimulated human dermal fibroblasts. An immunocytochemical and fluorescent in situ hybridization study. J Immunol 1990;144:153-61

269. Swensson O, Schubert C, Christophers E, et al. Inflammatory properties of neutrophil-activating protein-1/ interleukin 8 (NAP-1/ IL-8) in human skin: a light- and electronmicroscopic study. J Invest Dermatol 1991;96:682-9

270. Sekido N, Mukaida N, Harada A, et al. Prevention of lung reperfusion injury in rabbits by a monoclonal antibody against interleukin-8. Nature 1993;365:654-7

271. Sica A, Matsushima K, Van Damme J, et al. IL-1 transcriptionally activates the neutrophil chemotactic factor/ IL-8 gene in endothelial cells. Immunology 1990;69:548-53

272. Van Zee KJ, DeForge LE, Fischer E, et al. IL-8 in septic shock, endotoxemia, and after IL-1 administration. J Immunol 1991;146:3478-82

273. Martich GD, Danner RL, Ceska M, et al. Detection of interleukin 8 and tumor necrosis factor in normal humans after intravenous endotoxin: the effect of antiinflammatory agents. J Exp Med $1991 ; 173: 1021-4$

274. Van Deventer SJ, Hart M, Van der Poll T, et al. Endotoxin and tumor necrosis factor-alpha-induced interleukin-8 release in humans. J Infect Dis 1993;167:461-54

275. Redl H, Schlag G, Ceska M, et al. Interleukin-8 release in baboon septicemia is partially dependent on tumor necrosis factor. J Infect Dis 1993;167:1464-6

276. Metinko AP, Kunkel SL, Standiford T], et al. Anoxia-hyperoxia induces monocyte-derived interleukin-8. J Clin Invest 1992;90:791-8

277. Rodriguez JL, Miller CG, DeForge LE, et al. Local production of interleukin-8 is associated with nosocomial pneumonia. J Trauma 1992;33:74-81

278. Donnelly SC, Strieter RM, Kunkel SL, et al. Interleukin-8 and development of adult respiratory distress syndrome in at-risk patient groups. Lancet 1993;341:643-7

279. Miller EJ, Cohen AB, Matthay MA. Increased interleukin- 8 concentrations in the pulmonary edema fluid of patients with acute respiratory distress syndrome from sepsis. Crit Care Med 1996;24:144854

280. Chollet-Martin S, Montravers P, Gibert C, et al. High levels of interleukin- 8 in the blood and alveolar spaces of patients with pneumonia and adult respiratory distress syndrome. Infect Immun 1993;61:4553-9 
281. Miller EJ, Cohen AB, Nagao S, et al. Elevated levels of NAP-1/ interleukin-8 are present in the airspaces of patients with the adult respiratory distress syndrome and are associated with increased mortality. Am Rev Respir Dis 1992;146:427-32

282. Marty C, Misset B, Tamion F, et al. Circulating interleukin-8 concentrations in patients with multiple organ failure of septic and nonseptic origin. Crit Care Med 1994;22:673-9

283. Hack CE, Hart M, Strack van Schijndel RJ, et al. Interleukin-8 in sepsis: relation to shock and inflammatory mediators. Infect Immun 1992;60:2835-42

284. Arnould T, Michiels C, Remacle J. Increased PMN adherence on endothelial cells after hypoxia: involvement of PAF, CD18/ CD11b, and ICAM-1. Am J Physiol 1993;264:C1102-10

285. Yoshida N, Granger DN, Anderson DC, et al. Anoxia/ reoxygenation-induced neutrophil adherence to cultured endothelial cells. Am J Physiol 1992;262:H1891-8

286. Bevilacqua MP, Pober JS, Mendrick DL, et al. Identification of an inducible endothelial-leukocyte adhesion molecule. Proc Natl Acad Sci U S A 1987;84:9238-42

287. Smith CW, Marlin SD, Rothlein R, et al. Cooperative interactions of LFA-1 and Mac-1 with intercellular adhesion molecule-1 in facilitating adherence and transendothelial migration of human neutrophils in vitro. J Clin Invest 1989;83:2008-17

288. Ruoslahti E. Integrins. J Clin Invest 1991;87:1-5

289. Diamond MS, Staunton DE, De Fougerolles AR, et al. ICAM-1 (CD54): a counter-receptor for Mac-1 (CD11b/ CD18). J Cell Biol 1990;111:3129-39

290. Pober JS, Bevilacqua MP, Mendrick DL, et al. Two distinct monokines, interleukin 1 and tumor necrosis factor, each independently induce biosynthesis and transient expression of the same antigen on the surface of cultured human vascular endothelial cells. J Immunol 1986;136:1680-7

291. Cotran RS, Gimbrone Jr MA, Bevilacqua MP, et al. Induction and detection of a human endothelial activation antigen in vivo. J Exp Med 1986;164:661-6

292. Bevilacqua MP, Stengelin S, Gimbrone Jr MA, et al. Endothelial leukocyte adhesion molecule 1: an inducible receptor for neutrophils related to complement regulatory proteins and lectins. Science 1989;243:1160-5

293. Bevilacqua M, Butcher E, Furie B, et al. Selectins: a family of adhesion receptors. Cell 1991;67:233

294. Leeuwenberg JF, Smeets EF, Neefjes JJ, et al. E-selectin and intercellular adhesion molecule-1 are released by activated human endothelial cells in vitro. Immunology 1992;77:543-9

295. Pigott R, Dillon LP, Hemingway IH, et al. Soluble forms of E-selectin, ICAM-1 and VCAM-1 are present in the supernatants of cytokine activated cultured endothelial cells. Biochem Biophys Res Commun 1992;187:584-9

296. Newman W, Beall LD, Carson CW, et al. Soluble E-selectin is found in supernatants of activated endothelial cells and is elevated in the serum of patients with septic shock. J Immunol 1993;150:64454

297. Rothlein R, Mainolfi EA, Czajkowski M, et al. A form of circulating ICAM-1 in human serum. J Immunol 1991;147:3788-93

298. Kuster H, Degitz K. Circulating ICAM-1 in neonatal sepsis. Lancet 1993;341:506

299. Larsen GR, Sako D, Ahern TJ, et al. P-selectin and E-selectin. Distinct but overlapping leukocyte ligand specificities. J Biol Chem 1992;267:11104-10

300. Foxall C, Watson SR, Dowbenko D, et al. The three members of the selectin receptor family recognize a common carbohydrate epitope, the sialyl Lewis $(x)$ rligosaccharide. J Cell Biol 1992;117:895-902

301. Leeuwenberg JF, Jeunhomme GM, Buurman WA. Adhesion of polymorphonuclear cells to human endothelial cells. Adhesion-molecule-dependent, and Fc receptor-mediated adhesion-moleculeindependent mechanisms. Clin Exp Immunol 1990;81:496-500

302. Leeuwenberg JF, Jeunhomme TM, Buurman WA. Role of ELAM-1 in adhesion of monocytes to activated human endothelial cells. Scand J Immunol 1992;35:335-41 
303. Shimizu Y, Shaw S, Graber N, et al. Activation-independent binding of human memory $T$ cells to adhesion molecule ELAM-1. Nature 1991;349:799-802

304. Lawrence MB, Smith CW, Eskin SG, et al. Effect of venous shear stress on CD18-mediated neutrophil adhesion to cultured endothelium. Blood 1990;75:227-37

305. Lawrence MB, Springer TA. Leukocytes roll on a selectin at physiologic flow rates: distinction from and prerequisite for adhesion through integrins. Cell 1991;65:859-73

306. Mulligan MS, Varani J, Dame MK, et al. Role of endothelial-leukocyte adhesion molecule 1 (ELAM1) in neutrophil-mediated lung injury in rats. J Clin Invest 1991;88:1396-406

307. Engelberts I, Van Hoof SC, Samyo SK, et al. Generalized inflammation during peritonitis evidenced by intracutaneous E-selectin expression. Clin Immunol Immunopathol 1992;65:330-4

308. Redl H, Dinges HP, Buurman WA, et al. Expression of endothelial leukocyte adhesion molecule-1 in septic but not traumatic/ hypovolemic shock in the baboon. Am J Pathol 1991;139:461-6

309. Engelberts I, Samyo SK, Leeuwenberg JF, et al. A role for ELAM-1 in the pathogenesis of MOF during septic shock. J. Surg. Res. 1992;53:136-144

310. Cowley HC, Heney D, Gearing AJ, et al. Increased circulating adhesion molecule concentrations in patients with the systemic inflammatory response syndrome; a prospective cohort study. Crit Care Med 1994;22:651-7

311. Lobb RR, Chi-Rosso G, Leone DR, et al. Expression and functional characterization of a soluble form of endothelial-leukocyte adhesion molecule 1. J Immunol 1991;147:124-9

312. Dustin ML, Rothlein R, Bhan AK, et al. Induction by IL 1 and interferon-gamma: tissue distribution, biochemistry, and function of a natural adherence molecule (ICAM-1). J Immunol 1986;137:245-54

313. Rothlein R, Czajkowski M, O'Neill MM, et al. Induction of intercellular adhesion molecule 1 on primary and continuous cell lines by pro-inflammatory cytokines. Regulation by pharmacologic agents and neutralizing antibodies. J Immunol 1988;141:1665-9

314. Leeuwenberg JF, Jeunhomme TM, Buurman WA. Induction of an activation antigen on human endothelial cells in vitro. Eur J Immunol 1989;19:715-20

315. Ma XL, Lefer DJ, Lefer AM, et al. Coronary endothelial and cardiac protective effects of a monoclonal antibody to intercellular adhesion molecule-1 in myocardial ischemia and reperfusion. Circulation 1992;86:937-46

316. Vedder NB, Winn RK, Rice CL, et al. A monoclonal antibody to the adherence-promoting leukocyte glycoprotein, CD18, reduces organ injury and improves survival from hemorrhagic shock and resuscitation in rabbits. J Clin Invest 1988;81:939-44

317. Horgan MJ, Ge M, Gu J, et al. Role of ICAM-1 in neutrophil-mediated lung vascular injury after occlusion and reperfusion. Am J Physiol 1991;261:H1578-84

318. Mileski WJ, Winn RK, Vedder NB, et al. Inhibition of CD18-dependent neutrophil adherence reduces organ injury after hemorrhagic shock in primates. Surgery 1990;108:206-12

319. Kawasaki K, Yaoita E, Yamamoto T, et al. Antibodies against intercellular adhesion molecule-1 and lymphocyte function-associated antigen-1 prevent glomerular injury in rat experimental crescentic glomerulonephritis. J Immunol 1993;150:1074-83

320. Cosimi AB, Conti D, Delmonico FL, et al. In vivo effects of monoclonal antibody to ICAM-1 (CD54) in nonhuman primates with renal allografts. J Immunol 1990;144:4604-12

321. Seth R, Raymond FD, Makgoba MW. Circulating ICAM-1 isoforms: diagnostic prospects for inflammatory and immune disorders. Lancet 1991;338:83-4

322. Carson CW, Beall LD, Hunder GG, et al. Serum ELAM-1 is increased in vasculitis, scleroderma, and systemic lupus erythematosus. J Rheumatol 1993;20:809-14

323. Hviid L, Theander TG, Elhassan IM, et al. Increased plasma levels of soluble ICAM-1 and ELAM-1 (E-selectin) during acute Plasmodium falciparum malaria. Immunol Lett 1993;36:51-8 
324. Ou MC, Kambayashi J, Kawasaki T, et al. Potential etiologic role of PAF in two major septic complications; disseminated intravascular coagulation and multiple organ failure. Thromb Res 1994,73:227-38

325. Qian C, Guo ZM, Peters CJ, et al. Platelet-activating factor (PAF)-induced cardiopulmonary dysfunctions and their reversal with a PAF antagonist (BN 52021) in strain 13 guinea pigs. J Lipid Mediat 1993;7:223-37

326. Braquet $\mathrm{P}$, Touqui $\mathrm{L}$, Shen TY, et al. Perspectives in platelet-activating factor research. Pharmacol Rev 1987;39:97-145

327. Anderson $\mathrm{BO}$, Bensard DD, Harken $\mathrm{AH}$. The role of platelet activating factor and its antagonists in shock, sepsis and multiple organ failure. Surg Gynecol Obstet 1991;172:415-24

328. Chang SW, Feddersen CO, Henson PM, et al. Platelet-activating factor mediates hemodynamic changes and lung injury in endotoxin-treated rats. J Clin Invest 1987;79:1498-509

329. Doebber TW, Wu MS, Robbins JC, et al. Platelet activating factor (PAF) involvement in endotoxininduced hypotension in rats. Studies with PAF-receptor antagonist kadsurenone. Biochem Biophys Res Commun 1985;127:799-808

330. Terashita Z, Imura Y, Nishikawa K, et al. Is platelet activating factor (PAF) a mediator of endotoxin shock? Eur J Pharmacol 1985;109:257-61

331. Bonavida B, Mencia-Huerta JM, Braquet P. Effects of platelet-activating factor on peripheral blood monocytes: induction and priming for TNF secretion. J Lipid Mediat 1990;2:S65-76

332. Kuipers B, Van der Poll T, Levi M, et al. Platelet-activating factor antagonist TCV-309 attenuates the induction of the cytokine network in experimental endotoxemia in chimpanzees. J Immunol 1994;152:2438-46

333. Handley DA, Tomesch JC, Saunders RN. Inhibition of PAF-induced systemic responses in the rat, guinea pig, dog and primate by the receptor antagonist SRI 63-441. Thromb Haemost 1986;56:40-4

334. Yamanaka S, Miura K, Yukimura T, et al. Putative mechanism of hypotensive action of plateletactivating factor in dogs. Circ Res 1992;70:893-901

335. Oda M, Satouchi K, Yasunaga K, et al. Polymorphonuclear leukocyte-platelet interactions: acetylglyceryl ether phosphocholine-induced platelet activation under stimulation with chemotactic peptide. J Biochem Tokyo 1986;100:1117-23

336. Del Maschio A, Evangelista V, Rajtar G, et al. Platelet activation by polymorphonuclear leukocytes exposed to chemotactic agents. Am J Physiol 1990;258:H870-9

337. Bussolino F, Camussi G, Baglioni C. Synthesis and release of platelet-activating factor by human vascular endothelial cells treated with tumor necrosis factor or interleukin 1 alpha. J Biol Chem 1988;263:11856-61

338. Bussolino F, Sironi M, Bocchietto E, et al. Synthesis of platelet-activating factor by polymorphonuclear neutrophils stimulated with interleukin-8. J Biol Chem 1992;267:14598-603

339. Dubois C, Bissonnette E, Rola-Pleszczynski M. Platelet-activating factor (PAF) enhances tumor necrosis factor production by alveolar macrophages. Prevention by PAF receptor antagonists and lipoxygenase inhibitors. J Immunol 1989;143:964-70

340. Sun XM, Hsueh W. Bowel necrosis induced by tumor necrosis factor in rats is mediated by plateletactivating factor. J Clin Invest 1988;81:1328-31

341. Ruis NM, Rose JK, Valone FH. Tumor necrosis factor release by human monocytes stimulated with platelet-activating factor. Lipids 1991;26:1060-4

342. Barthelson RA, Valone FH. Platelet-activating factor stimulates expression of IL-1 beta mRNA in THP-1 cells. Lipids 1991;26:257-60

343. Cassatella MA, Bazzoni F, Ceska M, et al. IL-8 production by human polymorphonuclear leukocytes. The chemoattractant formyl-methionyl-leucyl-phenylalanine induces the gene expression and release of IL-8 through a pertussis toxin-sensitive pathway. J Immunol 1992:148:3216-20 
344. Rabinovici R, Esser KM, Lysko PG, et al. Priming by platelet-activating factor of endotoxin-induced lung injury and cardiovascular shock. Circ Res 1991;69:12-25

345. Kawamura M, Terashita Z, Imura Y, et al. Inhibitory effect of TCV-309, a novel platelet activating factor (PAF) antagonist, on endotoxin-induced disseminated intravascular coagulation in rats: possible role of PAF in tissue factor generation. Thromb Res 1993;70:281-93

346. Bessin P, Bonnet J, Apffel D, et al. Acute circulatory collapse caused by platelet-activating factor (PAF-acether) in dogs. Eur J Pharmacol 1983;86:403-13

347. Rabinovici R, Yue TL, Farhat M, et al. Platelet activating factor (PAF) and tumor necrosis factoralpha (TNF alpha) interactions in endotoxemic shock: studies with BN 50739, a novel PAF antagonist. J Pharmacol Exp Ther 1990;255:256-63

348. Ogata M, Matsumoto T, Koga K, et al. An antagonist of platelet-activating factor suppresses endotoxin-induced tumor necrosis factor and mortality in mice pretreated with carrageenan. Infect Immun 1993;61:699-704

349. Lang CH, Dobrescu C, Hargrove DM, et al. Attenuation of endotoxin-induced increase in glucose metabolism by platelet-activating factor antagonist. Circ Shock 1987;23:179-88

350. Yamanaka S, Iwao H, Yukimura T, et al. Effect of the platelet-activating factor antagonist, TCV-309, and the cyclo-oxygenase inhibitor, ibuprofen, on the haemodynamic changes in canine experimental endotoxic shock, Br J Pharmacol 1993;110:1501-7

351. Terashita Z, Kawamura M, Takatani M, et al. Beneficial effects of TCV-309, a novel potent and selective platelet activating factor antagonist in endotoxin and anaphylactic shock in rodents. J Pharmacol Exp Ther 1992;260:748-55

352. Fletcher JR, DiSimone AG, Earnest MA. Platelet activating factor receptor antagonist improves survival and attenuates eicosanoid release in severe endotoxemia. Ann Surg 1990;211:312-6

353. Chang SW, Fernyak S, Voelkel NF. Beneficial effect of a platelet-activating factor antagonist, WEB 2086, on endotoxin-induced lung injury. Am J Physiol 1990;258:H153-8

354. Yue TL, Farhat M, Rabinovici R, et al. Protective effect of BN 50739, a new platelet-activating factor antagonist, in endotoxin-treated rabbits. J Pharmacol Exp Ther 1990;254:976-81

355. Dobrowsky RT, Voyksner RD, Olson NC. Effect of SRI 63-675 on hemodynamics and blood PAF levels during porcine endotoxemia. Am J Physiol 1991;260:H1455-65

356. Fink A, Geva D, Zung A, et al. Adult respiratory distress syndrome: roles of leukotriene C4 and platelet activating factor. Crit Care Med 1990;18:905-10

357. Bussolino F, Porcellini MG, Varese L, et al. Intravascular release of platelet activating factor in children with sepsis. Thromb Res 1987;48:619-20

358. Creange A, Belec L, Clair B, et al. Circulating tumor necrosis factor (TNF)-alpha and soluble TNFalpha receptors in patients with Guillain-Barre syndrome. J Neuroimmunol 1996;68:95-9

359. Nakayama T, Hashimoto S, Amemiya E, et al. Elevation of plasma-soluble tumour necrosis factor receptors (TNF-R) in sarcoidosis. Clin Exp Immunol 1996;104:318-24

360. Deloron P, Roux-Lombard P, Ringwald P, et al. Plasma levels of TNF-alpha soluble receptors correlate with outcome in human falciparum malaria. Eur Cytokine Netw 1994:5:331-6

361. Pilz G, Fraunberger P, Appel R, et al. Early prediction of outcome in score-identified, postcardiac surgical patients at high risk for sepsis, using soluble tumor necrosis factor receptor-p55 concentrations. Crit Care Med 1996;24:596-600

362. Halwachs G, Tiran A, Reisinger EC, et al. Serum levels of the soluble receptor for tumor necrosis factor in patients with renal disease. Clin Investig 1994;72:473-6

363. Bemelmans MH, Gouma DJ, Buurman WA. Influence of nephrectomy on tumor necrosis factor clearance in a murine model. J Immunol 1993;150:2007-17

364. Hernandez LA, Grisham MB, Twohig B, et al. Role of neutrophils in ischemia-reperfusion-induced microvascular injury. Am. J. Physiol. 1987;253:H699-H703 
Chapter 1

365. Romson Л, Hook BG, Kunkel SL, et al. Reduction of the extent of ischemic myocardial injury by neutrophil depletion in the dog. Circulation 1983;67:1016-1023

366. Chaudry IH. Cellular mechanisms in shock and ischemia and their correction. Am. J. Physiol. 1983;245:R117-R134

367. Deitch EA, Ma L, Ma WJ. Inhibition of endotoxin induced bacterial translocation in mice. J. Clin. Invest. 1989;84:36-42

368. Rush BF, Redan JA, Flanagan JJ. Does the bacteremia obsereved in hemorrhagic shock have clinical significance? A study in germ-free animals. Ann. Surg. 1989;210:342-347 
THE ICU PATIENT POPULATION 


\section{INTRODUCTION}

One of the arguments to develop an ICU database, is to analyze characteristics of the ICU patient population. These characteristics include demographic data, admission diagnosis, length of ICU stay, mortality and mortality associated factors.

This overview illustrates the distribution of the diagnoses in patients admitted to an ICU and corresponding mortality rates. In addition, mortality and mortality associated factors were studied. The clinical suitability of APACHE II was studied by comparing observed and predicted mortality rates in each diagnostic category and by analyzing its sensitivity and specificity. Finally, two categories of patients with high mortality rates were studied in detail: patient with severe sepsis and patients with an ICU stay of less than 24 hours.

\section{PATIENTS AND METHODS}

In the period between January 1991 and July 1993 the ICU patient population of the University Hospital Maastricht, The Netherlands, was studied. The ICU is a 16-bed ward with patients from the departments of surgery/ trauma, internal medicine, pulmonology, neurology, and neurosurgery. Patients admitted to the separate coronary care unit and cardiac surgery unit were excluded. All adult patients $(\geq 18$ years) admitted to the ICU were registered prospectively. All data were collected on a daily basis by one resident. The study was reviewed and approved by the hospital's Institutional Review Board, which deemed that informed consent was not required.

The APACHE II severity of disease classification consist of the Acute Physiology Score (APS), the Chronic Health Evaluation, and Age Points. APS includes 12 physiologic variables calculated during the first 24 hours of ICU admission. Age is divided into five categories with matching Age Points. If a patient had a history of severe organ system insufficiency or a compromised immune system, chronic health points were assigned. To predict death rates, patients are assigned to specific diagnostic categories. Predicted death rates are computed using APACHE II score, surgical state, and diagnostic category.

APACHE II mortality prediction is based on data derived from the first 24 hours of ICU admission. Therefore, only patients with an ICU stay of more than 24 hours were included. In case of more than one admission at ICU, only the most recent admission was included. Finally, a suitable diagnostic category was a prerequisite for inclusion.

Data regarding ICU mortality and hospital mortality are analyzed dependent on the population studied. ICU mortality is analyzed for each ICU admission (including re-admissions). In contrast, hospital mortality is analyzed considering only the most recent ICU admission i.e. excluding previous ICU admissions. Hospital mortality rate 
in patients re-admitted to the ICU are confusing, since one deceased patient contributes to hospital mortality as much as the times that one is admitted at the ICU. For example, patient ' $b$ ' does not survive the fourth admission at ICU, whereas patient ' $a$ ' survives its only admission (Table 1). ICU mortality is 1 out of 5 cases, and hospital mortality is 4 out of 5 cases. In addition, the number of cases associated with hospital mortality exceeds the number of patients actually involved.

Table 1: Example of ICU versus hospital mortality

\begin{tabular}{lclcc}
\hline Patient & Admission & Diagnostic category & ICU mortality & Hospital mortality \\
\hline a & 1 & drug overdose & no & no \\
b & 1 & R.i. after surgery & no & yes \\
b & 2 & C.i. from sepsis & no & yes \\
b & 3 & R.i. from aspiration & no & yes \\
b & 4 & C.i. from cardiac arrest & yes & yes \\
\hline
\end{tabular}

Data are expressed as median values with ranges within parentheses unless stated otherwise. Statistical analysis is performed using the Mann-Whitney U-test. A probability value of less than .05 was deemed significant.

\section{RESULTS}

Characteristics of the ICU patient population

Between January 1991 and July 19931043 patients were admitted to ICU. A total of 934 patients were admitted to ICU only once in the period studied. Another 109 patients were admitted to ICU more than once ( 2 to 5 times). As a result 1171 admissions were registered in 1043 patients.

Male/ female ratio in 1043 ICU admissions amounted to 563/480. Females were significantly younger $(\mathrm{P}<.0001)$ on admission compared to males: 58 (18-94) and 66 (1896) years, respectively. ICU mortality was $243 / 1043$ patients $(23.3 \%)$. In addition, from the 800 patients discharged from the ICU 92 patients deceased on a general ward. As a result, hospital mortality was $32,1 \%$ ( 335 out of 1043 patients admitted to the ICU). The cumulative number of days spend on ICU was 9666 days in 1171 patients. Patients with a fatal hospital stay $(n=370)$ spend a total of 3908 days to the ICU (median 5, range 1144 days/ admission), whereas survivors $(n=801)$ were admitted for 5758 days to the ICU (median 3, range 1-350 days/ admission).

\section{Diagnostic categories and mortality in 1171 patients}

Using APACHE II (1), patients were assigned to specific diagnostic categories according to the principal reason for ICU admission. In 1022 out of 1043 patients the 
diagnostic categories could be determined. Reasons for ICU admission in the 21 remaining patients ranged from logistic reasons to hysterical psychoneurosis. The number of patients in each diagnostic group is given in table 2, including mortality rates. Sepsis $(n=123)$, 'not further specified' respiratory failure $(n=113)$ and drug overdose $(n=109)$ were involved in $29.5 \%$ of all ICU admissions. Sepsis and cardiac arrest were associated with high ICU mortality rates: $58 / 123$ pts $(47 \%)$ and $35 / 73$ pts $(48 \%)$, respectively. These two categories were involved in $38 \%$ of ICU mortality. Patients with intracranial hemorrhage and head trauma were associated with relatively high ICU mortality rates: $18 / 29(28 \%)$ and $9 / 17$ pts $(53 \%)$, respectively. Both categories contributed to ICU mortality with $7 \%$ and $4 \%$, respectively. ICU mortality in drug overdose patients was $<1 \%$ ( 1 out of $113 \mathrm{pts}$ ).

Table 2: ICU admission diagnosis, number of cases, and mortality

\begin{tabular}{lrrlrc}
\hline Diagnostic category & Pts (n) & $\dagger(\mathrm{n})$ & Diagnostic category & Pts (n) & $\dagger(\mathrm{n})$ \\
\hline C.i. from cardiac arrest & 73 & 35 & Intracranial hemorrhage & 29 & 18 \\
C.i. from cardiogenic shock & 2 & 2 & Metabolic/ renal & 20 & 0 \\
C.i. from congestive heart failure & 43 & 3 & Multiple trauma & 37 & 7 \\
C.i. from coronary artery disease & 13 & 0 & Neurologic & 27 & 4 \\
C.i. from hemorrhage/ hypovolemia & 16 & 5 & No diagnosis & 21 & 2 \\
C.i. from rhythm disturbance & 2 & 1 & Peripheral vascular surgery & 10 & 2 \\
C.i. from sepsis & 123 & 58 & R.i. after surgery & 78 & 9 \\
Cardiovascular & 23 & 1 & R.i. from aspiration/ toxic & 19 & 4 \\
Chronic cardiovascular disease & 21 & 3 & R.i. from asthma/ allergy & 5 & 0 \\
Craniotomy for hemorrhage & 19 & 1 & R.i. from COPD & 35 & 6 \\
Craniotomy for neoplasm & 52 & 0 & R.i. from infection & 54 & 21 \\
Diabetic ketoacidosis & 9 & 0 & R.i. from neoplasm & 3 & 2 \\
Drug overdose & 109 & 1 & R.i. from pulmonary embolus & 4 & 1 \\
Gastrointestinal & 1 & 0 & R.i. from respiratory arrest & 22 & 6 \\
GI bleeding & 68 & 9 & Renal neoplasm & 3 & 0 \\
GI perforation/ obstruction & 24 & 4 & Renal transplant & 6 & 0 \\
GI surgery for neoplasm & 16 & 1 & Respiratory & 113 & 15 \\
Head trauma & 17 & 9 & Seizure disorder & 10 & 1 \\
Hemorrhagic shock & 35 & 13 & Thoracic surgery for neoplasm & 9 & 0 \\
Total & & & & 1171 & 244 \\
\hline
\end{tabular}

$\mathrm{t}=\mathrm{ICU}$ mortality; Pts=patients; $\mathrm{C} . \mathrm{i} .=$ Cardiovascular insufficiency; $\mathrm{R} . \mathrm{i} .=$ Respiratory insufficiency

\section{Mortality and associated factors}

A total of 468 cases were excluded from mortality prediction since they did not fulfil the inclusion criteria. Thus, predicted mortality was analyzed in 703 cases. First, the association between the variables APS, age, chronic health points and surgical state with mortality was verified. Age distribution of the patients admitted at ICU is given 
in table 3. The age categories $51-80$ accounted for $59.1 \%$ of the ICU admissions. Mortality rates increased with age, ranging from less than $9 \%$ in the category $18-30$ years up to $83 \%$ ( 5 out of 6 patients) in the category $91-100$ years.

Table 3: Hospital mortality in relation to age

\begin{tabular}{lcccc}
\hline Age (years) & Patients (n) & $\mathrm{H} \dagger(\mathrm{n})$ & $\mathrm{H}+\mathrm{I}(\%)$ & $\mathrm{H}+\mathrm{II}(\%)$ \\
\hline $18-20$ & 23 & 2 & 8.7 & 0.6 \\
$21-30$ & 87 & 6 & 6.9 & 1.8 \\
$31-40$ & 97 & 21 & 21.6 & 6.3 \\
$41-50$ & 128 & 29 & 22.7 & 8.7 \\
$51-60$ & 142 & 41 & 28.9 & 12.2 \\
$61-70$ & 265 & 81 & 30.6 & 24.2 \\
$71-80$ & 209 & 403 & 49.3 & 30.7 \\
$81-90$ & 86 & 57 & 54.7 & 14.0 \\
$91-100$ & 6 & 335 & 83.3 & 1.5 \\
Total & 1043 & 32.1 & 100 \\
\hline
\end{tabular}

$\mathrm{H} \dagger=$ hospital mortality; $\mathrm{I}=$ mortality in relation to age category; II=mortality in relation to total mortality

Table 4: APS and APACHE II score in relation to hospital mortality

\begin{tabular}{lcrclrrc}
\hline APS & Pts $(\mathrm{n})$ & $\mathrm{H}+(\mathrm{n})$ & $\mathrm{H}+(\%)$ & APACHE II & $\mathrm{Pts}(\mathrm{n})$ & $\mathrm{H}+(\mathrm{n})$ & $\mathrm{H} \dagger(\%)$ \\
\hline $0-5$ & 63 & 5 & 7.9 & $0-5$ & 27 & 0 & 0.0 \\
$6-10$ & 197 & 39 & 19.8 & $6-10$ & 94 & 9 & 9.6 \\
$11-15$ & 190 & 55 & 28.9 & $11-15$ & 163 & 25 & 15.3 \\
$16-20$ & 159 & 84 & 52.8 & $16-20$ & 192 & 69 & 35.9 \\
$21-25$ & 68 & 40 & 58.8 & $21-25$ & 129 & 69 & 53.5 \\
$26-30$ & 15 & 8 & 53.3 & $26-30$ & 70 & 47 & 67.1 \\
$31-35$ & 9 & 7 & 77.8 & $31-35$ & 17 & 12 & 70.6 \\
$36-40$ & 2 & 2 & 100.0 & $36-40$ & 8 & 6 & 75.0 \\
$41-45$ & N.A. & N.A. & N.A. & $41-45$ & 3 & 3 & 100.0 \\
total & 703 & 240 & & total & 703 & 240 & \\
\hline
\end{tabular}

$\mathrm{H} \dagger=$ hospital mortality in relation to APS/ APACHE II category; Pts=patients

Mortality in relation to surgical state was analyzed in 1043 patients (most recent admissions). In nonoperative patients $(n=686)$ mortality was $35.6 \%$, comparable with mortality rate $(36.7 \%)$ in patients with emergency surgery $(n=199)$. In patients admitted to the ICU after elective surgery $(n=158)$ mortality rate was substantially lower $(11.4 \%)$. Surgical state determines the height of adjudged chronic health points in APACHE II score. Similar to surgical state, chronic health points were associated with hospital mortality in the population studied. Mortality rates in patients with $0(n=926)$ and 2 
( $n=13$ ) chronic health points were $29.3 \%$ and $30.8 \%$, respectively, whereas in patients with 5 chronic health points $(n=104)$ mortality rate was as high as $57.7 \%$.

The association between APS and APACHE II versus mortality was analyzed by calculating mortality rates in five point categories (Table 4). The APS was strongly correlated with mortality. The correlation between APACHE II scores and hospital mortality was even more pronounced. Whereas mortality rate in the lowest APACHE II category was $0 \%$, mortality rate was $100 \%$ in patient with an APACHE II score exceeding 41. A total of 484 out of 703 patients were assigned to the 'intermediate' APACHE II category (11-25 points). In this category contributed to $69.7 \%$ of all hospital mortality ( 163 out of $240 \mathrm{pts})$.

Table 5: Discrepancy between observed and predicted hospital mortality

\begin{tabular}{lcccc}
\hline Diagnostic category & $\mathrm{Pts}(\mathrm{n})$ & Predicted $\mathrm{H}+(\mathrm{n})$ & Observed H+ (n) & Discrepancy (\%) \\
\hline Cardiovascular & 14 & 5.279 & 2 & -62.1 \\
GI perforation/ obstruction & 18 & 7.434 & 4 & -46.2 \\
R.i. after surgery & 60 & 17.697 & 11 & -37.8 \\
GI bleeding & 29 & 9.308 & 7 & -24.8 \\
C.i. from sepsis & 88 & 45.902 & 52 & +13.3 \\
C.i. from cardiac arrest & 44 & 24.75 & 29 & +17.2 \\
Hemorrhagic shock & 24 & 9.958 & 13 & +30.5 \\
Intracranial hemorrhage & 10 & 5.745 & 8 & +39.3 \\
R.i. from infection & 44 & 16.532 & 24 & +45.2 \\
R.i. from respiratory arrest & 18 & 6.723 & 10 & +48.7 \\
R.i. from COPD & 22 & 4.534 & 8 & +76.4 \\
Multiple trauma & 33 & 3.047 & 6 & +96.9 \\
Respiratory & 84 & 9.167 & 20 & +118.2 \\
Others & 215 & 41.385 & 46 & +11.2 \\
Total & 703 & 207.461 & 240 & \\
\hline
\end{tabular}

$\mathrm{H} \dagger=$ hospital mortality; C.i. =Cardiovascular insufficiency; $\mathrm{R} . \mathrm{i} .=$ Respiratory insufficiency

\section{Observed hospital versus predicted mortality}

Using the APACHE II mortality predicting model, mortality risks were calculated in 703 patients. In individual patients, predicted risk on mortality ranged from $0.1 \%$ (drug overdose) to $95.3 \%$ (sepsis). The summarized predicted mortality risk was 207 in 703 patients $(29.5 \%)$. The observed hospital mortality rate exceeded the predicted one: 240 / 703 patients $(34.1 \%)$.

Mortality prediction is considered helpful to compare patient populations. Therefore the discrepancy between observed hospital mortality and predicted mortality was of special interest. The discrepancy between observed and predicted 
mortality was calculated as follows: predicted minus observed mortality/ predicted mortality. Differences between observed mortality and predicted mortality ranged from $-62.1 \%$ to $+118.2 \%$. Diagnostic categories with the most extreme discrepancies (i.e. $\geq 2$ patients) are included in table 5 , in order of discrepancy.

Sensitivity and specificity values illustrate the clinical suitability of APACHE II. Both values depend on the cut-off point used. When patients with a predicted death risk $>.50$ were excluded from further intensive care treatment, sensitivity and specificity of APACHE II were 0.417 and 0.909 , respectively. These data are displayed in a receiver operator characteristic (ROC) curve (Fig. 1). The predictive ability of APACHE II included data considering 703 patients. The area under the curve is 0.771 . The area under the curve reflects the suitability of APACHE II to predict outcome (ideal value: $0.8-1$ ).

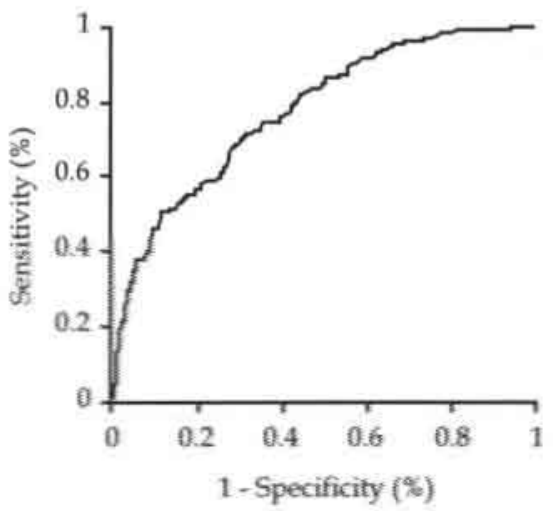

Figure 1: ROC curve demonstrating predictive ability of APACHE II

Table 6: Classification for a .50 predicted risk

\begin{tabular}{|c|c|c|c|}
\hline & \multicolumn{2}{|c|}{ Predicted } & \multirow[b]{2}{*}{ Total } \\
\hline & Alive & Dead & \\
\hline \multicolumn{4}{|c|}{ Observed } \\
\hline Alive & 421 & 42 & 463 \\
\hline Dead & 140 & 100 & 240 \\
\hline Total & 561 & 142 & 703 \\
\hline
\end{tabular}

The classification matrix for a predicted death risk $>.50$ is given in table 6 . If patients with a predicted death risk $>.50$ were excluded from further intensive care treatment $(\mathrm{n}=142), 1827$ ICU days were saved on a total of 7812 days in 703 patients. 
But, a total of 42 patients predicted to die, survived probably as a result of intensive care treatment. In conclusion, a decision criterion of .50 saved 1827 ICU days $(23.4 \%)$ at the cost of 42 lifes. Ages in these 42 patients ranged from 28 to 85 years with a median 67 years.

The predictive ability of APACHE II in the present study was compared with the original data on the development of APACHE II (1) (Table 7). The differences between the 2 studies were $5.3 \%$ for sensitivity and $0.8 \%$ for positive predictive value indicating that there are no major differences in the ability to define correctly the nonsurvivors. Apparently, the applicability of APACHE II in the present study is comparable with the original data presented by Knaus.

Table 7: Classification matrix APACHE II: Knaus vs. present study

\begin{tabular}{lcc}
\hline & Knaus & Present study \\
\hline sensitivity & $47.0 \%$ & $41.7 \%$ \\
specificity & $94.9 \%$ & $90.9 \%$ \\
correct & $85.5 \%$ & $74.1 \%$ \\
positive predicted value & $69.6 \%$ & $70.4 \%$ \\
negative predicted value & $87.9 \%$ & $75.0 \%$ \\
\hline
\end{tabular}

classification for a .50 predicted risk

\section{Patients admitted at the ICU for less than 24 hours}

Patients discharged from ICU within 24 hours as well as patients deceased in this period were excluded from APACHE II mortality prediction ('short ICU admissions'). A total of 358 cases with an ICU stay less than 24 hours were registered (Table 8). The male/ female ratio was 112 / 246 , with ages ranging from $18-90$ years. A total of 165 out of 358 short ICU admissions were referred by the first aid department. ICU mortality rate was $75 / 358(20.9 \%)$ patients. Interestingly, no mortality was observed in drug overdose patients, 'not further specified' respiratory failure, congestive heart failure, and in patients after elective craniotomy for neoplasm. In contrast, a high mortality rate within 24 hours was found in patients with sepsis, after cardiac arrest, and intracranial hemorrhage, respectively.

A total of 283 cases were discharged from the ICU to a general ward after an ICU stay of less than 24 hours. After exclusion of previous ICU admissions, 19 out of 252 patients $(7.5 \%)$ died in hospital after discharge from ICU.

\section{Severe sepsis}

Among 1043 ICU admissions (previous ICU admissions excluded) a total of 112 patients fulfilled the criteria of severe sepsis (2) on admission. These 112 patients were 
registered as 'cardiovascular insufficiency from sepsis'. Patients that developed sepsis during ICU stay are not included here.

Table 8: Short ICU admissions: admission diagnosis and mortality

\begin{tabular}{lcccc}
\hline Diagnostic category & Cases $(\mathrm{n})$ & Age (years) & $\dagger(\mathrm{n})$ & $\dagger(\%)$ \\
\hline Drug overdose & 75 & $31(18-87)$ & 0 & 0.0 \\
Craniotomy for neoplasm & 44 & $50(18-75)$ & 0 & 0.0 \\
GI bleeding & 31 & $65(38-86)$ & 3 & 9.7 \\
C.i. from cardiac arrest & 26 & $69(35-87)$ & 16 & 61.5 \\
C.i. from sepsis & 26 & $72(38-88)$ & 16 & 61.5 \\
Respiratory & 15 & $58(32-80)$ & 0 & 0.0 \\
Intracranial hemorrhage & 14 & $47(32-76)$ & 11 & 78.6 \\
C.i. from congestive heart failure & 11 & $74(67-88)$ & 0 & 0.0 \\
Others & 116 & $63(19-90)$ & 29 & 25.0 \\
Total & 358 & & 75 & 20.9 \\
\hline
\end{tabular}

note: Data include ICU re-admissions. $t=I C U$ mortality; $C . i=$ Cardiovascular insufficiency; age represent median (range).

ICU and hospital mortality in septic patients was 58/ $112(52 \%)$ and $71 / 112(63 \%)$, respectively. APACHE II scores in nonsurvivors of sepsis syndrome were significantly higher compared to survivors $(\mathrm{P}=.002)$ : $26(8-44)$ and $21 \quad(10-34)$, respectively. In contrast, the Grading of Sepsis score (3) on admission failed to discriminate between survivors and nonsurvivors: $14(6-21)$ and 15 (7-26), respectively. Using a decision criterion of .50 with respect to individual estimated death rates, 591 ICU days could be saved at the cost of 11 lifes, whereas 16 out of 41 patients predicted to survive finally died after a total of 276 days ICU stay.

Twenty-five septic patients were admitted at ICU for less than 24 hours. Among these patients, 17 patients deceased within 24 hours of ICU admission (68\%). Septic patients spend a total of 1138 days on ICU: nonsurvivors $(n=71)$ stayed 667 days (median 5 days/ admission; range 1-50 days) and survivors $(n=41)$ stayed 471 days on ICU (median 8 days/ admission; range 1-71 days).

\section{DISCUSSION}

Predicting mortality is a topic of increasing interest in intensive care medicine. Intensive care medicine is a major consumer of hospital budget, and the demand for care often exceeds available resources. The identification of patients who really benefit from ICU admission may be helpful to manage available resources more efficiently. Therefore, a distinction needs to be made between patients that are likely to survive as 
a result of intensive care and those that will not survive despite this care. In the present study, 370 nonsurvivors spend a total of 3908 days on ICU.

The APACHE II severity of disease classification is based on 5815 ICU admissions from 13 hospitals in the United States of America. The classification system is proposed to stratify a wide variety of ICU patients. APACHE II was used in numerous studies and was found, although not consistently, to be useful in predicting mortality (4-9). Although APACHE II scores were strongly correlated with hospital mortality in the ICU population studied, predicted and observed mortality differed $15.7 \%$ with regard to the entire population studied (703 pts). The discrepancy between predicted and observed mortality was even more pronounced when separate diagnostic categories were analyzed. The discrepancy ranged from $-62.1 \%$ (observed mortality relatively low) in patients with cardiovascular disease to $+118.2 \%$ (observed mortality relatively high) in patients with respiratory disease. Both diagnostic categories are heterogeneous rest categories. Patients which can not be assigned to the well defined diagnostic categories are classified to these rest categories. As a result, the difficulty to assign complex cases to the one principal reason leading to ICU admission influences the accuracy of mortality prediction in a negative way.

APACHE II is proposed to stratify acutely ill patients. Studies concerning experimental drugs include APACHE II scores to compare the subgroups studied and to support the efficacy of the drugs tested (10). The discrepancy between observed and predicted mortality indicates that APACHE II is not as suitable for stratifying patient populations as it is suggested. Severity of disease classification systems such as APACHE II may be helpful in stratifying patient populations. However, some significant limitations have been demonstrated above.

Decision making in individual patients with the use of scoring systems is a subject of controversy at the moment. Positive predictive value of APACHE II in the present analysis is comparable with data on its development, suggesting that APACHE II, although validated in the USA, is suitable for the Dutch ICU. The number of days spend at ICU can be decreased by $23.4 \%$ when patients with a predicted mortality $>.50$ were excluded from intensive care treatment. However, using . 50 as cut-off point, hospital mortality increased from $34.1 \%$ to $40.4 \%$.

The suitability of APACHE II for individual decision making is limited. APACHE III, introduced in 1991, is still not used on a large scale. The clinical value of APACHE III has to be confirmed by each clinic that intends to use the scoring system for individual decision making. At the moment, medical decision making still best relies on clinical experience. 


\section{REFERENCES}

1. Knaus WA, Draper EA, Wagner DP, et al. APACHE II: a severity of disease classification system. Crit Care Med 1985;13:818-29

2. Bone RC, Balk RA, Cerra FB, et al. Definitions for sepsis and organ failure and guidelines for the use of innovative therapies in sepsis. The ACCP/ SCCM Consensus Conference Committee. American College of Chest Physicians/ Society of Critical Care Medicine. Chest 1992;101:1644-55

3. Elebute EA, Stoner HB. The grading of sepsis. Br J Surg 1983;70:29-31

4. Dellinger EP. Use of scoring systems to assess patients with surgical sepsis. Surg Clin North Am $1988 ; 68: 123-45$

5. Lemeshow S, Teres D, Avrunin JS, et al. A comparison of methods to predict mortality of intensive care unit patients. Crit Care Med 1987;15:715-22

6. Fagon JY, Chastre J, Novara A, et al. Characterization of intensive care unit patients using a model based on the presence or absence of organ dysfunctions and/ or infection: the ODIN model. Intensive Care Med 1993;19:137-44

7. Fisher Jr CJ, Opal SM, Dhainaut JF, et al. Influence of an anti-tumor necrosis factor monoclonal antibody on cytokine levels in patients with sepsis. The CB0006 Sepsis Syndrome Study Group. Crit Care Med 1993;21:318-27

8. Arregui LM, Moyes DG, Lipman J, et al. Comparison of disease severity scoring systems in septic shock. Crit Care Med 1991;19:1165-71

9. Brown PE, McClave SA, Hoy NW, et al. The Acute Physiology and Chronic Health Evaluation II classification system is a valid marker for physiologic stress in the critically ill patient. Crit Care Med 1993;21:363-7

10. Ziegler EJ, Fisher Jr CJ, Sprung CL, et al. Treatment of gram-negative bacteremia and septic shock with HA-1A human monoclonal antibody against endotoxin. A randomized, double-blind, placebocontrolled trial. The HA-1A Sepsis Study Group. N Engl J Med 1991;324:429-36 



\section{CHAPTER 3}

INCREASED PLASMA LEVELS OF SOLUBLE TUMOR NECROSIS FACTOR RECEPTORS IN SEPSIS SYNDROME: CORRELATION WITH PLASMA CREATININE

A.H.M. Froon, M.H.A. Bemelmans, J.W.M. Greve, C.J. van der Linden, W.A. Buurman Crit Care Med 1994; 22: 803-9 


\section{SUMMARY}

Objectives: Tumor necrosis factor (TNF) is an important mediator in the complex pathophysiology of sepsis syndrome. Although a positive correlation with mortality has been demonstrated, TNF has not been found consistently in sepsis. Since prolonged elevations in soluble TNF receptor levels were demonstrated after endotoxin and TNF administration, it was investigated here whether the measurement of TNF receptor levels could provide a better parameter of disease compared to plasma TNF and interleukin-6 (IL-6) levels.

Design: Prospective analysis.

Setting: General ICU of a University Hospital.

Patients: Patients with sepsis syndrome and proven bacteremia.

Results: Plasma peak levels of the soluble $55 \mathrm{kD}$ molecular weight TNF receptor were significantly higher $(\mathrm{P}<.005)$ in nonsurvivors compared to survivors of sepsis syndrome, whereas the difference in peak levels of the soluble $75 \mathrm{kD}$ TNF receptor did not reach significancy $(\mathrm{P}=.06)$. In contrast to TNF peak levels $(\mathrm{P}=.14)$, significantly higher IL-6 peak levels were measured in nonsurvivors $(\mathrm{P}<.05)$. Besides the positive correlation between the soluble $55 \mathrm{kD}$ TNF receptor and the soluble $75 \mathrm{kD}$ TNF receptor $\left(\mathrm{r}^{2}=.68 ; \mathrm{P}<.0001\right)$, peak levels of both soluble $55 \mathrm{kD}$ and $75 \mathrm{kD}$ TNF receptor correlated significantly with plasma creatinine, an indicator of renal function $\left(\mathrm{r}^{2}=.60 ; \mathrm{P}<.0001\right.$ and $\mathrm{r}^{2}=.44 ; \mathrm{P}<.001$, respectively). Plasma creatinine levels were significantly higher in nonsurvivors $(\mathrm{P}<.001)$.

Conclusions: In the population studied, plasma soluble TNF receptor levels correlated with outcome as well as with plasma creatinine levels. The data presented suggest that increased plasma soluble TNF receptor levels in sepsis syndrome are merely the result of renal failure complicating sepsis, and are likewise correlated with mortality. 


\section{INTRODUCTION}

Tumor necrosis factor (TNF) is a cytokine primarily secreted by mononuclear phagocytes and is considered to play an important role in the metabolic and hemodynamic alterations seen in endotoxemia (1-3). Evidence for the involvement of TNF in the pathophysiology of sepsis was obtained in animal studies (4) as well as in volunteer studies (5). Moreover prophylactic administration of anti-TNF antibodies reduced the lethality after induced endotoxemia (6) and gram-negative bacteremia (7) in animal models.

TNF has been demonstrated to play an important role in the defense against infections (8). However, high plasma levels of TNF as seen in endotoxemia are considered to be harmful and can lead to organ failure and death (9). Although a positive correlation between plasma TNF and mortality has been demonstrated in sepsis syndrome (9-11) and meningococcal sepsis (12), this correlation has not been found consistently $(13,14)$. In plasma both $55 \mathrm{kD}$ and $75 \mathrm{kD}$ molecular weight soluble TNF receptors are able to affect the detection of TNF in some assays by complexing TNF (15). The inconsistency in observed TNF data can be explained by differences between assays in the ability to detect TNF complexed to the TNF receptor. In addition, the short half life of TNF (16) makes detection dependent on frequency of sampling.

The measurement of TNF induced factors with slower kinetics (interleukin-6, soluble TNF receptors) may offer better opportunities to assess the severity of disease. For interleukin-6 (IL-6) a positive correlation with mortality has been reported $(16,17)$. Since increased soluble TNF receptor levels were detected after TNF (18) and endotoxin administration in humans $(19,20)$, soluble TNF receptor levels appeared to reflect TNF induced inflammation, and could therefore be useful as a parameter of disease. The exact function of soluble TNF receptors is thus far not known. However, soluble TNF receptors have been demonstrated to bind and to inactivate TNF. Although elevations in soluble TNF receptor levels have been demonstrated in inflammation, impaired renal clearance of soluble TNF receptor as in chronic renal failure also leads to increased soluble TNF receptor levels (21).

In this study the hypothesis was investigated whether soluble TNF receptor plasma levels are a more useful parameter to asses the severity of disease compared to plasma TNF and IL-6 levels. Therefore soluble TNF receptor levels were determined in patients that fulfilled the criteria of sepsis syndrome in combination with a positive blood culture. Results were correlated with mortality and plasma creatinine levels. 


\section{MATERIALS AND METHODS}

\section{Patient selection}

All patients admitted to the general intensive care unit (ICU) of the University Hospital of Maastricht are registered prospectively. A registration system is used, composed of the following parts: the Apache II score (22); the 'Grading of Sepsis score' (23); daily registration of sepsis syndrome parameters (24) (Table 1); registration of positive bacterial cultures; and daily blood sampling for cytokine measurements.

This ICU patient database was used to select the patient population studied. Patients were included if they fulfilled the criteria of sepsis syndrome in combination with a positive blood culture. One or more plasma samples had to be available for the determination of inflammatory mediators. Patients with pre-existing severe organ failure (including chronic renal failure) were excluded from the study. The study was reviewed and approved by our Institutional Review Board, which deemed that informed consent was not required.

Table 1: Definition of sepsis syndrome*

\section{OBLIGATORY SEPSIS CRITERIA:}

\section{Clinical evidence of infection}

Fever or hypothermia: temperature $>38.3$ or $<35.6^{\circ} \mathrm{C}$

Tachycardia: $>90$ beats per $\min$

Tachypnoea: $>20$ breaths per min or the requirement of mechanical ventilation

AND EITHER HYPOTENSION:

Systolic blood pressure $\leq 90 \mathrm{mmHg}$ or a sustained drop in systolic pressure $>40 \mathrm{mmHg}$

OR TWO OR MORE OF THE 6 FOLLOWING SIGNS OF SYSTEMIC TOXICITY OR PERIPHERAL HYPOPERFUSION:

\section{Hypoxemia: $\mathrm{PaO} 2 \leq 75$ torr $(\leq 10 \mathrm{kPa})$ or $\mathrm{PaO} 2 / \mathrm{FiO} 2 \leq 250$}

Metabolic acidosis: $\mathrm{pH}<7.3$ or base deficit $>5 \mathrm{mmol} / \mathrm{L}$ or elevated plasma lactate level

Acute renal failure: urinary output $<0.5 \mathrm{~mL} / \mathrm{kg}$ body weight/ hour

Quick $>1.5 x$ normal value or APTT $>1.2 x$ normal value or platelet count $<100 \times 10 \mathrm{E} 9 / \mathrm{L}$ or $<50 \%$ of the

baseline value

Sudden decrease in mental aquity

Cardiac index $>4 \mathrm{~L} / \mathrm{min} / \mathrm{m}^{2}$ with systemic vascular resistance $<800$ dyn $\bullet \mathrm{sec} / \mathrm{cm}^{5}$

*definition of sepsis syndrome similar as proposed by Bone (24)

\section{Blood samples}

From the day of ICU admission, blood samples were taken daily from each patient and collected in tubes containing ethylenediaminetetraacetic (EDTA). Daily blood samples were always collected together with the first daily round of routine blood sampling at approximately $6 \mathrm{AM}$. The blood samples were immediately put on ice and plasma was 
prepared at $4^{\circ} \mathrm{C}$ by centrifugation at $3000 \mathrm{rpm}$ for 5 minutes. Samples were stored at $-70^{\circ} \mathrm{C}$ until use. Levels of TNF, IL-6, and both the soluble $55 \mathrm{kD}$ and $75 \mathrm{kD}$ TNF receptor were determined as described below. Since plasma samples were collected prospectively, the above mentioned levels were determined in plasma samples collected for 7 days (from 3 days before up to 3 days after study entry). In patients fulfilling the inclusion criteria at ICU admission, no pre-sepsis samples were available. The highest cytokine/ receptor levels measured in each patient, further designated as peak levels, were correlated with mortality.

\section{Assays}

Plasma TNF concentrations were determined using an enzyme-linked immunosorbent assay (ELISA) developed in our laboratory, which correlates well with TNF detected by bioassay $(15,25)$. In short, samples and the standard titration curve (recombinant TNF kindly provided by BASF/ Knoll, Ludwigshafen, FRG) were incubated with a murine anti-human TNF mAb $61 \mathrm{E} 71$ absorbed to a microtiter plate (Nunc, Roskilde, Denmark). Subsequently the plates were incubated with a polyclonal rabbit antihuman TNF antiserum, followed by a peroxidase conjugated goat anti-rabbit-IgG (Jackson, Westgrove, PA) and substrate (O-phenyldiamine, Sigma, St. Louis, MO). Optical density was read, and TNF concentrations were calculated from the standard TNF curve. The detection limit for TNF was $20 \mathrm{pg} / \mathrm{mL}$.

Plasma IL- 6 concentrations were determined in a procedure largely parallel to the TNF ELISA mentioned above. As capture antibody the murine anti-human IL-6 antibody 5E1 (developed in our laboratory) was used. Plasma samples and the standard titration curve with recombinant IL-6 (kindly provided by Prof. Dr. W. Sebald, Würzberg, FRG) were added to the plates and subsequently incubated with polyclonal rabbit anti-IL-6 antiserum followed by peroxidase conjugated goat antirabbit-IgG. Substrate was added, and optical density was read. The detection limit for IL-6 was $10 \mathrm{pg} / \mathrm{mL}$.

In order to detect and to quantify TNF receptors, the microtiter plates were coated with TNF receptor antibodies (htr-20 and utr-4 for the $55 \mathrm{kD}$ and $75 \mathrm{kD}$ TNF receptor, respectively) as has been described before (26). Plasma samples and peroxidase labeled TNF were added and incubated simultaneously. During the incubation period the human TNF receptor present in the samples binds with both the immobilized antihuman TNF receptor antibodies and the human TNF-peroxidase conjugate. Thereafter the unbound material is eliminated through a washing step, and the quantity of bound peroxidase determined enzymatically through the addition of substrate. The color intensity was read, and the quantity of human TNF receptor in the samples calculated from the standard curve with the soluble $55 \mathrm{kD}$ and $75 \mathrm{kD}$ TNF receptor, respectively. Detection limit for both the soluble $55 \mathrm{kD}$ and $75 \mathrm{kD}$ TNF receptor was $100 \mathrm{pg} / \mathrm{mL}$. All reagents for the soluble TNF receptor assay ( $h$ tr-20, utr-4, peroxidase labeled TNF, soluble $55 \mathrm{kD}$ TNF receptor, and soluble $75 \mathrm{kD}$ TNF receptor) were kindly provided by Drs. H. Gallati and M. Brockhaus, Hoffmann-La Roche, Basel, Switzerland. 
Creatinine levels were determined as described previously (27).

\section{Statistical analysis}

Cytokine/ receptor data are shown as peak levels, and in each patient group (survivors and nonsurvivors) mean peak value \pm SEM are given. Mann-Whitney test was used for statistical analysis of the data. Differences were considered significant at $\mathrm{P}<.05$. Correlations between plasma creatinine and soluble TNF receptor peak levels were analyzed by using Spearman's rank correlation test.

Table 2: Patient selection

Patients admitted to ICU 1991-1992

Patients fulfilled sepsis syndrome criteria

Sepsis syndrome and positive blood culture

After excluding long-term hemodialysis patients

Patients of which plasma samples were available

ICU mortality at day $30(38 \%)$

Final hospital mortality (62\%)

\section{RESULTS}

\section{Patients}

Between January 1991 and March 1992, 516 patients were admitted at the ICU (Table 2). On admission or later during their stay on the ICU, 28 patients fulfilled the inclusion criteria. Patients of which blood samples were available $(n=26 ; 14$ female, 12 male) were included in the study (range 1 to 7 blood samples). Their ages ranged from 33 to 91 years (mean age $63 \pm 2.9$ years (SEM)). A gram-negative bacteremia was found in 10 patients, a gram-positive blood culture in 11 patients, and a mixed bacteremia in 5 patients.

The study population was divided in 2 groups according to survival of sepsis syndrome. The first group $(n=10)$ consisted of nonsurvivors; patients deceased in ICU within 30 days after sepsis syndrome was diagnosed. Patients alive at day 30 or patients discharged from ICU $(n=16)$ were classified as survivors. The ICU mortality rate at day 30 was $38 \%(n=10)$ and the final hospital mortality rate $62 \%(n=16)$.

\section{Correlation of tumor necrosis factor and interleukin-6 with mortality}

In 3 of the 10 nonsurvivors biologically active TNF could not be detected. Although the highest TNF peak levels were found in nonsurvivors, the difference in TNF peak levels between survivors and nonsurvivors was not significant $(\mathrm{P}=14)$. Mean TNF peak levels were $80 \pm 30 \mathrm{pg} / \mathrm{mL}$ and $185 \pm 65 \mathrm{pg} / \mathrm{mL}$ in survivors and nonsurvivors, respectively (Fig. 1, left). 
In contrast to TNF, plasma IL-6 peak levels were significantly higher in nonsurvivors $(\mathrm{P}<.05)$. Although IL- 6 could not be detected in 2 of the 10 nonsurvivors, the highest IL-6 peak levels were found in this group with a mean peak level of 9.6 \pm 3.0 $\mathrm{ng} / \mathrm{mL}$. Moreover, 6 out of 7 patients with plasma IL-6 peak levels exceeding $3 \mathrm{ng} /$ $\mathrm{mL}$ died, whereas 15 out of 19 patients with IL-6 peak levels less than $3 \mathrm{ng} / \mathrm{mL}$ survived. In survivors mean IL-6 peak level was $1.0 \pm 0.5 \mathrm{ng} / \mathrm{mL}$ (Fig. 1, right).
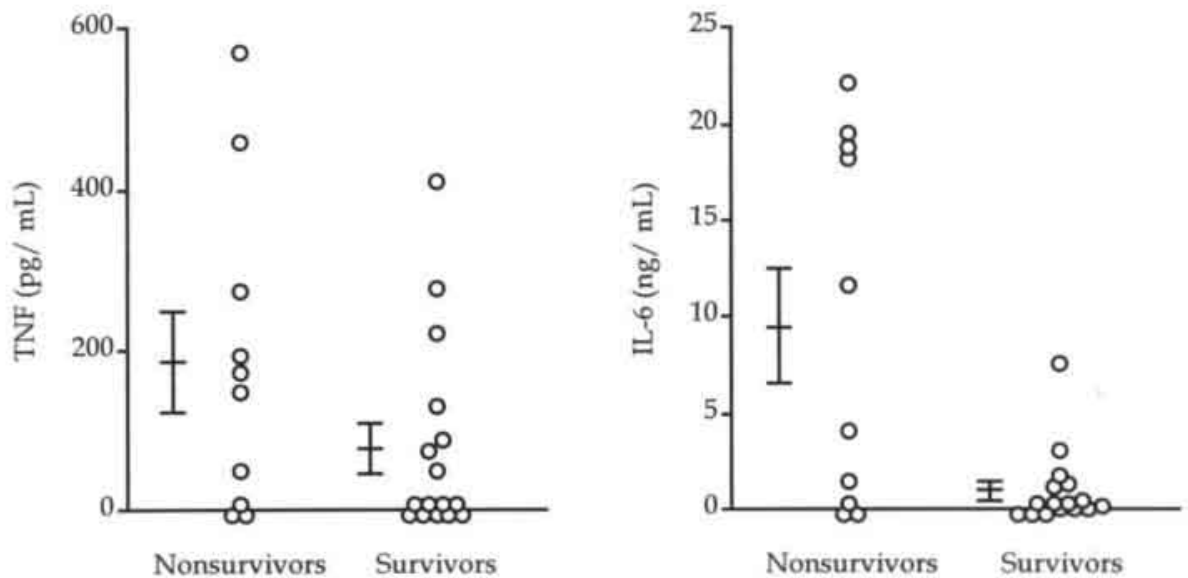

Figure 1: Cytokine peak levels in sepsis syndrome. The difference in plasma TNF peak levels (left) between survivors $(n=16)$ and nonsurvivors $(n=10)$ was not significant $(P=14)$, whereas plasma $I L-6$ peak levels (right) were significantly higher in nonsurvivors $(\mathrm{P}<.05)$. The error bar in each patient group represents the mean peak value \pm SEM.

Correlation of soluble TNF receptor plasma levels with mortality

Both soluble $55 \mathrm{kD}$ and $75 \mathrm{kD}$ TNF receptors were detected in all plasma samples tested and a positive correlation between the soluble $55 \mathrm{kD}$ TNF receptor and soluble $75 \mathrm{kD}$ TNF receptor was found $\left(\mathrm{r}^{2}=.68 ; \mathrm{P}<.0001\right)$. Soluble $55 \mathrm{kD}$ TNF receptor peak levels were significantly higher in nonsurvivors of sepsis syndrome compared to survivors $(\mathrm{P}<.005)$. Mean soluble $55 \mathrm{kD}$ TNF receptor peak levels were $12.2 \pm 1.6 \mathrm{ng} / \mathrm{mL}$ (range $3.4-20.5 \mathrm{ng} / \mathrm{mL}$ ) and $5.2 \pm 1.0 \mathrm{ng} / \mathrm{mL}$ (range 1.5-13.3 ng/ mL) in nonsurvivors and survivors, respectively (Fig. 2, left). Similar data were found for soluble $75 \mathrm{kD}$ TNF receptor peak levels (Fig. 2, right). In nonsurvivors mean soluble $75 \mathrm{kD}$ TNF receptor peak level was $11.3 \pm 1.8 \mathrm{ng} / \mathrm{mL}$ and in survivors $6.6 \pm 1.2 \mathrm{ng} / \mathrm{mL}$. The difference between survivors and nonsurvivors however, was not significant $(\mathrm{P}=.06)$. 
Correlation between plasma creatinine and plasma soluble TNF receptor levels

As a parameter, although not absolute, of renal function, plasma creatinine levels were measured and correlated with soluble TNF receptor levels (Fig. 3). The data showed a significant correlation between both soluble $55 \mathrm{kD}$ and $75 \mathrm{kD}$ TNF receptor peak levels and corresponding plasma creatinine levels $\left(\mathrm{r}^{2}=.60 ; \mathrm{P}<.0001\right.$ and $\mathrm{r}^{2}=.44 ; \mathrm{P}<.001$, respectively).
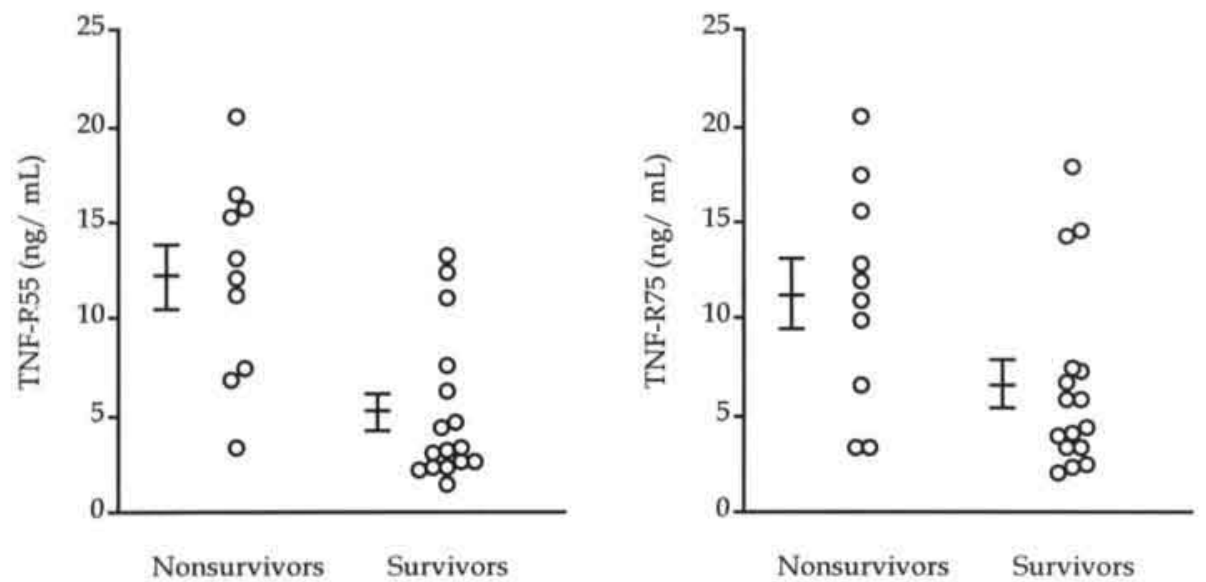

Figure 2: soluble TNF receptor peak levels in sepsis syndrome. In contrast to soluble $75 \mathrm{kD}$ TNF receptor peak levels (right), soluble $55 \mathrm{kD}$ TNF receptor peak levels (left) were significantly higher in nonsurvivors $(n=10)$ compared to survivors $(n=16)(P=.06$ and $P<, 005$, respectively). The error bar in each patient group represents the mean peak value \pm SEM.

\section{DISCUSSION}

Several inflammatory mediators involved in the pathophysiology of the sepsis syndrome are reported to be associated with fatal outcome (e.g. IL-6, TNF). Since plasma TNF levels were not detected consistently in sepsis, it was investigated here whether the measurement of soluble TNF receptor levels provides a better parameter of disease. Both soluble $55 \mathrm{kD}$ TNF receptor and soluble $75 \mathrm{kD}$ TNF receptor levels were measured and results were correlated with mortality and compared with TNF and IL-6 data.

In the present study 6 out of 7 patients with plasma IL-6 peak levels exceeding 3 $\mathrm{ng} / \mathrm{mL}$ died. Moreover, plasma IL-6 peak levels were significantly higher in nonsurvivors compared to survivors. These IL-6 data are consistent with earlier reports on the involvement of IL-6 in the pathophysiology of sepsis syndrome $(16,17)$. 
For TNF no correlation with mortality was observed, in contrast to previous reports (9-12), but in agreement with others (13). There are several explanations for the inconsistency in TNF data. First, it was reported recently that assays such as used here detect free TNF, whereas other assays detect free TNF as well as the TNF/ soluble TNF receptor complex (15). The relative lack of information about the properties of most assays used, complicates comparison of earlier reported TNF data. Second, TNF is only in short intervals present in plasma during sepsis syndrome as was shown in meningococcal sepsis (16) and in studies with experimentally induced sepsis and endotoxemia $(5,19)$. A rapid decrease in circulating TNF levels can be explained by both its short half life and by an active feedback mechanism as reported in endotoxemia, which appeared to be regulated by the hypothalamic adrenal axis (28, 29).
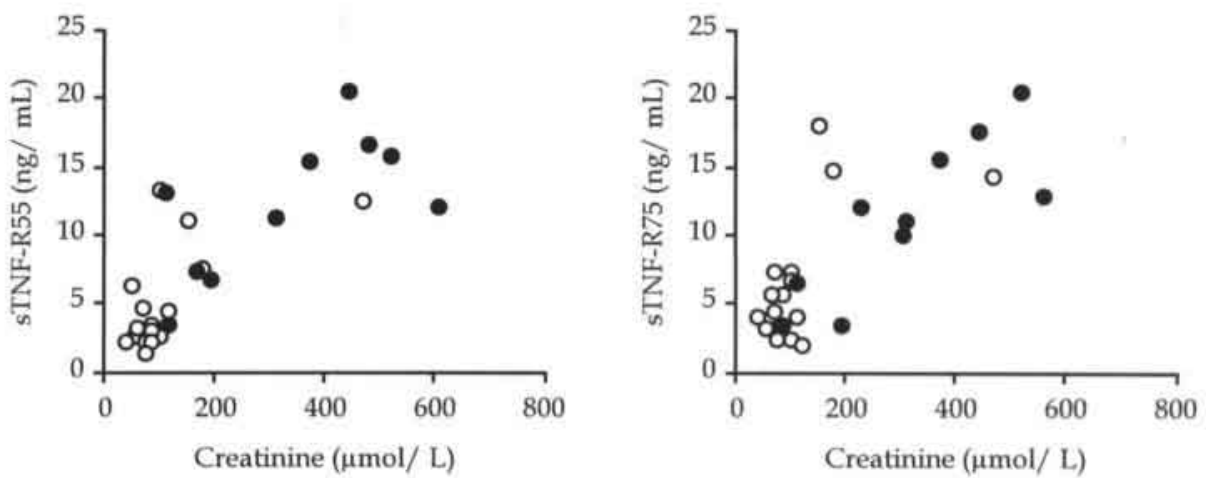

Figure 3: Correlation between soluble TNF receptor peak levels and plasma creatinine in sepsis syndrome. Both soluble $55 \mathrm{kD}$ TNF receptor (upper) and soluble $75 \mathrm{kD}$ TNF receptor (lower) peak levels correlated significantly with corresponding plasma creatinine levels: $\mathrm{r}^{2}=.60 ; \mathrm{P}<.0001$ and $\mathrm{r}^{2}=.44 ; \mathrm{P}<.001$, respectively (open symbols, survivors $n=16$; closed symbols, nonsurvivors $n=10$ ).

Besides TNF, soluble TNF receptors are considered to be involved in inflammation. Soluble TNF receptors, which consist of the proteolytically cleaved extra-cellular part of the TNF cell surface receptor (30), were first detected in urine of febrile patients (31), and later also in urine and plasma of patients with chronic renal failure (32). The shedding of the TNF receptor may function as a protection mechanism against the harmful effects of TNF. Loss of TNF cell surface receptors could lead to a decreased responsiveness of the cell to TNF. In addition, circulating soluble TNF receptor bind TNF with high affinity, resulting in an inhibition of the biological activity of TNF (32). Shedding of TNF receptor has been demonstrated after endotoxin $(19,20)$ and TNF administration (18), therefore soluble TNF receptor levels could reflect a 
TNF/ endotoxin induced inflammatory response. Since soluble TNF receptor levels show slower kinetics compared to the short-lived elevations in TNF levels, soluble TNF receptor levels could be more useful as a parameter of disease.

Increased soluble TNF receptor levels have been reported in critically ill patients (19), and a positive correlation with mortality has been demonstrated in meningococcemia (26). The results presented here are in agreement with these data. Although the differences in soluble $75 \mathrm{kD}$ TNF receptor levels did not reach significancy $(\mathrm{P}=.06)$, soluble $55 \mathrm{kD}$ TNF receptor peak levels were significantly higher $(\mathrm{P}<.005)$ in nonsurvivors compared to survivors.

However, increased soluble TNF receptor levels have not only been demonstrated in inflammation, soluble TNF receptor levels are also known to be influenced by renal function. Elevated soluble TNF receptor levels were detected in patients with chronic renal failure (32) and a positive correlation with plasma creatinine was demonstrated in patients with different degrees of chronic renal failure (21). Moreover experimental animal data from our laboratory demonstrated a central role for the kidney in the clearance of TNF receptor and TNF/ TNF receptor complexes in mice (33).

Table 3: Plasma creatinine peak levels in sepsis syndrome and ICU mortality*

\begin{tabular}{lcc}
\hline & $\begin{array}{c}\text { Creatinine } \\
\leq 150 \mu \mathrm{mol} / \mathrm{L}\end{array}$ & $\begin{array}{c}\text { Creatinine } \\
>150 \mu \mathrm{mol} / \mathrm{L}\end{array}$ \\
\hline Survivors $(\mathrm{n}=16)$ & 12 & 4 \\
Nonsurvivors $(\mathrm{n}=10)$ & 1 & 9 \\
\hline
\end{tabular}

*Plasma creatinine peak levels correlated significantly with mortality. Chi-square: $\mathrm{P}<, 005$.

In order to investigate whether soluble TNF receptor kinetics in the population studied were influenced by renal function, soluble TNF receptor peak levels were correlated with corresponding plasma creatinine levels. Since long-term hemodialysis patients were excluded from the study, increased plasma creatinine levels were considered to reflect acute renal failure complicating sepsis syndrome. Both soluble $55 \mathrm{kD}$ TNF receptor and soluble $75 \mathrm{kD}$ TNF receptor peak levels were correlated significantly with corresponding plasma creatinine levels $\left(\mathrm{r}^{2}=.60 ; \mathrm{P}<.0001\right.$ and $\mathrm{r}^{2}=.40$; $\mathrm{P}<.001$, respectively). In contrast, TNF $\left(\mathrm{r}^{2}=.05 ; \mathrm{P}=.25\right)$ and IL-6 $\left(\mathrm{r}^{2}=.17 ; \mathrm{P}<.05\right)$ correlated poorly with plasma creatinine. In long-term hemodialysis patients $(n=4)$, which were excluded from this study, high soluble TNF receptor levels were detected even before sepsis syndrome was diagnosed $(17.3 \pm 0.8 \mathrm{ng} / \mathrm{mL}$ and $12.5 \pm 0.4 \mathrm{ng} / \mathrm{mL}$ for soluble $55 \mathrm{kD}$ and $75 \mathrm{kD}$ TNF receptor, respectively). Although soluble TNF receptor peak levels were high in the excluded patients, 3 out of 4 patients did survive.

Acute renal failure is a severe complication of sepsis and plays an important role in the mortality due to septic shock and multiple organ failure (34). In the present study, 
the positive correlation between acute renal failure, as assessed by plasma creatinine, and mortality was confirmed (Table 3). Plasma creatinine peak levels were significantly higher in nonsurvivors compared to survivors $(\mathrm{P}<.001)$. Since the kidney was reported to play an important role in soluble TNF receptor clearance, impaired renal function will lead to the accumulation of these proteins in plasma. This is supported by the demonstrated positive correlation between plasma creatinine and soluble TNF receptor levels. Moreover the correlation of soluble TNF receptor levels with plasma creatinine was more pronounced than the correlation with mediators, such as TNF and IL-6, involved in the pathophysiology of sepsis syndrome (data not shown). The present data strongly suggest that increased soluble TNF receptor levels do not directly reflect inflammatory state, but merely the degree of renal failure.

The physiological role of increased soluble TNF receptor levels in sepsis syndrome is not yet resolved. When sepsis is complicated by an impaired renal function, a decreased clearance of both soluble TNF receptor and TNF/ soluble TNF receptor complexes will lead to increased plasma levels. Although TNF complexed with the receptor is biologically inactive, such complexes may serve as a 'slow release reservoir' of biologically active TNF (35). On the other hand, pre-existing increased soluble TNF receptor levels, may mitigate the impact of over-production of TNF in patients suffering from severe infections.

In conclusion, soluble TNF receptor levels correlated with outcome as well as with plasma creatinine levels. The data presented suggest that, in the ICU patients studied, increased soluble TNF receptor levels do not directly reflect inflammation, but appear to be the result of renal failure complicating sepsis syndrome and are likewise correlated with mortality. The usefulness of soluble TNF receptor levels as a parameter of disease is therefore limited. The clinical importance of elevated soluble TNF receptor levels remains to be elucidated. 


\section{REFERENCES}

1. Cerami A, Ikeda $\mathrm{Y}$, Le Trang N, et al. Weight loss associated with an endotoxin-induced mediator from peritoneal macrophages: the role of cachectin (tumor necrosis factor). Immunol Lett 1985;11:173-7

2. Suffredini AF, Fromm RE, Parker MM, et al. The cardiovascular response of normal humans to the administration of endotoxin. N Engl J Med 1989;321:280-7

3. Giroir BP. Mediators of septic shock: New approaches for interrupting the endogenous inflammatory cascade. Crit Care Med 1993;21:780-9

4. Tracey $\mathrm{KJ}$, Beutler B, Lowry SF, et al. Shock and tissue injury induced by recombinant human cachectin. Science 1986;234:470-4

5. Michie HR, Manogue KR, Spriggs DR, et al. Detection of circulating tumor necrosis factor after endotoxin administration. N Engl J Med 1988;318:1481-6

6. Beutler B, Milsark IW, Cerami A. Passive immunization against cachectin/ tumor necrosis factor protects mice from lethal effect of endotoxin. Science 1985;229:869-71

7. Tracey KJ, Fong Y, Hesse DG, et al. Anti-cachectin/ TNF monoclonal antibodies prevent septic shock during lethal bacteraemia. Nature 1987;330:662-4

8. Echtenacher B, Falk W, Mannel DN, et al. Requirement of endogenous tumor necrosis factor/ cachectin for recovery from experimental peritonitis. J Immunol 1990;145:3762-6

9. Marks JD, Marks CB, Luce JM, et al. Plasma tumor necrosis factor in patients with septic shock. Mortality rate, incidence of adult respiratory distress syndrome, and effects of methylprednisolone administration. Am Rev Respir Dis 1990;141:94-7

10. Damas P, Reuter A, Gysen P, et al. Tumor necrosis factor and interleukin-1 serum levels during severe sepsis in humans. Crit Care Med 1989;17:975-8

11. Debets JM, Kampmeijer R, van der Linden MP, et al. Plasma tumor necrosis factor and mortality in critically ill septic patients. Crit Care Med 1989;17:489-94

12. Waage A, Halstensen A, Espevik T. Association between tumour necrosis factor in serum and fatal outcome in patients with meningococcal disease. Lancet 1987;1:355-7

13. Hamilton G, Hofbauer S, Hamilton B. Endotoxin, TNF-alpha, Interleukin-6 and parameters of the cellular immune system in patients with intraabdominal sepsis. Scand J Infect Dis 1992;24:361-8

14. Fischer. Influence of an anti-tumor necrosis factor monoclonal antibody on cytokine levels in patients with sepsis. Crit Care Med 1993;21:318-27

15. Engelberts I, Stephens S, Francot GJ, et al. Evidence for different effects of soluble TNF-receptors on various TNF measurements in human biological fluids. Lancet 1991;338:515-6

16. Waage A, Brandtzaeg P, Halstensen A, et al. The complex pattern of cytokines in serum from patients with meningococcal septic shock. Association between interleukin 6, interleukin 1 , and fatal outcome. J Exp Med 1989;169:333-8

17. Hack CE, de Groot ER, Felt BRJ, et al. Increased plasma levels of interleukin- 6 in sepsis. Blood 1989;74:1704-10

18. Lantz M, Malik S, Slevin ML, et al. Infusion of tumor necrosis factor (TNF) causes an increase in circulating TNF-binding protein in humans. Cytokine 1990;2:402-6

19. van Zee KJ. Kohno T, Fischer E, et al. Tumor Necrosis Factor soluble receptors circulate during experimental and clinical inflammation and can protect against excessive Tumor Necrosis Factoralpha in vitro and in vivo. Proc Natl Acad Sci Usa 1992;89:4845-9

20. Spinas GA, Keller U, Brockhaus M. Release of soluble receptors for tumor necrosis factor (TNF) in relation to circulating TNF during experimental endotoxinemia. J Clin Invest 1992;90:533-536

21. Brockhaus M, Bar-Khayim Y, Gurwicz S, et al. Plasma tumor necrosis factor soluble receptors in chronic renal renal failure. Kidney Int 1992;42:663-7 
22. Knaus WA, Draper EA, Wagner DP, et al. APACHE II: A severity of disease classification system. Crit Care Med 1985;13:818-29

23. Elebute EA, Stoner HB. The grading of sepsis. Br J Surg 1983;70:29-31

24. Bone RC. Sepsis, the sepsis syndrome, multi-organ failure: a plea for comparable definitions. Ann Intern Med 1991;114:332-3

25. Engelberts I, Moller A, Schoen GJ, et al. Evaluation of measurement of human TNF in plasma by ELISA. Lymphokine Cytokine Res 1991;10:69-76

26. Girardin E, Rouxlombard P, Grau GE, et al. Imbalance between tumour necrosis factor-alpha and soluble TNF receptor concentrations in severe meningococcaemia. Immunology 1992;76:20-23

27. Larsen K. Creatinine assay by a reaction-kinetic approach. Clin Chem Acta 1972;41:209-17

28. Bertini R, Bianchi M, Ghezzi P. Adrenalectomy sensitizes mice to the lethal effects of interleukin 1 and tumor necrosis factor. J Exp Med 1988;167:1708-12

29. Zuckerman SH, Shellhaas J, Butler LD. Differential regulation of lipopolysaccharide-induced interleukin 1 and tumor necrosis factor synthesis: effects of endogenous and exogenous glucocorticoids and the role of the pituitary-adrenal axis. Eur J Immunol 1989;19:301-5

30. Porteu F, Brockhaus M, Wallach D, et al. Human neutrophil elastase releases a ligand-binding fragment from the $75-\mathrm{kDa}$ tumor necrosis factor (TNF) receptor. Comparison with the proteolytic activity responsible for shedding of TNF receptors from stimulated neutrophils. J Biol Chem 1991;266:18846-53

31. Seckinger P, Isaaz S, Dayer JM. A human inhibitor of tumor necrosis factor alpha. J. Exp Med 1988;167:1511-6

32. Peetre $\mathrm{C}$, Thysell $\mathrm{H}$, Grubb A, et al. A tumor necrosis factor binding protein is present in human biological fluids. Eur J Haematol 1988;41:414-9

33. Bemelmans MHA, Gouma DJ, Buurman WA. Influence of nephrectomy on tumor necrosis factor clearance in a murine model. J Immunol 1993;150:2007-17

34. Manship L, McMillin RD, Brown JJ. The influence of sepsis and multisystem organ failure on mortality in the surgical intensive care unit. Am Surg 1984;50:94-101

35. Aderka D, Engelmann $\mathrm{H}$, Maor $\mathrm{Y}$, et al. Stabilization of the bioactivity of tumor necrosis factor by its soluble receptors. J Exp Med 1992;175:323-9 

INCREASED CONCENTRATIONS OF CYTOKINES AND ADHESION MOLECULES IN PATIENTS AFTER REPAIR OF ABDOMINAL AORTIC ANEURYSM

Inflammatory response after prolonged hypotension

A.H.M. Froon, J.W.M. Greve, C.J. van der Linden, W.A. Buurman Eur J Surg 1996; 162: 287-96 


\section{SUMMARY}

Objective: To evaluate the association between inflammatory mediators and clinical outcome in patients after repair of abdominal aortic aneurysms.

Design: Prospective study.

Setting: University Hospital, The Netherlands.

Patients: 30 Consecutive patients who had undergone elective or acute repair of abdominal aortic aneurysms.

Main outcome measures: Plasma concentrations of the cytokines tumor necrosis factor (TNF), interleukin-6 (IL-6) and interleukin-8 (IL-8) as well as soluble TNF receptors and the soluble (s) adhesion molecules E-selectin and intercellular adhesion molecule 1 (ICAM-1) were measured and correlated with the degree of systemic hypotension (shock: hypotension more than 15 minutes) and clinical outcome.

Results: Peak plasma concentrations of TNF and IL-6 were significantly higher in shocked patients $(\mathrm{P}<.005$ and $\mathrm{P}<.0005$, respectively) and those who died (both $\mathrm{P}<.01$ ), whereas concentrations of IL-8 increased only when shock complicated rupture of the aneurysm $(\mathrm{P}<.01)$. Increases in the concentrations of TNF receptors reflected impaired renal function. In contrast to sE-selectin concentrations, peak sICAM-1 concentrations were significantly higher in shocked patients $(\mathrm{P}<.01)$ and those that died $(\mathrm{P}<.01)$.

Conclusions: These results strongly suggest that increased concentrations of sICAM-1 and IL- 6 reflect the inflammatory response induced by ischemia after repair of an abdominal aortic aneurysm, and indicate that the postoperative course is likely to be complicated. 


\section{INTRODUCTION}

Repair of abdominal aortic aneurysms is associated with considerable mortality: in patients in whom the aneurysm has not ruptured, mortality ranges from $1.4 \%-6.5 \%$ whereas among those with ruptured aneurysms up to $70 \%$ mortality has been reported (1). Rupture of an aneurysm often leads to hemorrhagic shock, which is considered to be responsible for serious complications during the postoperative course (2).

Hemorrhagic shock in an experimental animal model results in an inflammatory reaction with increased concentrations of cytokines such as tumor necrosis factor (TNF) and interleukin-6 ( $\mathrm{IL}-6)$ in plasma (3). Although TNF and IL-6 have immunostimulatory capabilities, increased concentrations after hemorrhagic shock are associated with profound depression of immunity and an increased susceptibility to infection and sepsis (4). In addition, treatment with reagents that inhibit synthesis, release, and activity of cytokines has a beneficial effect on the immune response $(5,6)$. Soluble TNF receptors (sTNF-R), the circulating extracellular part of the TNF cell surface receptor (7), can bind and inactivate TNF (8), and are thought to be involved in the physiological control of the cytokine response $(9,10)$. TNF receptors are released after endotoxin or TNF administration (10-12). Increased plasma concentrations of sTNF-R with or without detectable circulating TNF may therefore reflect a systemic inflammatory state.

In the ischemia and reperfusion-induced inflammatory response, neutrophil activation and extravasation $(13,14)$ are thought to have an important role. Neutrophil adhesion to the vessel wall and migration into reperfused tissue is mediated by chemotactic proteins such as interleukin-8 (IL-8) and adhesion molecules expressed on neutrophils and endothelial cells (15-18). IL-8 release in an in vitro model initiated by anoxia-hyperoxia has suggested that IL-8 may be involved in the ischemia-reperfusion injury in vivo (19). Interference with neutrophil adhesion by inhibition of the interaction between the CD11/ CD18 complex and its ligand intercellular adhesion molecule-1 (ICAM-1) can reduce organ injury caused by hemorrhagic shock in an experimental animal model (20). This supports the role of adhesion molecules in inflammation induced by ischemia. Greatly increased expression of E-selectin has been reported in inflammation and septic shock, which suggests that E-selectin has a role in acute inflammation (21-23). Interestingly, adhesion molecules are present either cell bound or as soluble molecules in the circulation (24-26). In vitro, the quantity of adhesion molecules released by cells correlates directly with expression of adhesion molecules on the cell surface (27). These data indicate that plasma concentrations of circulating adhesion molecules may reflect the inflammatory state in vivo.

In this study, the association between inflammatory mediators and clinical course was examined in patients after repair of abdominal aortic aneurysms. Patients were divided into those who were hemodynamically stable and those who underwent prolonged systemic hypotension. To assess the inflammatory response, plasma concentrations of TNF, IL-6, IL-8, sTNF-R, soluble E-selectin, and soluble ICAM-1 were 
measured. In addition, we calculated the correlation between the plasma concentrations of these mediators and the presence of shock and mortality.

\section{PATIENTS AND METHODS}

\section{Subjects}

Patients were studied for five days after repair of the aneurysm. For statistical analysis the study population was divided according to the presence of prolonged systemic hypotension (systolic blood pressure less than $80 \mathrm{mmHg}$ for at least 15 minutes) on admission to hospital or during the repair. Patients who underwent a similar operation, but who did not develop prolonged hypotension, were regarded as control patients. Patients without hypotension who were operated acutely were therefore included in the control group as well as elective patients. Those who survived the repair were compared with those who died to analyze the prognostic value of the inflammatory mediators. The study was reviewed and approved by the medical ethics committee of Maastricht University Hospital, which deemed that informed consent was not required.

Table 1: Details of patients studied

\begin{tabular}{|c|c|c|c|c|}
\hline & \multicolumn{2}{|c|}{ Hemodynamic state } & \multicolumn{2}{|c|}{ Mortality } \\
\hline & $\begin{array}{l}\text { Stable } \\
(\mathrm{n}=11)\end{array}$ & $\begin{array}{c}\text { Prolonged } \\
\text { hypotension } \\
(n=19)\end{array}$ & $\begin{array}{l}\text { Survived } \\
\quad(n=21)\end{array}$ & $\begin{array}{l}\text { Died } \\
(n=9)\end{array}$ \\
\hline \multicolumn{5}{|l|}{ Sex: } \\
\hline Male (n) & 10 & 16 & 18 & 8 \\
\hline Female (n) & 1 & 3 & 3 & 1 \\
\hline Age (years) & $71(63-83)$ & $74(63-88)$ & $71(63-88)$ & $74(66-83)$ \\
\hline Duration of operation (mins) & $130(92-205)$ & $135(95-300)$ & $130(92-270)$ & $145(100-300)$ \\
\hline Blood transfused ${ }^{\#}$ (units) & $3(0-11)^{* *}$ & $10(2-26)^{n+*}$ & $4(0-26)^{*}$ & $8(5-22)^{*}$ \\
\hline Survived (n) & 11 & 10 & - & - \\
\hline Died (n) & 0 & 9 & - & - \\
\hline Prolonged hypotension (n) & - & - & 10 & 9 \\
\hline Hemodynamically stable (n) & - & - & 11 & 0 \\
\hline
\end{tabular}

Figures represent number of patients unless otherwise stated. Values are medians and ranges within parentheses; " in first 24 hours after surgery. ${ }^{*} \mathrm{P}<.05$, and $* \mathrm{P}<.005$. 
Blood samples

Within 24 hours of operation blood samples were taken daily from each patient and collected in tubes containing EDTA. Daily blood samples were collected at about 0600 hours. The blood samples were immediately put on ice, and plasma was prepared at $4^{\circ} \mathrm{C}$ by centrifugation at $2,200 \mathrm{G}$ for five minutes. Samples were stored at $-70^{\circ} \mathrm{C}$ until use. Concentrations of inflammatory mediators, receptors, and adhesion molecules were measured in duplicate as described below.

\section{Reagents}

Reagents used were recombinant (r) TNF, rIL-6, rIL-8, recombinant sTNF-R55 and sTNF-R75 (molecules produced by cell lines transfected with sTNF-R55 and sTNF-R75, respectively), E-selectin and ICAM-1 (Bender MedSystems, Vienna, Austria).

\section{Antibodies}

The following antibodies were used: $\mathrm{mAb}$ 61E71 anti-TNF; 5E1 anti-IL-6; mAb anti-IL8; MR1-1 (anti-TNF-R55); MR2-2 (anti-TNF-R75); anti-ICAM-1 mAb F7-16 and F10-3, anti-E-selectin mAb ENA-1 and ENA-2 (28).

\section{Assays}

Plasma concentrations of TNF were measured with an enzyme linked immunosorbent assay (ELISA) developed in our laboratory, which correlates well with bioassay results (29). In short, plasma samples (diluted 1/ 1) and the standard titration curve with rTNF were incubated with a murine anti-human TNF mAb $61 \mathrm{E} 71$ absorbed on a microtiter plate (Nunc, Roskilde, Denmark). The plates were subsequently incubated with a polyclonal rabbit anti-human TNF antibody, followed by a peroxidase conjugated goat anti-rabbit IgG (Jackson, Westgrove, PA) and TMB (3',5,5',-tetramethylbenzidine) substrate (Kirkegaard \& Perry Lab., Gaithersburg, MD). The optical density was read, and TNF concentrations were calculated from the standard TNF curve. Detection limit for the TNF assay was $10 \mathrm{pg} / \mathrm{mL}$.

IL-6 and IL- 8 were measured by a procedure largely parallel to the TNF ELISA mentioned above. Plasma concentrations were measured using the murine anti-human IL-6 antibody 5E1 (developed in our laboratory) and a anti-human IL-8 mAb as capture antibody, respectively. Diluted plasma samples (1/1) and the standard titration curve with rIL- 6 and rIL- 8 were added to the plates. The amount of IL- 6 and IL- 8 bound to the wells was quantified by sequential incubation with a polyclonal rabbit anti-IL-6 antibody and a polyclonal rabbit anti-IL- 8 antibody, respectively, followed by adding peroxidase conjugated goat anti-rabbit IgG and substrate. Detection limits for the IL-6 and $I L-8$ assays were $10 \mathrm{pg} / \mathrm{mL}$ and $20 \mathrm{pg} / \mathrm{mL}$, respectively.

In order to quantify sTNF-R55 and sTNF-R75, microtiter plates were coated with MR1-1 and MR2-2, respectively (both developed in our laboratory). Plasma samples 
(diluted 1/ 5) and the standard titration curve with recombinant sTNF-R55 and sTNFR75 were added to the plates and subsequently incubated with a biotine labelled polyclonal rabbit antibody specific for sTNF-R55 and sTNF-R75, respectively, followed by peroxidase conjugated streptavidin (Dakopatts, Glostrup, Denmark). Substrate was added, and the optical density was read. The detection limit for the sTNF-R55 and sTNF-R75 assay was $100 \mathrm{pg} / \mathrm{mL}$. Plasma sE-selectin and sICAM-1 concentrations were measured using mAb ENA-1 and mAb F7-16 as capture antibodies. Plasma samples were diluted $1 / 20$ and $1 / 10$ for the sE-selectin and sICAM-1 ELISA, respectively. Samples and standard titration curves with sE-selectin and sICAM-1 were added to the plates and subsequently incubated with biotinylated mAb ENA-2 or F10-3 for detection of sE-selectin and sICAM-1, respectively. Substrate was added, and the optical density was read. All steps of the sE-selectin ELISA were done using a buffer containing calcium and magnesium. Detection limits for the sE-selectin and sICAM-1 assays were $0.1 \mathrm{ng} / \mathrm{mL}$ and $1 \mathrm{ng} / \mathrm{mL}$, respectively.

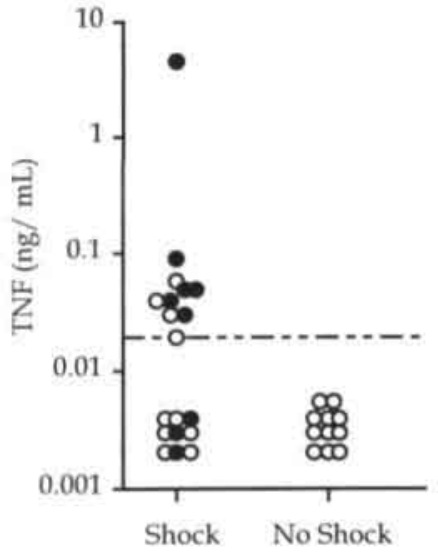

\section{Statistical analysis}

To asses the significance of differences between patients with and without shock, Mann-Whitney test was applied to the highest concentrations detected in each patient (peak concentrations) during the postoperative period. Peak values are shown to give insight in individual patients with and without shock, whereas daily median concentrations are given to illustrate the kinetics in those who survived and those who died, respectively. Kinetics were assessed in each patient by linear regression of concentrations obtained daily during the same period. The resulting slopes were compared between the subgroups by application of the Mann-Whitney test. Probabilities of less than .05 were accepted as significant. 


\section{RESULTS}

\section{Patients}

30 Consecutive patients ( 26 man and four women) were included in the study, with a mean age of 73 years (range 63 to 88). Nineteen of the 21 patients with ruptured aneurysms underwent periods of prolonged systemic hypotension, whereas in two patients the systolic blood pressure remained normal $(>120 \mathrm{mmHg})$. In these two patients the rupture had resulted in only a small retroperitoneal hematoma. Blood pressure was within normal limits in those patients who underwent repair for aneurysms that had not ruptured $(n=9)$. The amount of blood transfused within 24 hours of the operation in each group is shown in Table 1. Operation times in patients with and without shock were comparable. The mortality at day 30 was $20 \%(n=6 / 30)$ and the final hospital mortality was $30 \%(n=9 / 30)$. Patients who died had all had ruptured aneurysms complicated by hemorrhagic shock (9/19). A total of 143 of the 150 plasma samples were obtained correctly during the five day study period for laboratory processing.
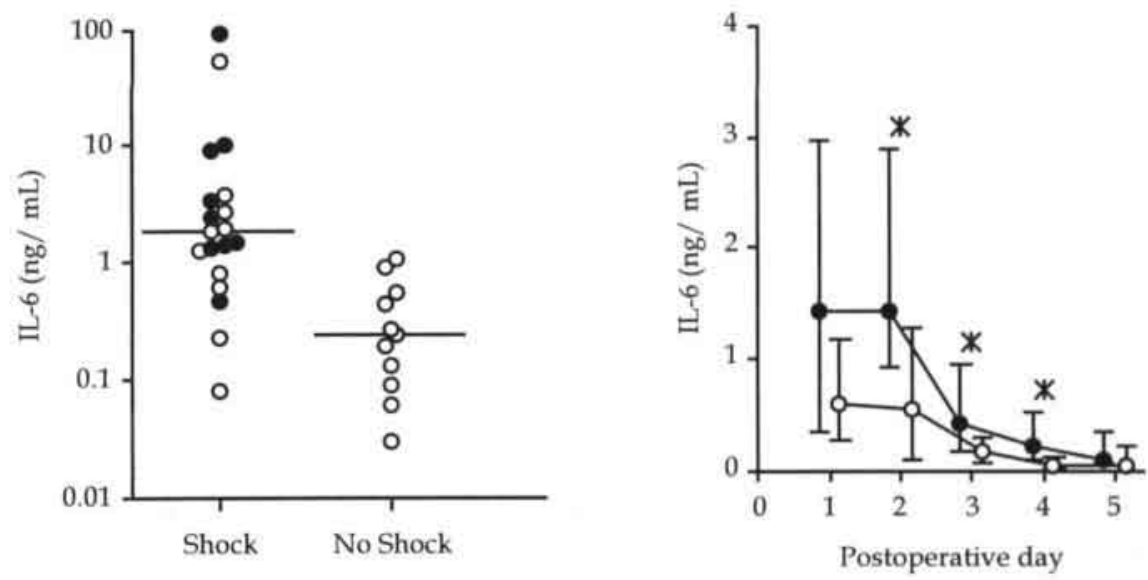

Figure 2: Kinetics and peak plasma concentrations of IL-6. The peak values were significantly higher in patients with hemorrhagic shock than in those who were hemodynamically stable (left) and in those that died (closed circles, $n=9$ ) than in those that survived (open circles, $n=21, P<.0005$ and $P<.01$, respectively). IL-6 concentrations were raised mainly during the first two postoperative days (right). Horizontal lines represent median peak values (left), and in the right panel data are expressed as median (interquartile). $\mathrm{XP}<.05$. 


\section{TNF, interleukin-6, and interleukin-8}

Remarkable differences in plasma concentrations of TNF were observed between the subgroups studied. TNF was detectable in 10 out of 19 patients with shock (range $0.02-$ $4.42 \mathrm{ng} / \mathrm{mL}$ ), but in none of the patients without shock (Fig. $1 ; \mathrm{P}<.005$ ). Concentrations were highest on day 2 of the study period. In those patients in whom it was detected $(n=10)$, however, it was detectable only in $34 \%$ of all samples during the five day course. In nine patients peak concentrations did not exceed $0.1 \mathrm{ng} / \mathrm{mL}$. It was detected in six of the nine who died, and in four of 21 survivors. Peak plasma concentrations were significantly higher $(\mathrm{P}<.01)$ in those that died than in survivors, ranging from $<0.02-4.42 \mathrm{ng} / \mathrm{mL}$ and from $<0.02-0.06 \mathrm{ng} / \mathrm{mL}$, respectively.
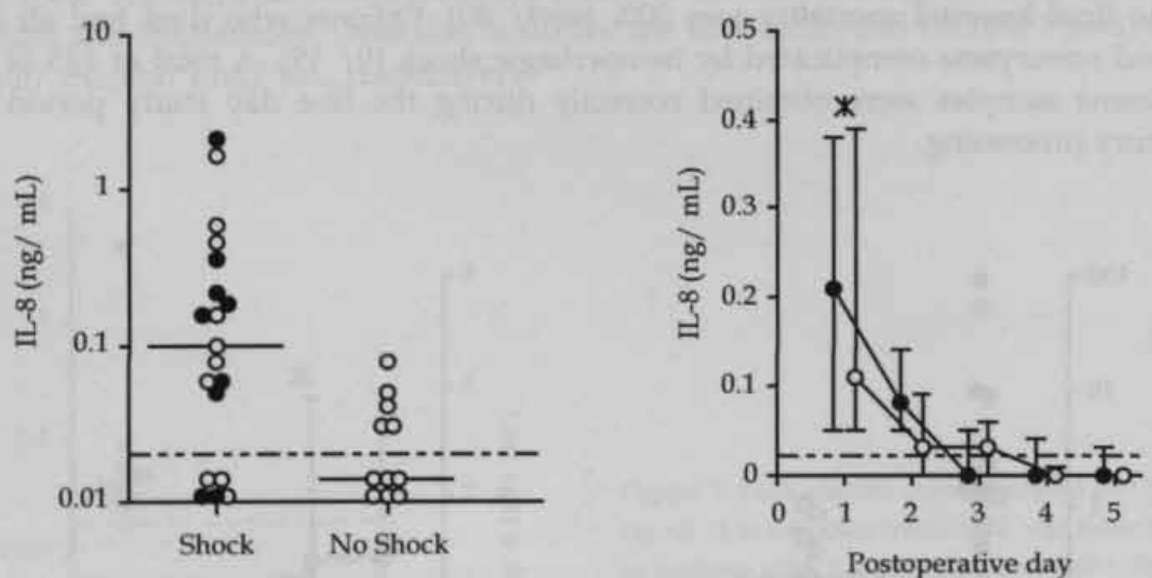

Figure 3: Kinetics and peak plasma concentrations of IL-8. The peak values were significantly higher in patients with hemorrhagic shock than in those who were hemodynamically stable (left) $(\mathrm{P}<.01)$. There was no correlation with mortality (survivors are indicated by open circles, $n=21$, and those that died by closed circles, $n=9$ ). IL- 8 concentrations were raised mainly during the first two postoperative days (right). The horizontal line indicates the median peak value (left), and the dashed line indicates the detection limit. Data are expressed as median (interquartile) (right), $\mathrm{XP}=.06$.

In contrast to TNF, IL-6 was detected in all patients studied (Fig. 2, left). In shocked patients peak concentrations were significantly higher than in patients who were not shocked $(\mathrm{P}<.0005)$, ranging from $0.08-92.6 \mathrm{ng} / \mathrm{mL}$ (median $1.86 \mathrm{ng} / \mathrm{mL}$ ) and from $0.03-1.05 \mathrm{ng} / \mathrm{mL}$ (median $0.24 \mathrm{ng} / \mathrm{mL}$ ), respectively. In addition, peak concentrations were significantly higher in those that died than in survivors $(\mathrm{P}<.01)$. Median peak IL-6 concentrations were $2.44 \mathrm{ng} / \mathrm{mL}$ (range $0.47-92.6 \mathrm{ng} / \mathrm{mL}$ ) and 0.56 $\mathrm{ng} / \mathrm{mL}$ (range $0.03-54.9 \mathrm{ng} / \mathrm{mL}$ ) in those who died and survivors, respectively. In shocked patients and in those who died median IL-6 concentrations were considerably 
raised during the first two days after operation. Remarkably, however, the initial high IL- 6 concentrations in those that died decreased and reached concentrations similar to those in survivors before day 5 , the time point at which the first patient died (Fig. 2, right).
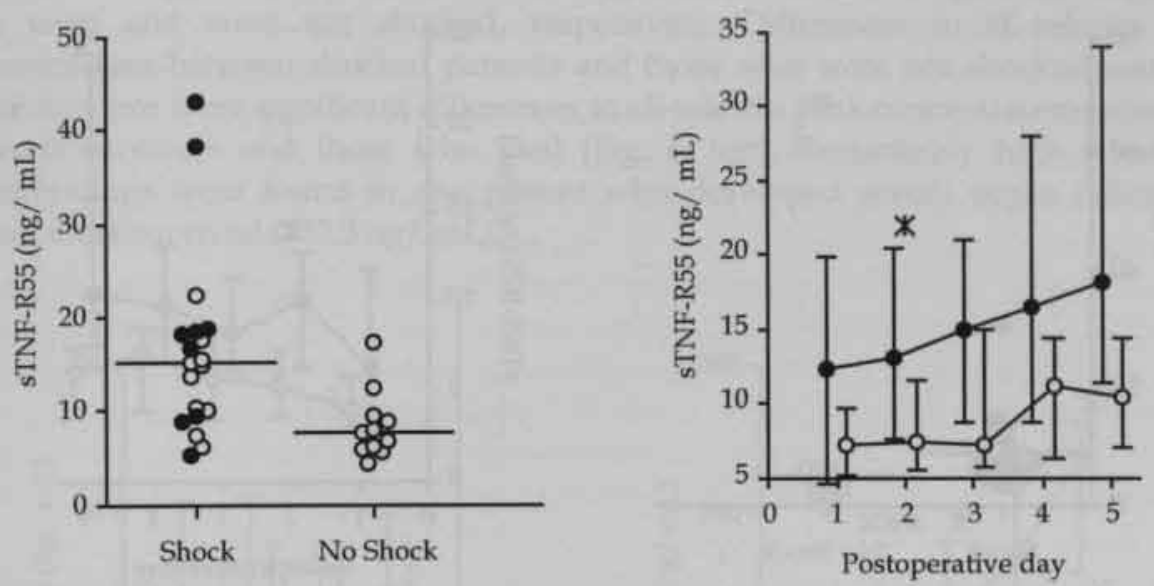

Figure 4: Kinetics and peak plasma concentrations of sTNF-R55. The peaks were significantly higher in patients with hemorrhagic shock than in those who were hemodynamically stable (left) $(\mathrm{P}<, 01)$, and in those that died (closed circles, $n=9$ ) than in those that survived (open circles, $n=21, P<.05$ ). During the period studied the increases in sTNF-R55 concentrations were more pronounced in those that died than in those that survived (right; $\mathrm{P}<.05$ ). Horizontal lines indicate median peak concentrations (left), and in the right panel data are expressed as median (interquartile). $Ж \mathrm{P}<.05$.

The chemotactic factor IL- 8 was detectable in 14 out of 19 shocked patients, and in five of 11 patients who were not shocked (Fig. 3, left). Plasma IL-8 peak concentrations ranged from $<0.02-2.1 \mathrm{ng} / \mathrm{mL}$ (median $0.1 \mathrm{ng} / \mathrm{mL}$ ) and from $<0.02-0.08 \mathrm{ng} / \mathrm{mL}$ (median $<0.02 \mathrm{ng} / \mathrm{mL}$ ) in patients who were and were not shocked, respectively. IL-8 peak concentrations were significantly higher in shocked patients than in those who were not shocked $(\mathrm{P}<.01)$. There were, however, no significant differences between survivors and those who died. IL-8 kinetics showed a similar trend to those of IL-6. In patients in who IL-8 could be measured, the increased concentrations were mainly seen during the first two days after operation (Fig. 3, right).

\section{Soluble tumor necrosis factor receptors}

Both sTNF-R55 and sTNF-R75 were detected in all but one patient, in whom sTNF-R75 could not be detected, and there was a significant correlation between sTNF-R55 and sTNF-R75 peak concentrations $\left(\mathrm{r}^{2}=0.71 ; \mathrm{P}<.0001\right)$. Both sTNF-R55 and sTNF-R75 peak 
concentrations were significantly higher in shocked patients than in those who were not shocked ( $\mathrm{P}<.01$ for sTNF-R55 and sTNF-R75) (Fig. 4, left; Fig. 5, left, respectively). In addition, plasma concentrations of both receptors were higher in those who died than in those who survived ( $\mathrm{P}<.05$ for sTNF-R55 and sTNF-R75).
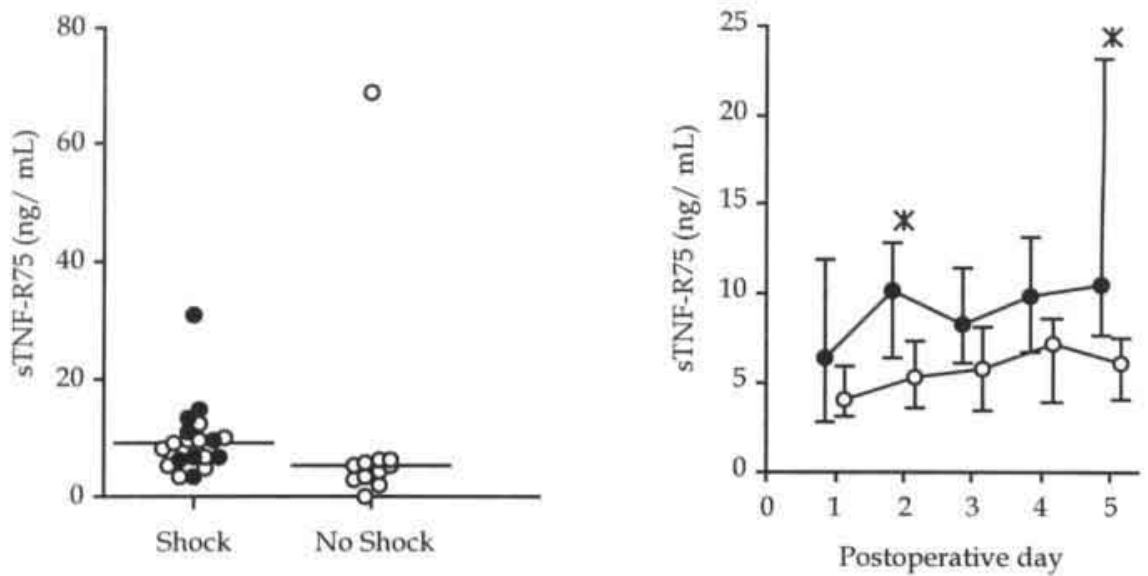

Figure 5: Kinetics and peak plasma concentrations of sTNF-R75. Peak concentrations (left) were significantly higher in patients with hemorrhagic shock than in those who were hemodynamically stable $(\mathrm{P}<.01$ ), and in those that died (closed circles, $\mathrm{n}=9$ ) than in those that survived (open circles, $\mathrm{n}=21, \mathrm{P}<, 05$ ). The increase in STNF-R75 concentrations was slightly but not significantly more pronounced in those that died than in those that survived (right) $(\mathrm{P}=08)$. Horizontal lines indicate median sTNF-R75 peak concentrations (left), and data (right) are expressed as median (interquartile). $Ж \mathrm{P}<.05$.

With regard to survivors and those who died, sTNF-R concentrations showed different kinetics during the period studied (Fig. 4, right; Fig. 5, right). The increase in sTNF-R55 and sTNF-R75 concentrations was more pronounced in those who died than in survivors $(\mathrm{P}<.05$ and $\mathrm{P}=.08$, respectively).

sTNF-R concentrations have been reported to be dependent on renal sTNF-R clearance (30-32), so we assessed the correlation between plasma creatinine concentrations, as a measure of renal function, and sTNF-R concentrations. Both sTNFR55 and sTNF-R75 peak concentrations correlated significantly with the corresponding plasma creatinine concentrations $\left(\mathrm{r}^{2}=0.36 \mathrm{P}<.005\right.$ and $\mathrm{r}^{2}=0.25 \mathrm{P}<.01$, respectively). In only one patient were high soluble TNF receptor concentrations observed when the plasma creatinine peak concentration was within the reference range ( 17.3 and $68.7 \mathrm{ng}$ / $\mathrm{mL}$ for sTNF-R55 and sTNF-R75, respectively; creatinine $93 \mu \mathrm{mol} / \mathrm{L}$ ). 


\section{Soluble adhesion molecules}

As putative measures of inflammation the plasma concentrations of circulating adhesion molecules sE-selectin and SICAM-1 were assayed in the population studied. Both sE-selectin and sICAM-1 were detectable in all samples tested.

Postoperative sE-selectin peak concentrations ranged from 15.4-353.3 ng/ mL (median $35.5 \mathrm{ng} / \mathrm{mL}$ ) and from 15.9-71.7 ng/ mL (median $29.2 \mathrm{ng} / \mathrm{mL}$ ) in patients who were and were not shocked, respectively. Differences in sE-selectin peak concentrations between shocked patients and those who were not shocked were not significant, nor were significant differences in sE-selectin peak concentrations observed between survivors and those who died (Fig. 6, left). Remarkably high sE-selectin concentrations were found in one patient who developed severe organ failure but nevertheless survived $(353.3 \mathrm{ng} / \mathrm{mL})$.
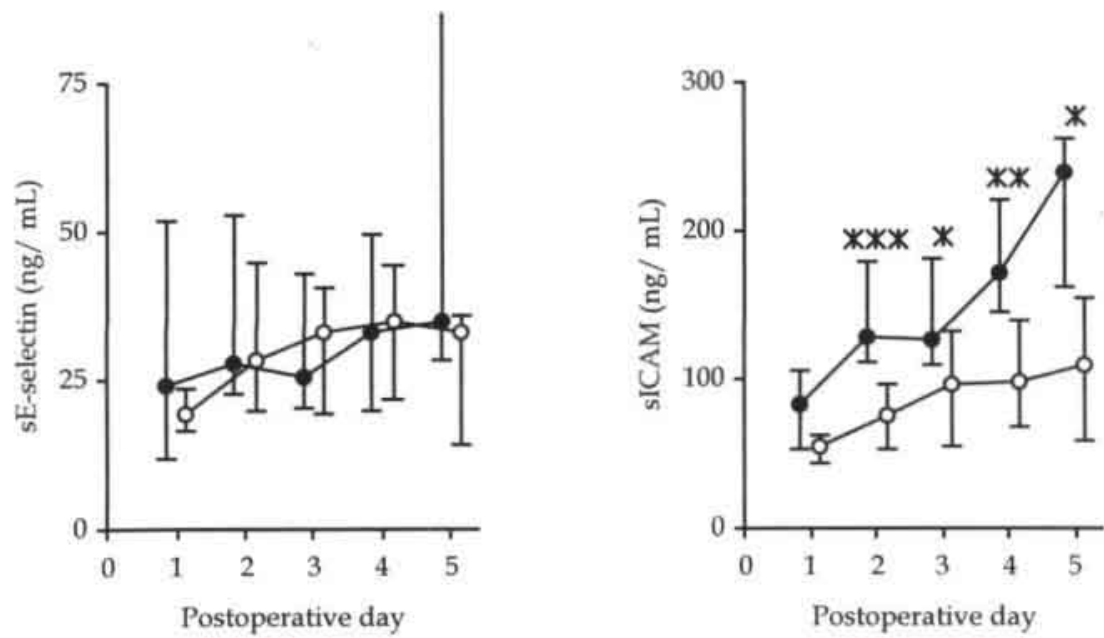

Figure 6: Circulating adhesion molecules: During the observation period the increase in concentrations of sICAM-1 was significantly more pronounced in those that died (closed circles, $n=9$ ) than in those that survived (open circles, $\mathrm{n}=21, \mathrm{P}<.01$ ) (right). $\mathbb{\mathrm { P }}<.05 ; \mathbb{X} \mathrm{XP}<.01 ; \mathbb{X} \mathbb{X}<<.001$. The kinetics of sE-selectin (left) were similar in the two groups. Data are expressed as median (interquartile).

In patients in whom shock complicated the rupture peak concentrations of sICAM1 were significantly higher than in patients who were not shocked $(\mathrm{P}<.01)$. In addition, increased sICAM-1 peak concentrations were significantly associated with death $(\mathrm{P}<.01$ ), ranging from 65.2-270.0 ng/ $\mathrm{mL}$ (median $148.9 \mathrm{ng} / \mathrm{mL}$ ) and 40.3-232.7 (median $96.7 \mathrm{ng} / \mathrm{mL}$ ), in those who died and survivors, respectively. During the study period clear differences in sICAM-1 kinetics were observed in the subgroups. The increase in sICAM-1 concentrations was more pronounced in shocked patients than in those who were not shocked $(\mathrm{P}<.005)$ and in survivors than in those who died $(\mathrm{P}<, 01)$. 
Moreover, differences in median sICAM-1 concentrations between survivors and those who died increased in time (Fig. 6, right). The highest sICAM-1 concentrations were found mainly during the last two days of the study period. In contrast to sTNF-R concentrations, those of sICAM-1 did not correlate with serum creatinine concentrations (data not shown).

\section{DISCUSSION}

The pathophysiology of the perioperative systemic inflammatory reaction following repair of an abdominal aortic aneurysm is complex. Shock, surgical trauma and ischemia induced by aortic clamping all trigger the inflammatory response. Because surgical trauma (assessed by operation time) was similar in patients with ruptured and elective aneurysm, differences in the inflammatory responses between these groups may be explained by the presence of prolonged systemic hypotension in most of the patients treated for rupture (3). Hemorrhage is known to lead to regional hypoxia (33), bacterial translocation, and transient endotoxemia $(34,35)$. In addition, both hypoxia (36) and endotoxemia contribute to increased production of inflammatory cytokines (TNF, IL-6 and IL-8) (37) and shedding of cytokine receptors (TNF-R) (38).

In the present study hemorrhagic shock was associated with increased plasma TNF concentrations and death. The prognostic value of TNF concentrations in inflammation, however, is still controversial (39-42). The inconsistency in observed TNF data can at least in part be explained by differences between assays in their ability to detect TNF complexed to the TNF receptor (43). The relative lack of information about the properties of most assays used makes comparison of reported TNF data difficult. The TNF assay used in the present study merely detects free, biologically active TNF, and not TNF/ TNF-R complexes. In an experimental animal study Alaya et al. (3) used a TNF bioassay that detected free TNF, and showed that TNF could be detected only after trauma when it was combined with hemorrhagic shock. This correlates well with our observations in which TNF was detectable only in shocked patients.

Shock was also correlated with increased IL-6 concentrations, which were subsequently associated with an unfavorable outcome. These data are consistent with the IL- 6 response described by Ayala et al. (3). The IL- 6 response after repair of an aneurysm was restricted to the first two days. Similar data have recently been reported after elective repair (44). The authors described a maximal IL-6 response after 48 hours, which was associated with a complicated subsequent course. This correlates well with the observed association between early increased IL-6 concentrations and mortality in the present study.

Hemorrhagic shock was, as expected, strongly correlated with transfusion of a large amount of blood products. It is, however, unlikely that increased plasma concentrations of the variables tested are caused by blood transfusion, as a recent study 
showed that concentrations of TNF and IL- 6 were low in stored blood (45). Moreover, careful analysis showed that the plasma constituents investigated in the present study did not correlate with the amount of blood products transfused (data not shown). The values found in the present study therefore provide a measure of the severity of hemorrhagic shock. The increased plasma concentrations of both TNF and IL-6 correlated positively with death. Differences in IL- 6 concentrations between survivors and those who died, however, were more pronounced, implicating IL-6 to be the more useful prognostic variable.

The involvement of IL- 8 in the inflammatory response after hemorrhage and ischemia, has not been reported before to our knowledge. In an in vitro model, however, anoxia has been shown to increase IL-8 production by monocytes (19). In our study significantly higher concentrations of IL-8 were detected in shocked patients than in those who were not shocked, but there was no association between plasma IL-8 concentrations and mortality. The highest IL-8 concentrations, like those of IL-6, were detected on the first two postoperative days after repair. In addition, there was a significant correlation between plasma IL-8 and IL-6 concentrations (data not shown). These data suggest that IL-8 concentrations, although they did not correlate with outcome, seemed to reflect the perioperative inflammatory response after hemorrhagic shock.

Soluble TNF receptor molecules are thought to have a central role in plasma TNF control. On the basis of increased TNF concentrations in patients with hemorrhagic shock increased concentrations of sTNF-R were expected. Because raised sTNF-R concentrations in critically ill patients were reported to be correlated with impaired renal clearance (30-32), we also investigated the correlation between renal function (as assessed by plasma creatinine concentrations) and sTNF-R concentrations. In contrast to the other mediators measured in this study, sTNF-R concentrations were found to be significantly correlated with plasma creatinine concentrations. The extent to which differences in sTNF-R concentrations and kinetics are attributable to inflammation or to renal function, however, remains to be resolved.

Plasma concentrations of soluble adhesion molecules reflected expression of tissue adhesion molecules and subsequently the inflammatory state (25-27). The data presented are to our knowledge the first to suggest that sICAM-1 concentrations reflect an inflammatory response induced by ischemia. Prolonged systemic hypotension and death correlated significantly with raised SICAM-1 concentrations. Moreover, it seemed that the increase in sICAM-1 concentrations during the first days after repair was significantly higher in those that died than in those that lived.

In contrast to ICAM-1, differences in E-selectin concentrations were less obvious. A slight increase in E-selectin concentrations was observed during the study period in both survivors and those that died, but differences between shocked patients and those who were not shocked, and between survivors and those that died were not significant. These data are in line with results of an experimental animal study that showed that expression of E-selectin was marginally influenced by traumatic and 
hypovolemic shock, whereas in septic shock E-selectin expression was greatly increased (23).

In conclusion, hemorrhagic shock complicating repair of abdominal aortic aneurysms was associated with increased plasma concentrations of the inflammatory mediators TNF, IL-6 and SICAM-1, which correlated positively with death. Similar data, although less pronounced, were found in the subgroup of patients operated on acutely (data not shown). These data may be instrumental in developing strategies to reduce the mortality from hemorrhagic shock in such patients. Moreover, the data suggest that IL-6 and sICAM-1 concentrations are additional predictors of a complicated course. 


\section{REFERENCES}

1. Ernst CB. Abdominal aortic aneurysm. N. Engl. J. Med. 1993,328:1167-1172

2. Gloviczki P, Pairolero PC, Mucha PJ, et al. Ruptured abdominal aortic aneurysms: repair should not be denied. J. Vasc. Surg. 1992;15:851-857

3. Ayala $A$, Wang $P, B a$ ZF, et al. Differential alterations in plasma $I L-6$ and TNF levels after trauma and hemorrhage. Am. J. Physiol. 1991;260:R167-R171

4. Chaudry IH, Ayala A, Ertel W, et al. Hemorrhage and resuscitation: immunological aspects. Am. J. Physiol. 1990;259:R663-R678

5. Ertel W, Morrison MH, Ayala A, et al. Anti-TNF monoclonal antibodies prevent haemorrhageinduced suppression of Kupffer cell antigen presentation and MHC class II antigen expression. Immunology 1991;74:290-297

6. Wang $\mathrm{P}, \mathrm{Ba} \mathrm{ZF}$, Morrison $\mathrm{MH}$, et al. Mechanism of the beneficial effects of pentoxifylline on hepatocellular function after trauma hemorrhage and resuscitation. Surgery 1992;112:451-457

7. Peetre $\mathrm{C}$, Thysell $\mathrm{H}$, Grubb A, et al. A tumor necrosis factor binding protein is present in human biological fluids. Eur. J. Haematol. 1988;41:414-419

8. Porteu F, Brockhaus M, Wallach D, et al. Human neutrophil elastase releases a ligand-binding fragment from the 75-kDa tumor necrosis factor (TNF) receptor. Comparison with the proteolytic activity responsible for shedding of TNF receptors from stimulated neutrophils. J. Biol. Chem. 1991;266:18846-18853

9. Girardin E, Rouxlombard P, Grau GE, et al. Imbalance between tumour necrosis factor-alpha and soluble TNF receptor concentrations in severe meningococcaemia. Immunology 1992;76:20-23

10. van Zee $\mathrm{KJ}$, Kohno T, Fischer E, et al. Tumor necrosis factor soluble receptors circulate during experimental and clinical inflammation and can protect against excessive tumor necrosis factoralpha in vitro and in vivo. Proc, Natl. Acad. Sci. 1992;89:4845-4849

11. Lantz M, Malik S, Slevin ML, et al. Infusion of tumor necrosis factor (TNF) causes an increase in circulating TNF-binding protein in humans. Cytokine 1990;2:402-406

12. Spinas GA, Keller U, Brockhaus $M$. Release of soluble receptors for tumor necrosis factor (TNF) in relation to circulating TNF during experimental endotoxinemia. J. Clin. Invest. 1992;90:533-536

13. Romson JL, Hook BG, Kunkel SL, et al. Reduction of the extent of ischemic myocardial injury by neutrophil depletion in the dog. Circulation 1983;67:1016-1023

14. Hernandez LA, Grisham MB, Twohig B, et al. Role of neutrophils in ischemia-reperfusion-induced microvascular injury. Am. J. Physiol. 1987;253:H699-H703

15. Arnould T, Michiels C, Remacle J. Increased PMN adherence on endothelial cells after hypoxia: involvement of PAF, CD18/ CD11b, and ICAM-1. Am. J. Physiol. 1993;264:C1102-C1110

16. Yoshida N, Granger DN, Anderson DC, et al. Anoxia/ reoxygenation-induced neutrophil adherence to cultured endothelial cells. Am. J. Physiol. 1993;264:H1891-H1898

17. Bevilacqua MP, Pober JS, Mendrick DL, et al. Identification of an inducible endothelial-leukocyte adhesion molecule. Proc. Natt. Acad. Sci. 1987;84:9238-9242

18. Smith CW, Marlin SD, Rothlein R, et al. Cooperative interactions of LFA-1 and Mac-1 with intercellular adhesion molecule-1 in facilitating adherence and transendothelial migration of human neutrophils in vitro. J. Clin. Invest. 1989;83:2008-2017

19. Metinko AP, Kunkel SL, Standiford TJ, et al. Anoxia-hyperoxia induces monocyte-derived interleukin-8. J. Clin. Invest. 1992,90:791-798 
20. Vedder NB, Winn RK, Rice CL, et al. A monoclonal antibody to the adherence-promoting leukocyte glycoprotein, CD18, reduces organ injury and improves survival from hemorrhagic shock and resuscitation in rabbits. J. Clin. Invest. 1988;81:939-944

21. Engelberts I, Hoof v SJ, Samyo SK, et al. Generalized inflammation during peritonitis evidenced by intracutaneous E-Selectin expression. Clin. Immunol. Immunopathol. 1992;65:330-334

22. Engelberts I, Samyo SK, Leeuwenberg JF, et al. A role for ELAM-1 in the pathogenesis of MOF during septic shock. J. Surg. Res. 1992;53:136-144

23. Redl H, Dinges HP, Buurman WA, et al. Expression of endothelial leukocyte adhesion molecule-1 in septic but not traumatic/ hypovolemic shock in the baboon. Am. J. Pathol. 1991;139:461-466

24. Rothlein R, Mainolfi EA, Czajkowski M, et al. A form of circulating ICAM-1 in human serum. J. Immunol. 1991;147:3788-3793

25. Newman W, Beall LD, Carson CW, et al. Soluble E-selectin is found in supernatants of activated endothelial cells and is elevated in the serum of patients with septic shock. J. Immunol. 1993;150:644-654

26. Kuster H, Degitz K. Circulating ICAM-1 in neonatal sepsis. Lancet 1993;341:506

27. Leeuwenberg JF, Smeets EF, Neefjes JJ, et al. E-selectin and intercellular adhesion molecule-1 are released by activated human endothelial cells in vitro. Immunology 1992;77:543-549

28. Leeuwenberg JF, Jeunhomme GM, Buurman WA. Characterization of two monoclonal antibodies directed against an adhesion molecule on human endothelial cells. Transplant Proc. 1990;22:19911993

29. Engelberts I, Moller A, Schoen GJ, et al. Evaluation of measurement of human TNF in plasma by EL.ISA. Lymphokine Cytokine Res. 1991;10:69-76

30. Froon AHM, Bemeimans MHA, Greve JW, et al. Increased plasma levels of soluble Tumor Necrosis Factor receptors in sepsis syndrome; correlation with plasma creatinine. Crit Care Med 1994;22:8039

31. Bemelmans MHA, Gouma DJ, Burman WA. Influence of nephrectomy on tumor necrosis factor clearance in a murine model. J. Immunol. 1993;150:2007-2017

32. Brockhaus M, Bar-Khayim Y, Gurwicz S, et al. Plasma tumor necrosis factor soluble receptors in chronic renal renal failure. Kidney Int. 1992;42:663-667

33. Chaudry IH. Cellular mechanisms in shock and ischemia and their correction. Am. J. Physiol. 1983;245:R117-R134

34. Deitch EA, Ma L, Ma WJ. Inhibition of endotoxin induced bacterial translocation in mice. J. Clin. Invest. 1989;84:36-42

35. Rush BF, Redan JA, Flanagan JJ. Does the bacteremia obsereved in hemorrhagic shock have clinical significance? A study in germ-free animals. Ann. Surg. 1989;210:342-347

36. Ayala A, Perrin MM, Ertel W, et al. Differential effects of hemorrhage on Kupffer cells: decreased antigen presentation despite increased inflammatory cytokine (IL-1, IL-6 and TNF) release. Cytokine 1992;4:66-75

37. Hesse DG, Tracey KJ, Fong $\mathrm{Y}$, et al. Cytokine appearance in human endotoxemia and primate bacteremia. Surg. Gynecol. Obstet. 1988;166:147-153

38. Scannell G, Waxman K, Kaml GJ, et al. Hypoxia induces a human macrophage cell line to release tumor necrosis factor- $\alpha$ and its soluble receptors in vitro. J. Surg. Res. 1993;54:281-285

39. Debets JM, Kampmeijer R, Linden vd MP, et al, Plasma tumor necrosis factor and mortality in critically ill septic patients. Crit. Care Med. 1989;17:489-494 
40. Waage A, Halstensen A, Espevik T. Association between tumour necrosis factor in serum and fatal outcome in patients with meningococcal disease. Lancet 1987;1:355-357

41. Hamilton G, Hofbauer S, Hamilton B. Endotoxin, TNF-alpha, interleukin-6 and parameters of the cellular immune system in patients with intraabdominal sepsis. Scand. J. Infect. Dis. 1992;24:361-368

42. Fischer CJ, Opal SM, Dhainaut JF, et al. Influence of an anti-tumor necrosis factor monoclonal antibody on cytokine levels in patients with sepsis. Crit. Care Med. 1993:21:318-327

43. Engelberts I, Stephens S, Francot GJ, et al. Evidence for different effects of soluble TNF-receptors on various TNF measurements in human biological fluids. Lancet 1991;338:515-516

44. Baigrie RJ, Lamont PM, Kwiatkowski D, et al. Systemic cytokine response after major surgery. Br. J. Surg. 1992;79:757-760

45. Stack G, Snyder EL. Cytokine generation in stored platelet concentrates. Transfusion 1994;34:20-5 


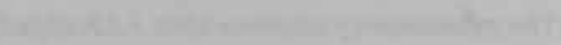

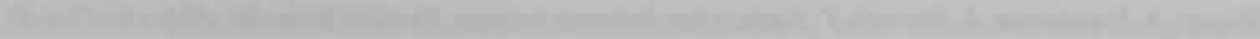

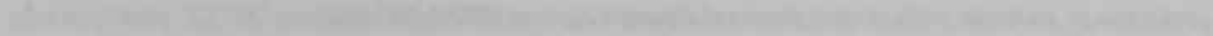

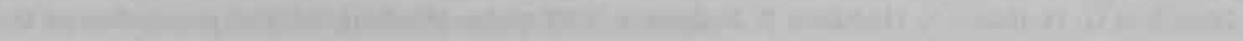

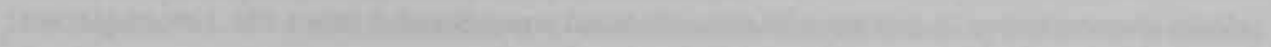
The

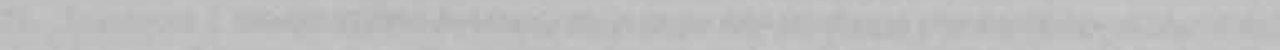

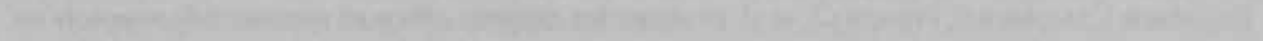

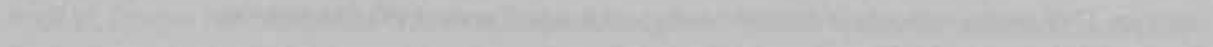
Than

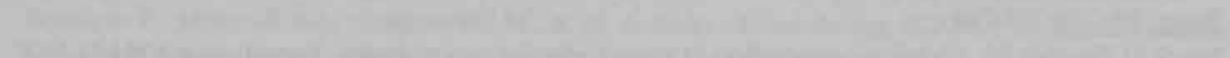

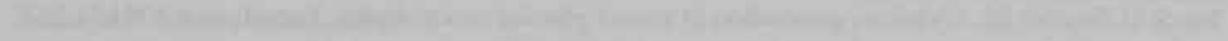

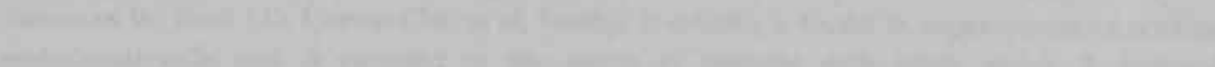

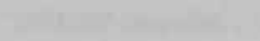

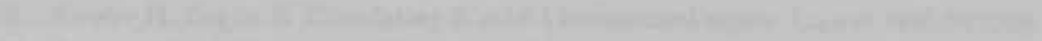

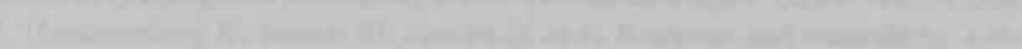

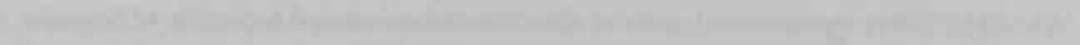

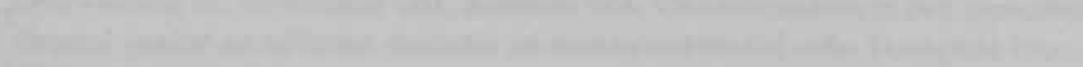




\section{CHAPTER 5}

\section{LPS TOXICITY REGULATING PROTEINS IN BACTEREMIA}

LPS Toxicity Regulating Proteins

A.H.M. Froon, M.A. Dentener, J.W.M. Greve, G. Ramsay, W.A. Buurman J Infect Dis 1995; 171: 1250-7 


\section{SUMMARY}

The toxicity of lipopolysaccharide (LPS), is modified by several proteins such as bactericidal/ permeability-increasing protein (BPI), and LPS binding protein (LBP). BPI and LBP plasma levels were measured in patients with either gram-negative bacteremia $(n=36)$ or gram-positive bacteremia $(n=28)$. Levels of BPI and LBP, proteins neutralizing and enhancing LPS effects, respectively, were already increased before bacteremia was first detected. The BPI/ neutrophil ratio, reflecting neutrophil activation, was significantly associated with the presence of sepsis syndrome and fatal outcome in bacteremic patients: $1.06(0.11-6.49)$ vs. $0.57(0.06-3.82)$ in patients with and without sepsis syndrome $(\mathrm{P}<.01)$, and $0.64(0.06-3.82)$ vs. $1.02(0.12-6.49)$ in survivors and nonsurvivors $(\mathrm{P}<.05)$, respectively (ratio in ng BPI/ 10E6 neutrophils). High LBP peak levels were significantly associated with the presence of sepsis syndrome $(\mathrm{P}<.01)$. No differences in BPI and LBP levels were observed between gram-negative and grampositive bacteremia. BPI/ neutrophil ratio, as a parameter of neutrophil activation, may be useful in monitoring infectious disease. 


\section{INTRODUCTION}

Infections with gram-negative and gram-positive bacteria can lead to a systemic inflammatory response syndrome (SIRS). In gram-negative infections endotoxin or lipopolysaccharide (LPS), a component of the gram-negative bacterial cell wall, is considered to be the principal initiator of $\operatorname{SIRS}(1,2)$. LPS activates mononuclear phagocytes to produce inflammatory mediators, such as tumor necrosis factor (TNF), interleukin (IL)-1 and IL-6, which are responsible for many of the clinical features of endotoxemia $(3,4)$. The LPS-induced release of these inflammatory mediators is regulated by endogenous proteins of different origin. In this regard, sCD14, the soluble form of the putative LPS-receptor CD14 (5-9), and LPS binding protein (LBP), a carrier molecule for LPS, are of importance (10-14). Also, LPS inactivating factors such as bactericidal/ permeability-increasing protein (BPI) are considered to play an important role in regulating LPS effects during endotoxemia (15-19).

BPI, specifically cytotoxic for gram-negative bacteria $(20)$, is a $55 \mathrm{kD}$ cationic protein stored in the azurophilic granules (21), but also expressed on the cell surface, of polymorphonuclear leukocytes (PMN) $(22,23)$. Binding of BPI to LPS in the cell wall of gram-negative bacteria induces membrane alterations and finally bacterial death (24). Besides being bactericidal, BPI was demonstrated to inhibit LPS-induced phagocyte activation $(10,22,25-29)$. In addition, BPI was reported to be protective in experimental animal studies of gram-negative infection (15-19). Activation of PMN induces release of a part of their BPI content in vitro $(21,22)$ and limited survey studies showed that BPI was present in large quantities in several body fluids during infection, whereas in plasma of healthy volunteers BPI was not detectable (30).

LPS binding protein (LBP), a $60 \mathrm{kD}$ acute phase protein, appears to function in an opposing fashion to BPI, despite a striking homology in DNA sequence $(31,32)$. LBP facilitates binding of LPS to the LPS-receptor CD14, whereas BPI prevents this interaction $(10,11,33,34)$. Specifically in the presence of low LPS concentrations LBP was demonstrated to enhance LPS induced cell activation $(10-12,14)$. It was recently reported that LBP also neutralizes LPS effects by transfering LPS to high-density lipoproteins (35). However, increased LBP levels, as demonstrated after LPS administration in an animal model (36), may as in vitro, antagonize BPI effects and enhance LPS toxicity $(10,12,37)$.

The role of sCD14, normally present in plasma, in modulating LPS toxicity seems to be twofold. For CD14 negative cells such as endothelial and epithelial cells, sCD14 has been shown to strongly enhance LPS-induced cell activation (5-8). In contrast, for CD14 positive monocytes SCD14 has been demonstrated to neutralize LPS effects by competing with cell bound CD14 (9).

In order to investigate the role of LPS activity modulating proteins in infectious disease, BPI, LBP and SCD14 plasma levels were measured in patients with culture proven gram-negative bacteremia. Data were compared with those obtained from bacteremic patients in which a gram-positive, consequently LPS lacking, micro- 
organism was isolated. In addition, the correlation between plasma levels and clinical parameters was assessed.

Table 1: Micro-organisms isolated from the blood

\begin{tabular}{lcll}
\hline Bacillus Spp. & 2 & Proprionibacterium Spp. & 2 \\
Bacteroides Spp. & 3 & P. mirabilis & 5 \\
E. cloacae & 1 & P. aeruginosa & 4 \\
E. faecalis & 6 & S. marcescens & 1 \\
E. coli & 11 & S. aureus & 9 \\
H. influenza & 3 & S. epidermidis & 3 \\
K. pneumonia & 6 & Staphylococcus Spp. & 4 \\
M. morganii & 2 & Streptococcus Spp. & 7 \\
N. meningitides & 1 & & \\
\hline
\end{tabular}

In 58 patients 1 micro organism was isolated, whereas is 6 patients 2 micro organisms were cultured. Patients in which a S. epidermidis was isolated were only included when simultaneously another grampositive micro organism was detected.

\section{PATIENTS AND METHODS}

\section{Patients}

In a prospective study, in which all patients admitted to the intensive care unit (ICU) were enrolled, clinical data, sepsis syndrome parameters and plasma samples were collected daily. Patients were included in the present study when during their presence on the ICU bacteremia was proven by at least one positive blood culture. Blood for culture was obtained by vein puncture. Exclusion criteria were 1) detection of a single blood culture with Staphylococcus epidermidis (considered as contamination), 2) presence of a mixed gram-negative/ gram-positive bacteremia (to analyze differences between gram-negative vs. gram-positive bacteremia), 3) surgical interventions within 2 weeks before bacteremia (to exclude the putative effect of surgery on the parameters studied). Patients were divided in the following subgroups: 1) absence or presence of sepsis syndrome as a parameter of severity of disease $(38) ; 2$ ) survivors and nonsurvivors at day 28 after first positive blood culture; 3 ) presence of gram-negative vs. gram-positive bacteremia.

Plasma samples obtained during the study period, i.e. from 3 days before up to 3 days after first positive blood culture was demonstrated, were analyzed and the data were compared with those obtained in 49 healthy volunteers. Further the kinetics of BPI and LBP were investigated in 10 patients which were selected on the basis that plasma samples from a 14 day follow-up period were available.

The study was reviewed and approved by the Medical Ethical Committee of University Hospital Maastricht. 


\section{Blood samples}

As part of a larger surveillance study blood samples were taken daily from each ICU patient. Blood was obtained using evacuated blood collection tubes containing EDTA. Blood samples were always collected at the first daily round of routine blood sampling at approximately $6 \mathrm{AM}$. The blood samples were immediately put on ice and plasma was prepared by centrifugation at $2,200 \mathrm{G}$ for 5 minutes at $4^{\circ} \mathrm{C}$. Care was taken to prevent contamination of the plasma samples with PMN, which may release BPI after freeze/ thawing. Furthermore, hemolytic plasma samples were excluded from laboratory measurements. This procedure was demonstrated to minimize artificial BPI release (30). Samples were stored at $-70^{\circ} \mathrm{C}$ until use. Levels of BPI, LBP and sCD14 were determined, as described below, in plasma samples collected during the study period.

Table 2: Blood culture data and prevalence of sepsis syndrome and mortality in the study population

\begin{tabular}{lcc}
\hline & Yes $\mathrm{n}=30$ & Sepsis Syndrome \\
Blood culture & & No $\mathrm{n}=34$ \\
\hline gram-negative & $20(11)$ & $16(4)$ \\
gram-positive & $10(7)$ & $18(3)$ \\
\hline
\end{tabular}

$0=$ number of nonsurvivors

\section{Reagents and materials}

Human recombinant BPI (rBPI; kindly provided by M. Marra, InCyte, Palo Alto, CA) was produced by transfected Chinese hamster ovary cells. Purification was performed sequentially by ion exchange column and by size exclusion column. A BPI neutralizing monoclonal antibody (mAb) 4E3 (IgG1) was developed in our laboratory and described elsewhere (10). This antibody has been shown to react specifically with human rBPI, with no cross-reactivity with recombinant LBP (rLBP). Polyclonal antibodies to human rBPI were obtained by immunizing rabbits with human rBPI. This anti-BPI antiserum did not cross-react with human rLBP as tested in an enzyme-linked immunosorbent assay (ELISA). After protein A purification the polyclonal IgG was biotinylated.

Human rLBP was produced by the transfected human embryonic kidney cell line 293 EBNA kindly provided by Invitrogen (San Diego, CA). Polyclonal antibodies to human rLBP were obtained by immunizing rabbits with human rLBP. After protein $A$ purification the polyclonal IgG was biotinylated.

The murine anti-human CD14 mAb MEM-18 (IgG1), sCD14 and polyclonal rabbit anti-sCD14 antibodies were kindly provided by Horesji, Institute of Organic Chemistry and Biochemistry, Prag, Czech Republic $(39,40)$.

Peroxidase conjugated goat anti-rabbit IgG was purchased from Jackson (Westgrove, PA), peroxidase conjugated streptavidin from Dakopatts (Glostrup, Denmark), and TMB (3', 5, 5'-tetramethylbenzidine) substrate from KPL (Gaithersburg, 
MD). ELISA plates used were: Nunc immunomaxisorp plates (Nunc, Roskilde, Denmark).

\section{Immunoassays}

Plasma BPI, LBP and sCD14 levels were measured using sandwich ELISAs.

BPI was detected as described elsewhere (30). In short, 96-well plates were coated with human $\mathrm{rBPI}$ specific $\mathrm{mAb} 4 \mathrm{E} 3$ and free sites were blocked with PBS $1 \%$ BSA. Washing and dilution buffer used contained $80 \mathrm{mM} \mathrm{MgCl}$. The use of $\mathrm{Mg}^{++}$ions prevented disturbance by LPS of BPI measurement. Human rBPI was used for standard titration curve. Test samples diluted in assay buffer (1:2) were incubated for 2 $\mathrm{h}$ at room temperature. Next, a biotinylated polyclonal rabbit anti-human BPI IgG was used followed by peroxidase labeled streptavidin. TMB was used as a substrate and photospectrometry $(450 \mathrm{~nm})$ was performed using a micro ELISA autoreader. Detection limit for the BPI assay was $100 \mathrm{pg} / \mathrm{mL}$.

For LBP detection plates were coated with polyclonal anti-human LBP antibodies. Washing and dilution of reagents, was performed in the buffer containing $40 \mathrm{mM}$ $\mathrm{MgCl}$. The use of $\mathrm{Mg}^{++}$ions prevented disturbance by LPS of LBP recovery in the ELISA. Diluted plasma samples (1:5000) and the standard titration curve with rLBP were added to the plate. Detection occurred with a biotinylated polyclonal rabbit antihuman LBP IgG, followed by peroxidase conjugated streptavidin and substrate. Detection limit for the LBP assay was $200 \mathrm{pg} / \mathrm{mL}$.

Plasma sCD14 levels were measured using MEM-18 as capture reagent. Diluted plasma samples $(1: 2000)$ and the standard titration curve with SCD14 were added to the plates. The amount of sCD14 bound to the wells was quantified by sequential incubation with a polyclonal rabbit anti-sCD14 antibody, followed by peroxidase conjugated goat anti-rabbit. Detection limit for the sCD14 assay was $50 \mathrm{pg} / \mathrm{mL}$.

All plasma samples were analyzed in the same run. When plasma levels exceeded the detection limit of the assay, samples were additionally diluted and analyzed in a separate run with an overlap to correct for inter assay variation. The intra and inter assay coefficient of variance of the various assays performed were all $<10 \%$.

\section{Statistical analysis}

To analyze differences between the subgroups studied, Mann-Whitney test was performed by using the highest levels detected in each patient (peak levels) during the study period (day 3 before to day 3 after first bacteremia was registered). Correlations were analyzed by using Spearman's rank correlation test. The incidence of sepsis syndrome and mortality in the studied subgroups was assessed by Chi-square test. Unless stated otherwise plasma levels are given as median (range). Differences were considered significant at $\mathrm{P}<, 05$. 

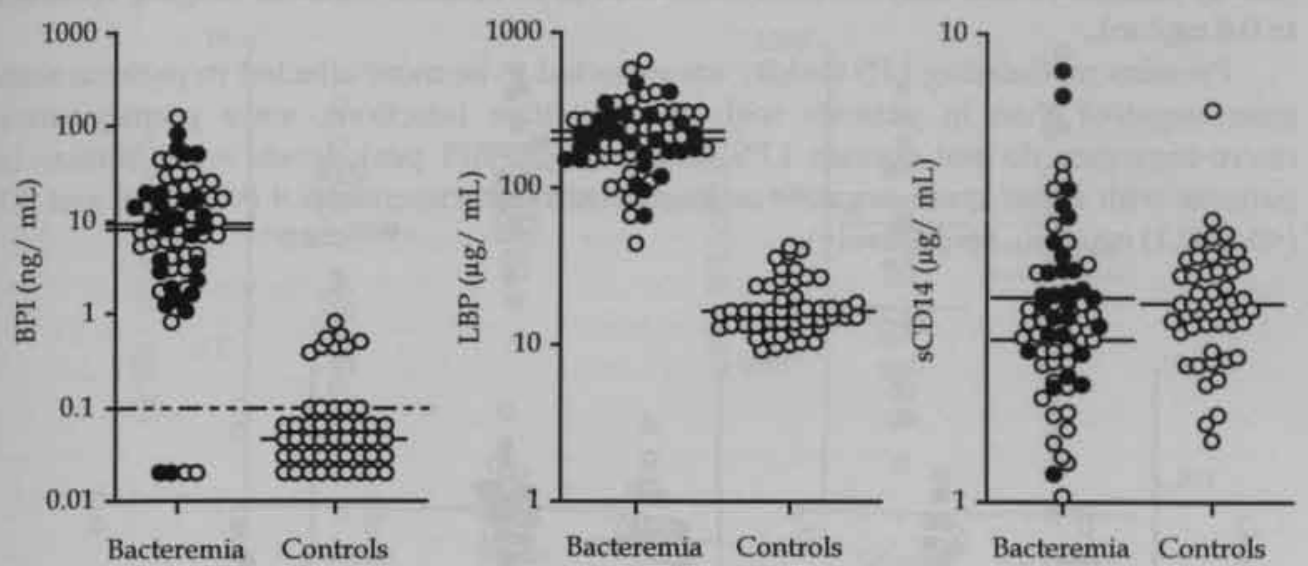

Figure 1: BPI, LBP and sCD14 levels in bacteremic patients $(n=64)$ and healthy controls $(n=49)$. Data in bacteremic patients represent peak levels. In bacteremia open circles represent gram-negative; closed circles represent gram-positive; horizontal bars are median values in gram-negative, gram-positive, and in healthy controls. Detection limit of the assay ....

\section{RESULTS}

\section{Patients}

A total of 64 patients were included in the study (male/ female: 36/ 28) with ages ranging from 29 to 95 years (averagetSEM $62+2$ years). The micro-organisms isolated from the blood are given in Table 1. The severity of clinical symptoms varied from mild fever to severe multiple organ dysfunction. According to sepsis criteria (38), 30 patients could be identified as suffering from sepsis syndrome (Table 2). The incidence of sepsis syndrome was similar in gram-negative and gram-positive bacteremia. On the day bacteremia was first detected, designated day 0, APACHE II scores (41) in sepsis syndrome patients were significantly higher compared to those of patients without sepsis syndrome (APACHE II $20(11-36)$ vs. 14.8 (8-22); P<.0001). In addition, mortality in patients with sepsis syndrome was significantly higher $(P<.005)$ compared to patients without sepsis syndrome (18 out of $30(60 \%)$ vs. 7 out of $34(21 \%)$ patients, respectively).

\section{$B P I, L B P$, and SCD14 plasma levels in bacteremic patients}

BPI, usually not detectable in plasma of healthy volunteers (30), was found in large amounts in 60 out of 64 bacteremic patients (Fig. 1, left). As a result, peak levels of BPI were significantly higher in patients with bacteremia (median (range) $8.39(<0.2-120)$ $\mathrm{ng} / \mathrm{mL}$ ) compared to healthy volunteers $(\mathrm{P}<.0001)$. In these healthy volunteers (age: 57 
(21-82) years) BPI was only detectable in 8 out of 49 subjects studied, ranging from 0.4 to $0.8 \mathrm{ng} / \mathrm{mL}$.

Proteins modulating LPS toxicity are expected to be more affected in patients with gram-negative than in patients with gram-positive infections, since gram-positive micro-organism do not contain LPS. Interestingly, BPI peak levels were similar in patients with either gram-negative or gram-positive bacteremia $(7.9(<0.2-120)$ and 9.3 $(<0.2-82.1) \mathrm{ng} / \mathrm{mL}$, respectively).
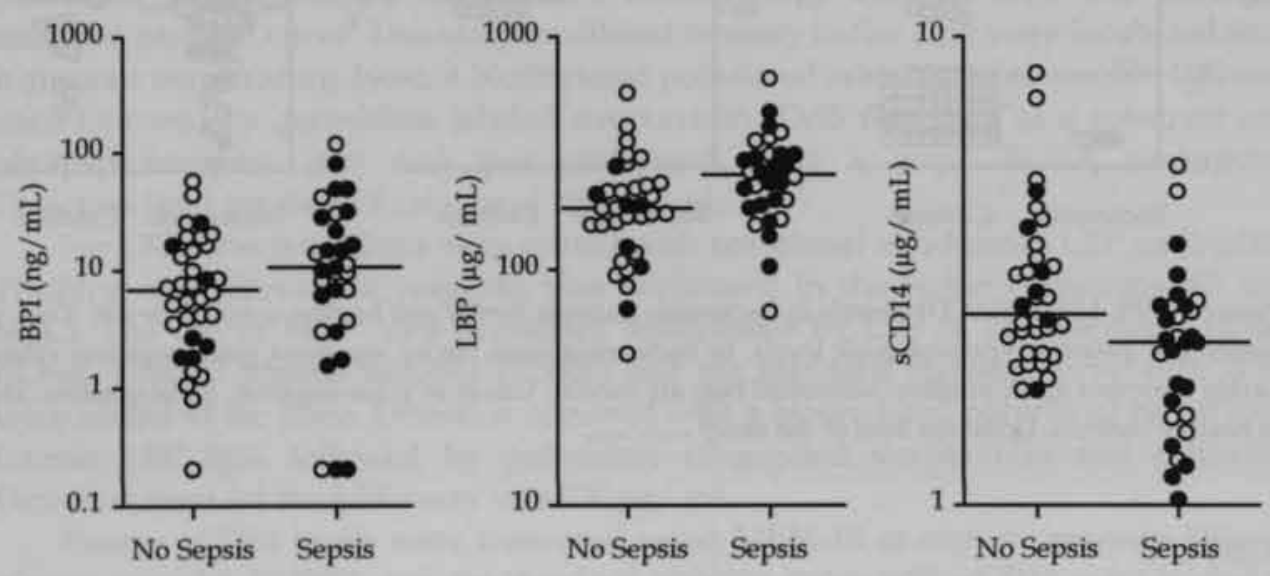

Figure 2: Correlation BPI, LBP and sCD14 with sepsis syndrome and mortality. Data represent peak levels. Survivors and nonsurvivors of bacteremia are given by open and closed symbols, respectively; horizontal lines represent median peak levels in patients with and without sepsis.

LBP was detectable in all blood samples of bacteremic patients and healthy volunteers. Peak levels of LBP in bacteremic patients (Fig. 1, middle) were significantly higher $(\mathrm{P}<.0001)$ compared to LBP levels in healthy controls $(216(44-656) \mu \mathrm{g} / \mathrm{mL}$ vs. $16.2(9.1-43.2 \mu \mathrm{g} / \mathrm{mL})$. However, again no differences were observed in LBP peak levels between patients with either gram-negative $(228(44-656) \mu \mathrm{g} / \mathrm{mL})$ or grampositive bacteremia (203 (68-475) $\mu \mathrm{g} / \mathrm{mL}$; $\mathrm{P}=\mathrm{NS}$ ).

For sCD14 (Fig. 1, right), peak levels were significantly lower in the gram-negative subgroup $(2.23(0.82-5.30) \mu \mathrm{g} / \mathrm{mL})$ when compared with either the gram-positive subgroup (2.74 (1.15-8.34) $\mathrm{gg} / \mathrm{mL}$ ) or healthy controls $(2.64(1.36-6.82) \mu \mathrm{g} / \mathrm{mL})$; both $P<.01$ (gram-negative $(n=36)$ vs. gram-positive bacteremia $(n=28)$ and gram-negative bacteremia vs. controls). When all 64 bacteremic patients $(2.42(0.82-8.34) \mu \mathrm{g} / \mathrm{mL})$, however, were compared with the healthy controls, it appeared that differences in peak levels did not reach significance. 

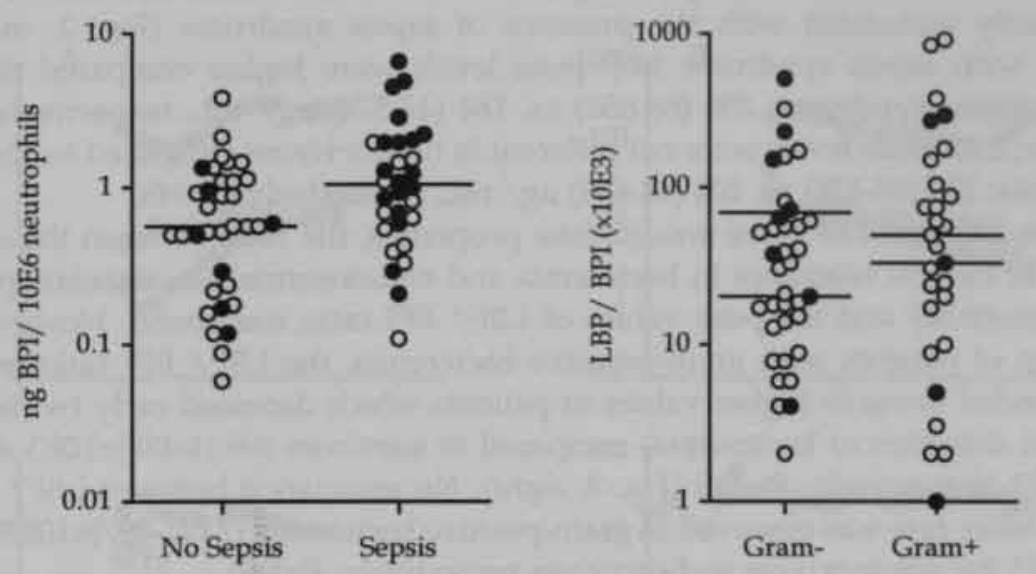

Figure 3: Prognostic value of BPI in relation to blood neutrophil count and LBP levels. Data represent peak values of BPI/ blood neutrophil ratio (left). Median levels in patients with and without sepsis are given by horizontal lines. (open circles, survivors; closed circles, nonsurvivors). The right panel represents LBP/ BPI ratio at the day bacteremia was first detected according to early mortality (day 7). Median values are given in survivors and nonsurvivors (right).

\section{$B P I, L B P$, and sCD14 plasma levels and clinical course}

Severity of disease in bacteremic patients was assessed by the presence or absence of sepsis syndrome and mortality at day 28. For BPI, peak levels in bacteremic patients (Fig. 2, left) were similarly enhanced in patients with and without sepsis syndrome $(\mathrm{P}=19)$ and no correlation with outcome was observed $(\mathrm{P}=\mathrm{NS})$.

Sepsis syndrome may be accompanied by leukocytosis as well as leukopenia. Since BPI is released by blood neutrophils, the number of blood neutrophils during bacteremia was expected to affect plasma BPI levels. Therefore, the correlation between plasma BPI levels and corresponding neutrophil count was investigated. In patients with detectable BPI levels a significant correlation was found between neutrophil count and BPI levels ( $r=0.49 ; \mathrm{P}<.0001$; data not shown). In accordance, in patients with severe neutropenia $(\mathrm{n}=4 ; \mathrm{WBC} \leq 2 \times 10 \mathrm{E} 9 / \mathrm{L})$ BPI was not detectable $(\leq 0.2 \mathrm{ng} / \mathrm{mL})$. In order to consider BPI levels independent of blood neutrophil count, the BPI/ neutrophil ratio, as indicator of neutrophil activation, was analyzed in the studied subgroups. In patients suffering from sepsis syndrome peak values of BPI/ neutrophil ratio (Fig. 3, left) were significantly higher $(\mathrm{P}<.01)$ compared to those of patients without sepsis syndrome (1.06 (0.11-6.49) vs. $0.57(0.06-3.82) \mathrm{ng} \mathrm{BPI}$ 10E6 neutrophils). In addition, peak values of BPI/ neutrophil ratio were significantly higher $(\mathrm{P}<.05)$ in nonsurvivors (1.02 (0.12-6.49) ng BPI/ 10E6 neutrophils) compared to survivors of bacteremia (0.64 (0.06-3.82 ng BPI/ $10 \mathrm{E} 6$ neutrophils). 
Analysis of LBP levels in patients with bacteremia revealed that LBP levels were significantly associated with the presence of sepsis syndrome (Fig. 2, middle). In patients with sepsis syndrome LBP peak levels were higher compared to patients without sepsis syndrome; $256(66-656)$ vs. $184(44-574) \mu \mathrm{g} / \mathrm{mL}$, respectively; $(\mathrm{P}<.01)$. However, LBP peak levels were not different in nonsurvivors compared to survivors of bacteremia; $223(68-475)$ vs. $204(44-656) \mu \mathrm{g} / \mathrm{mL}$, respectively ( $\mathrm{P}=\mathrm{NS}$ ).

Since BPI and LBP have antagonistic properties, the ratio between these proteins may be of clinical relevance in bacteremia and endotoxemia. No association between day 28 mortality and the peak values of LBP/ BPI ratio was found. However, in the subgroup of patients with gram-negative bacteremia, the LBP/ BPI ratio assessed at day 0 tended towards higher values in patients which deceased early (within 7 days after first detection of bacteremia) compared to survivors (69 (4-488) x10E3 and 20 (2330) $x 10 \mathrm{E} 3$, respectively; $\mathrm{P}=.06$ ) (Fig. 3, right). No association between LBP/ BPI ratio and mortality rate was observed in gram-positive bacteremia ( 34 (1-297) x10E3 vs. 51 (2907) $\times 10 \mathrm{E} 3$, for nonsurvivors and survivors respectively; $\mathrm{P}=\mathrm{NS}$ ).

With regard to SCD14 levels, absolute differences between the subgroups studied were small (Fig. 2, right). No differences in $\mathrm{SCD} 14$ peak levels were observed between nonsurvivors and survivors $(2.29(0.82-4.64)$ and $2.43(1.25-8.34) \mu \mathrm{g} / \mathrm{mL}$, respectively; $\mathrm{P}=.21$ ). However, in patients with sepsis syndrome sCD14 peak levels were significantly lower compared to patients without sepsis syndrome: $2.23(0.82-5.30)$ vs. $2.56(1.76-8.34) \mu \mathrm{g} / \mathrm{mL}$, respectively $(\mathrm{P}<.01)$.

\section{Kinetics of BPI and LBP in individual patients}

Kinetics of BPI and LBP were assessed in a subgroup of 10 patients. Data of 4 typical cases with either an early recovery or an early fatal course, are given in Fig. 4. Both plasma BPI and LBP levels were already increased in the first samples tested compared to control values. Fluctuations in plasma levels, assessed during a 14 day period after bacteremia, were more pronounced for BPI than for LBP. The ratio between maximum and minimum levels in these 4 patients ranged from 11 to 133 for BPI and from 1.8 to 3.3 for LBP.

Two of four patients presented survived day 28 , whereas the other two deceased at day 14 and 21, respectively. In a survivor of gram-negative pulmonary sepsis (Fig. 4a), a significant correlation between BPI and blood neutrophil kinetics was observed $(\mathrm{r}=0.86 ; \mathrm{P}<.0001)$. This case demonstrates that during severe sepsis BPI levels may normalize as a result of neutropenia complicating sepsis syndrome and not because neutrophils are not activated. 
BPI (ng/ mL) •; LBP $(\mu \mathrm{g} / \mathrm{mL}) \bullet ;$ Blood neutrophil count $(10 \mathrm{E} 9 / \mathrm{L}) \circ$
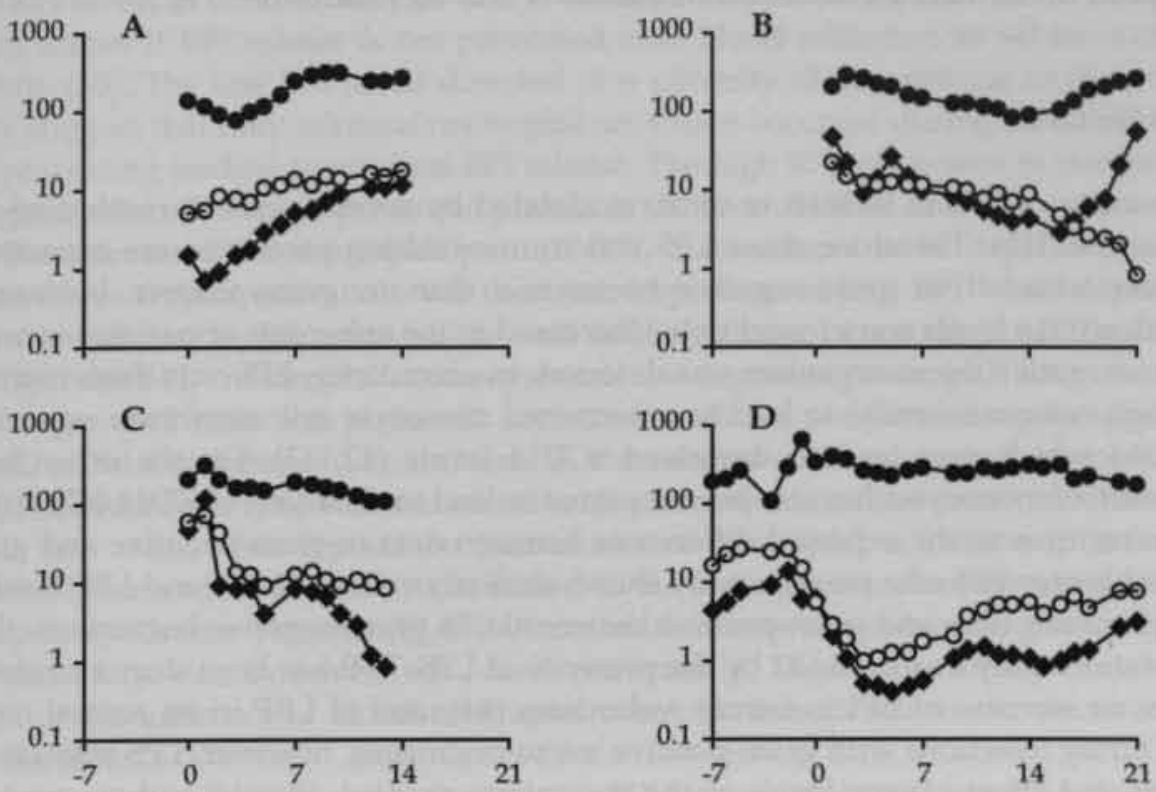

Day relative to first positive blood culture

Day relative to first positive blood culture

Figure 4: Kinetics of BPI and LBP in individual patients. Data represent a survivor of gram-negative pulmonary sepsis (A), a patient who recovered from gram-negative bacteremia accompanying strangulation ileus (B), a nonsurvivor of gram-positive abdominal sepsis (C), and a nonsurviving patient suffering from gram-positive osteomyelitis (D).

The second survivor was suffering from gram-negative bacteremia accompanying strangulation ileus (Fig. 4b). After surgical intervention (between day 2 and day 3), the patient recovered quickly, and BPI levels decreased rapidly (from 120 to $0.9 \mathrm{ng} / \mathrm{mL}$ ) with normalizing neutrophil levels, whereas LBP levels remained enhanced (from 313 to $109 \mu \mathrm{g} / \mathrm{mL}$, maximum and day 14 value respectively).

BPI and LBP both increased in a patient suffering from gram-positive abdominal sepsis, which died at day 14 (Fig. 4c). Interestingly, the ratio between plasma BPI levels and blood neutrophil count increased from 0.1 to $0.6 \mathrm{ng}$ BPI/ $10 \mathrm{E} 6$ circulating neutrophils shortly before dying. These data strongly suggest an ongoing activation of neutrophils until death occurred as a result of multiple organ dysfunction.

Similarly, in a patient suffering from osteomyelitis caused by Staphylococcus aureus, both BPI levels and BPI/ neutrophil ratio increased shortly before dying (Fig. $4 \mathrm{~d}$ ) as a result of deterioration of sepsis syndrome complicated by multiple organ dysfunction. The increase in BPI/ neutrophil ratio (from 0.5 to $63 \mathrm{ng} \mathrm{BPI} / 10 \mathrm{E} 6$ 
neutrophils; day 14 and day 21 values, respectively), however, was more pronounced compared to the increase in BPI levels (from 4.6 to $57 \mathrm{ng} / \mathrm{mL}$ ).

\section{DISCUSSION}

The toxicity of LPS is, at least in vitro, modulated by several proteins, including BPI, LBP, and SCD14. Therefore, these LPS toxicity modulating proteins were expected to be more affected in gram-negative bacteremia than in gram-positive bacteremia. Indeed, sCD14 levels were found to be decreased in the subgroup of patients in which a gram-negative micro-organism was detected. In accordance, LPS was demonstrated, although not consistently, to lead to a decreased monocyte cell membrane expression of CD14 which may lead to decreased SCD14 levels $(42,43)$. On the other hand, activation of monocytes has also been reported to lead to shedding of CD14 (42).

In contrast to the expected differences between data in gram-negative and grampositive bacteremia, the present study shows similarly enhanced BPI and LBP levels in both gram-negative and gram-positive bacteremia. In gram-negative bacteremia, these observations may be explained by the presence of LPS. LPS has been demonstrated to induce an increase of BPI in human volunteers (44), and of LBP in an animal model (36). During infections with gram-positive micro-organisms, however, LPS may also be present and affect plasma levels of the parameters studied. Several authors reported the presence of endotoxemia in critically ill patients without a gram-negative infection $(45,46)$. In such patients, endotoxin may leak from the gut into the circulation following failure of gut mucosal barrier (47-49). The presence of endotoxemia during gram-positive infections could also be explained by failure to detect gram-negative micro-organisms.

In patients with bacteremia LPS levels are reported to be time dependent, usually not exceeding $100 \mathrm{pg} / \mathrm{mL}$ (46). It remains, therefore, unclear whether LPS is the most important stimulus for the increase in BPI and LBP levels. Besides LPS, other stimuli may be responsible for the increase in BPI and LBP levels. Aspecific inflammatory responses elicited by, for example, extra-corporeal circulation as during hemodialysis, were reported to induce a temporary BPI increase (50). Furthermore, turpentine administration and gram-positive bacterial infection were accompanied by an increase of LBP levels in an animal model (36).

In a majority of the patients BPI and LBP levels were increased in the first samples studied, indicating that the inflammatory response was already triggered before bacteremia was detected. Fluctuations of plasma levels with time were more pronounced for BPI than for LBP, whereas changes in SCD14 levels (data not shown) were minimal.

BPI levels were remarkably enhanced in patients with bacteremia, but no correlation with the presence of sepsis syndrome or mortality was observed. Our data are supported by a recent paper describing high BPI levels in sepsis syndrome patients 
(44). These authors reported, however, also high BPI levels in healthy controls. These high BPI levels in controls may be due to artificial release of BPI after blood sampling, which occurs if BPI release is not prevented after blood collection as we have shown recently (30). The low BPI levels detected in a minority of the controls in the present study suggest that only minimal neutrophil activation occurred during blood sampling and processing leading to minimal BPI release. The high BPI levels seen in our patients therefore reflect BPI levels present in plasma at the time of blood drawing.

The release of the neutrophil product BPI, is considered to be dependent on the extent of neutrophil activation. We therefore hypothesized that BPI levels depend on the extent of neutrophil activation as well as the number of activated neutrophils. In this light the BPI/ neutrophil ratio represents the degree of neutrophil activation. The BPI/ neutrophil ratio was positively correlated with the presence of sepsis syndrome as well as fatal outcome. In accordance, in the selected cases presented, an increase in the BPI/ neutrophil ratio was associated with a subsequently fatal outcome. These data are in line with other reports on parameters of neutrophil activation in infectious disease. Enhanced levels of elastase, stored in the same granules as BPI, were detected in sepsis syndrome patients (51-53). A correlation between enhanced elastase levels and mortality was, however, not found consistently. This inconsistency may be the result of the influence of blood neutrophil count on these levels as we demonstrated here for BPI.

Increased LBP levels were, similarly to BPI/ neutrophil ratio, associated with the presence of sepsis syndrome. Highest levels were detected between 24-48 hour after onset of bacteremia, confirming the acute phase nature of LBP, whereas BPI/ neutrophil ratio reached highest values within the first 24 hour (data not shown). The results presented are in line with C-Reactive Protein (CRP) data published by others (54). Increased plasma levels of CRP, also an acute phase protein, were associated with the presence of bacteremia, and severity of infection, whereas no correlation was found with causative micro-organisms.

Based on in vitro data, LBP appears to enhance LPS toxicity, and antagonizes the effects of BPI, which is considered to be protective by inactivating LPS. Therefore we investigated the ratio between LBP and BPI levels. This parameter may reflect the net result of these proteins on LPS effects. Only in a subgroup of patients with a gramnegative bacteremia, an enhanced LBP/ BPI ratio on the day of detection of bacteremia was indeed associated with poor outcome, suggesting that this ratio may be of value in gram-negative infections. The exact role of enhanced circulating BPI and LBP levels, remains unclear, since BPI and LBP probably exert their main functions locally at the site of infection.

The present study shows that decreased SCD14 levels were associated with gramnegative bacteremia and the presence of sepsis syndrome. However, differences between the subgroups studied were not substantial and therefore monitoring sCD14 levels seems to be of limited value. 
In conclusion, enhanced levels of BPI and LBP characterized the inflammatory response during bacteremia. An increased BPI/ neutrophil ratio, as a parameter of neutrophil activation, as well as increased LBP levels were positively correlated with the presence of sepsis syndrome. In addition, enhanced BPI/ neutrophil ratio was associated with a fatal clinical course. Further studies on BPI and LBP will be required to elucidate the exact role of these LPS toxicity modulating proteins in infectious disease. 


\section{REFERENCES}

1. Morrison DC, Ryan JL. Endotoxins and disease mechanisms. Annu Rev Med 1987;38:417-32

2. Martich GD, Boujoukos AJ, Suffredini AF. Response of man to endotoxin. Immunobiology 1993;187:403-16

3. Tracey $\mathrm{KJ}$, Beutler B, Lowry SF, et al. Shock and tissue injury induced by recombinant human cachectin. Science 1986;234:470-4

4. Akira S, Hirano T, Taga T, et al. Biology of multifunctional cytokines: IL 6 and related molecules (IL 1 and TNF). Faseb J 1990;4:2860-7

5. Pugin J, Schurer-Mally CC, Leturcq D, et al. Lipopolysaccharide activation of human endothelial and epithelial cells is mediated by lipopolysaccharide-binding protein and soluble CD14. Proc Natl Acad Sci US A 1993;90:2744-8

6. Haziot A, Rong GW, Silver J, et al. Recombinant soluble CD14 mediates the activation of endothelial cells by lipopolysaccharide. J Immunol 1993;151:1500-7

7. Frey EA, Miller DS, Jahr TG, et al. Soluble CD14 participates in the response of cells to lipopolysaccharide. J Exp Med 1992;176:1665-71

8. von Asmuth EJ, Dentener MA, Bazil V, et al. Anti-CD14 antibodies reduce responses of cultured human endothelial cells to endotoxin. Immunology 1993;80:78-83

9. Haziot A, Rong GW, Bazil V, et al. Recombinant soluble CD14 inhibits LPS-induced tumor necrosis factor- $\alpha$ production by cells in whole blood. J Immunol 1994;152:5868-5876

10. Dentener MA, von Asmuth EJ, Francot GJ, et al. Antagonistic effects of lipopolysaccharide binding protein and bactericidal/ permeability-increasing protein on lipopolysaccharide-induced cytokine release by mononuclear phagocytes. Competition for binding to lipopolysaccharide. I Immunol 1993;151:4258-65

11. Wright SD, Ramos RA, Tobias PS, et al. CD14, a receptor for complexes of lipopolysaccharide (LPS) and LPS binding protein. Science 1990;249:1431-3

12. Heumann D, Gallay P, Barras C, et al. Control of lipopolysaccharide (LPS) binding and LPSinduced tumor necrosis factor secretion in human peripheral blood monocytes. J Immunol 1992;148:3505-12

13. Gallay P, Heumann D, Le Roy D, et al. Lipopolysaccharide-binding protein as a major plasma protein responsible for endotoxemic shock. Proc. Natl. Acad. Sci. USA 1993;90:9935-8

14. Mathison JC, Tobias PS, Wolfson E, et al. Plasma lipopolysaccharide (LPS)-binding protein. A key component in macrophage recognition of gram-negative L.PS. J Immunol 1992;149:200-6

15. Fisher CJ, Marra MN, Palardy JE, et al. Human neutrophil bactericidal/ permeability-increasing protein reduces mortality rate from endotoxin challenge: A placebo-controlled study. Crit Care Med 1994;22:553-558

16. Kelly CJ, Cech AC, Argenteanu M, et al. Role of bactericidal permeability-increasing protein in the treatment of gram-negative pneumonia. Surgery 1993;114:140-6

17. Kohn FR, Ammons WS, Horwitz A, et al. Protective effect of a recombinant amino-terminal fragment of bactericidal/ permeability-increasing protein in experimental endotoxemia. J Infect Dis 1993;168:1307-10

18. Lin $\mathrm{Y}$, Kohn FR, Kung AH, et al. Protective effect of a recombinant fragment of bactericidal/ permeability increasing protein against carbohydrate dyshomeostasis and tumor necrosis factoralpha elevation in rat endotoxemia. Biochem Pharmacol 1994;47:1553-9

19. Ammons WS, Kung AHC. Recombinant amino terminal fragment of Bactericidal/ PermeabilityIncreasing Protein prevents hemodynamic responses to endotoxin. Circ Shock 1993;41:176-184

20. Gazzano-Santoro H, Parent JB, Grinna L, et al. High-affinity binding of the bactericidal/ permeability-increasing protein and a recombinant amino-terminal fragment to the lipid A region of lipopolysaccharide. Infect Immun 1992;60:4754-61 
21. Weiss J, Olsson I. Cellular and subcellular localization of the bactericidal/ permeability-increasing protein of neutrophils. Blood 1987;69:652-9

22. Marra MN, Wilde CG, Collins MS, et al. The role of bactericidal/ permeability-increasing protein as a natural inhibitor of bacterial endotoxin. J Immunol 1992;148:532-7

23. Weersink AJ, van Kessel KP, van den Tol ME, et al. Human granulocytes express a 55-kDa lipopolysaccharide-binding protein on the cell surface that is identical to the bactericidal/ permeability-increasing protein. J Immunol 1993;150:253-63

24. Weiss J, Elsbach P, Olsson I, et al. Purification and Characterization of a Potent Bactericidal/ Permeability-Increasing Protein from the Granules of Human Polymorphonuclear Leucocytes. J Biol Chem 1978;253:2664-2672

25. Marra MN, Wilde CG, Griffith JE, et al. Bactericidal/ permeability-increasing protein has endotoxin-neutralizing activity. J Immunol 1990;144:662-6

26. Ooi $\mathrm{CE}$, Weiss J, Doerfler ME, et al. Endotoxin-neutralizing properties of the $25 \mathrm{kD} \mathrm{N}$-terminal fragment and a newly isolated $30 \mathrm{kD}$ C-terminal fragment of the 55-60 kD bactericidal/ permeability-increasing protein of human neutrophils. J Exp Med 1991;174:649-55

27. Weiss J, Elsbach P, Shu C, et al. Human bactericidal/ permeability-increasing protein and a recombinant NH2-terminal fragment cause killing of serum-resistant gram-negative bacteria in whole blood and inhibit tumor necrosis factor release induced by the bacteria. J Clin Invest 1992;90:1122-30

28. Corradin SB, Heumann D, Gallay P, et al. Bactericidal/ permeability-increasing protein inhibits induction of macrophage nitric oxide production by lipopolysaccharide. J Infect Dis 1994;169:105-11

29. Meszaros K, Parent JB, Gazzano SH, et al. A recombinant amino terminal fragment of bactericidal/ permeability-increasing protein inhibits the induction of leukocyte responses by LPS.J Leukoc Biol 1993;54:558-63

30. Dentener MA, Francot GJM, Smit FT, et al. Presence of bactericidal/ permeability-increasing protein in disease; detection by ELISA. J Infect Dis 1994,in press:

31. Schumann RR, Leong SR, Flaggs GW, et al. Structure and function of lipopolysaccharide binding protein. Science 1990;249:1429-31

32. Gray PW, Flaggs G, Leong SR, et al. Cloning of the cDNA of a human neutrophil bactericidal protein. Structural and functional correlations. J Biol Chem 1989;264:9505-9

33. Tobias PS, Soldau K, Ulevitch RJ. Isolation of a lipopolysaccharide-binding acute phase reactant from rabbit serum. J Exp Med 1986;164:777-93

34. Hailman E, Lichenstein HS, Wurfel MM, et al. Lipopolysaccharide (LPS)-binding protein accelerates the binding of LPS to CD14. J Exp Med 1994;179:269-277

35. Wurfel MM, Kunitake ST, Lichtenstein H, et al. Lipopolysaccharide (LPS)-Binding Protein is carried on lipoproteins and acts as a cofactor in the neutralization of LPS. J Exp Med 1994;180:1025-1035

36. Geller DA, Kispert PH, Su GL, et al. Induction of hepatocyte lipopolysaccharide binding protein in models of sepsis and the acute-phase response. Arch Surg 1993;128:22-7

37. Gazzano-Santoro H, Meszaros K, Birr C, et al. Competition between rBPI23, a recombinant fragment of bactericidal/ permeability-increasing protein, and lipopolysaccharide (LPS)-binding protein for binding to LPS and gram-negative bacteria. Infect Immun 1994;62:1185-91

38. Bone RC. Sepsis, the sepsis syndrome, multi-organ failure: a plea for comparable definitions. Ann Intern Med 1991;114:332-3

39. Bazil V, Horejsi V, Baudys M, et al. Biochemical characterization of a soluble form of the 53-kDa monocyte surface antigen. Eur J Immunol 1986;16:1583-9

40. Bazil V, Baudys M, Hilgert I, et al. Structural relationship between the soluble and membranebound forms of human monocyte surface glycoprotein CD14. Mol Immunol 1989;26:657-62

41. Knaus WA, Draper EA, Wagner DP, et al. APACHE II: A severity of disease classification system. Crit Care Med 1985;13:818-29 
42. Bazil V, Strominger JL. Shedding as a mechanism of down-modulation of CD14 on stimulated human monocytes. J Immunol 1991;147:1567-1574

43. Payne JB, Nichols FC, Peluso JF. The effects of interferon-gamma and bacterial lipopolysaccharide on CD14 expression in human monocytes. J Interferon Res 1992,12:307-10

44. Calvano SE, Thompson WA, Marra MN, et al. Changes in Polymorphonuclear Surface and Plasma Bactericidal/ Permeability-Increasing Protein and Plasma Lipopolysacccharide Binding Protein During Endotoxemia or Sepsis. Arch Surg 1994;129:220-226

45. Rush BF, Sori AJ, Murphy TF. Endotoxemia and bacteremia during hemorrhagic shock. Ann. Surg. 1988;207:549-554

46. Boom SJ, Reidy J, Ramsay G. Endotoxemia in severe staphylococcal infection. Surg Res Comm 1992;12:25-31

47. Ryan CM, Yarmush ML, Burke JF, et al. Increased gut permeability early after burns correlates with the extent of burn injury. Crit Care Med 1992;20:1508-12

48. Sori AJ, Rush BJ, Lysz TW, et al. The gut as source of sepsis after hemorrhagic shock. Am J Surg 1988;155:187-92

49. Herndon DN, Zeigler ST. Bacterial translocation after thermal injury. Crit Care Med 1993;21:S50S54

50. Schindler R, Marra MN, Mckelligon BM, et al. Plasma Levels of Bactericidal PermeabilityIncreasing Protein (BPI) and Lipopolysaccharide-Binding Protein (LBP) During Hemodialysis. Clin Nephrol 1993;40:346-351

51. Gardinali M, Padalino P, Vesconi S, et al. Complement activation and polymorphonuclear neutrophil leukocyte elastase in sepsis. Correlation with severity of disease. Arch Surg 1992;127:1219-24

52. Nuijens JH, Abbink JJ, Wachtfogel YT, et al. Plasma elastase alpha 1-antitrypsin and lactoferrin in sepsis: evidence for neutrophils as mediators in fatal sepsis. J Lab Clin Med 1992;119:159-68

53. Pacher R, Redl H, Frass M, et al. Relationship between neopterin and granulocyte elastase plasma levels and the severity of multiple organ failure. Crit Care Med 1989;17:221-6

54. Ligtenberg PC, Hoepelman IM, Oude Sogtoen GA, et al. C-reactive protein in the diagnosis and management of infections in granulocytopenic and non-granulocytopenic patients. Eur J Clin Microbiol Infect Dis 1991;10:25-31 


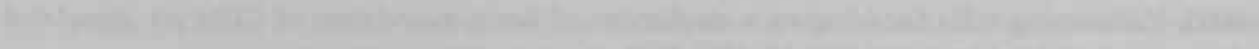

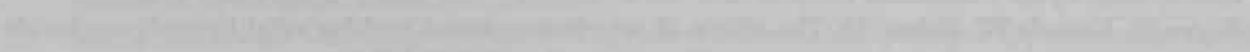

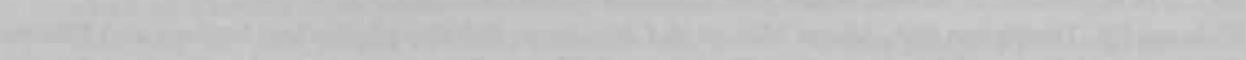

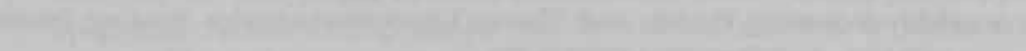

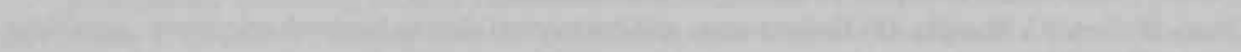

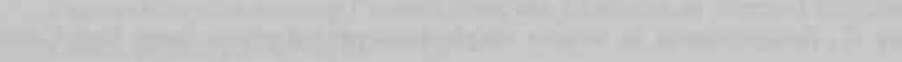
(19)

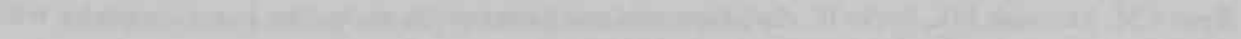

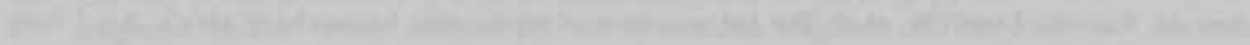
Thent

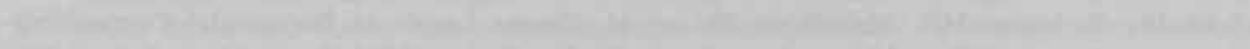
and

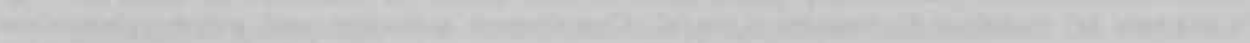
Then

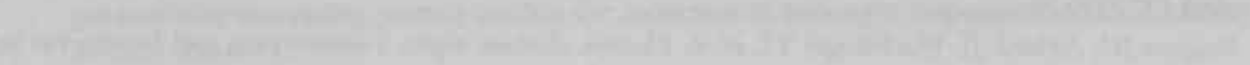

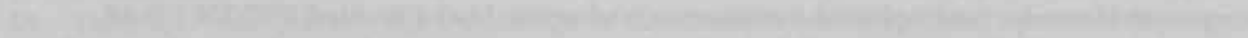

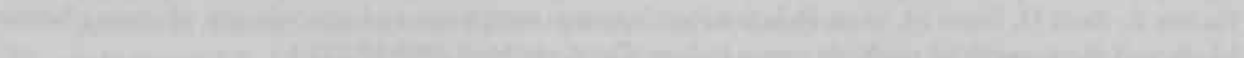

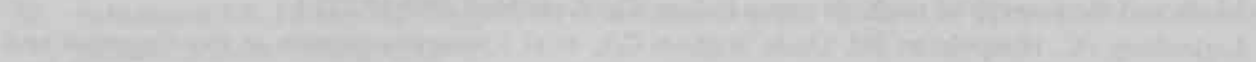

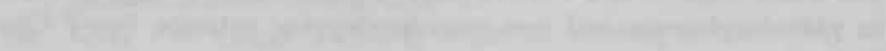


TREATMENT WITH THE PLATELET-ACTIVATING FACTOR ANTAGONIST TCV309 IN PATIENTS WITH SEVERE SYSTEMIC INFLAMMATORY RESPONSE SYNDROME. A PROSPECTIVE, MULTI-CENTER, DOUBLE-BLIND, RANDOMIZED PHASE II TRIAL

A.H.M. Froon, J.W.M. Greve, W.A. Buurman, C.J. van der Linden, H.J.M. Langemeijer, C. Ulrich, M. Bourgeois. Shock 1996; 5: 313-9 


\section{SUMMARY}

In a prospective randomized, double-blind, placebo-controlled clinical study, the safety and efficacy of the platelet-activating factor antagonist TCV-309 in the treatment of systemic inflammatory response syndrome (SIRS) was studied. In total 29 patients were treated with $1.0 \mathrm{mg} / \mathrm{kg} \mathrm{TCV}-309$ twice daily during seven days or with placebo. Study parameters were: adverse events, 28 and 56 day all cause mortality, multi-organ failure scores and the inflammatory mediators tumor necrosis factor, interleukin-6, interleukin-8, soluble E-selectin. There was no difference in number and severity of adverse events between TCV-309 and placebo-treated patients. Day 28 and day 56 mortality was similar in both groups (day 56: 7/ 12 TCV-309 vs. 9/ 16 placebo, NS). Pulmonary and hematological failure scores improved significantly in TCV-309-treated patients $(\mathrm{P}<.05)$. There was no difference in inflammatory mediator levels between TCV-309 and placebo-treated patients. Treatment with TCV-309 appears to be safe in patients with SIRS and does improve organ failure significantly. 


\section{INTRODUCTION}

Septic shock is still associated with a high morbidity and mortality (1-3). Extensive studies have unraveled important pathways which are mainly characterized by an uncontrolled release of various mediators resulting in shock and multi-organ failure (47). These inflammatory mediators, such as tumor necrosis factor (TNF) and the interleukins 1,6 and 8 (IL-1, IL-6, IL-8), are considered to play an important role in regulating local defense mechanisms against infectious events $(2,4,5,8)$.

Several inhibitors have been developed against these inflammatory mediators. Also inhibitors were developed against lipopolysaccharides (LPS). LPS are potent inducers of the release of most of the inflammatory mediators that are considered to be responsible for shock and multi-organ failure (MOF) in patients with a gram-negative sepsis $(2,3,8-12)$. In the experimental situation antibodies against TNF and LPS and the IL-1 receptor antagonist were shown to be effective to prevent sepsis $(2,3,8)$. In clinical studies it was suggested that subgroups of patients might benefit from treatment with these antibodies. However, so far the overall efficacy of these treatments with respect to outcome in severely septic patients is still disappointing (2$5,9,10,12,13)$. Moreover, these inhibitors (such as monoclonal antibodies) are complex and expensive compounds. Their use is often limited to short interventions and to a single treatment session due to possible sensitization $(2,3,10,13,14)$.

Platelet-activating factor (PAF), a natural occurring lipid derived from the phospholipid components of cell membranes, is an important mediator that was also shown to be involved in the pathogenesis of sepsis $(5,15-18)$. PAF is released by, among other cells, neutrophils, mononuclear phagocytes and endothelial cells (19). When administered experimentally to animals it results in a condition remarkably similar to sepsis (16-18). Furthermore PAF was shown to be strongly related to the cytokine network, in the respect that IL-1, IL-8 and TNF can all stimulate PAF release and PAF is able to induce synthesis of these cytokines resulting in a positive feedback mechanism (19).

In animal models platelet-activating factor antagonists (PAF antagonist) were shown to inhibit several pathophysiologic pathways in, endotoxin induced, septic shock $(15,20-25)$. The PAF antagonist TCV-309 was shown to attenuate the endotoxin induced hemodynamic response in rabbits and to reduce the endotoxin induced disseminated intravascular coagulation in rats $(19,22-24)$. Furthermore it prevented endotoxin induced mortality in mice (25). Most of these effects might be beneficial in patients with systemic inflammatory response syndrome (SIRS) and SIRS with shock.

The aim of the present study was to evaluate the safety and efficacy of administration of the PAF antagonist TCV-309 in patients with SIRS and SIRS with shock. The drug was applied as additional therapy to standard intensive care treatment. The safety and efficacy of TCV-309 were studied by means of vital signs, laboratory parameters, hemodynamic parameters and Multiple Organ Failure (MOF) 
scores (26). Moreover plasma values of the inflammatory parameters in sepsis, TNF, IL-6, IL-8 and soluble E-selectin (sE-selectin) were assessed $(6,7,27-29)$. The study was performed as a multi-center double-blind, randomized, prospective, phase II clinical trial.

Table 1: Summary of the multiple organ failure score according to Goris et al.

\begin{tabular}{|c|c|c|c|}
\hline $\begin{array}{l}\text { Score } \\
\text { Organ system }\end{array}$ & 0 & 1 & 2 \\
\hline pulmonary & no mechanical ventilation & $\begin{array}{l}\text { mechanical ventilation } \\
\mathrm{PEEP} \leq 10 \mathrm{~cm} \mathrm{H} 2 \mathrm{O} \\
\mathrm{FiO} 2 \leq 0.4\end{array}$ & $\begin{array}{l}\text { mechanical ventilation } \\
\mathrm{PEEP}>10 \mathrm{~cm} \mathrm{H} 2 \mathrm{O} \text { and } / \text { or } \\
\mathrm{FiO} 2>0.4\end{array}$ \\
\hline cardiac & $\begin{array}{l}\text { normal blood pressure } \\
\text { no vasoactive medication }\end{array}$ & $\begin{array}{l}\text { hypotension } \\
\text { volume loading } \\
\text { dopamine } 510 \mu \mathrm{g} / \mathrm{kg} / \mathrm{min}\end{array}$ & $\begin{array}{l}\text { hypotension }<100 \mathrm{mmHg} \\
\text { and/ or } \\
\text { dopamine }>10 \mu \mathrm{g} / \mathrm{kg} / \mathrm{min}\end{array}$ \\
\hline renal & $\begin{array}{l}\text { serum creatinine } \\
<175 \mu \mathrm{mol} / \mathrm{L}\end{array}$ & $\begin{array}{l}\text { serum creatinine } \\
2175 \mu \mathrm{mol} / \mathrm{L}\end{array}$ & $\begin{array}{l}\text { hemodialysis or peritoneal } \\
\text { dialysis necessary }\end{array}$ \\
\hline hepatic & $\begin{array}{l}\text { bilirubin }<35 \mu \mathrm{mol} / \mathrm{L} \\
\text { and }\end{array}$ & $\begin{array}{l}\text { bilirubin } 235<102 \mu \mathrm{mol} / \mathrm{L} \\
\text { or }\end{array}$ & $\begin{array}{l}\text { bilirubin } \geq 102 \mu \mathrm{mol} / \mathrm{L} \\
\text { or }\end{array}$ \\
\hline hematologic & $\begin{array}{l}\text { SGOT } \angle 25 \mathrm{U} / \mathrm{L} \\
\text { normal thrombocytes and } \\
\text { leukocytes }\end{array}$ & $\begin{array}{l}\text { SGOT } 225<50 \mathrm{U} / \mathrm{L} \\
\text { thrombocytes }<50 \times 10 \mathrm{E} 9 / \mathrm{L} \\
\text { and / or } \\
\text { leukocytes } 230<60 \times 10 \mathrm{E} 9 / \mathrm{L}\end{array}$ & $\begin{array}{l}\text { SGOT } 250 \mathrm{U} / \mathrm{L} \\
\text { hemorrhagic diathesis or } \\
\text { leukocytes }<2.5 \text { or } \\
\geq 60 \times 10 \mathrm{E} 9 / \mathrm{L}\end{array}$ \\
\hline gastro-intestinal & normal function & $\begin{array}{l}\text { acalculous cholecystitis } \\
\text { or stress ulcer }\end{array}$ & $\begin{array}{l}\text { bleeding stress ulcer; } \\
\text { necrotizing enterocolitis; } \\
\text { pancreatitis }\end{array}$ \\
\hline central nervous & normal & $\begin{array}{l}\text { clearly diminished } \\
\text { responsiveness }\end{array}$ & $\begin{array}{l}\text { severely disturbed } \\
\text { responsiveness and/ or } \\
\text { neuropathy }\end{array}$ \\
\hline
\end{tabular}

\section{PATIENTS AND METHODS}

\section{Study design and patient recruitment}

A randomized, double-blind, multi-center, multi-national study was undertaken to compare the safety and efficacy of intravenously (i.v.) administered TCV-309 versus placebo. TCV-309 was used in addition to conventional therapy in the treatment of patients with severe SIRS and SIRS with shock. TCV- 309 was administered twice daily for seven days.

Patients $(n=35)$ were enrolled from four medical centers in The Netherlands and Belgium. The study was approved by the Institutional Review Boards of each participating center. Written informed consent was obtained for each patient, either from the patient or in case of impaired mental status from the next of kin. The results 
were analyzed according to prospectively developed clinical definitions. After informed consent, patients were randomized, double-blind, to receive either TCV-309 or placebo. Prior to breaking the randomization code, all data were processed and validated in a blinded fashion. Only thereafter, was analysis of the treatment groups performed.

\section{Patient selection}

All patients included into this study were suffering from severe SIRS and SIRS with shock. Criteria for entry into the study were:

1) Clinical diagnosis of sepsis with suspected gram-negative, gram-positive, fungal, rickettsial or viral infection.

2) Presence of fever $\left(>38.3^{\circ} \mathrm{C}\right.$ rectal $)$ or hypothermia $\left(<35.6^{\circ} \mathrm{C}\right.$ rectal).

3) Heart rate $>90$ beats / $\min$ (in the absence of beta-adrenergic receptor blockade).

4) Respiratory rate of $>20$ breaths/ $\mathrm{min}$ (or the requirement of mechanical ventilation).

5) either hypotension (systolic blood pressure $<90 \mathrm{mmHg}$ or a sustained drop of $\geq 40$ $\mathrm{mmHg}$ in the presence of adequate fluid challenge and absence of antihypertensive therapy)

or two or more of the following six signs of systemic toxicity or peripheral hypoperfusion:

a) unexplained metabolic acidosis $(\mathrm{pH}<7.3$, base deficit of $>5 \mathrm{mmol} / \mathrm{L}$ or elevated plasma lactate);

b) arterial hypoxemia (partial pressure of oxygen $575 \mathrm{mmHg}$ or ratio to fraction of inspired oxygen <250);

c) acute renal failure (urinary output $<0.5 \mathrm{~mL} / \mathrm{kg}$ body weight/ h);

d) elevated PT or APTT or reduction in platelet count to less than half of the baseline value or $<10 \mathrm{E} 5 / \mu \mathrm{L}$;

e) sudden decrease in mental activity;

f) cardiac index $>4 \mathrm{~L} / \mathrm{min} / \mathrm{m}^{2}$ body surface area with SVR $<800$ dyn $\bullet \mathrm{sec} / \mathrm{cm}^{5}$.

These criteria are in accordance with the recently published guidelines for clinical studies in septic patients published by the American College of Chest Physicians, the Society of Critical Care Medicine and the European Society of Intensive Care Medicine (30).

Women were only entered if they were postmenopausal (no menstrual period within 12 months prior to entry into the study), surgically sterilized or using a progestogen only oral contraceptive. Patients were excluded from the trial if they were $<18$ years or $>74$ years of age. Patients were also not eligible if they were suffering from uncontrollable hemorrhage, cardiogenic shock, burn injury covering $\geq 5 \%$ of the body surface area, a clearly irreversible condition with an expected rapidly fatal course or if patients had received any investigational drug within 28 days prior to study entry. 
After establishing the diagnosis of SIRS the patients were entered in the study as soon as possible but within 24 hours.

\section{Treatment and dose schedule}

All patients included in the study received standard intensive care support. Conventional treatment was applied as appropriate and according to the clinical judgement of the investigator. If eligible, patients were randomized to receive either TCV-309 (Takeda Chemical Industries Ltd. Osaka, Japan) or placebo. TCV-309 (3bromo-5-[N-phenyl-N-[2-[[2- (1，2, 3, 4-tetrahydro-2-iso-quinolylcarboxyloxy)ethyl] carbamoyl]ethyl]carbamoyl]-1-propylpyridinium nitrate) is a chemically produced compound with very strong PAF antagonist capacities $(23,24)$.

Initially the trial medication was administered at $0.25 \mathrm{mg} / \mathrm{kg}$ body weight i.v. over 30 minutes on a twice daily schedule for seven days, as adjunct therapy to conventional treatment. After inclusion of the first six patients the study was temporarily discontinued to implement a planned protocol amendment. Based on experimental results the most effective dosage of TCV-309 was suggested to be $1.0 \mathrm{mg} /$ $\mathrm{kg}$ (24). Therefore, when the additional data from the Phase I study (unpublished data) concerning safety and tolerance became available, it was proposed to increase the dose of TCV-309 to $1.0 \mathrm{mg} / \mathrm{kg}$ body weight twice daily (diluted in a total volume of $300 \mathrm{~mL}$ saline, i.v. infused over two hours). After evaluation and consent by the institutional review boards of each participating hospital, the study was resumed with the high dose schedule.

All patients were included in the safety analysis on an intent-to-treat basis. When efficacy of the treatment was analyzed, only the patients from the high dose treatment protocol were included.

\section{Objectives and study parameters}

The study was performed to investigate the efficacy and safety of TCV-309 in the treatment of patients with sepsis syndrome. Therefore, day 28 and day 56 mortality was recorded in the treatment and placebo group. In addition, the following parameters were serially recorded during the 28 day study period: hematologic profiles, blood chemistry, urinary output and urine analysis (pre-study and at day 1,2, $3,4,5,6,7,14,21,28$ ); blood pressure, pulse, respiratory rate, body and skin temperature, E.C.G. (pre-study and day 1, 2, 3, 5, 7, 14, 21, 28). Hemodynamic assessment took place pre-study and at day 1, 2, 3 .

The APACHE II score was recorded on the day of admission to the study to asses the severeness of the SIRS and to compare treatment groups (31).

Based on the multi-organ failure (MOF) score, as proposed by Goris et al, the different organ systems were evaluated by calculating the change in organ-failure score from baseline to the subsequent evaluation points (26). The parameters used in this scoring system are summarized in Table 1 . The MOF score was recorded pre-study, day $1,2,3,5,7$, and 28 . 
Adverse experiences were recorded the first 28 days and at day 56. Further parameters were results of bacteriological examinations, the medical history, physical examination and body weight.

Finally the effects of TCV-309 were studied by measuring several inflammatory mediators and soluble adhesion molecules as mentioned in the following section.

\section{Analysis of the inflammatory mediators and soluble adhesion molecules Blood samples}

The plasma parameters studied were determined using enzyme linked immunosorbent assays (ELISA) (developed in our laboratory) as described below (32-34). Plasma samples for cytokine and adhesion molecule measurement were obtained at study entry and twice daily for seven days just before infusion of TCV-309. From each patient, blood samples were collected in tubes containing EDTA, which were immediately put on ice. Plasma was prepared at $4^{\circ} \mathrm{C}$ by centrifugation at $2,200 \mathrm{G}$ for 5 minutes. Samples were stored at $-70^{\circ} \mathrm{C}$ until analyzed.

\section{Rengents}

Reagents used were recombinant ( $\mathrm{r}$ ) TNF (kindly provided by BASF/ Knoll, Ludwigshafen, FRG), rIL-6 (kindly provided by Prof. Dr. Sebald, Würzberg, FRG), and rIL-8 (a kind gift of Dr. Lindley, Sandoz, Vienna, Austria).

\section{Assays}

Plasma TNF concentrations were determined using an ELISA which correlates well with bioassay results (32). In short, plasma samples (1:1 diluted) and the standard dilution series with rTNF were incubated with a murine anti-human TNF mAb 61E71 absorbed to a microtiter plate (Nunc, Roskilde, Denmark). Subsequently the plates were incubated with a polyclonal rabbit anti-human TNF antibody, followed by a peroxidase conjugated goat anti-rabbit IgG (Jackson, Westgrove, PA) and TMB $\left(3^{\prime}, 5,5\right.$, , -tetramethylbenzidine) substrate (Kirkegaard \& Perry Lab., Gaithersburg, MD). Optical density was read and TNF concentrations were calculated from the standard TNF curve. Detection limit for the TNF assay was $10 \mathrm{pg} / \mathrm{mL}$.

IL- 6 and IL- 8 were determined in a procedure largely parallel to the TNF ELISA mentioned above (33). Plasma levels were measured using the murine anti-human IL-6 mono clonal antibody 5E1 (developed in our laboratory) and anti-IL-8 monoclonal antibody HM.5 as capture antibody, respectively. Diluted plasma samples (1:1) and the standard dilution series with rL-6 and rIL- 8 were added to the plates. The amount of IL- 6 and IL-8 bound to the wells was quantified by sequential incubation with a polyclonal rabbit anti-IL-6 antibody and a polyclonal rabbit anti-IL-8 antibody, respectively, followed by adding peroxidase conjugated goat anti-rabbit IgG and substrate. Detection limit for the IL-6 and IL-8 assay was $10 \mathrm{pg} / \mathrm{mL}$ and $20 \mathrm{pg} / \mathrm{mL}$, respectively. 
Plasma sE-selectin levels were measured using mAb ENA-1 as capture antibody (34). Plasma samples were diluted 1:20 and standard dilution series with sE-selectin were added to the plates and subsequently incubated with biotinylated mAb ENA-2. Substrate was added, and optical density was read. All steps of the sE-selectin ELISA were performed using a buffer containing Calcium and Magnesium. Detection limit for the $\mathrm{sE}$-selectin was $0.1 \mathrm{ng} / \mathrm{mL}$.

Levels of the inflammatory mediators and adhesion molecules were determined in duplicate, moreover all plasma samples were assessed in one run.

Table 2: Demographic data of all patients in the high treatment protocol*

\begin{tabular}{|c|c|c|}
\hline & TCV-309 $(\mathrm{N}=13)$ & Placebo $(\mathrm{N}=16)$ \\
\hline age (years) & $61.2(20-73)$ & $60.1(33-73)$ \\
\hline male/ female & $12 / 1$ & $11 / 5$ \\
\hline \multicolumn{3}{|l|}{ APACHE II } \\
\hline$<20$ & $6(46.2 \%)$ & $7(43.8 \%)$ \\
\hline$\geq 20$ and $<30$ & $1(7.7 \%)$ & $5(31.3 \%)$ \\
\hline 230 & $6(46.2 \%)$ & $4(25.0 \%)$ \\
\hline \multicolumn{3}{|l|}{ etiology of SIRS } \\
\hline pulmonary & $7(53.8 \%)$ & $7(43.8 \%)$ \\
\hline abdominal & $5(38.5 \%)$ & $7(43.8 \%)$ \\
\hline other & $1(7.7 \%)$ & $2(12.5 \%)$ \\
\hline \multicolumn{3}{|l|}{ past medical history } \\
\hline cardiovascular & $7(53.8 \%)$ & $5(31.3 \%)$ \\
\hline digestive system & $5(38.5 \%)$ & $9(56.3 \%)$ \\
\hline
\end{tabular}

data are expressed as mean values (range). ${ }^{\circ} \mathrm{TCV}-3091.0 \mathrm{mg} / \mathrm{kg}$ twice daily.

\section{Statistical analysis}

The statistical analysis was performed with SAS® release 6.06. Tests used were one way analysis of variance and Chi-square test for the demographic and baseline disease characteristics, log rank tests and Kaplan-Meier survival estimates for survival, Cochran Mantel-Haenzel for the MOF scores, and Wilcoxon Rank Sum test and MannWhitney test for the inflammatory parameters of sepsis. Predictive values below .05 were considered statistically significant.

\section{RESULTS}

\section{Patients}

In total, 35 patients were included in the study. The first six patients were included before the protocol amendment (low dose treatment protocol $0.25 \mathrm{mg} / \mathrm{kg}$ ) and were 
divided equally into treatment $(\mathrm{N}=3)$ and placebo-treated patients $(\mathrm{N}=3)$. The following 29 patients were included in the high dose treatment protocol $(1.0 \mathrm{mg} / \mathrm{kg})$. Thirteen of these patients were randomized to receive TCV-309 and 16 to be treated with placebo. One patient of the TCV-309 group was excluded from the study due to protocol violation (no fever or hypothermia on admission).

Table 3: Distribution of severity of the adverse experiences according to the WHOART classification

\begin{tabular}{lcccc}
\hline & \multicolumn{2}{c}{ TCV-309 $(\mathrm{n}=13)$} & \multicolumn{2}{c}{ Placebo $(\mathrm{n}=16)$} \\
Maximum intensity & $\mathrm{n}$ & $\%$ & $\mathrm{n}$ & $\%$ \\
\hline mild $^{*}$ & 8 & 22.2 & 18 & 26.5 \\
moderate* $^{*}$ & 12 & 33.3 & 20 & 29.4 \\
severe* $_{\text {total }}^{*}$ & 16 & 44.4 & 30 & 44.1 \\
\hline
\end{tabular}

*there was no significant difference between the two treatment groups.

All patients in the low dose treatment protocol died before completion of the study. In these patients there were no statistical significant differences with respect to all studied parameters, nor with respect to adverse events possibly related to the study medication (data not shown).

In the remaining 28 patients, high dose treatment protocol, there was no statistically significant difference between the treatment groups with respect to age, gender and APACHE II score on admission (Table 2). Furthermore there were no differences with respect to the clinically established cause of sepsis and past medical history.

\section{Clinical adverse experiences}

Clinical adverse experiences were defined as any unintended change in structure (signs), including laboratory test results, or function (symptoms) of the body, whether or not considered to be related to the study medication. The data were recorded using the World Health Organization Adverse Reaction Terminology (WHOART). On an intention to treat basis the excluded patient from the TCV-309 group was included in the analysis of adverse events. There was no statistically significant difference between the two groups with respect to the number of clinical adverse experiences in any body system. Nor was there a difference in the severity of the adverse experiences in both groups. In all patients in both treatment groups clinical adverse experiences were reported. The likelihood that the most severe occurring adverse experience, mortality before day 28 , was related to the study drug in the TCV-309 group ( $7 / 13$ patients) was considered possible in one, unlikely in two and none in four patients. In the corresponding placebo group (8/ 16 patients), this was considered possible in one, unlikely in two and none in five patients. Further adverse experiences of the different 
organ systems were categorized as mild, moderate or severe and are summarized in Table 3. No difference was noted between the two treatment groups. The same holds true for the likelihood that these adverse experiences, including mortality, were related to the study medication (Table 4).

\section{Mortality}

Of the 28 evaluable patients nine patients died before the end of the treatment with the trial medication, two out of 12 patients $(16.7 \%)$ in the TCV-309 group and seven out of 16 patients $(43.8 \%)$ in the placebo group. Retrospectively, the data demonstrate no statistically significant difference $(\mathrm{P}=.22)$ in survival (Fig. 1). There was no difference in survival at day 28 . Mortality on day 56 was seven out of 12 in the TCV-309 group $(58.3 \%)$ and nine out of 16 in the placebo group (56.3\%) (NS). There was no significant difference in mortality between the participating hospitals.

Table 4: Distribution of possible relationship of clinical adverse experiences to study drug

\begin{tabular}{lrrrr}
\hline & \multicolumn{2}{c}{ TCV-309 $(\mathrm{n}=13)$} & \multicolumn{2}{c}{ Placebo $(\mathrm{n}=16)$} \\
Likelihood of relation to study drug & \multicolumn{1}{c}{$\mathrm{n}$} & \multicolumn{1}{c}{$\%$} & $\mathrm{n}$ & \multicolumn{1}{c}{$\%$} \\
\hline none (intercurrent event)* & 20 & 46.5 & 51 & 67.1 \\
unlikely (remote)* & 19 & 44.2 & 22 & 28.9 \\
possible* & 4 & 9.3 & 3 & 4.0 \\
total & 43 & & 76 & \\
\hline
\end{tabular}

"there was no significant difference between the two treatment groups

\section{Organ failure scores}

Within the active treatment period, changes in organ failure scores were consistent between the two treatment groups with exception of the cardiac failure score. On admission in the study, seven patients in both treatment groups had a cardiac failure score of 2. In the TCV-309 group, of these seven patients, three patients shifted to category 1 and four patients shifted to category 0 . In the placebo group of the patients with a cardiac failure score of 2 , one patient shifted to category 1 and one patient to category 0 , the remaining patients died before day seven measurements (Table 5 ). In the overall group (including all patients) these changes in cardiac failure score were not statistically different.

The mean scores for renal failure, hematologic failure and central nervous system failure changed from baseline to day 28 (last measured value for deceased patients carried forward) in the TCV-309 group by decreasing $0.2,0.3$ and 0.4 respectively. These organ failure scores were increased by 0.1 in each score in the placebo group. In contrast the hepatic failure score increased in the TCV-309 group $(+0.3)$ but decreased in the placebo group (-0.1). The cardiac failure and gastrointestinal failure scores 
decreased in both treatment groups (decrease 1.2 and 0.3 for TCV-309, 0.6 and 0.1 for placebo respectively). None of these changes were statistically significant.

With respect to the pulmonary failure score a significant difference was found between the TCV-309 and the placebo groups (Table 6). Pulmonary failure scores on day 28 decreased by a mean of 0.9 (SD 0.83) in the TCV-309 group whereas the pulmonary failure scores in the placebo group increased by 0.1 (SD 1.06) $(\mathrm{P}<.05)$. On day seven, this difference was even more pronounced with a similar reduction of the pulmonary failure score in the TCV-309 group $(\mathrm{P}<.03)$. Mean change in the hematological failure score was also significantly different between the groups at day seven $(\mathrm{P}=.05)$.

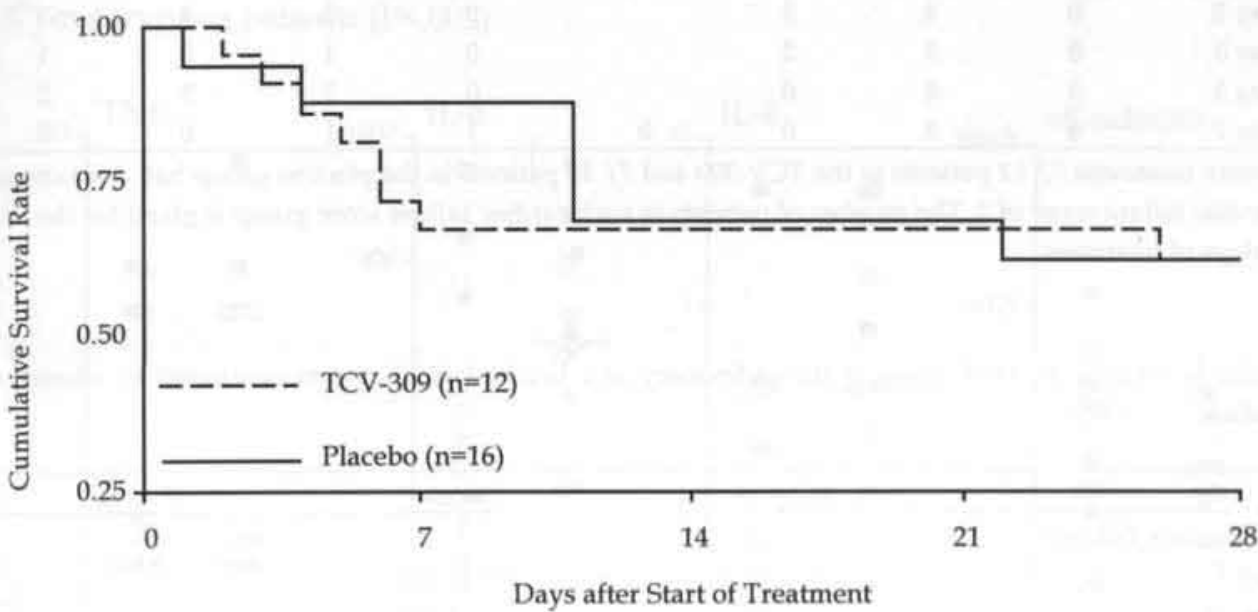

Figure 1: Kaplan-Meier survival estimate of TCV-309 treatment versus placebo. Survival in the TCV-309 group $(n=12)$ was compared to the survival in the placebo group $(n=16)$. A tendency towards improved survival in the TCV-309 group is seen during active treatment. There was no statistically significant difference in survival on day 7,28 and 56 between the two treatment groups.

\section{Inflammatory parameters, effect of TCV-309 treatment}

The septic shock parameters TNF, IL-6, IL-8 and sE-selectin were measured twice daily in all patients during the active treatment period and in intervals during the further part of the study. Only the values of the inflammatory mediators measured during the first seven days of treatment were used for analysis. Pretreatment IL- 6 and IL-8 levels were higher in the TCV-309 group compared to placebo, this was however not statistically significant. Median IL-6 levels were $24.6 \mathrm{ng} / \mathrm{mL}$ (range 0.15-623) $(\mathrm{n}=12)$ vs. $2.37(0.25-558)(\mathrm{n}=15) \mathrm{P}<.06$ and median IL-8 levels were $0.34 \mathrm{ng} / \mathrm{mL}(0.02-5.15)$ vs. $0.04(0.02-5.2) \mathrm{P}<.07$ (Fig. 2). Furthermore, there appeared to be a more rapid decrease of both IL- 6 and IL- 8 levels in patients in the TCV-309 group during the first seven 
days of treatment. Again this difference was not statistically significant. Pretreatment TNF and sE-selectin levels were similar in both groups. Although there were elevated TNF levels in most patients, there were no differences between the treatment groups.

Table 5: Change in cardiac failure in patients with a predose MOF score of 2 for the cardiac system

\begin{tabular}{|c|c|c|c|c|c|c|c|c|}
\hline \multirow[b]{2}{*}{ Score } & \multicolumn{4}{|c|}{ TCV-309 } & \multicolumn{4}{|c|}{ Placebo } \\
\hline & 0 & 1 & 2 & deceased & 0 & 1 & 2 & deceased \\
\hline predose & & & 7 & & & & 7 & \\
\hline day 1 & 0 & 2 & 5 & & 0 & 1 & 6 & \\
\hline day 2 & 0 & 4 & 3 & & 0 & 2 & 4 & 1 \\
\hline day 3 & 0 & 5 & 2 & & 0 & 1 & 5 & 1 \\
\hline day 5 & 3 & 4 & 0 & & 0 & 2 & 3 & 2 \\
\hline day 7 & 4 & 3 & 0 & 0 & 1 & 1 & 0 & 5 \\
\hline
\end{tabular}

Before treatment $7 / 12$ patients in the TCV-309 and $7 / 16$ patients in the placebo group had a maximum cardiac failure score of 2 . The number of patients in each cardiac failure score group is given for the first 7 days of treatment.

Table 6: Change in MOF score of the pulmonary and hematological system compared to admission values

\begin{tabular}{llll}
\hline & TCV-309 & Placebo & P value \\
\hline pulmonary failure* & & & $<.03$ \\
day 7 & $-0.5(0.82)$ & $0.3(0.68)$ & $<.05$ \\
day 28 & $-0.9(0.83)$ & $0.1(1.06)$ & .05 \\
hematological failure & & & NS \\
day 7 & $-0.3(0.65)$ & $0.2(0.40)$ & $0.1(0.34)$ \\
day 28 & $-0.3(0.65)$ & & \\
\hline
\end{tabular}

"Values are mean, standard deviation in brackets, last value was carried forward if no day 7 values were available.

In general, TCV-309 treatment did not significantly alter peak levels of the measured inflammatory mediators when compared to placebo, nor was there a significant difference in levels of the inflammatory mediators when survivors and nonsurvivors within the two treatment groups were compared.

\section{Inflammatory parameters, relation with survival}

In accordance with previous studies in septic patients we also studied the relation of the inflammatory parameters TNF, IL-6, IL-8 and sE-selectin with respect to survival and nonsurvival (Fig. 3). Peak levels of TNF were similar in nonsurvivors (median 0.03 $\mathrm{ng} / \mathrm{mL}$ (range $<0.02-0.08)$ ) compared to survivors $(0.02(<0.02-0.1))$ during the first 
seven days of treatment. These peak TNF levels tended to be higher with respect to day 28 mortality $(\mathrm{P}=.053)$. Peak levels of $\mathrm{sE}$-selectin were not different between survivors and nonsurvivors. However, a more rapid decrease of sE-selectin during the first seven days of treatment (analysis of the regression of sE-selectin levels in each individual patient) was significantly related to survival $(\mathrm{P}<.04$, median regression coefficient 1.20 (range -69.7 to 59.9 ) versus -8.65 (range -30.8 to 1.78 ), nonsurvivors vs. survivors respectively). Furthermore, peak levels of both IL-6 and IL- 8 were significantly related with day 28 mortality. During the active treatment period IL-6 peak levels were higher in nonsurvivors (median $58.2 \mathrm{ng} / \mathrm{mL}$ (range 1.58-692)) compared to survivors (5.65 $(0.19-558))(\mathrm{P}<.05)$. This difference was even more pronounced for IL-8, with median peak levels of $1.51 \mathrm{ng} / \mathrm{mL}$ (range $0.06-6.28)$ in nonsurvivors versus $0.11 \mathrm{ng} / \mathrm{mL}(0.02-$ $1.57)$ in surviving patients $(\mathrm{P}<.002)$.
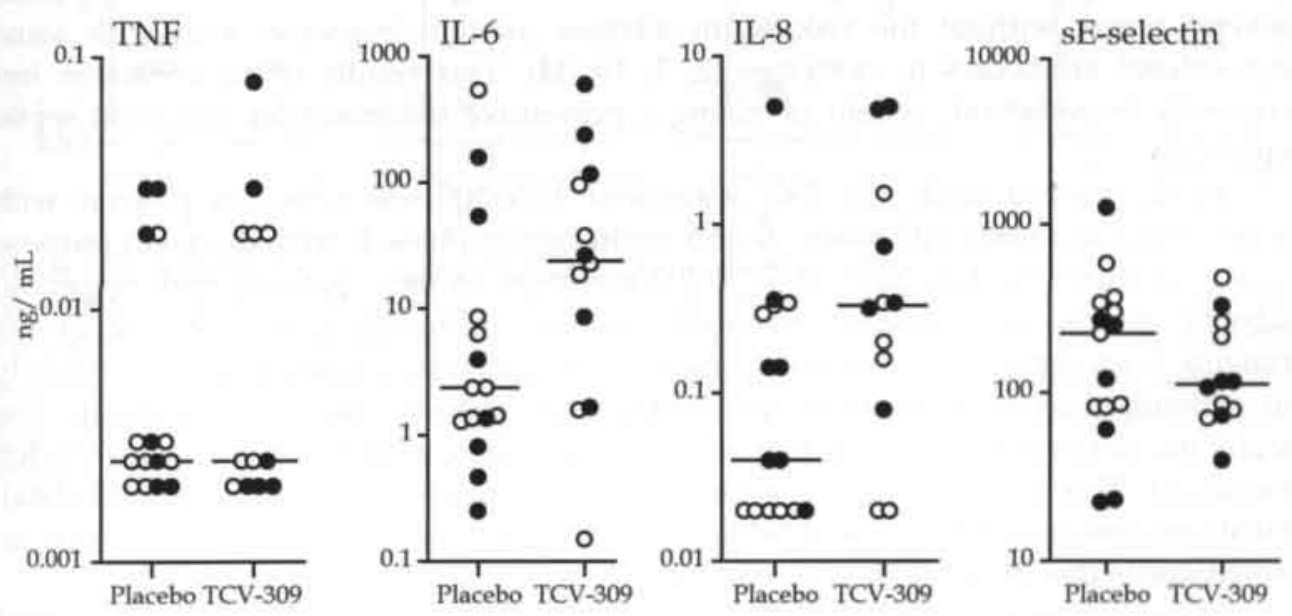

Figure 2: Pre-admission levels of TNF, IL-6, IL-8 and sE-selectin were not different between TCV-309 and placebo-treated patient groups. Pre-admission levels were compared in the different treatment groups to judge severity of disease. Non of the measured inflammatory mediators was significantly different between the treatment groups on admission. nonsurvivors, o survivors.

\section{DISCUSSION}

Platelet-activating factor is strongly related to the cytokine network and is suggested to play an important role in the pathogenesis in septic shock (19). Furthermore, Kuipers et al demonstrated in a chimpanzee model that the PAF antagonist TCV-309 significantly attenuated the release of TNF, IL-6, IL-8 and soluble TNF receptors, all important mediators of septic shock, in response to endotoxin administration $(6,7,19,28,29)$. It is therefore not surprising that PAF antagonists were shown to have protective effects 
against the development of sepsis in experimental animal models $(15,22-25)$. In contrast to most cytokine antibodies, however, it was recently shown that a PAF antagonist given several hours after an endotoxin insult could reduce mortality significantly (18). This was also found in models with traumatic and hypotensive shock $(18,20)$. Among many other modes of action, PAF probably increases tissue damage by prolonging impaired tissue perfusion, finally resulting in MOF (18). Hypothetically, this ongoing process can be blocked by PAF antagonists which may explain the positive effect in established sepsis were most other anti-inflammatory treatments fail. In other words, PAF antagonists may be able to improve outcome even after the cascade of events in SIRS, consisting of an uncontrolled release of inflammatory mediators, has been initiated. Another advantage of the PAF antagonist is that treatment apparently can be continued for several days without the risk of adverse effects as was shown in the present study. Furthermore, treatment can be repeated several times, without the risk of an adverse immune response seen with some monoclonal antibodies to cytokines $(2,3,10,14)$. This results in an attractive, but currently hypothetical, benefit of giving a preventive treatment for recurrent septic episodes.

In the present study the PAF antagonist TCV-309 was tested in patients with severe SIRS and SIRS with shock. In this multi-center, phase II trial, the main purpose was to evaluate the feasibility of TCV-309 treatment in these patients with respect to adverse effects and possible beneficial outcome. Although many adverse events ranging from changes in laboratory parameters to mortality occurred in these critically ill patients, there was no difference between the TCV-309 and placebo group. The study did not provide evidence that adverse events were a direct result of the TCV-309 treatment. This is in accordance with a previous phase I study (unpublished data). Final outcome was not different between the two treatment groups, i.e. there was no difference in day 28 nor in day 56 mortality.

In contrast to the effect of PAF antagonists on cytokine levels in the experimental situation, no significant changes in cytokine levels (TNF, IL-6, IL-8 or sE-selectin) were found in TCV-309-treated patients in the present study. This may be due to the relatively small number of patients in each treatment group with a wide variety of severity and causes of SIRS. Moreover, in contrast to the experimental situation where treatment is started at exactly the same moment in all treated subjects, initiation of the drug treatment in septic patients largely depends on clinical symptoms and judgement of the treating physician. On the other hand, when the studied patients were divided according to survival and nonsurvival, the inflammatory mediators IL-6, IL-8 and sEselectin were significantly related to survival. Peak levels of IL-6 and IL-8 were increased in nonsurviving patients. Furthermore a more rapid decrease of sE-selectin levels was significantly related to survival. TNF peak levels were higher in nonsurviving patients, the latter however did not reach statistical significance $(\mathrm{P}=.053)$. These results are clearly in accordance with previous studies in septic patients and do confirm the prognostic value of these parameters $(6,7,27-29,35)$. However, although 
inflammatory mediators are predictive of outcome if groups of patients are studied, they appear to be of limited value in the evaluation of individual patients.
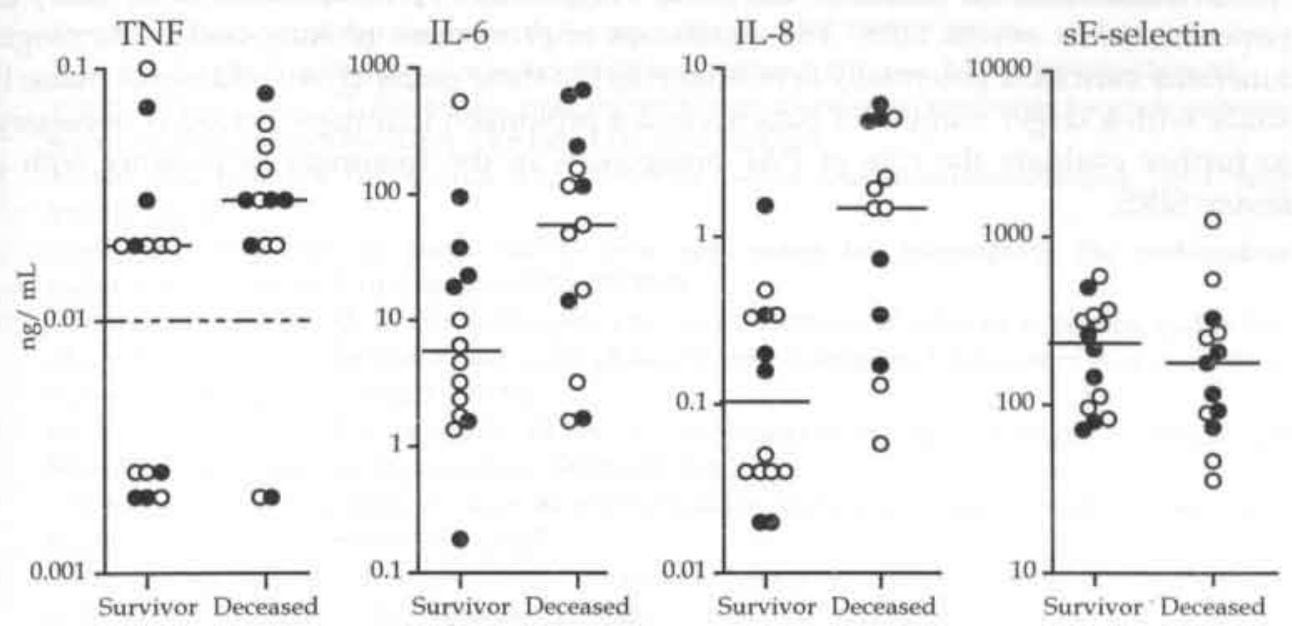

Figure 3: IL-6 and IL-8 levels are significantly increased in nonsurvivors compared to survivors. Peak levels of the cytokines TNF, IL-6 and IL-8 and of sE-selectin measured during the first 7 days of the treatment were compared between survivors and nonsurvivors. Both IL- 6 and IL- 8 were significantly related with day 28 mortality ( $\mathrm{P}<.05$ and $\mathrm{P}<.002$ respectively). Difference in TNF peak levels approached significance $(\mathrm{P}=.053)$. Peak levels of sE-selectin did not show a difference. Closed circles, TCV-309treated patients; open circles, placebo-treated patients.

Important differences were found with respect to the different organ failure scores in the patients treated with TCV- 309 when compared to placebo-treated patients. This correlates clearly with the hypothesis from experimental work that PAF plays an important role in the etiology of MOF and thus that treatment with a PAF antagonist may attenuate MOF (18). It was shown that PAF antagonists attenuate organ damage in experimental sepsis and after ischemia and reperfusion $(20,21)$. Moreover, PAF was shown to mediate endotoxin induced lung injury and was suggested to be involved in the development of bacterial pneumonia $(20,36)$. Furthermore, endotoxin or PAF induced lung injury could be prevented with a PAF antagonist, even when given some time after the administration of endotoxin or $\operatorname{PAF}(16,20)$. The latter correlates clearly with the significantly improved pulmonary failure scores at day 7 and 28 in the TCV309-treated patients. Similar results were found, in animal experiments, for other organ systems such as the heart and the hemostasis (disseminated intravascular coagulation) $(15,22-24)$. Again these data correlate well with the present study in which the hematology failure score was significantly improved in patients treated with the PAF 
antagonist compared to controls. A less pronounced improvement was seen in patients with high cardiac failure scores before treatment.

In conclusion, the results of this study suggest that TCV-309 can be used safely in patients with a severe SIRS. The significant improvement of lung and hematologic functions indicate a potentially beneficial effect in these patients. An additional phase II study with a larger number of patients and a prolonged treatment period is necessary to further evaluate the role of PAF antagonists in the treatment of patients with a severe SIRS. 


\section{REFERENCES.}

1. Bone RC, Fisher Jr CJ, Clemmer TP, et al. Sepsis syndrome: a valid clinical entity. Methylprednisolone Severe Sepsis Study Group. Crit Care Med 1989;17:389-93

2. Bone RC. A critical evaluation of new agents for the treatment of sepsis. JAMA 1991;266:1686-91

3. Wenzel RP, Andriole VT, Bartlett JG, et al. Antiendotoxin monoclonal antibodies for gram-negative sepsis: guidelines from the IDSA. Clin Infect Dis 1992;14:973-6

4. Molloy RG, Mannick JA, Rodrick ML. Cytokines, sepsis and immunomodulation. Br J Surg 1993;80:289-97

5. Giroir BP. Mediators of septic shock: new approaches for interrupting the endogenous inflammatory cascade. Crit Care Med 1993;21:780-9

6. Dofferhoff AS, Bom VJ, De Vries-Hospers HG, et al. Patterns of cytokines, plasma endotoxin, plasminogen activator inhibitor, and acute-phase proteins during the treatment of severe sepsis in humans. Crit Care Med 1992;20:185-92

7. Hack CE, Hart M, Van Schijndel RJ, et al. Interleukin-8 in sepsis: relation to shock and inflammatory mediators. Infect Immun 1992;60:2835-42

8. Ohlsson $\mathrm{K}$, Bjork $\mathrm{P}$, Bergenfeldt $\mathrm{M}$, et al. Interleukin-1 receptor antagonist reduces mortality from endotoxin shock. Nature 1990;348:550-2

9. Ziegler EJ, Fisher Jr CJ, Sprung CL, et al. Treatment of gram-negative bacteremia and septic shock with HA-1A human monoclonal antibody against endotoxin. A randomized, double-blind, placebocontrolled trial. The HA-1A Sepsis Study Group. N Engl J Med 1991;324:429-36

10. Exley AR, Cohen J, Buurman WA, et al. Monoclonal antibody to TNF in severe septic shock. Lancet 1990;335:1275-7

11. Moller A, Emling F, Blohm D, et al. Monoclonal antibodies to human tumor necrosis factor alpha: in vitro and in vivo application. Cytokine 1990;2:162-9

12. Fisher Jr CJ, Dhainaut JF, Opal SM, et al. Recombinant human interleukin-1 receptor antagonist in the treatment of patients with sepsis syndrome. Results from a randomized, double-blind, placebocontrolled trial. JAMA 1994;271:1836-43.

13. Fisher Jr Cl, Opal SM, Dhainaut JF, et al. Influence of an anti-tumor necrosis factor monoclonal antibody on cytokine levels in patients with sepsis. The CB0006 Sepsis Syndrome Study Group. Crit Care Med 1993;21:318-27

14. LoBuglio AF, Wheeler $\mathrm{RH}$, Trang J, et al. Mouse/ human chimeric monoclonal antibody in man: kinetics and immune response. Proc Natl Acad Sci USA 1989;86:4220-4

15. Ou MC, Kambayashi J, Kawasaki T, et al. Potential etiologic role of PAF in two major septic complications; disseminated intravascular coagulation and multiple organ failure. Thromb Res 1994;73:227-38

16. Qian C, Guo ZM, Peters CJ, et al. Platelet-activating factor (PAF)-induced cardiopulmonary dysfunctions and their reversal with a PAF antagonist (BN 52021) in strain 13 guinea pigs. J Lipid Mediat 1993;7:223-37

17. Braquet $\mathrm{P}$, Touqui L, Shen TY, et al. Perspectives in platelet-activating factor research. Pharmacol Rev 1987;39:97-145

18. Anderson $\mathrm{BO}$, Bensard DD, Harken $\mathrm{AH}$. The role of platelet activating factor and its antagonists in shock, sepsis and multiple organ failure. Surg Gynecol Obstet 1991;172:415-424

19. Kuipers B, Van der Poll T, Levi M, et al. Platelet-activating factor antagonist TCV-309 attenuates the induction of the cytokine network in experimental endotoxemia in chimpanzees. J Immunol $1994 ; 152: 2438-46$

20. Chang SW, Fernyak S, Voelkel NF. Beneficial effect of a platelet-activating factor antagonist, WEB 2086, on endotoxin-induced lung injury. Am J Physiol 1990;258:H153-8 
21. Yue TL, Farhat M, Rabinovici R, et al. Protective effect of BN 50739, a new platelet-activating factor antagonist, in endotoxin-treated rabbits. J Pharmacol Exp Ther 1990;254:976-81

22. Yamanaka S, Iwao H, Yukimura T, et al. Effect of the platelet-activating factor antagonist, TCV-309, and the cyclo-oxygenase inhibitor, ibuprofen, on the haemodynamic changes in canine experimental endotoxic shock. Br J Pharmacol 1993;110:1501-7

23. Terashita Z, Kawamura M, Takatani M, et al. Beneficial effects of TCV-309, a novel potent and selective platelet activating factor antagonist in endotoxin and anaphylactic shock in rodents. J Pharmacol Exp Ther 1992;260:748-55

24. Kawamura M, Terashita Z, Imura $\mathrm{X}$, et al. Inhibitory effect of TCV-309, a novel platelet activating factor (PAF) antagonist, on endotoxin-induced disseminated intravascular coagulation in rats: possible role of PAF in tissue factor generation. Thromb Res 1993;70:281-93

25. Ogata M, Matsumoto T, Koga K, et al. An antagonist of platelet-activating factor suppresses endotoxin- induced tumor necrosis factor and mortality in mice pretreated with carrageenan. Infect Immun 1993;61:699-704

26. Goris RJA, Te Boekhorst TP, Nuytinck JKS, et al. Multiple-Organ failure. Generalized autodestructive inflamation? Arch Surg 1985;120;1109-15

27. Damas P, Ledoux D, Nys M, et al. Cytokine serum level during severe sepsis in human IL-6 as a marker of severity. Ann Surg 1992;215:356-62

28. Pinsky MR, Vincent JL, Deviere J, et al. Serum cytokine levels in human septic shock. Relation to multiple-system organ failure and mortality. Chest 1993;103:565-75

29. Calandra T, Baumgartner JD, Grau GE, et al. Prognostic values of tumor necrosis factor/ cachectin, interleukin-1, interferon-alpha, and interferon-gamma in the serum of patients with septic shock. Swiss-Dutch 55 Immunoglobulin Study Group. J Infect Dis 1990;161:982-7

30. Bone RC. American College of Chest Physicians/ Society of Critical Care Medicine Consensus Conference: definitions for sepsis and organ failure and guidelines for the use of innovative therapies in sepsis. Crit Care Med 1992:20:864-74

31. Knaus WA, Draper EA, Wagner DP, et al. A pache II: A severity of disease classification for severely ill patients. Crit Care Med 1985;13:818-29

32. Engelberts I, Moller A, Schoen GJ, et al. Evaluation of measurement of human TNF in plasma by ELISA. Lymphokine Cytokine Res 1991;10:69-76

33. Dentener MA, Bazil V, Von Asmuth EJ, et al. Involvement of CD14 in lipopolysaccharide-induced tumor necrosis factor-alpha, IL-6 and IL-8 release by human monocytes and alveolar macrophages. J Immunol 1993;150:2885-91

34. Leeuwenberg JF, Smeets EF, Neefjes JJ, et al. E-selectin and intercellular adhesion molecule-1 are released by activated human endothelial cells in vitro. Immunology 1992;77:543-9

35. Newman W, Beall LD, Carson CW, et al. Soluble E-selectin is found in supernatants of activated endothelial celis and is elevated in the serum of patients with septic shock. J Immunol 1993;150:64454

36. Makristathis A, Stauffer F, Feistauer SM, et al. Bacteria induce release of platelet-activating factor (PAF) from polymorphonuclear neutrophil granulocytes: possible role for PAF in pathogenesis of experimentally induced bacterial pneumonia. Infect Immun 1993;61:1996-2002 
THE SYSTEMIC INFLAMMATORY RESPONSE IN THE DEVELOPMENT OF VENTILATOR-ASSOCIATED PNEUMONIA

M.J.M. Bonten, A.H.M. Froon, C.A. Gaillard, J.W.M. Greve, P.W. de Leeuw, M. Drent, E.E. Stobberingh, W.A. Buurman. Am J Resp Crit Care Med 1996; 156:1105-13 


\section{SUMMARY}

Ventilator-associated pneumonia (VAP) is the most frequent occurring infection among mechanically ventilated patients. The clinical presentation of VAP ranges from relatively benign to a severe illness with septic shock. The influence of VAP on patient outcome has not been elucidated and its effects on the inflammatory response of the host are unknown. In a case-control study, the systemic inflammatory response was investigated in patients developing VAP as compared to control patients matched on duration of mechanical ventilation and underlying diseases. Patients developing VAP $(n=42)$ were matched to one control each (without VAP), which were matched on 7 variables. VAP was diagnosed with bronchoscopic techniques. The inflammatory response, reflected by circulating levels of interleukin-6 (IL-6) and interleukin-8 (IL-8), was determined on the day of diagnosis (or day of matching for controls), 4 and 2 days before diagnosis and 2 days after diagnosis. The development of VAP was not associated with an increase in circulating levels of IL-6 or IL-8. Among patients in which VAP was associated with a clinical presentation of severe sepsis or septic shock $(n=10), I L-6$ and IL-8 levels increased and levels were higher than in the corresponding controls. Moreover, $60 \%$ of cases with sepsis syndrome or septic shock died as compared to $20 \%$ of their matched controls $(\mathrm{P}=.06)$. Mortality rates were similar in cases with uncomplicated VAP and their matched controls; $25 \%$ and $34 \%$ respectively. High circulating levels of IL- 6 and IL- 8 were associated with higher mortality rates. The clinical picture of VAP can be subdivided into different types, ranging from uncomplicated to an infection associated with sepsis syndrome or septic shock, elevated circulating levels of IL-6 and IL-8 and an increased mortality rate. 


\section{INTRODUCTION}

Ventilator-associated pneumonia (VAP) is the most frequently observed nosocomial infection among mechanically ventilated ICU patients (1). The clinical presentation of VAP varies widely: from a relatively benign to a devastating illness resulting in septic shock. Colonization of the respiratory tract with potentially pathogenic microorganisms is the first step in the pathogenesis of this infection (2-4). However, only a minority of the colonized patients will eventually develop VAP (2-4). The progression from colonization to infection of the respiratory tract has not been studied extensively.

If indeed VAP is to be a severe infection of the lung, one would expect that it would also be accompanied by a massively activated inflammatory response. On the other hand, rather uncomplicated episodes of VAP would be accompanied by a much smaller inflammatory response. The inflammatory response of the host to an infection is associated by increased circulating levels of cytokines, such as interleukin-6 (IL-6) and interleukin-8 (IL-8). Several studies have demonstrated that high circulating levels of IL-6 and IL-8 are related to the severity of illness in septic patients and are prognostic markers for outcome in critically ill patients (5-9). Both cytokines represent different parts of the inflammatory response: IL-6 is an acute phase hormone inducing synthesis of proteins by the liver, whereas $\mathrm{L}-8$ has chemoattractant activity and is able to activate and degranulate neutrophils $(10,11)$. The aim of the present study was to investigate whether the development of VAP was associated with an increase in circulating levels of IL-6 and IL-8. Therefore, we analyzed circulating levels of these cytokines in blood samples obtained in the four days prior to the diagnosis of VAP. In addition, we determined the relationship between the clinical severity of VAP, the degree of inflammatory response and mortality. Since the severity of underlying illness has an important bearing on the inflammatory response and the outcome in critically ill patients $(12,13)$, we studied the development of VAP in a case-control design, in which patients were matched on variables representing underlying illness.

\section{MATERIAL AND METHODS}

\section{Study population}

The study was conducted in the intensive care unit (ICU) of the University Hospital, Maastricht, The Netherlands. The ICU is a 16-bed ward with patients from the departments of surgery, internal medicine, trauma, pulmonology, neurology, and neurosurgery. The study period extended from January 1st, 1992 until January 1st, 1994. All mechanically ventilated patients admitted to this ward were enrolled and plasma samples were collected daily from all patients. The study was reviewed and approved by our Institutional Review Board, which deemed that informed consent was not required. 
In addition, demographic data were obtained on admission and clinical data were recorded on a daily basis from admission until death, or discharge. On admission, the APACHE II score was assessed as described by Knaus (14). The following information was recorded: age, sex, dates of admission and discharge from ICU, period of hospitalization prior to admission to the ICU, list of medical history, the surgical procedures performed, body temperature, the number of leukocytes in peripheral blood, the levels of blood urea, creatinine, aspartate aminotransferase (AST), alanine aminotransferase (ALT), total bilirubin, the use and indication of antibiotics, and the administration of immunosuppressive therapy. In this way a computerized data system was created containing demographic and clinical data from a large cohort of mechanically ventilated patients.

Table 1: Criteria used for the diagnosis of ventilator-associated pneumonia

\section{Criteria}

I $\quad \geq 3$ positive of the following 4 :

(a) rectal temperature above $38.0^{\circ} \mathrm{C}$ or below $35.5^{\circ} \mathrm{C}$

(b) blood leukocytosis $\left(>10 \times 10 \mathrm{E} 3 / \mathrm{mm}^{3}\right)$ and / or left shift or blood leukopenia $\left(<3 \times 10 \mathrm{E} 3 / \mathrm{mm}^{3}\right)$

(c) $>10$ leukocytes per high-power field in gram stain of tracheal aspirate

(d) positive culture from tracheal aspirate and

II new, persistent or progressive infiltrate on chest radiograph and

III $\geq 1$ positive of the following 3 :

(a) positive quantitative culture of a sample obtained by BAL (cutoff point $>10 \mathrm{E} 4 \mathrm{cfu} / \mathrm{mL}$ ) or PSB (cutoff $\geq 10 \mathrm{E} 3 \mathrm{cfu} / \mathrm{mL}$ )

(b) positive blood culture unrelated to another source and obtained within 48 hours before and after respiratory sampling

(c) positive pleural fluid culture in the absence of previous pleural instrumentation

$\mathrm{BAL}=$ bronchoalveolar lavage, $\mathrm{PSB}=$ protected specimen brush

Pneumonia was diagnosed if I and II and III were positive.

\section{Study design}

A case-control study was performed. For the purpose of this study, patients who developed VAP were defined as 'cases' and those without VAP as 'controls'. The diagnosis of VAP was established on the criteria listed in Table 1, or when histological evidence of pneumonia was found at autopsy. Since mechanical ventilation for at least three days is a prerequisite in the definition of VAP, only patients who fulfilled this criterium were included in the analysis. Patients with leukopenia $\left(<1.0 \times 10 \mathrm{E} 9 / \mathrm{mm}^{3}\right)$ were excluded from analysis. 
All patients who developed an episode of VAP were included in a computergenerated list of potential cases. If a patient developed more than one episode of VAP, only the first episode was used in the analysis. In addition, a list was created from all patients who needed mechanical ventilation for at least three days, but who did not develop VAP.

In order to control for the length of ICU stay, each potential control needed to have a total length of ICU stay at least equal to the duration of ICU stay of the case on the day VAP was diagnosed. This day of matching was labeled D0. In addition to the length of stay, the following variables were used for matching individual cases: Diagnosis on admission, global renal and hepatic function, and preceding surgery, antibiotic use and immunosuppressive therapy.

Diagnoses on admission were subdivided into four groups according to the presence of infection and the presumed effect on cytokine release. Patients in groups 1 and 2 were admitted with an infection, either of the respiratory tract (group 1) or at another site (group 2). Patients in group 3 did not have an infection on admission, but had an illness which probably was associated with release of cytokines (for instance abdominal surgery, pancreatitis, or trauma) (15-17). The final group consisted of patients who did not fit in any of these groups (group 4).

A further subdivision of the patients was performed according to global renal and hepatic function on the day of matching. Renal function was labeled normal (creatinine $<100 \mu \mathrm{mol} / \mathrm{L}$ and urea $<12 \mathrm{mmol} / \mathrm{L}$, group R1), lightly decreased (creatinine 100-200 $\mu \mathrm{mol} / \mathrm{L}$ and urea $12-25 \mathrm{mmol} / \mathrm{L}$, group R2), or severely decreased (creatinine $>200$ $\mu \mathrm{mol} / \mathrm{L}$ and urea $>25 \mathrm{mmol} / \mathrm{L}$, group R3). Patients needing renal replacement therapy formed group R4. Patients of group R1 could be matched to patients of groups R1 and R2, and patients of groups R3 and R4 could be matched as well. For hepatic function patients were subdivided into three groups for levels of transferases (group A, AST and ALT <100 U/ L; group B, AST and ALT 100-200 U/ L; group C, AST and ALT $>200 \mathrm{U} / \mathrm{L}$ ) and for bilirubin levels (group A, $<45 \mu \mathrm{mol} / \mathrm{L}$; group B, 45-100 $\mu \mathrm{mol} / \mathrm{L}$; group C, $>100 \mu \mathrm{mol} / \mathrm{L}$ ). For hepatic function patients were in group H1 if both transferases and bilirubin levels were from group $\mathrm{A}$, in group $\mathrm{H} 2$ if transferases and/ or bilirubin were from group B, and in group $\mathrm{H} 3$ if transferases and/ or bilirubin were from group $\mathrm{C}$. Patients of groups $\mathrm{H} 1$ and $\mathrm{H} 2$, and patients of groups $\mathrm{H} 2$ and $\mathrm{H} 3$ could be matched.

Furthermore, patients were grouped if they had, or had not, undergone abdominal and/ or thoracic surgery during hospital-stay and before D0. Similarly, patients who had, or had not, received antimicrobial therapy during ICU stay and before D0 were grouped. Finally, patients were grouped if they had or had not received immunosuppressive therapy before D0.

For each case patient a control was sought which could be matched for each variable, given highest priority to duration at risk. The order of importance of the other matching variables was diagnosis on admission, renal function, hepatic function, preceding infection, preceding surgery and immunosuppressive therapy. When more 
than one potential control could be matched to a case, the control with the best match for APACHE II-score and age was selected. The clinical presentation of VAP was defined according to the criteria of the American College of Chest Physicians and the Society of Critical Care Medicine (18). According to these criteria all patients with VAP had sepsis, those with organ dysfunction or hypotension had severe sepsis and those with hypotension despite fluid resuscitation or with hypoperfusion abnormalities had septic shock. In order to determine whether cases and controls were indeed comparable at the time of diagnosis of VAP, the Simplified Acute Physiology Score II as described by LeGall (19) was calculated at D-2 for all patients.

\section{Blood samples}

During 1992 and 1993 blood samples were taken daily from each ICU patient. Blood was obtained using evacuated blood collection tubes containing EDTA. Blood was always collected at the first daily round of routine blood sampling at approximately 6 am. Blood samples were immediately put on ice and plasma was separated by centrifugation at 2,200G for 5 minutes at $4^{\circ} \mathrm{C}$. Hemolytic plasma samples were excluded from analysis. Samples were stored at $-70^{\circ} \mathrm{C}$ until use.

\section{Levels of interleukin-6 and interleukin-8}

After the matching procedure, levels of IL-6 and IL- 8 were determined in serum samples obtained from cases and controls at four time points: the day of diagnosis of VAP for cases and the matching day for controls (D0), and two and four days before this day (D-2 and D-4, respectively), and at two days after matching (D+2). To assess kinetics of IL-6 and IL-8, the difference between the first (D-4) and last sample (D+2) was calculated for each patient.

\section{Cytokine assays}

Reagents used were recombinant human IL-6 (kindly provided by Prof.dr. Sebald, Würzberg, Germany), and rhlL-8 (kindly provided by Dr. Lindley, Sandoz Vienna, Austria). Plasma IL-6 and IL-8 concentrations were determined using enzyme-linked immunosorbent assays (ELISA) developed in our laboratory. Each sample was assayed at least in duplicate. In short, 96-well immunomaxisorp plates (Nunc Inc., Roskilde, Denmark) were coated overnight at $4^{\circ} \mathrm{C}$ with cytokine-specific murine mAb 5E1 (antiIL-6) and HM5 (anti-IL-8). Plasma samples (1:1 diluted) and the standard dilution series with rhIL-6 and rhIL-8, respectively, were added to the plates. The amount of IL6 and IL- 8 bound to the wells was quantified by sequential incubation with polyclonal rabbit anti-human IL-6, and biotinylated polyclonal rabbit anti-human IL-8 Abs, followed by adding a peroxidase conjugated goat anti-rabbit IgG (Jackson, Westgrove, PA), and peroxidase labeled streptavidin (Dakopatts, Glostrup, Denmark). Finally 3', 5 , 5 '-tetramethylbenzidine (KPL, Gaithersburg, MD) was added as substrate. The reaction was stopped after 15 minutes, and photospectrometry was performed at $450 \mathrm{~nm}$. The lower detection limits of the ELISAs were $10 \mathrm{pg} / \mathrm{mL}$ for IL- 6 and $20 \mathrm{pg} / \mathrm{mL}$ for IL- 8 . 
All plasma samples were analyzed in the same run. When plasma levels exceeded the detection limit of the assay, samples were additionally diluted and analyzed in a separate run with an overlap to correct for inter-assay variation. The intra- and interassay coefficient of variance of the assays were all $<10 \%$.

\section{Mortality}

Mortality rates were calculated 10 and 28 days after the day of matching.

\section{Statistical analysis}

For statistical analysis, the Mann-Whitney U-test (MWU), the t-test, Kruskal-Wallis test or Chi-square test were used when appropriate. A p-value $<.05$ was significant. Levels of IL- 6 and IL-8 are presented as median values with the 25- and 75-percentiles (interquartile range $=\mathrm{IQR}$ ).

\section{RESULTS}

\section{Study population}

Data were collected from 233 patients, who received mechanical ventilation for at least three days. Fifty-eight of these patients developed an episode of VAP and 42 of them could be matched successfully to a control patient. Sixteen patients developing VAP were not included in the analysis, because blood samples were not obtained $(n=2)$, or clinical data were missing $(n=1)$. The remaining 13 patients had at least one clinical variable for which no suitable control could be found, for example a long duration of ventilation before development of VAP, renal replacement therapy or severe hepatic failure. The mortality rate of these 16 patients was $27 \%$.

The diagnosis of VAP was based on positive quantitative cultures from bronchoscopic samples in 38 of 42 patients, in five patients in combination with positive cultures from blood or pleural fluid. The diagnosis was established on microbiological cultures and histology of lung tissue obtained during autopsy in three patients, and on positive blood cultures in another patient. For the 42 cases included in the case-control analysis Pseudomonas aeruginosa and Staphylococcus aureus were the most frequently isolated microorganisms causing VAP. P. aeruginosa was cultured in significant amounts from BAL or PSB samples in 22 patients, and was cultured at autopsy or in cultures from blood or pleural fluid in 3 other patients (Table 2). S. aureus was isolated in significant amounts from lavage fluid in six patients and from blood and pleural fluid in another patient. Fifteen of 42 episodes of VAP were polymicrobial; i.e. more than one microorganism was cultured in significant amounts from bronchoscopic samples or at autopsy. In all patients developing VAP, empiric antibiotic therapy was instituted, or current therapy changed following bronchoscopy. Empiric therapy was occasionally narrowed after the causative pathogens and their in vitro antibacterial susceptibilities had been established. 
Table 2: Clinical and relevant bacleriologic characteristics of patients with ventilator-associated pineumonia

\begin{tabular}{|c|c|c|c|c|c|}
\hline & \multicolumn{2}{|c|}{ Culture results } & \multicolumn{2}{|c|}{ Clinical parameters } & \multirow[t]{2}{*}{ Antimicrobial therapy } \\
\hline & $\begin{array}{l}\text { Bronchoalveolar } \\
\text { lavage }\end{array}$ & Other positive results & $\begin{array}{c}\text { Temperature }\left({ }^{\circ} \mathrm{C} \text { ) }\right. \\
\text { mean (range) }\end{array}$ & $\begin{array}{l}\text { Leukacyte count } \\
\left(\times 10 \mathrm{E} 9 / \mathrm{mm}^{3} \text { ) }\right. \\
\text { mean (range) }\end{array}$ & \\
\hline \multirow{10}{*}{$\begin{array}{l}\text { Patients } \\
\text { with } \\
\text { sertere sepsis } \\
\text { oir } \\
\text { septic shock } \\
(n=10)\end{array}$} & P. aeruginsa $(n=5)$ & A.utopsy: $P$. aeruginosa $(n=1)$ & $38.5(36.8-40.3)$ & $15.7(3.4-29.6)$ & piperacillin + gentamicin $(n=5)$ \\
\hline & E. coli $(n=3)$ & Autopsy: S, marcescens $(n=1)$ & & & ceftazidime + gentamicin $(n=2)$ \\
\hline & E. cloacae $(n=2)$ & Blood: P: seruginosa $(n=3)$ & & & amoxicilin - clavulanic acid $(\mathrm{n}=1)$ \\
\hline & S. aureus $(n=2)$ & Blood: S. marcescens $(n=1)$ & & & fiucloxacillin $(n=1)$ \\
\hline & $N A * 1(n=3)$ & Blood: S. aureus $(n=1)$ & & & cotrimoxazole $(n=1)$ \\
\hline & & Pleural fluid: $P$ aeruginosa $(n=1)$ & & & \\
\hline & & Pleural fluid: $S$ aureus $(n=1)$ & & & \\
\hline & & $\mathrm{PSB}^{4} 2 \mathrm{P}$. aeruginosa $(n=1)$ & & & \\
\hline & & PSB: 5 , aureus $(n=1)$ & & & \\
\hline & & PSB. E. cali $(n=1)$ & & & \\
\hline \multirow{12}{*}{$\begin{array}{l}\text { Patients } \\
\text { without } \\
\text { severe sepsis } \\
\text { oir } \\
\text { septic shock } \\
(n=32)\end{array}$} & P. aeruginosa $(n=179)$ & Autopsy: $P$. aeruginosa $(n=1)$ & $38.9(3.7-40.8)$ & $15.4(5.1-23.0)$ & piperacillin + gentamicin $(n=8)$ \\
\hline & S. aureus $\left(\mathrm{n}^{-9}\right)$ & Autopsy: 5 marcescens $(n=1)$ & & & amoxicillin - clavulanic acid $(n=7)$ \\
\hline & $E$ coli $(n=5)$ & Bloodl: E. coli $(n=1)$ & & & piperacillin $(\mathrm{n}=6)$ \\
\hline & $H$. influenzate $(n=4)$ & Blood: P. aeruginosa $(n=1)$ & & & ceftazidime $(n=3)$ \\
\hline & K. preumoniae $(n-4)$ & Pleural fluid: E. cloncae $(n=1)$ & & & amoxicillin - clavulanic acid \\
\hline & S. pneumoniae $(n=3)$ & PSB: S. aureus $(n=4)$ & & & + gentamicin $(n=2)$ \\
\hline & E. cloacae $(n=2)$ & PSB: S. preumonise $(n=3)$ & & & fucloxacillin ( $n=2$ ) \\
\hline & E. aerogenes $(n=1)$ & PSB: $K$ pneumoniae $(n=2)$ & & & ciprofloxacin + gentamicin $(n=1)$ \\
\hline & M. catarhalis $(n=1)$ & PSB: $\mathrm{H}$, influenzae $(\mathrm{n}=1)$ & & & ciprofloxacin $(n=1)$ \\
\hline & P. mirabilis $(n=1)$ & PSB: P. murabilis $(n=1)$ & & & ticarcillinı - clavulanic acid $(n=1)$ \\
\hline & S. mitis $(n=1)$ & & & & pericillin $G(n=1)$ \\
\hline & NA $(n=2)$ & & & & \\
\hline
\end{tabular}

"1: NA =: not available: "2: PSB = protected specimen brush 
Table 3: Clinical characteristics and mean values of variables used for matching for cases with sepsis and their corresponding controls and cases with severe sepsis or septic shock and their corresponding controls

\begin{tabular}{|c|c|c|c|c|c|c|}
\hline Variable & $\begin{array}{l}\text { Cases with severe } \\
\text { sepsis or septic shock }\end{array}$ & Controls & P-value & Cases with sepsis & Controls & P-value \\
\hline & $n=10$ & $n=10$ & & $n=32$ & $\mathrm{n}=32$ & \\
\hline Duration at risk & $8.4 \pm 4.9$ & $8.0 \pm 4.8$ & NS & $7.6 \pm 3.5$ & $7.5 \pm 3.4$ & NS \\
\hline \multicolumn{7}{|c|}{ Diagnosis on admisison } \\
\hline group 1 & 1 & 1 & & 15 & 15 & \\
\hline group 2 & 5 & 2 & & 7 & 7 & \\
\hline group 3 & 3 & 4 & & 7 & 7 & \\
\hline group 4 & 1 & 3 & NS & 3 & 3 & NS \\
\hline \multicolumn{7}{|l|}{ Renal function } \\
\hline Urea (mmol/ L) & $17.6 \pm 11.4$ & $13.0 \pm 8.9$ & NS & $12.5 \pm 3.3$ & $14.1 \pm 17.0$ & NS \\
\hline Creatinine (jmol/ L) & $166.4 \pm 119.3$ & $102.3 \pm 99.4$ & NS & $108.7 \pm 92.5$ & $91.0 \pm 63.3$ & NS \\
\hline \multicolumn{7}{|l|}{ Hepatic function } \\
\hline $\mathrm{AST}^{\text {मै }} 1(\mathrm{U} / \mathrm{L})$ & $61.4 \pm 46.2$ & $59.0 \pm 70.2$ & NS & $46.3 \pm 31.9$ & $53.9 \pm 14.7$ & NS \\
\hline $\mathrm{ALT}^{\#} 2(\mathrm{U} / \mathrm{L})$ & $56.9 \pm 33.8$ & $43.7 \pm 37.2$ & NS & $58.2 \pm 48.5$ & $64.9 \pm 74.5$ & NS \\
\hline Bilirubin ( $\mu \mathrm{mol} / \mathrm{L}$ ) & $191.2+323.3$ & $45.4 \pm 40.8$ & $N G$ & $34.2 \pm 36.1$ & $35.5 \pm 46.8$ & NS \\
\hline \multicolumn{7}{|l|}{ Preceding infection } \\
\hline Yes & 5 & 7 & & 12 & 13 & \\
\hline No & 5 & 3 & NS & 30 & 19 & NS \\
\hline \multicolumn{7}{|l|}{ Preceding surgery } \\
\hline Yes & 4 & 4 & & $\delta$ & 8 & \\
\hline No & 6 & ó & NS & 24 & 24 & NS \\
\hline \multicolumn{7}{|l|}{$\begin{array}{l}\text { Immunosuppressive } \\
\text { therapy }\end{array}$} \\
\hline Yes & 4 & 4 & & 2 & 2 & \\
\hline No & 6 & 6 & NS & 30 & 30 & NS \\
\hline Age & $53.0 \pm 21.2$ & $58.6 \pm 18.6$ & NS & $61.2+16.9$ & $62.9 \pm 17.8$ & NS \\
\hline $\begin{array}{l}\text { APACHE II score } \\
\text { on admission }\end{array}$ & $23.5 \pm 5.2$ & $21.6 \pm 4.3$ & $N G$ & $20.5 \pm 7.3$ & $21.1 \pm 7.7$ & NS \\
\hline
\end{tabular}

\#1: AST $=$ aspartate aminotransferase; ${ }_{2}:$ AL. $\mathrm{T}=$ alanine aminotransferase 
One of the cases (patient number 29) received inappropriate antimicrobial therapy. He was colonized in his respiratory tract with S. aureus, developed VAP with septic shock, was empirically treated with flucloxacillin and succumbed within 24 hours. Cultures from BAL and blood subsequently grew $\mathrm{P}$. aeruginosa.

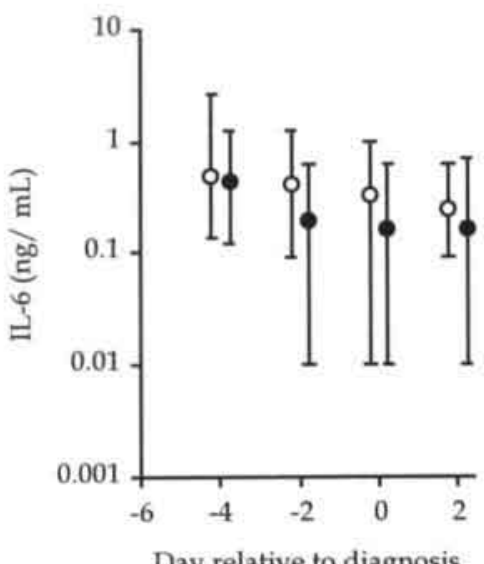

Figure 1: Interleukin-6 levels (median and interquartile range) in cases (open circles) and controls (closed circles).

\section{Effectiveness of matching}

For each variable included in the matching procedure the percentage of successful matching was at least $90 \%$, and success of matching was achieved in $282(96 \%)$ of 294 variables used for matching. The percentage of successful matching for duration at risk was $93 \%$. Three control patients had a shorter duration at risk as compared to their corresponding cases, but in each case the difference in ICU stay between cases and controls was one day. There were no significant differences in the mean values of any of the matching variables between cases and controls (Table 3). When cases and controls were compared with respect to age and APACHE II score there appeared to be adequate matching (Table 3). In addition the numbers of patients with pre-existing diseases were similar for cases and controls respectively: Cardiovascular disease (18 and 19 patients), diabetes mellitus ( 8 and 7 patients), pulmonary disease ( 8 and 5 patients), gastrointestinal disease ( 4 and 6 patients), and malignancies (4 and 5 patients). The proportion of cases and controls admitted for different specialties was similar as well (data not shown).

\section{Number of samples analyzed}

For D-4, 73 of 84 samples ( $87 \%)$ were available; 36 cases $(86 \%)$ and 37 controls $(88 \%)$. For D-2 and D0 all samples $(n=84)$ were available. Two days after the day of matching $(\mathrm{D}+2)$ samples were available from $39(93 \%)$ cases and $34(81 \%)$ controls. 
Interleukin- 6 and interleukin-8 levels according to diagnosis on admission Circulating levels of IL-6 and IL-8 on D-4 were significantly different between the four groups categorized according to diagnosis on admission: P<.001 for IL-6 and IL-8, Kruskal-Wallis. IL-6 levels were lowest $(0.19 \mathrm{mg} / \mathrm{mL}$; $\mathrm{IQR}=0.1-0.51)$ in group 4 (e.g. diagnoses with unknown influence on IL-6), and highest $(1.72 \mathrm{ng} / \mathrm{mL} ; \mathrm{IQR}=0.31-3.53$ ) in those with expected cytokine release but without infection (group 3), or admitted with infections other than those of the respiratory tract (group 2: $0.97 \mathrm{ng} / \mathrm{mL}$; $\mathrm{IQR}=0.74-5.3$ ). IL-8 levels on D-4 were also lowest for patients categorized in group 4 (0.06 ng/ mL, IQR=0.03-0.09).

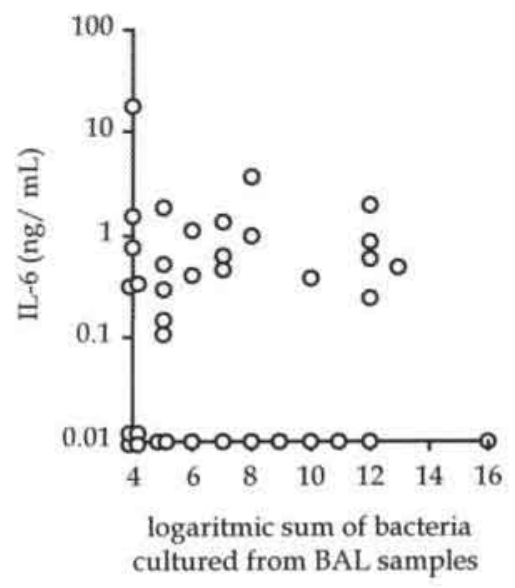

Figure 2: Interleukin-6 levels according to the logarithmic sum of bacteria cultured from samples of bronchoalveolar lavage.

\section{VAP and interleukin-6}

IL-6 was detectable in $29(81 \%), 32(76 \%)$, and $28(67 \%)$ samples on D-4, D-2, and D0 for cases, and in respectively $28(76 \%), 28(67 \%)$, and $26(62 \%)$ samples obtained from controls (ns). At D+2 IL-6 was detectable in $30(77 \%)$ samples from cases and $21(62 \%)$ samples from controls (ns). The development of VAP was not associated with an increase in the circulating levels of IL-6, nor were significant differences demonstrated between both study groups on any single day of study (Fig. 1).

No significant differences in median levels of IL-6 were found between cases in whom VAP was polymicrobial $(n=15)$ and their corresponding controls at D0 $(0.28$ versus $0.11 \mathrm{ng} / \mathrm{mL})$, or on $\mathrm{D}+2(0.47$ versus $0.40 \mathrm{ng} / \mathrm{mL})$. Moreover, there were no significant correlations between levels of IL- 6 on D0 or the difference between IL- 6 levels in samples at D+2 and D-4 and the logarithmic sum of bacteria cultured from samples of bronchoscopic techniques (e.g. bacterial burden of infection) (Fig. 2). 


\section{VAP and interleukin-8}

At D-4, IL-8 was detectable in $26(72 \%)$ and in $27(73 \%)$ samples from cases and controls respectively (ns). The number of samples with detectable IL-8 levels decreased to 19 $(45 \%)$ and $14(33 \%)$ for cases and to $16(38 \%)$ and $13(31 \%)$ for controls on D-2 and D0 respectively (ns). Finally, at D+2 IL-8 was found in $20(51 \%)$ samples from cases and in $11(32 \%)$ samples from control patients (ns).

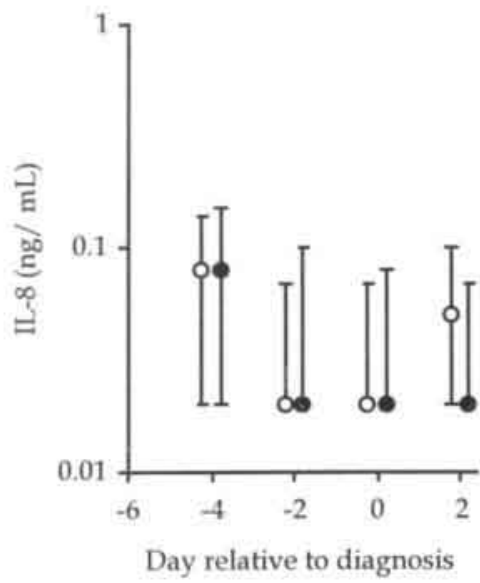

Figure 3: Interleukin-8 levels (median, interquartile range) in cases (open circles) and controls (closed circles).

Neither an increase in circulating levels of IL-8 in patients developing VAP, nor statistically significant differences in levels of IL-8 between cases and controls were found (Fig. 3). Furthermore, similar IL-8 levels were found throughout in patients with polymicrobial VAP and their corresponding controls, and no correlation between IL-8 levels and the bacterial burden was found (data not shown).

Severe sepsis, septic shock and levels of interleukin-6 and interleukin-8

Two patients who developed VAP met the criteria of severe sepsis and eight developed septic shock. P. aeruginosa was involved in seven of ten cases of VAP which were accompanied by severe sepsis or septic shock, and in 18 out of the remaining 32 cases (ns). Circulating levels of IL-6 on D0 were $0.32 \mathrm{ng} / \mathrm{mL}$ (IQR=0.01-1.43) for cases with VAP caused by $\mathrm{P}$. aeruginosa and $0.10 \mathrm{ng} / \mathrm{mL}(\mathrm{IQR}=0.01-0.45)$ for their corresponding controls (ns), and levels of IL- 8 were $0.02 \mathrm{ng} / \mathrm{mL}$ for both patient groups. Four of ten patients with severe sepsis or septic shock had bacteremia as compared to two of 32 patients with VAP but without severe sepsis or septic shock $(\mathrm{P}=.01)$.

In patients developing both VAP and a clinical condition of severe sepsis or septic shock $(\mathrm{n}=10)$, levels of IL-6 on D0 tended to be higher (median $1.27 \mathrm{ng} / \mathrm{mL}$ ) than those obtained from the corresponding controls $(\mathrm{n}=10$; median $0.15 \mathrm{ng} / \mathrm{mL}, \mathrm{P}=.06)$ (Fig. 4). 
Interestingly, at D+2 median IL-6 levels were $3.0 \mathrm{ng} / \mathrm{mL}$ for cases and $0.21 \mathrm{ng} / \mathrm{mL}$ for corresponding controls $(\mathrm{P}=.02)$. Moreover, the two patients with VAP with the highest IL-6 levels on D0 died before D+2.

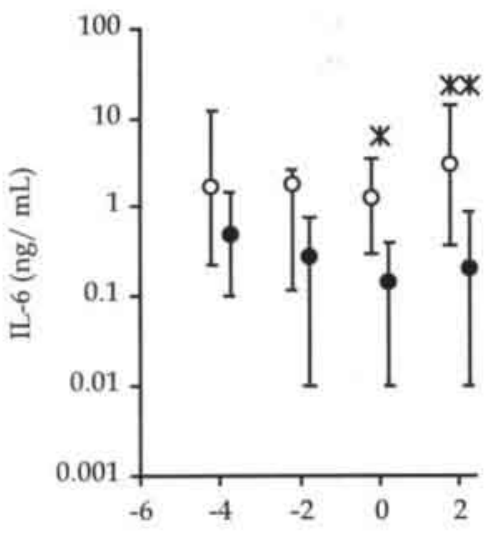

Figure 4: Interleukin-6 levels in cases with sepsis syndrome or septic shock (open circles, $n=10$ ) and the corresponding controls (closed circles, $n=10$ ); * $\mathrm{P}=06, * * \mathrm{P}=.02$.

Day relative to diagnosis

For cases developing severe sepsis or septic shock, the median difference between the levels of IL- 6 in samples at D+2 and D-4 was $1.3 \mathrm{ng} / \mathrm{mL}$ as compared to $-0.31 \mathrm{ng} /$ $\mathrm{mL}$ for control patients $(\mathrm{P}=.03)$. No significant differences in IL-6 levels were found between cases who did not develop severe sepsis or septic shock and their corresponding controls.

Comparable observations were made for IL-8. Levels at D+2 were $0.23 \mathrm{ng} / \mathrm{mL}$ for cases with severe sepsis or septic shock and $0.02 \mathrm{ng} / \mathrm{mL}$ for the corresponding controls $(\mathrm{P}=.07)$ (Fig. 5). The differences in median IL-8 levels between the first (D-4) and the last sample $(\mathrm{D}+2)$ were $0.11 \mathrm{ng} / \mathrm{mL}$ for cases and $-0.07 \mathrm{ng} / \mathrm{mL}$ for control patients $(\mathrm{P}=.09)$.

\section{VAP, interleukin-6, interleukin-8 and mortality}

Ten days after D0, 9 cases (21\%) and 11 control patients (26\%) had succumbed (ns). On day 28 after matching 14 cases (33\%) and 13 controls (31\%) (ns) had died. In patients developing VAP with severe sepsis or septic shock $(n=10)$ the mortality rate at day 28 was $60 \%$, as compared to $20 \%$ in their corresponding controls $(n=10)(P=.06)$. The SAPS II scores at D-2 for both patient groups were 42 (range 26-57) and 38 (range 14-53) respectively $(\mathrm{P}=\mathrm{ns})$. The mortality rate was $25 \%$ for patients developing VAP without sepsis syndrome or septic shock $(n=32)$ and $34 \%$ in their corresponding controls $(n=32)$ $(\mathrm{P}=\mathrm{ns}$ ) (Fig. 5). The SAPS II scores at D-2 of these patients were 36 (range 17-64) and 38 (range 14-86) respectively $(\mathrm{P}=\mathrm{ns})$. The mortality rates for cases with VAP caused by $\mathrm{P}$. 
aeruginosa were $27 \%$ at day 10 after matching and $38 \%$ at day 28 , and $31 \%$ and $38 \%$ on these time points for the corresponding controls respectively (ns).

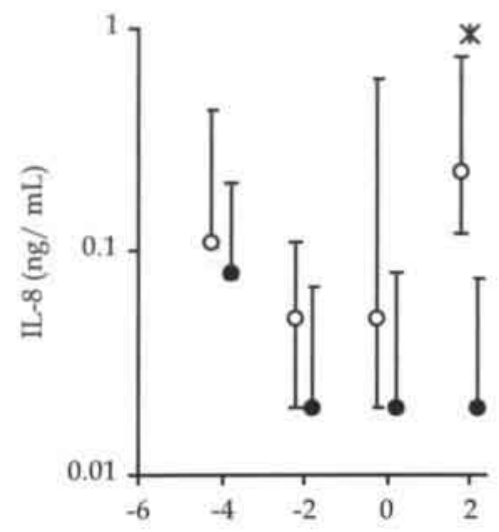

Day relative to diagnosis
Figure 5: Interleukin-8 levels in cases with sepsis syndrome or septic shock (open circles, $\mathrm{n}=10$ ) and the corresponding controls (closed circles, $n=10$ ); * $\mathrm{P}=07$.

For those patients who succumbed within ten days of matching, the median of last IL-6 levels measured was $0.45 \mathrm{ng} / \mathrm{mL}$ as compared to $0.18 \mathrm{ng} / \mathrm{mL}$ for surviving patients $(\mathrm{P}=.009)$. For $\mathrm{IL}-8$, the last levels were $0.09 \mathrm{ng} / \mathrm{mL}$ and $0.02 \mathrm{ng} / \mathrm{mL}$ respectively $(\mathrm{P}=.0007)$. At day $28,4(27 \%)$ of the 15 patients with polymicrobial VAP had died as compared to $10(37 \%)$ of 27 patients with monobacterial VAP (ns). In addition, no significant differences in mortality were found between patients with polymicrobial VAP and their matched controls.

\section{DISCUSSION}

The results of this study suggest that the clinical picture of VAP, when diagnosed by our best possible means, is heterogenous: On the one hand it may present as a devastating infection accompanied by severe sepsis or septic shock, with an increased systemic inflammatory response, elevated circulating levels of IL-6 and IL-8, and an increased mortality rate. On the other hand, patients diagnosed as having VAP may have a rather uncomplicated disease, without an increase in inflammatory response or mortality. Whether this difference is due to limitations of the methods that are currently used to diagnose VAP remains to be established.

This is the first study in which patients developing VAP are studied prospectively and prior to the moment of diagnosis, using levels of circulating IL-6 and IL-8 as marker of inflammatory activity before and after establishing the diagnosis. The ranges 
of levels of IL-6 and IL-8 as determined in the present study are comparable to those reported by others in patients with sepsis (9), sepsis syndrome (5), septic shock (20), and pneumonia and the adult respiratory distress syndrome (ARDS) (8). Both elevated circulating levels of IL-6 and IL-8 were associated with an increased mortality rate, thereby confirming observations that have been reported previously by others $(5,7,9$, 20). In addition, patients with an episode of VAP accompanied by severe sepsis or septic shock had persistently higher circulating levels of IL-6 and IL-8 as compared to matched control patients. This finding is compatible with findings from Meduri and coworkers, who also found that persistent elevation of cytokines after the diagnosis of ARDS predicted a poor outcome (6).

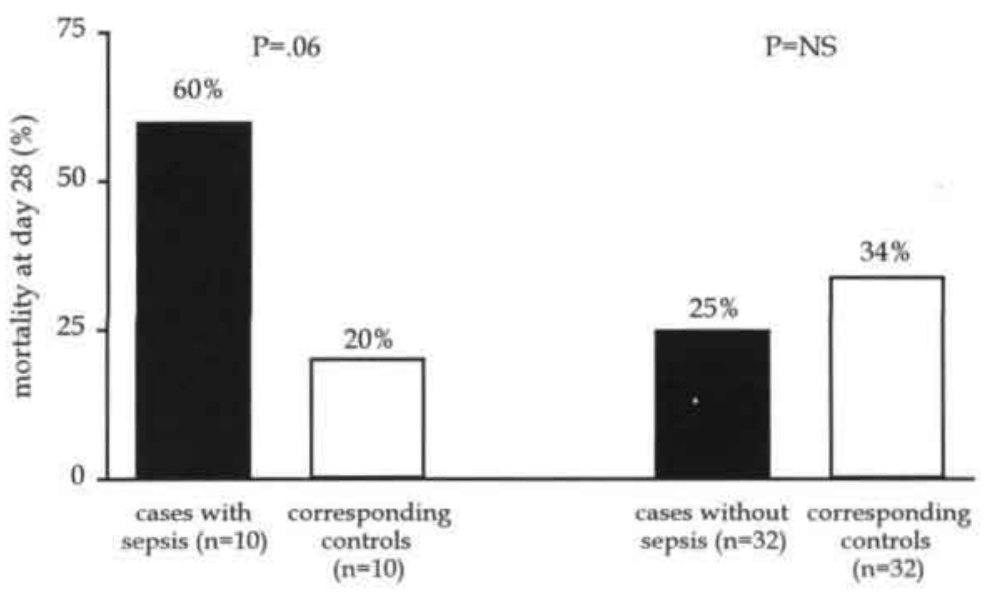

Figure 6: Mortality at day 28 in cases with sepsis syndrome or septic shock and their corresponding controls $(\mathrm{P}=06)$, and in cases without sepsis syndrome or septic shock and their corresponding controls.

The development of uncomplicated VAP was not associated with increased levels of circulating IL-6 or IL-8. This observation emphasizes some aspects in the pathogenesis of VAP and the limitations of the diagnostic tests yet available. Quantitative cultures of samples obtained by bronchoscopy are believed to provide a yes or no answer to the question whether a patient has VAP, but the microbiological results of these diagnostic procedures may not be related to the severity of the clinical condition. Therefore, with regard to the treatment of critically ill patients suspected of having VAP two important questions emerge: are the results from the diagnostic procedures accurate, and, if positive, is there an association between these results and the severity of pneumonia?

Based on the absence of an increased inflammatory response in a large proportion of patients with VAP, one may question whether all patients really suffered an episode 
of infection, even though the number of bacteria isolated from samples obtained by BAL and/ or PSB reached the generally accepted cutoff points for VAP (21). These cutoff points reflect the presence of $>10 \mathrm{E} 4 \mathrm{cfu} / \mathrm{g}$ at the site of infection, the estimated bacterial burden that has been associated with histologic pneumonia (21). The occurrence of false-positive culture results from samples obtained by bronchoscopy in patients that were not suspected of having VAP has been determined recently $(22,23)$. Among 27 patients, of whom 23 were receiving antibiotics, Torres et all found a specificity for BAL (cutoff $10 \mathrm{E} 4 \mathrm{cfu} / \mathrm{mL}$ ) of $65 \%$ and for PSB (cutoff $10 \mathrm{E} 3 \mathrm{cfu} / \mathrm{mL}$ ) of $59 \%$. Six patients died, $4 \pm 2$ days after study sampling, and histopathological examination of the lungs showed no signs of pneumonia (22). De Castro and coworkers studied 32 ventilated patients that did not receive antibiotics for $>5$ days. They found higher specificities: $82 \%$ for BAL (cutoff $10 \mathrm{E} 5 \mathrm{cfu} / \mathrm{mL}$ ) and $82 \%$ for PSB (cutoff $10 \mathrm{E} 3$ $\mathrm{cfu} / \mathrm{mL}$ ). Moreover, four of the six patients with false-positive culture results developed pneumonia on subsequent follow-up (23).

It is unknown to what extent circulating levels of cytokines correspond either to the histological severity of the infection or to the bacterial burden of infection in the lung. The data on associations between these phenomena are full of contradictory evidence. Some data suggest a poor correlation between the severity of a localized or compartmentalized infection and the systemic inflammatory response. In animal studies, pyelonephritis and peritonitis caused by Escherichia coli were associated with local cytokine production, without elevation of cytokines in serum $(24,25)$. Consistent with these findings, high levels of IL- 6 and IL- 8 were found in samples obtained by bronchoalveolar lavage at the site of infection in unilateral community-acquired pneumonia, whereas much lower levels were found in serum and in the contralateral, non-affected, lung $(26,27)$. In contrast, high circulating levels of IL-8 have been demonstrated in patients with community-acquired pneumonia caused by Streptococcus pneumoniae (28), an infection that is usually compartmentalized (26). Because several studies demonstrated that VAP was not limited to a single lobe or segment (29-31), it seems unlikely that VAP should be regarded as a compartmentalized infection.

To the best of our knowledge, the present study is the first one in which the bacterial burden of the lung, although not obtained by autopsy but by bronchoscopy, and the systemic inflammatory response could be compared. We did not find significant associations between these phenomena, which may suggest that the local infection in the lung is not reflected by the systemic inflammatory response or that cultures from BAL and PSB do not correlate with the severity of infection. However, it is obvious that more studies are needed to determine whether the intensity of local infection corresponds to the inflammatory response and the clinical severity of VAP.

With regard to the pathogenesis of VAP, the results of the present study suggest the occurrence of several overlapping clinical stages ranging from colonization of the respiratory tract to pneumonia accompanied by septic shock and resulting in death. In previous studies we found that approximately $60 \%$ of long-term mechanically 
ventilated patients are colonized in their respiratory tract with potential pathogenic microorganisms (32). About $40 \%$ of these colonized patients eventually develop VAP and preceding colonization of the upper respiratory tract was the most important risk factor for this infection (4). The questions, of course, are, which colonized patients will develop VAP and which of them will develop septic shock or will die. Although bacteremia was highly associated with a severe clinical presentation of VAP, it has, of course, no predictive value for colonized patients. A decreased host defense may facilitate the development from colonization to fulminate infection. However, more studies are needed to address this issue.

The absence of an exaggerated inflammatory response in combination with a mortality rate comparable to that of matched controls, which was found in many patients developing VAP, suggests that the underlying illness rather than the development of VAP is the major determinant of outcome. Our findings with regard to mortality may have been influenced by the exclusion of 16 patients with VAP from the case-control analysis. Thirteen of them were excluded because no suitable control could be found. Although the mortality rate of these 16 patients was $27 \%$, similar to the population under study, one may feel that their exclusion decreases the validity of the overall results. On the other hand, in doing so, successful matching for each variable was at least $90 \%$.

The fact that mortality due to VAP in the entire patient population was not increased, confirms some $(4,12,13)$, but not all observations reported in the literature (33-35). Fagon and coworkers described an attributable mortality of $27 \%$ and a risk ratio for death of 2.0 for patients developing VAP, and the risk ratio even increased to 2.5 when VAP was caused by Pseudomonas aeruginosa or Acinetobacter species (33). Despite a similar study population and comparable methods used for the diagnosis of VAP, several differences between that study and the present one are apparent. The total mortality rate among patients with VAP 28 days after matching in the present study was $33 \%$, as compared to $54 \%$ in Fagon's study, whereas the mortality rates among control patients were $31 \%$ in the present study and $27 \%$ in Fagon's study. Rello and coworkers found an attributable mortality of $13.5 \%$ for ventilated patients developing VAP due to P. aeruginosa (36). In that study, $42.3 \%$ of patients with VAP died and $28.8 \%$ of the matched controls (36). With comparable mortality rates for controls, the differences between the present study and the studies from Fagon and Rello evidently are caused by different mortality rates of patients with VAP. This may be explained, in part, by the different criteria used in the matching procedure. Interestingly, we found a mortality rate of $60 \%$ in the subgroup of patients in whom VAP was complicated by severe sepsis or septic shock, which was higher than the mortality rate among their matched controls. These data suggest that attributable mortality due to VAP and differences in mortality due to institution of preventive measures for VAP may depend on the selection of patients.

In conclusion, the results of this study demonstrate that in most patients the development of VAP was not associated with a rise in circulating levels of IL-6, IL-8 or 
increased mortality. However, to what extent the systemic inflammatory response is related to the bacterial burden of VAP or to the histopathological severity of infection remains to be established. Among patients in whom VAP was not associated with a clinical condition of severe sepsis or septic shock, mortality seemed to be influenced primarily by the severity of the underlying illness. On the contrary, VAP with a clinical presentation of severe sepsis and septic shock was accompanied by increased levels of IL-6 and IL-8 and a higher mortality rate. Further studies are needed to specifically characterize this subgroup of patients. 


\section{REFERENCES}

1. Emori TG, Gaynes RP. An overview of nosocomial infections, including the role of the microbiology laboratory. Clin Microbiol Rev 1993;6:428-42

2. Johanson WG, Pierce AK, Sanford JP. Nosocomial respiratory infections with Gram-negative bacilli: the significance of colonization of the respiratory tract. Ann Intern Med 1992;77:701-6

3. Bonten MJM, Gaillard CA, Van Tiel FH, et al. The stomach is not a source for colonization of the upper respiratory tract and pneumonia in ICU patients. Chest 1994;105:878-84

4. Bonten MJM, Bergmans DCJ, Ambergen AW, et al. Risk factors for pneumonia, and colonization of respiratory tract and stomach in mechanically ventilated ICU patients. Am J Respir Crit Care Med 1996;154:1339-46

5. Casey LC, Balk RA, Bone RC. Plasma cytokine and endotoxin levels correlate with survival in patients with the sepsis syndrome, Ann Intern Med 1993;119:771-8

6. Meduri GU, Headley S, Kohler G, et al. Persistent elevation of inflammatory cytokines predicts a poor outcome in ARDS. Chest 1995;107:1062-73

7. Hack CE, De Groot ER, Felt-Bersma RJF, et al. Increased plasma levels of interleukin-6 in sepsis. Blood 1989;74:1704-10

8. Chollet-Martin S, Montravers P, Gibert C, et al. High levels of interleukin- 8 in the blood and alveolar spaces of patients with pneumonia and adult respiratory distress syndrome. Infect Immun 1993;61:4553-9

9. Hack CE, Hart M, Strack van Schijndel RJM, et al. tumor necrosis factorkin-8 in sepsis: relation to shock and inflammatory mediators. Infect Immun 1992;60:2835-42

10. Colditz I, Zwahlen R, Dewald B, et al. In vivo inflammatory activity of neutrophIL-activating factor, a novel chemotactic peptide derived from human monocytes. Am J Pathol 1989;134:755-60.

11. Collins PD, Jose PJ, Williams TJ. The sequential generation of neutrophil chemoattractant proteins in acute inflammation in the rabbit in vivo: relationship between $\mathrm{C} 5 \mathrm{a}$ and proteins with the characteristics of IL-8/ neutrophIL-activating protein 1. J Immunol 1991;146:677-84

12. Craven DE, Kunches LM, Kilinsky V, et al, Risk factors for pneumonia and fatality in patients receiving continuous mechanical ventilation. Am Rev Respir Dis 1986;133:792-6

13. Torres A, Aznar R, Gatell JM, et al. Incidence, risk, and prognosis factors of nosocomial pneumonia in mechanically ventilated patients. Am Rev Respir Dis 1990;142:523-8

14. Knaus WA, Draper EA, Wagner DP, et al. APACHE II: a severity of disease classification system. Crit Care Med 1985;13:818-29

15. De, AK, Kodys K, Puyana JC, et al. Elevated IL-8 production by trauma patients monocytes is associated with elevated secretion of TNF-alpha. Shock 1995;4:171-7

16. Baigrie RJ, Lamont PL, Kwiatkowski D, et al. Systemic cytokine response after major surgery. Brit J Surg 1992; 79:757-60

17. Roumen RMH, Hendriks T, Van de Ven-Jongekrijg J, et al. Cytokine patterns in patients after major vascular surgery, hemorrhagic shock, and severe blunt trauma. Ann Surg 1993;218:769-76

18. American College of Chest Physicians, and Society of Critical Care Medicine. Consensus Conference: definitions for sepsis and organ failure and guidelines for the use of innovative therapies in sepsis. Crit Care Med 1992;20:864-74

19. Le Gall J, Lemeshow S, Saulnier F. A new simplified acute physiology score (SAPS II) based on a European/ North American multicenter study. J Am Med Assoc 1993;270:2957-63

20. Calandra T, Gerain J, Heumann D, et al. High circulating levels of interleukin-6 in patients with septic shock: evolution during sepsis, prognostic value, and interplay with other cytokines. Am J Med 1991;91:23-9

21. Pingleton SK, Fagon JY, Leeper Jr KV. Patient selection for clinical investigation of ventilatorassociated pneumonia: criteria for evaluating diagnostic techniques. Chest 1992;102:S553-6 
22. Torres A, Martos A, Puig de la Bellacasa J, et al Specificity of endotracheal aspiration, protected specimen brush, and bronchoalveolar lavage in mechanically ventilated patients. Am Rev Respir Dis 1993;147:952-7

23. Rodríguez de Castro F, Solé J, Elcuaz R. Quantitative cultures of protected brush specimens and bronchoalveolar lavage in ventilated patients without suspected pneumonia. Am J Respir Crit Care Med 1994;149:320-3

24. Rugo HS, O'Hanley P, Bishop AG, et al. Local cytokine production in a murine model of Escherichia coli pyelonephritis J Clin Invest 1992;89:1032-9

25 Bagby GJ, Plessala KJ, Wilson LA, et al. Divergent efficacy of antibody to tumor necrosis factoralpha in intravascular and peritonitis models of sepsis. J Infect Dis 1991;163:83-8

26. Boutten A, Dehoux MS, Seta N, et al. Compartmentalized $\mathrm{IL}-8$ and elastase release within the human lung in unilateral pneumonia. Am J Respir Crit Care Med 1996;153:336-42

27. Dehoux MS, Boutten A, Ostinelli J, et al. Compartmentalized cytokine production within the human lung in unilateral pneumonia. Am J Respir Crit Care Med 1994;150:710-6

28. Kragsbjerg P, Jones I, Vikerfors T, et al. Diagnostic value of blood cytokine concentrations in acute pneumonia. Thorax 1995;50:1253-7

29. Chastre J, Fagon JY, Bornet-Lecso M, et al. Evaluation of bronchoscopic techniques for the diagnosis of nosocomial pneumonia. Am J Respir Crit Care Med 1995;152:231-40

30. Rouby JJ, Martin de Lassale E, Poete P, et al. Nosocomial bronchopneumonia in the critically ill: histologic and bacteriologic aspects. Am Rev Respir Dis 1992;146:1059-66

31. Papazian L, Thomas P, Garbe L, et al. Bronchoscopic or blind sampling techniques for the diagnosis of ventilator-associated pneumonia. Am J Respir Crit Care Med 1995;152:1982-91

32. Bonten MJM, Gaillard CA, Van der Geest S, et al. The role of intragastric acidity and stress ulcer prophylaxis on colonization and infection in mechanically ventilated patients. A stratified, randomized, double blind study of sucralfate versus antacids. Am J Respir Crit Care Med 1995;152:1825-34

33. Fagon JY, Chastre J, Hance AJ, et al. Nosocomial pneumonia in ventilated patients: a cohort study evaluating attributable mortality and hospital stay. Am J Med 1993;94:281-8

34. Leu HS, Kaiser DL, Mori M, et al. Hospital-acquired pneumonia: attributable mortality and morbidity. Am J Epidemiol 1989;129:1258-67

35. Gross PA, Van Antwerpen C. Nosocomial infections and hospital deaths. A case-control study. Am J Med 1983;75:658-62

36. Rello J, Jubert P, Valles J, et al. Evaluation of outcome for intubated patients with pneumonia due to Pseudomonas aeruginosa. Clin Infect Dis 1996;23:973-8 
PREDICTION OF CLINICAL SEVERITY AND OUTCOME OF VENTILATORASSOCIATED PNEUMONIA

Comparison of simplified acute physiology score with systemic inflammatory mediators

A.H.M. Froon, M.J.M. Bonten, C.A. Gaillard, J.W.M. Greve, M.A. Dentener, P.W. de Leeuw, M. Drent, E.E. Stobberingh, W.A. Buurman

Am J Resp Crit Care Med 1998; 158:1026-31 


\section{SUMMARY}

Systemic kinetics of three inflammatory mediators (BPI, sICAM and sE-selectin) were studied during the development of Ventilator-Associated Pneumonia (VAP) $(n=42)$, diagnosed on quantitative cultures of bronchoscopic samples. From a pool of collected samples, nested samples were used to measure mediators on days $-4,-2,0$ and +2 , relative to diagnosis. Correlations between systemic levels of mediators and clinical severity of infection (VAP with or without severe sepsis or septic shock) and patient outcome (mortality at day 10 after diagnosis) were studied. Predictive values of inflammatory mediators were compared to daily SAPS II scores and the logarithmic number of bacteria in bronchoscopic samples. During the development of VAP, increasing SAPS II scores and rising systemic mediator levels were only found in patients in whom VAP was accompanied with severe sepsis or septic shock. Values of SAPS II and plasma levels of BPI and sE-selectin, but not sICAM, increased from the day of diagnosis on in patients that died within 10 days of diagnosis. Systemic levels of inflammatory mediators did not better predict clinical severity or patient outcome than daily SAPS II scores. The logarithmic number of bacteria in bronchoscopic samples poorly correlated with circulating levels of inflammatory mediators, severity of infection, and patient outcome. Our findings show that a clinical scoring system (SAPS II score) is at least as good as a predictor for the clinical severity of infection and patient outcome, and provide new information on the kinetics of inflammatory mediators during the development of VAP. 


\section{INTRODUCTION}

Ventilator-associated pneumonia (VAP) is a frequently occurring infection among critically ill patients. Even when the diagnosis of VAP is based on quantitative culture results from bronchoscopic techniques, the clinical presentation of infection may range from a devastating illness with irreversible septic shock to mild and almost unnoticed (1).

The inflammatory response of the host during the development of VAP has not been studied extensively. The roles of systemic and localized inflammatory responses in the pathophysiology have not been elucidated, and it is unknown to what extent systemic levels of cytokines or inflammatory mediators predict the clinical severity of infection and patient outcome, and how they correlate with values of a clinical scoring system of illness.

In a previous case-control study of patients with and without VAP, only patients with VAP accompanied with a clinical presentation of severe sepsis or septic shock had elevated circulating levels of the cytokines interleukin-6 (IL-6) and interleukin-8 (IL-8) and an increased mortality rate at day 10 after diagnosis (1). However, within individual patients the development of VAP was not associated with increasing levels of these cytokines and no correlation was found between the yield of quantitative culture results from bronchoscopic samples (bronchoscopic bacterial burden) and plasma levels IL-6 or IL-8 (1).

The primary aim of the present study was to determine whether systemic levels of three mediators, representing different parts of the inflammatory response to infection, correlated with clinical assessments of severity of illness and if they predicted the outcome of these patients. The severity of illness of patients with VAP was assessed on a daily SAPS II scores (2), and on the logarithmic number of bacteria isolated from bronchoscopic samples.

Additional aims of this study were to further determine the inflammatory response of critically ill patients during the development of VAP. Therefore, three parts of the inflammatory process were studied: bactericidal/ permeability-increasing protein (BPI), soluble intercellular adhesion molecule (sICAM) and soluble E-selectin (sE-selectin). BPI is released by activated or killed neutrophils and circulating levels represent a measure of activation and/ or killing of these cells $(3,4)$. ICAM is present on the surface of almost all cells and increased circulating levels of sICAM indicate the presence (and level) of inflammation (5-7). sE-selectin is only expressed on activated endothelial cells and is released by activation of these cells. Circulating levels, therefore, represent endothelial activation (5). Increased circulating levels of each of these inflammatory mediators have been associated with the presence of severe sepsis or septic shock in critically ill patients $(6,8-10)$. 


\section{MATERIAL AND METHODS}

\section{Study population}

The study was conducted at the intensive care unit (ICU) of the University Hospital, Maastricht, The Netherlands. The ICU is a 16-bed ward with a mixture of patients from the departments of surgery, internal medicine, traumatology, pulmonology, neurology, and neurosurgery. The 42 patients included in the present study have been studied previously in a matched-cohort analysis, and extensive clinical and microbiological characteristics of these patients have been reported (1).

\section{Definition of ventilator-associated pneumonia}

VAP was considered ICU acquired if a clinical condition fulfilling the criteria for pneumonia developed after the patient was in the ICU for at least 3 days. In case of a clinical suspicion of pneumonia, bronchoscopy with bronchoalveolar lavage (BAL) and protected specimen brush (PSB) were performed as described previously (11). The diagnosis VAP was established with either a positive quantitative culture of samples obtained by BAL (cutoff point $10 \mathrm{E} 4 \mathrm{cfu} / \mathrm{mL}$ ) or PSB (cutoff point $10 \mathrm{E} 3 \mathrm{cfu} / \mathrm{mL}$ ); a new or persistent infiltrate on chest radiograph; and when at least three of the following four criteria were met: (1) rectal temperature $>38.0^{\circ} \mathrm{C}$ or $<35.5^{\circ} \mathrm{C}$; (2) blood leukocytosis $\left(>10 \times 10 \mathrm{E} 3 / \mathrm{mm}^{3}\right)$ and/ or left shift or blood leukopenia $\left(<3 \times 10 \mathrm{E} 3 / \mathrm{mm}^{3}\right)$; (3) >10 leukocytes per high-power field in Gram stain of tracheal aspirate; and (4) a positive culture from tracheal aspirate. The logarithmic number of bacteria present in quantitatively cultured samples obtained by BAL was defined as the 'bronchoscopic bacterial burden'.

\section{Study design}

Plasma samples of all patients treated in the ICU from January 1, 1992 until January 1, 1994 were prospectively collected and frozen at $-70^{\circ} \mathrm{C}$ until use. From this pool, a nested group of patients was selected and their samples were used for analyses. Circulating levels of BPI, sICAM and sE-selectin were measured in samples obtained at the day of diagnosis of VAP (D0), four days (D-4) and two days (D-2) before diagnosis, and two days after diagnosis $(\mathrm{D}+2)$. In addition, the changes in circulating levels of these cytokines between D-4 and D+2, and between D0 and D+2 were determined. When blood samples were not available on D-4 $(n=5)$ the levels of D-2 were used to calculate the difference with levels on $\mathrm{D}+2$, and when samples were not available on $D+2(n=3)$ the levels of D0 were used. Patients with missing data at D+2 $(n=3)$ were excluded for the analysis of differences between levels of D0 and D+2. The Simplified Acute Physiology Score II (SAPS II) was calculated on each study day as described by Le Gall and coworkers (2). Furthermore, all patients were grouped on the presence or absence of severe sepsis or septic shock on the day that VAP was diagnosed, defined according to the criteria from the American College of Chest Physicians and the Society of Critical Care Medicine (12), and on survival of the first 10 days after VAP was 
diagnosed. The period of 10 days was chosen on the assumption that the infection contributed directly to death in these patients or that contribution of VAP to death of any other cause could not be excluded.

Four types of analyses were performed: (1) values of SAPS II scores and levels of circulating cytokines, and differences of these values between D+2 and D-4, were correlated to the clinical severity of VAP (i.e. the presence of severe sepsis or septic shock) and (2) to patient outcome (i.e. mortality at day 10); (3) correlations between the SAPS II score on D0 and the levels of circulating inflammatory mediators were determined; and (4) values of the bronchoscopic bacterial burden were correlated to SAPS II scores on D0 and to circulating levels of inflammatory mediators on D0.

\section{Reagents and immunoassays}

\section{Reagents and materials}

Human recombinant (r) BPI was kindly provided by M. Marra (InCyte, Palo Alto, CA). sICAM and sE-selectin standards were obtained by purification of supernatant produced by NSO cells that produce sICAM, and CHO cells that produce sE-selectin, respectively (kindly provided by M. Robinson, Celltech, Slough, UK).

A BPI specific and neutralizing monoclonal antibody (mAb) 4E3 (IgG1) was developed in our laboratory and described elsewhere (13). Polyclonal antibodies to human BPI were obtained by immunizing rabbits with human BPI.

For detection of ICAM-1, anti-ICAM-1 mAb HM2 and biotin labeled HM1 were used (14). Anti-E-selectin mAb ENA-1 and biotin labeled ENA-2 were used for measuring E-selectin (7). Peroxidase conjugated streptavidin was purchased from Dakopatts (Glostrup, Denmark), and TMB (3',5,5'-tetramethylbenzidine) substrate from KPL (Gaithersburg, MD). ELISA plates used were Nunc immunomaxisorp plates (Nunc, Roskilde, Denmark).

\section{Immunoassays}

Plasma BPI was measured using a sandwich ELISA as described elsewhere (15). In short, 96-well plates were coated with human BPI specific $\mathrm{mAb} 4 \mathrm{E} 3$ and free sites were blocked with PBS $1 \%$ BSA. Washing and dilution buffer used contained $80 \mathrm{mM} \mathrm{MgCl}$. The use of $\mathrm{Mg}^{++}$ions prevented disturbance by LPS of BPI measurement. Human rBPI was used for standard titration curve. Plasma samples diluted in assay buffer (at least 1:2) were incubated for $2 \mathrm{~h}$ at room temperature. Next, a biotinylated polyclonal rabbit anti-human BPI IgG was used followed by peroxidase labeled streptavidin. TMB was used as a substrate and photospectrometry $(450 \mathrm{~nm})$ was performed using a micro ELISA autoreader. Detection limit for the BPI was $200 \mathrm{pg} / \mathrm{mL}$.

Plasma E-selectin and sICAM-1 concentrations were measured using mAb ENA-1 and $\mathrm{mAb}$ HM2 as capture antibodies, respectively, in a procedure largely parallel to the BPI ELISA mentioned above. Plasma samples were diluted 1/ 20 and 1/ 10 for the sE-selectin and sICAM-1 ELISA, respectively. Samples and standard titration curves 
with sE-selectin and sICAM were added to the plates and subsequently incubated with biotinylated mAb ENA-2 or HM1 for detection of sE-selectin and sICAM, respectively. Substrate was added, and the optical density was read. All steps of the sE-selectin ELISA were done using a buffer containing calcium and magnesium. Detection limits for the sE-selectin and sICAM- 1 assays were $0.1 \mathrm{ng} / \mathrm{mL}$ and $0.4 \mathrm{ng} / \mathrm{mL}$, respectively.

All plasma samples were analyzed in the same run. When plasma levels exceeded the detection limit of the assay, samples were additionally diluted and analyzed in a separate run with an overlap to correct for inter-assay variation. The intra and interassay coefficient of variance of the various assays performed were all $<10 \%$.

\section{Statistical analysis}

Data are expressed as mean levels with standard deviations and ranges. Comparisons of median levels of BPI, sICAM and sE-selectin were performed using the MannWhitney U-test (MWU) for non-parametric values. Differences in parametric values were tested with Student's t-test. Categorical variables were compared by the Chisquare test. Correlations were tested by the Spearman rank test. In general, a P-value $<.05$ was deemed significant. When analyzing differences in circulating levels of mediators at four different time points the Bonferoni correction has been used and a Pvalue $<.0125$ was deemed statistical significant.

Table 1: SAPS II values and plasma levels of inflammatory mediators on days of study

\begin{tabular}{lccccc}
\hline $\begin{array}{l}\text { Day relative to } \\
\text { diagnosis of VAP }\end{array}$ & $\begin{array}{c}\text { SAPS II value } \\
(\text { mean } \pm \text { SD) }\end{array}$ & $\begin{array}{c}\text { Plasma samples } \\
\text { available }\end{array}$ & $\begin{array}{c}\text { BPI } \\
(\mathrm{ng} / \mathrm{mL})\end{array}$ & $\begin{array}{c}\text { sICAM } \\
(\mathrm{ng} / \mathrm{mL})\end{array}$ & $\begin{array}{c}\text { sE-selectin } \\
\text { (ng/ mL) }\end{array}$ \\
\hline day 4 & $39 \pm 11(19-66)$ & $36(85 \%)$ & $4.12 \pm 5.23$ & $224.2 \pm 220.0$ & $79.1 \pm 85.3$ \\
day -2 & $37 \pm 10(17-64)$ & $42(100 \%)$ & $3.00 \pm 3.12$ & $230.8 \pm 244.7$ & $71.0 \pm 62.3$ \\
day 0 & $43 \pm 18(20-102)$ & $42(100 \%)$ & $4.18 \pm 4.33$ & $252.0 \pm 270.7$ & $73.3 \pm 57.4$ \\
day +2 & $42 \pm 19(14-121)$ & $39(93 \%)$ & $3.76 \pm 4.12$ & $257.4 \pm 222.4$ & $74.3 \pm 53.4$ \\
\hline
\end{tabular}

Data are expressed as mean $\pm \mathrm{SD}$; ranges are displayed within parentheses unless stated otherwise

\section{RESULTS}

\section{Study population}

Forty-two patients who developed VAP were studied. The mean age was 59 years \pm 18 years (range 17 to 85 ) and the mean APACHE II score, as obtained on admission, was $21 \pm 7$ (range 7-36). The values of SAPS II scores and levels of circulating inflammatory mediators on each of the days of study are depicted in Table 1. Although values of SAPS II scores were highest on D0, no evident increase of inflammatory mediators was observed during the development of VAP. 

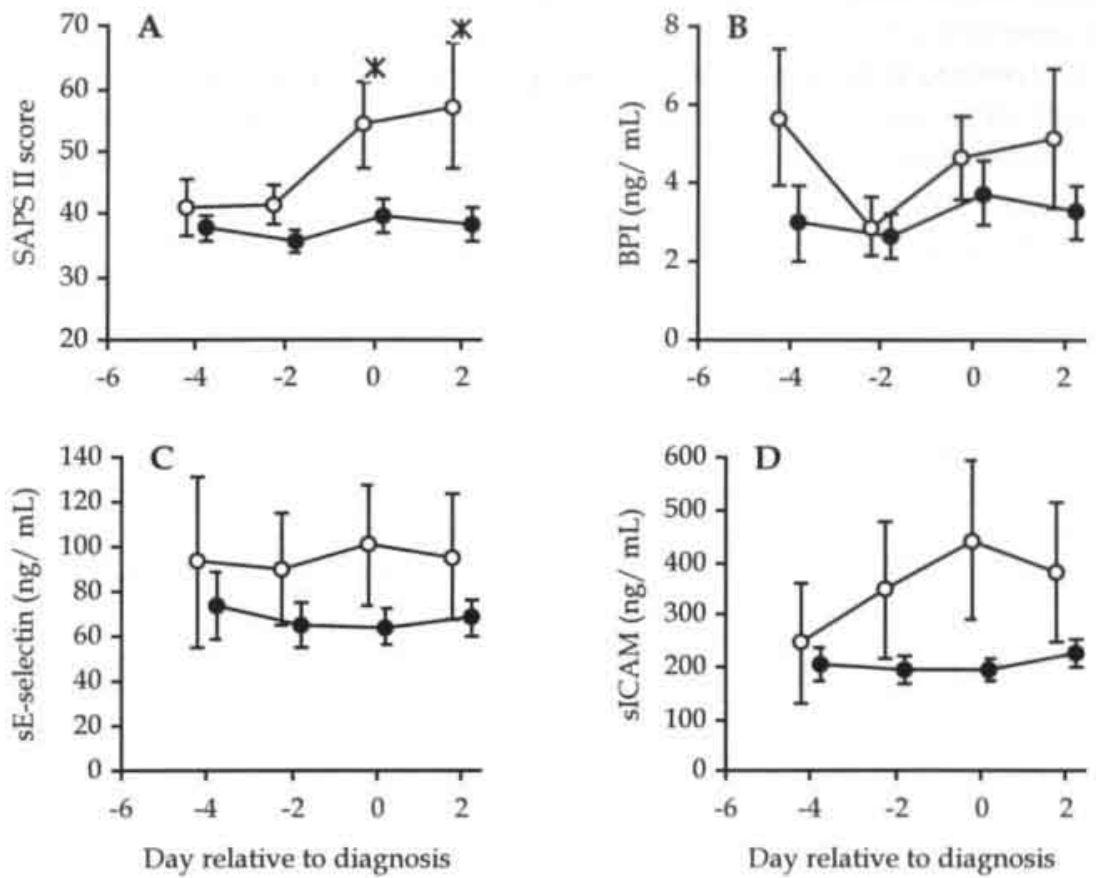

Figure 1: Mean SAPS II values and mean plasma levels of inflammatory mediators (with standard error) in patients with ventilator-associated pneumonia which was associated $(0)$ or was not associated ( $\bullet$ with severe sepsis or septic shock. The data are according to the day of diagnosis of ventilator-associated pneumonia (day 0). A SAPS II values. B Plasma levels of bactericidal/ permeability-increasing protein (BPI). C Plasma levels of soluble E-selectin. D Plasma levels of soluble intercellular adhesion molecule (sICAM-1). $Ж$ P $<.0125$.

VAP was diagnosed after $8 \pm 4$ days of mechanical ventilation. Fifteen patients had polymicrobial VAP, and Pseudomonas aeruginosa was isolated most frequently. VAP was monobacterial and caused by gram-positive microorganisms in only five patients (Staphylococcus aureus $(n=3)$ and Streptococcus pneumoniae $(n=2)$ ). Therefore, no comparisons were made between infections with gram-positive and gram-negative bacteria. The bacterial burden of infection ranged from 4 in 9 patients to 16 in one patient. Two patients fulfilled the criteria of severe sepsis at the day of diagnosis and eight $(19 \%)$ had septic shock. Mortality at day 10 was $9(21 \%)$ of 42 patients. 


\section{Correlations with the clinical severity of infection}

\section{SAPS II scores}

In 10 of 42 patients VAP was associated with a clinical presentation of severe sepsis or septic shock. The mean SAPS II scores on D-4 were similar for patients with severe sepsis or septic shock $(n=10)$ and the remaining patients $(n=32)$, but from D-2 on, mean SAPS II scores increased for patients who developed severe sepsis or septic shock, whereas SAPS II scores remained stable in the other patients (Fig. 1a).
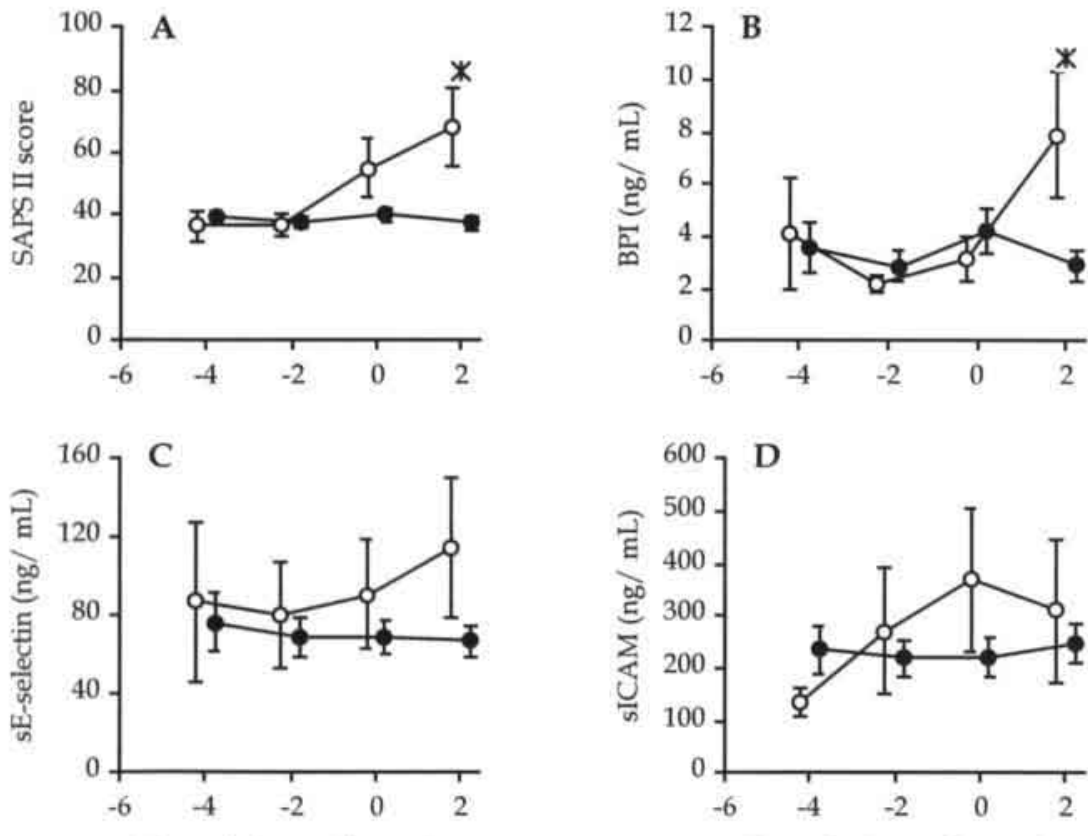

Day relative to diagnosis

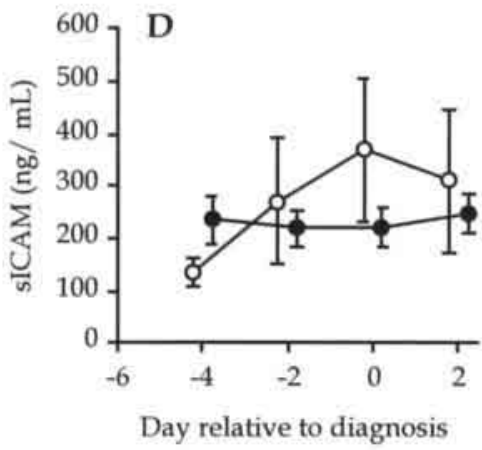

Figure 2: Mean SAPS II values and mean plasma levels of inflammatory mediators (with standard error) in patients who died $(0)$ or who survived $(\bullet)$ the first ten days after the diagnosis of ventilatorassociated pneumonia.The data are according to the day of diagnosis of ventilator-associated pneumonia (day 0). A SAPS II values. B Plasma levels of bactericidal/ permeability-increasing protein (BPI). C Plasma levels of soluble E-selectin. D Plasma levels of soluble intercellular adhesion molecule (sICAM-1). *P $<.0125$.

\section{Inflammatory mediators}

On the four days of study, BPI was detectable in $89-97 \%$ of plasma samples and sICAM and sE-selectin were detectable in all plasma samples. Circulating levels of BPI, sICAM and sE-selectin were higher for patients with a clinical presentation of severe sepsis or 
septic shock, although statistical significance was not reached (Figure 1b-d). Interestingly, differences in systemic levels of the inflammatory mediators between patients with and without severe sepsis or septic shock were not necessarily highest on D0, but levels tended to be higher in patients with severe sepsis or septic shock on all days of study.
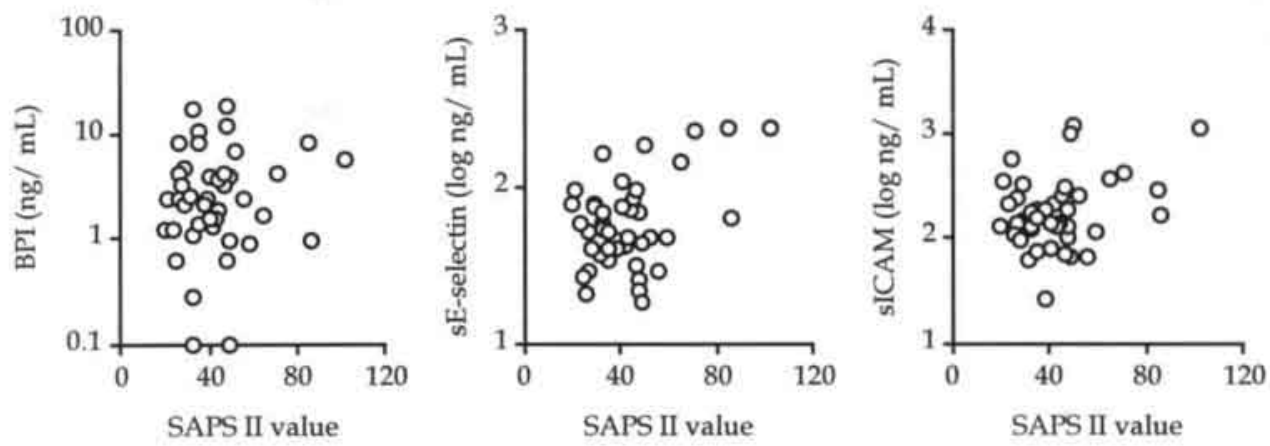

Figure 3: Correlations between the SAPS II values and the plasma levels of inflammatory mediators on the day of diagnosis of ventilator-associated pneumonia. A Plasma levels of bactericidal/ permeabilityincreasing protein (BPI), B Plasma levels of soluble E-selectin. C Plasma levels of soluble intercellular adhesion molecule (sICAM-1).

\section{Correlations with clinical outcome}

\section{SAPS II scores}

Before diagnosis of VAP, SAPS II scores were similar for patients that survived and that did not survive the first 10 days after diagnosis (Fig. 2a). From D0 on, patients that succumbed had higher SAPS II scores, although statistical significance was only approached on D0 ( $\mathrm{P}=.06, \mathrm{t}$-test). As a result, the mean differences in SAPS II scores between $D-4$ and $D+2$ were $-1 \pm 10$ (range -21 to 22 ) for patients that survived the first 10 days after VAP and $38 \pm 31$ (range 0-89) for those who died within this time period ( $\mathrm{P}=.0001$, Mann-Whitney U-test).

\section{Inflammatory mediators}

Circulating levels of BPI from D-4 to D0 were similar for patients that succumbed within 10 days of diagnosis and those who survived this period (Fig. 2b). However, levels of BPI on D+2 were $5.78 \mathrm{ng} / \mathrm{mL}$ in patients who died within 10 days of diagnosis as compared to $1.65 \mathrm{ng} / \mathrm{mL}$ in survivors ( $\mathrm{P}=.01$, Mann-Whitney U-test). The differences in BPI levels between D0 and D+2 were $3.22 \mathrm{ng} / \mathrm{mL}$ and $-0.39 \mathrm{ng} / \mathrm{mL}$ for succumbing and surviving patients respectively ( $\mathrm{P}=.0003$, Mann-Whitney U-test). An increase in circulating levels of BPI after the diagnosis of VAP was found in all $(100 \%)$ 
patients who died within ten days of diagnosis and from whom plasma samples were available $(n=6)$, but in only $11(33 \%)$ of 33 patients who survived $(P=.0007$, Chi-square test).

There were no significant differences between levels of sICAM on any of the four days of study for patients dying within or surviving the first 10 days after diagnosis of VAP, and for both groups, circulating levels of sE-selectin were similar on the first three days of study (Fig. 2c and 2d). However, circulating levels of sE-selectin at D+2 were $114.3 \pm 87.5 \mathrm{ng} / \mathrm{mL}$ and $67.0 \pm 42.8 \mathrm{ng} / \mathrm{mL}(\mathrm{P}=.04)$ for patients that died within 10 days of VAP and that survived, respectively. The differences in sE-selectin levels between $\mathrm{D} 0$ and $\mathrm{D}+2$ were $67.2 \mathrm{ng} / \mathrm{mL}$ and $-1.64 \mathrm{ng} / \mathrm{mL}$ for succumbing and surviving patients respectively $(\mathrm{P}=.06$, Mann-Whitney $\mathrm{U}$-test).

\section{Correlations between SAPS II scores and inflammatory mediators}

Poor correlations were found between the values of the SAPS II scores on D0 and circulating levels of BPI $(r=0.08, P=.59)$, $\operatorname{ICAM}(r=0.16, P=.30)$ and sE-selectin $(r=0.18$, $\mathrm{P}=.25$ ) on D0 (Fig. 3a-c).

\section{The bronchoscopic bacterial burden of infection}

Mean levels of the bronchoscopic bacterial burden (expressed as the logarithmic number of bacteria isolated from samples of BAL) were comparable for patients with and without severe sepsis or septic shock (6.7 \pm 2.4 and $7.4 \pm 3.5$, respectively), and for patients surviving and not-surviving the first ten days after diagnosis of VAP $(7.6 \pm 3.4$ and $5.2 \pm 1.3$, respectively). Correlations between the bronchoscopic bacterial burden of infection and any of the circulating inflammatory mediators on D0 as well as the SAPS II scores on D0 were poor: $\mathrm{r}=0.17(\mathrm{P}=.32)$ for the SAPS II scores; $\mathrm{r}=0.16(\mathrm{P}=.35)$ for BPI; $\mathrm{r}=-0.24(\mathrm{P}=.16)$ for sICAM; and $\mathrm{r}=0.3(\mathrm{P}=.85)$ for sE-selectin (Fig. 4a-b).

\section{DISCUSSION}

The present study shows, in a mixed population of critically ill patients with bronchoscopically established diagnoses of VAP, three aspects about interactions between systemic inflammatory mediators, clinical presentation of infection and prediction of outcome. The first and most important finding is that the SAPS II scoring system on the day of diagnosis correlated at least as good with the clinical severity of infection or 10-day mortality than plasma levels of inflammatory mediators. Second, the development of VAP is accompanied by increased SAPS II values and a tendency of higher levels of BPI, sICAM and sE-selectin only when there is a clinical presentation of severe sepsis or septic shock. When VAP is not complicated by this presentation, which applies for the majority of cases, levels of inflammatory mediators and SAPS II scores remain stable. Third, patients that succumb within ten days after the diagnosis of VAP have rising values of SAPS II scores and rising systemic levels of BPI, and sE- 
selectin, but not sICAM, from the day of diagnosis on. Again, stable levels were found for patients that survived the first ten days after diagnosis of VAP.

A

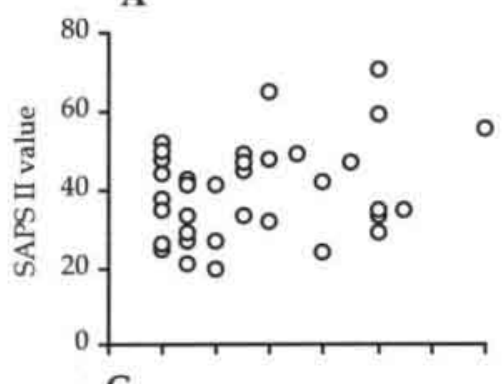

C

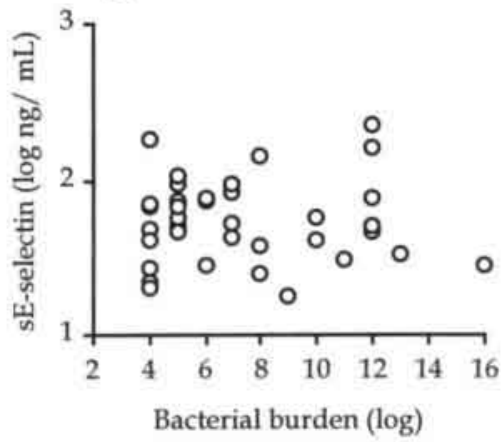

B

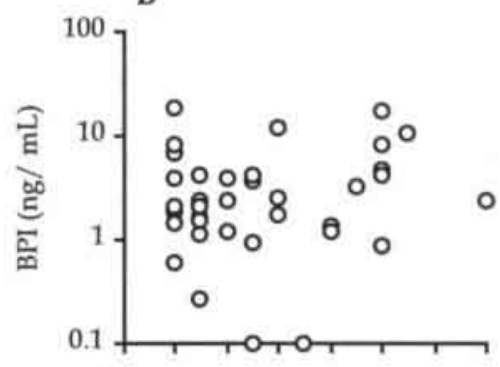

D

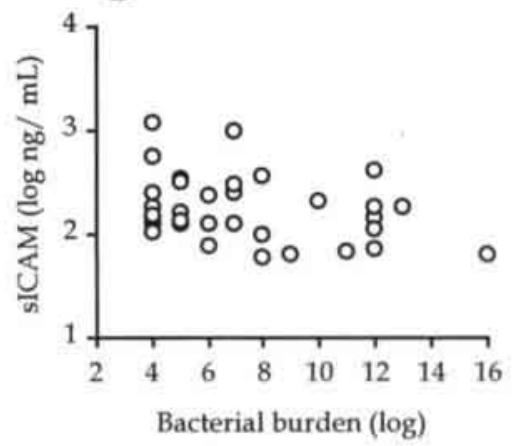

Figure 4: Correlations between the logarithmic number of bacteria per $\mathrm{mL}$ in samples of bronchoalveolar lavage and SAPS II values and plasma levels of inflammatory mediators on the day of diagnosis of ventilator-associated pneumonia. A SAPS II values. B Plasma levels of bactericidal/ permeabilityincreasing protein (BPI). C Plasma levels of soluble E-selectin. D Plasma levels of soluble intercellular adhesion molecule (sICAM).

We found that the SAPS II score on the day of diagnosis of VAP was at least as good a predictor of the clinical severity of infection and the prognosis of the patient, as were circulating levels of BPI, sICAM and sE-selectin. A simple bedside scoring system, therefore, seems to reflect the clinical severity of infection better than sophisticated measurements of the systemic inflammatory response. SAPS II scores can easily and rapidly be calculated on the patient's bed-side, and this method, obviously, has many advantages over the time-consuming, labour-intensive and expensive procedures to determine circulating levels of inflammatory mediators. In the present study the SAPS II score was used as a clinical severity scoring system, but other scoring systems such as the daily calculation of the APACHE II or APACHE III (16) score, or the Mortality Probability Model (17), may prove to be useful as well. Whether 
circulating levels of other inflammatory mediators or cytokines correlate better with clinical severity of VAP and outcome of patients remains to be established. Friedland and coworkers found that circulating levels of TNF-alpha, IL-1 beta, IL- 6 and IL- 8 poorly correlated with the clinical severity of illness of ICU patients, and only the presence of TNF-alpha in plasma was an independent predictor of mortality (18). In contrast, relationships between elevated levels of cytokines and both a clinical condition of severe sepsis or septic shock and mortality have been demonstrated repeatedly $(1,19)$.

The kinetics of BPI, sICAM and sE-selectin during the development of VAP resemble those of IL- 6 and IL-8, supporting the idea that VAP, even when diagnosed with bronchoscopic techniques, is not associated with increasing levels of systemic inflammatory mediators in patients that do not have severe sepsis or septic shock. Furthermore, our data provide new information on the kinetics of systemic inflammatory mediators in a feared nosocomial infection in critically ill patients.

Bactericidal permeability-increasing protein (BPI) is an endotoxin-neutralizing protein with potent bactericidal activity, providing protection against the toxic effects of lipopolysaccharides $(3,4)$. BPI is usually not detectable in plasma of healthy volunteers (15), but increased levels have been demonstrated in critically ill patients with bacteremia (8). In the present study, BPI was demonstrated in plasma samples of almost all patients developing VAP, both on the day of diagnosis as well as in the days preceding infection, and its detection was independent of a clinical status of severe sepsis or septic shock or the presence of bacteremia. Mortality within 10 days of diagnosing VAP was clearly accompanied with increasing levels of BPI. Our findings suggest that, in case of a serious infection, BPI is released from activated or killed neutrophils. Since intracellular killing of phagocytized bacteria is an important function of BPI, an increased systemic release of BPI, therefore, may represent a general activation and presence of neutrophils in an effort to control the burden of infection. Moreover, high levels of BPI may reflect overwhelming inflammation, irrespective of an infectious etiology, and are, therefore, associated with mortality. However, more studies are needed to determine the role of systemic BPI release in these conditions. In a previous study we found that the BPI/ neutrophil ratio, reflecting neutrophil activation, was associated with the presence of sepsis syndrome and death in bacteremic patients (8). In the present study the kinetics of BPI/ neutrophil ratios and systemic BPI levels were comparable (data not shown).

The adhesion molecules ICAM and E-selectin have a critical role in the activation and sequestration of circulating blood neutrophils in microvessels of systemic organs. The interaction between ICAM and neutrophils initiates migration of neutrophils out of the vascular space. Increased levels of circulating sICAM have been demonstrated in adult patients with sepsis, and positive correlations between levels of circulating sICAM and intensity of sepsis and severity of shock and subsequent organ failure have been reported (6). Animal studies of acute lung injury indicated that sE-selectin is 
present in lung parenchyma and mediates neutrophilic inflammation (5). sE-selectin was detectable in plasma of healthy subjects (9). In patients, elevated levels of sEselectin were found in bacteremic patients with hypotension (9) and in critically ill patients with microbiologically documented sepsis (10). Similar to BPI, our data demonstrate a tendency towards higher circulating levels of sICAM and sE-selectin when VAP was associated with the presence of severe sepsis or septic shock. Two days after diagnosis of VAP, levels of sE-selectin tended to be higher in patients that died within ten days, but the association between plasma levels of sICAM and patient outcome is less obvious.

Hypothetically there are several explanations for our observation that VAP is not accompanied with a detectable systemic inflammatory response, unless the patient has a clinical condition of severe sepsis or septic shock.

First, one might question whether these patients really had pneumonia, or just extensive colonization of the lower respiratory tracts. This would imply that the specificity of quantitative cultures of bronchoscopically obtained samples from the distal airways is much lower than generally assumed.

Second, these patients may be immunocompromised because of their critical illness, and, therefore, unable to generate an efficient immunoresponse. Since an effective host defense against bacterial invasion is essential to survive an infection, our findings may provide evidence for the use of adjuvant treatment in these patients (20). Although interest in this field is rising, few clinical data (for example on the use of human granulocyte-colony stimulating factor) are yet available (20).

Third, VAP may be a compartmentalized infection, with an inflammatory response restricted to the lungs. The latter has been suggested to occur in unilateral communityacquired pneumonia $(21,22)$, and in experimental studies on pneumonia in rats (23). Recently, Fox-Dewhurst and coworkers described the relationships between intrapulmonary and systemic inflammatory responses in rabbits with gram-negative pneumonia (24). They found a dose-relationship between the number of bacteria inoculated into the trachea and intrapulmonary and systemic inflammatory reactions. Animals treated with low inocula of bacteria had systemic changes which were comparable to those defined as systemic inflammatory response syndrome and bacteria were cleared from the lungs. In contrast, those treated with high inocula, failed to clear the bacteria from the lungs and developed severe inflammatory responses and septic shock (24). The findings of the present study, partly confirm and partly disagree with these experimental data. When VAP is not associated with severe sepsis or septic shock or 10-day mortality there is hardly any systemic inflammatory response, which may suggest that the threshold of intrapulmonary infection has not been exceeded, and bacteria were, with the help of antibiotics, cleared from the lungs. However, we failed to demonstrate an association between the bacterial inoculum in the lungs during infection (the bacterial burden) and the severity of the systemic inflammatory response, as was demonstrated in rabbits. However, our findings support the idea that VAP is a 
compartmentalized infection in most patients. Therefore, potential markers for infection would be levels of cytokines, inflammatory mediators or endotoxin in samples of bronchoalveolar lavage or the logarithmic number of bacteria isolated from these samples ('the bronchoscopic bacterial burden'). Kollef and coworkers demonstrated that elevated concentrations of endotoxin in BAL fluid accurately predicted the presence of gram-negative bacterial pneumonia (25). Under the circumstances tested, the bronchoscopic bacterial burden poorly correlated with the clinical severity of infection (e.g. presence of severe sepsis or septic shock, and values of SAPS II scores), and levels of circulating inflammatory mediators. In another study, however, a correlation of $0.585(\mathrm{P}<.001)$ was found between the yield of BAL fluid quantitative cultures for gram-negative bacteria and BAL fluid endotoxin concentrations (25). Whether the bronchoscopic bacterial burden is associated with local cytokine production remains to be established. 


\section{REFERENCES}

1 Bonten MJM, Froon AHM, Gaillard CA, et al. The systemic inflammatory response in the development of ventilator-associated pneumonia. Am J Respir Crit Care Med 1997;156:1105-13

2. Le Gall J, Lemeshow S, Saulnier F. A new simplified acute physiology score (SAPS II) based on a European/ North American multicenter study. J Am Med Assoc 1993;270;2957-63

3. Elsbach P, Weiss J. Bactericidal/ permeability increasing protein and host defense against Gramnegative bacteria and endotoxin. Curr Opin Immunol 1993;5:103-7

4. Marra MN, Wilde CG, Collins MS, et al. The role of bactericidal/ permeabability-increasing protein as a natural inhibitor of bacterial endotoxin. J Immunol 1992;148:532-7

5. Pilewski JM, Albelda SM. Adhesion molecules in the lung. An overview. Am Rev Respir Dis 1993;148 (Suppl):S31-7

6. Sessler CN, Windsor AC, Schwartz M, et al. Circulating ICAM-1 is increased in septic shock. Am J Respir Crit Care Med 1995;151:1420-7

7. Leeuwenberg JFM, Smeets EF, Neefjes JJ, et al. E-selectin and intercellular adhesion molecule-1 are released by activated human endothelial cells in vitro. Immunol 1992;77:543-9

8. Froon AHM, Dentener MA, Greve JWM, et al. Lipopolysaccharide toxicity-regulating proteins in bacteremia. J Infect Dis 1995;171:1250-7

9. Newman W, Beall LD, Carson CW, et al. Soluble E-selectin is found in supernatants of activated endothelial cells and is elevated in the serum of patients with septic shock. J Immunol 1993;150:64454

10. Cummings CJ, Sessler CN, Beall LD, et al. Soluble E-selectin levels in sepsis and critical illness. Correlation with infection and hemodynamic dysfunction. Am J Respir Crit Care Med 1997;156:4317

11. Bonten MJM, Gaillard CA, van Tiel FH, et al. The stomach is not a source for colonization of the upper respiratory tract and pneumonia in ICU patients. Chest 1994;105:878-84

12. American College of Chest Physicians, Society of Critical Care Medicine . Consensus Conference: definitions for sepsis and organ failure and guidelines for the use of innovative therapies in sepsis. Crit Care Med 1992;20:864-74

13. Dentener MA, Smit FT, Francot GJM, et al. Characterization of two monoclonal antibodies directed against bactericidal/ permeability-increasing protein. J Infect Dis 1994;170:1483-9

14. Bouma MG, Laan MP, Dentener MA, et al. Analysis of solubleadhesion molecules. In: Johnstone AP, Turner MW. Immunochemistry 2: A practical approach. Oxford: Oxford University Press, 1997:181-96

15. Dentener MA, Francot GJM, Smit FT, et al. Presence of bactericidal/ permeability-increasing protein in disease: detection by ELISA. J Infect Dis 1995;171:739-43

16. Knaus WA, Wagner DP, Draper EA, et al. The APACHE III prognostic system: risk prediction of hospital mortality for critically ill hospitalized adults. Chest 1991;100:1619-1639

17. Lemeshow S, Teres D, Klar J, et al. Mortality probability models (MPM II) based on an international cohort of intensive care unit patients. J Am Med Assoc 1993;270:2478-86

18. Friedland JS, Porter JC, Daryanani S, et al. Plasma proinflammatory cytokine concentrations, Acute Physiology and Chronic Health Evaluation (APACHE) III scores and survival in patients in an intensive care unit. Crit Care Med 1996;24:1775-81

19. Casey LC, Balk RA, Bone RC. Plasma cytokine and endotoxin levels correlate with survival in patients with the sepsis syndrome. Ann Intern Med 1993;119:771-8

20. Standiford TJ. Cytokines and pulmonary host defenses. Curr Opin Pulm Med 1997;3:81-8

21. Boutten A, Dehoux MS, Seta N, et al. Compartmentalized IL-8 and elastase release within the human lung in unilateral pneumonia. Am J Respir Crit Care Med 1996;153:336-42 
22. Dehoux MS, Boutten A, Ostinelli J, et al. Compartmentalized cytokine production within the human lung in unilateral pneumonia. Am J Respir Crit Care Med 1994;150:710-6

23. Nelson S, Bagby GJ, Bainton BG, et al. Compartmentalization of intraalveolar and systemic lipopolysaccharide-induced tumor necrosis factor and the pulmonary inflammatory response. J Infect Dis 1989;159:189-94

24. Fox-Dewhurst R, Alberts MK, Kajikawa O, et al. Pulmonary and systemic inflammatory responses in rabbits with Gram-negative pneumonia. Am J Respir Crit Care Med 1997;155:2030-40

25. Kollef M, Eisenberg PR, Ohlendorf MF, et al. The accuracy of elevated concentrations of endotoxin in bronchoalveolar lavage fluid for the rapid diagnosis of gram-negative pneumonia. Am J Respir Crit Care Med 1996;154:1020-8 
Intensive care medicine is a major consumer of hospital budgets, and the demand for care often exceeds available resources. This urges for the identification of patients who really benefit from ICU admission. It may be desirable for the future to be able to identify the patients who are likely to survive as a result of intensive care treatment.

Measuring severity of disease is an important factor in predicting outcome. Heart rate and body temperature are well known but unreliable parameters reflecting the severity of inflammation. Inflammatory activity may be more directly reflected by plasma concentrations of mediators involved in the inflammatory cascade. Changes in plasma levels of some of these mediators have already been demonstrated to reflect the clinical course (i.e. interleukin-6). The question is, whether these inflammatory mediators are more useful to evaluate the clinical condition and to predict outcome compared to the more conventional parameters such as heart rate and body temperature.

Over the past 15 years, several scoring systems have been developed to measure severity of illness. The 'Acute Physiology and Chronic Health Evaluation' (APACHE) is such a scoring systems predominantly used to stratify patient populations and to evaluate therapeutic strategies. The APACHE II score is based on physiologic variables (clinical and laboratory data), surgical state, age, medical history and present diagnosis. At the moment, scoring systems are not suitable to predict outcome in the individual patient.

In this thesis the severity of disease was assessed either by plasma concentrations of inflammatory mediators or scoring systems concerning patients with infectious and non-infectious disease, respectively (Table 1). Therefore, critically ill patients with the systemic inflammatory response syndrome (SIRS), positive blood cultures, ventilator associated pneumonia (VAP), and acute abdominal aneurysms (AAA) were studied. In addition, severity of disease was assessed in an intervention study regarding the effects of a platelet-activating factor antagonist in the treatment of SIRS.

In chapter 2 characteristics of the ICU patient population are reported. These characteristics included admission diagnosis and mortality and mortality associated factors. In addition, the clinical suitability of APACHE II was assessed.

APACHE II scores in our study population were strongly correlated with hospital mortality, which was comparable with the results from the original report. However, in separate diagnostic categories the discrepancy between observed and predicted mortality ranged from $-62.1 \%$ to $+118.2 \%$, indicating that APACHE II is not suitable for stratifying patient populations as it has been suggested. When the demand for intensive care treatment exceeds supply, patients are inevitably excluded from ICU admission. The question whether APACHE II mortality prediction may participate in 
the complex discussion to exclude patients from intensive care treatment still has to be answered. The suitability of APACHE II for individual decision making is limited.

One of the best known pro-inflammatory cytokines is tumor necrosis factor (TNF). TNF in plasma has a short half life, and the correlation with mortality in SIRS depends on the frequency of plasma sampling. TNF induces the shedding of the TNF receptor (TNF-R) from the cell surface resulting in a circulating TNF-R (sTNF-R) which has a longer half life. In chapter 3 it was investigated whether the measurement of sTNF-R levels could provide a better parameter of disease compared to the short lived TNF peaks in plasma.

In this thesis we demonstrated that sTNF-R levels, in contrast to TNF, significantly correlated with mortality in SIRS. sTNF-R levels are, however, influenced by renal sTNF-R clearance. The significant correlation between sTNF-R levels and creatinine levels indicate that increased STNF-R levels in SIRS may be the result of renal failure complicating SIRS, and are likewise correlated with mortality. Consequently, the clinical value of monitoring sTNF-R levels is limited in case of renal failure.

Table 1: Inflammatory mediators in disease and the correlation with clinical state and course

\begin{tabular}{|c|c|c|c|c|c|c|c|c|}
\hline $\begin{array}{l}\text { Study } \\
\text { population }\end{array}$ & TNF & sTNF-R & IL-6 & IL-8 & BPI & LBP & siCAM-1 & SAPS II \\
\hline SIRS & - & $t$ & $t$ & & & & & \\
\hline $\begin{array}{l}\text { AAA } \\
\text { bacteremia }\end{array}$ & shock $/ \dagger$ & $\dagger$ & shock/ † & shock & SIRS/ $\dagger$ & SIRS & shock/ † & \\
\hline $\begin{array}{l}\text { VAP } \\
\text { note* }\end{array}$ & $\begin{array}{c}\text { fast } \\
\text { 'kinetics' }\end{array}$ & $\begin{array}{c}\text { renal } \\
\text { clearance }\end{array}$ & SIRS/ $t$ & SIRS/ † & $\begin{array}{c}t \\
\text { PMN } \\
\text { count }\end{array}$ & $\begin{array}{c}\text { slow } \\
\text { 'kinetics' }\end{array}$ & - & SIRS $/ \dagger$ \\
\hline
\end{tabular}

Explanation of abbreviations see text. $\dagger$ mortality. "disturbing factors with regard to predictive value of mediators in disease. - no correlation observed between mediators and severity of disease. For example: high plasma IL-6 concentrations were positively correlated with the presence of shock and fatal course in AAA patients.

In chapter 4 the association between inflammatory mediators and clinical outcome was investigated in patients after repair of abdominal aortic aneurysms. Rupture of an aneurysm often leads to hemorrhagic shock, which is considered to be responsible for serious complications during the postoperative course. In animal models hemorrhagic shock results in an inflammatory reaction with increased concentrations of TNF and IL6 in plasma. In this inflammatory response, neutrophil activation and extravasation are thought to play an important role. Neutrophil adhesion to the vessel wall and migration into reperfused tissue is mediated by chemotactic proteins such as IL-8 and adhesion molecules expressed on neutrophils and endothelial cells (ICAM-1, Eselectin). Plasma concentrations of circulating adhesion molecules (sICAM-1, sE- 
selectin) are directly correlated with the expression of adhesion molecules on the cell surface.

TNF levels were correlated with the presence of shock and fatal outcome in AAA patients, but its clinical value is strongly limited by its short half life in plasma. IL-6 levels correlated with the presence of shock in AAA patients and with fatal outcome. The transfusion of a large amount of blood products did not disturb the data concerning inflammatory mediators. Shock in AAA patients was associated with high sICAM-1 levels and high mortality rates. These data complement the experimental data on the beneficial effects of ICAM-1 antibodies on ischemia and reperfusion injury. It remains, however, to be resolved whether ICAM-1 antibody administration in patients following AAA repair may favour clinical course.

Lipopolysaccharides (LPS) or endotoxins, which are cell wall components of gramnegative bacteria, are capable to initiate the inflammatory response known as gramnegative septic shock. The toxicity of LPS is modified by several proteins such as bactericidal/ permeability-increasing protein (BPI), and LPS binding protein (LBP). BPI is a protein that specifically binds LPS and reduces its toxicity by preventing the interaction with the LPS-receptor CD14, whereas LBP, an acute phase protein, functions in an opposite fashion to BPI. LBP facilitates binding of LPS to CD14. In chapter 5 the association between plasma concentrations of these proteins and clinical course was assessed in patients suffering from gram-negative bacteremia and data were compared with those obtained from bacteremic patients in which a grampositive, LPS lacking, micro-organism was isolated. BPI, produced by polymorphonuclear leucocytes (PMN), has a short half life and plasma levels were hypothesized to depend on the number of circulating PMN. Therefore data regarding the BPI/ PMN ratio were additionally analyzed.

Levels of BPI and LBP were already increased before bacteremia was first detected. Plasma LBP levels were correlated with the presence of SIRS in bacteremic patients, but no correlation between LBP levels and mortality was observed. Once enhanced LBP levels remain high for days/ weeks. As a result, the usefulness of LBP as a parameter of disease is limited. BPI/ PMN ratio was correlated with the presence of SIRS and mortality in bacteremic patients. Apparently, BPI levels reflect severity of inflammation, and the value for clinical use increases when BPI levels are considered in relation to PMN count.

In chapter 6 the safety and efficacy of the platelet-activating factor antagonist TCV309 in the treatment of SIRS was studied in a prospective randomized, double-blind, placebo-controlled clinical study. PAF is strongly related to the cytokine network. Cytokines like TNF and IL-8 can stimulate PAF release and PAF is able to induce synthesis of these cytokines.

There was no difference in number and severity of adverse events between TCV$309(n=13)$ and placebo treated patients $(n=16)$. Day 28 and day 56 mortality was 
similar in both groups (day 56: 7/12 TCV-309 vs 9/16 placebo, NS). Pulmonary and hematological failure scores improved significantly in TCV- 309 treated patients. There was no difference in inflammatory mediator levels between TCV-309 and placebo treated patients at the beginning of the study. The course of inflammatory mediators were similar in TCV-309 and placebo treated patients. Data from intervention studies in patients, however, are not directly comparable with experimental animal studies. In SIRS patients the inflammatory cascade is triggered before study entry, whereas in experimental models the intervention takes place 1-2 hours after the septic insult at the latest. Therefore, a therapy induced effect on cytokine release will be difficult to detect.

Ventilator-associated pneumonia is the most frequently occurring infection in mechanically ventilated patients. The clinical presentation of VAP ranges from relatively benign to a severe illness with septic shock. In chapter 7 the influence of VAP on the inflammatory response and outcome was studied in a case-control study.

The development of VAP was not associated with an increase in IL- 6 or IL-8 levels. Among patients in which VAP was associated with a clinical presentation of severe sepsis or septic shock, IL-6 and IL-8 levels were higher than in the corresponding controls, and high IL-6 and IL-8 levels were associated with higher mortality rates. Apparently, the clinical picture of VAP can be subdivided into different types, ranging from an uncomplicated infection to an infection associated with septic shock, elevated plasma levels of IL- 6 and IL-8 and an increased mortality rate.

In chapter 8 the inflammatory response during the development of VAP (assessed by BPI, sICAM-1 and sE-selectin) was studied in relation to clinical severity of VAP and outcome. The predictive value of plasma parameters was compared with the predictive value of the simplified acute physiology score (SAPS II).

During the development of VAP, increasing SAPS II scores and rising levels of inflammatory mediators were only found in patients in whom VAP was accompanied by severe sepsis or septic shock. Values of SAPS II, BPI and sE-selectin, but not of sICAM-1, increased from the day of diagnosis until death in patients that died within 10 days after diagnosis. Plasma levels of inflammatory mediators did not predict clinical severity or patient outcome better than daily SAPS II scores. Our findings show that a rather simple bed-side scoring system (SAPS II score) is at least as good a predictor for the clinical severity of infection and the outcome of patients with VAP as plasma values of inflammatory mediators.

In this thesis the involvement of various inflammatory mediators in infectious disease as well as in patients with hemorrhagic shock was studied. Apparently, high plasma levels of multiple inflammatory mediators reflect the extent of activation of the inflammatory cascade and are subsequently correlated with outcome (sTNF-R, IL-6, BPI, sICAM-1). However, some significant limitations were demonstrated with regard 
to clinical suitability i.e. renal failure on sTNF-R levels, PMN count and plasma processing on BPI levels.

In conclusion, plasma levels of inflammatory mediators as well as the scoring systems APACHE II and SAPS II are helpful to assess severity of disease at the population level. But, at present, there is no place for scoring systems nor for the measurement of inflammatory mediators in medical decision making of the individual patient. 

Intensive care geneeskunde legt beslag op een groot deel van het ziekenhuis budget en de vraag naar intensieve zorg overschrijdt veelal de beschikbare middelen. Dit noopt tot het identificeren van die patiënten die daadwerkelijk baat hebben bij intensieve zorg. Het zou wenselijk zijn om die patiënten te kunnen selecteren die gebaat zijn bij een opname op de afdeling intensieve zorg (ICU).

De ernst van ziekte is een belangrijke factor bij het voorspellen van het beloop. Hartfrequentie en lichaamstemperatuur zijn misschien wel de meest bekende, maar niet de meest betrouwbare parameters voor de ernst van ontstekingsprocessen. De ernst van onstekingsreacties zou mogelijk directer weerspiegeld kunnen worden door plasma concentraties van mediatoren betrokken in de ontstekingscascade. Van sommige mediatoren is aangetoond dat concentratie veranderingen in het bloed nauw gerelateerd zijn aan het klinisch beloop en overleving (b.v. interleukine-6). De vraag rijst, of deze ontstekingsmediatoren beter bruikbaar zijn om het klinisch beloop te evalueren en overleving te voorspellen in vergelijking met de meer conventionele parameters zoals hartfrequentie en lichaamstemperatuur.

De afgelopen 15 jaar zijn verschillende scores ontwikkeld om de ernst van ziekte te meten. De 'Acute Physiology and Chronic Health Evaluation' (APACHE) is zo'n toets en is voornamelijk bedoeld om patiënten te stratificeren en beleid te evalueren. APACHE II is gebaseerd op fysiologische variabelen (klinische en laboratorium gegevens), leeftijd, medische voorgeschiedenis, status na eventuele operatie, en reden van ICU opname. Momenteel zijn score systemen niet bruikbaar om adequaat overleving te voorspellen in de individuele patiënt.

In de studies vermeld in dit proefschrift wordt de ernst van ziekte gemeten enerzijds met behulp van ontstekingsmediatoren en anderzijds met behulp van score systemen bij patiënten met respectievelijk ziektes van infectieuze en niet-infectieuze origine (Tabel 1). Ernstig zieke patiënten met een gegeneraliseerde ontstekingsreactie (systemic inflammatory response syndrome/ SIRS), positieve bloedkweken (bacteriëmie), een nosocomiale pneumonie bij beademing (ventilator-associated pneumonia/ VAP), en een acuut abdominaal aneurysma (AAA) worden bestudeerd. Daarnaast wordt de ernst van ziekte vervolgd in een interventie studie over de effecten van een platelet-activating factor (PAF) antagonist bij de behandeling van SIRS.

De karakteristieken van de bestudeerde ICU patiënten populatie worden gerapporteerd in hoofdstuk 2. Deze karakteristieken omvatten opname diagnose, mortaliteit en de hiermee geassocieerde factoren. Daarnaast wordt de klinische waarde van de APACHE II score bestudeerd.

APACHE II scores correleren sterk met de mortaliteit overeenkomstig de resultaten uit het originele artikel. Bij sommige ziektebeelden is er echter een 
discrepantie tussen de geobserveerde en de voorspelde mortaliteit variërend van $-62.1 \%$ tot $+118.2 \%$. Dit suggereert dat de bruikbaarheid van APACHE II om patiënten populaties te stratificeren, in tegenstelling tot wat de auteurs beweren, beperkt is. Wanneer de vraag naar intensieve zorg het aanbod (beschikbare bedden) overschrijdt, zullen er onvermijdelijk patienten van ICU opname worden uitgesloten. De discussie wie dan voor ICU opname in aanmerking komt is zeer complex. Het blijft een vraag of de door APACHE II voorspelde mortaliteit in deze discussie een rol mag spelen.

Tabel 1: Ontstekingsmediatoren bij ziekte en de correlatie met klinisch beeld en beloop

\begin{tabular}{|c|c|c|c|c|c|c|c|c|}
\hline $\begin{array}{l}\text { Studie } \\
\text { populatie }\end{array}$ & TNF & sTNF-R & IL-6 & IL-8 & BPI & LBP & sICAM-1 & SAPS II \\
\hline SIRS & - & $t$ & $t$ & & & & & \\
\hline $\begin{array}{l}\text { AAA } \\
\text { bacteriëmie }\end{array}$ & shock/ t & $t$ & shock/ $t$ & shock & SIRS $/ t$ & SIRS & shock/ $t$ & \\
\hline $\begin{array}{l}\text { VAP } \\
\text { opmerking* }\end{array}$ & $\begin{array}{c}\text { snelle } \\
\text { 'kinetiek' }\end{array}$ & $\begin{array}{c}\text { renale } \\
\text { klaring }\end{array}$ & SIRS/ $t$ & SIRS/ + & $\begin{array}{c}\dagger \\
\mathrm{PMN}\end{array}$ & $\begin{array}{c}\text { trage } \\
\text { 'kinetiek' }\end{array}$ & - & SIRS/ † \\
\hline
\end{tabular}

Verklaring van de afkortingen zie tekst. $\dagger$ mortaliteit. "storende factoren met betrekking tot de voorspellende waarde bij ziekte. - geen positieve correlatie gevonden tussen mediatoren en ernst van ziekte. Voorbeeld: hoge plasma IL-6 spiegels zijn positief gecorreleerd aan shock en overlijden bij patiënten met AAA.

TNF (tumor necrosis factor) is één van de meest bekende pro-inflammatoire cytokines. TNF in plasma heeft een korte halfwaarde tijd en de correlatie met mortaliteit bij SIRS is afhankelijk van de frequentie van het plasma onderzoek. TNF induceert het loslaten van de TNF receptoren (TNF-R) van de celmembraan, hetgeen leidt tot circulerende TNF-R (sTNF-R) met een relatief lange halfwaarde tijd. In hoofstuk 3 is onderzocht of de bepaling van sTNF-R een betere prognostische parameter oplevert vergeleken met de kort durende pieken in plasma TNF spiegels.

In dit proefschrift wordt aangetoond dat sTNF-R spiegels, in tegenstelling tot die van TNF, significant gecorreleerd zijn met mortaliteit bij SIRS. Echter, de sTNF-R spiegels worden beinvloed door de renale TNF-R klaring. De significante correlaties tussen sTNF-R en creatinine spiegels suggereren dat verhoogde sTNF-R spiegels bij SIRS eerder het gevolg zijn van nierfalen (als onderdeel van SIRS) en derhalve gecorreleerd zijn aan een fataal beloop. Dientengevolge is de klinische waarde van het vervolgen van sTNF-R spiegels beperkt in het geval van nierfalen.

In hoofdstuk 4 wordt de associatie tussen ontstekingsmediatoren en het klinisch beeld besproken na het herstel van een aneurysma van de abdominale aorta. Een geruptureerd aneurysma leidt dikwijls tot hemorrhagische shock, die geassocieerd is met ernstige complicaties in het postoperatieve beloop. In experimentele modellen 
resulteert hemorrhagische shock in een inflammatoire reactie met een toename van TNF en IL-6 concentraties in plasma. Daarnaast speelt de activatie en extravasatie van neutrofiele leukocyten een belanrijke rol. De adhesie van neutrofielen aan de vaatwand en de migratie naar gereperfundeerd weefsel wordt gemedieerd door chemotactische eiwitten zoals IL-8 en adhesie moleculen gelokaliseerd op de membraan van neutrofielen en endotheel (ICAM-1, E-selectin). De plasma concentraties van circulerende adhesie moleculen (sICAM-1, sE-selectin) zijn direkt gecorreleerd met de expressie van de adhesie moleculen op de celmembraan.

De plasma TNF spiegels correleren met de aanwezigheid van shock en mortaliteit bij AAA patiënten, maar de klinische waarde wordt beperkt door de korte halfwaarde tijd. Plasma IL-6 spiegels correleren eveneens met de aanwezigheid van shock en een fataal beloop. De transfusie van grote hoeveelheden bloedproducten had geen invloed op de plasmaspiegels van ontstekingsmediatoren. Hemorragische shock bij AAA is geassocieerd met hoge sICAM-1 spiegels en een hoge mortaliteit. De resultaten in hoofdstuk 4 sluiten aan bij experimentele studies over het gunstige effect van ICAM-1 antilichaam toediening bij ischemie en reperfusie schade. Echter, de vraag of ICAM-1 antilichamen de mortaliteit bij patienten met AAA kan verminderen dient nog te worden opgehelderd.

LPS (lipopolysaccharides), een component van de cel wand van gram-negatieve bacteriën, is in staat om het beeld van SIRS te initiëren. De toxiciteit van LPS wordt beinvloed door verscheidene eiwitten zoals BPI (bactericidal/ permeability-increasing protein) en LBP (LPS binding protein). BPI is een eiwit dat specifiek bindt aan LPS waardoor de toxiciteit van LPS verminderd wordt door de interactie met de LPSreceptor te verhinderen. LBP, een acute fase eiwit, heeft een tegengestelde functie en stimuleert de binding van LPS aan CD14. In hoofdstuk 5 is de associatie tussen enerzijds BPI en LBP plasma spiegels en anderzijds klinisch beloop onderzocht bij patiënten met een gram-negatieve bacteriëmie. De resultaten werden vergeleken met die patiënten waarbij een gram-positief micro-organisme werd geisoleerd. BPI, een eiwit gemaakt door polymorphonucleaire leucocyten (PMN), heeft een korte halfwaarde tijd, en derhalve kan de plasma spiegel afhankelijk zijn van het aantal circulerende PMN. Dus werd de BPI/ PMN ratio in de analyse betrokken.

Uit de resultaten blijkt dat plasma spiegels van zowel BPI als LBP reeds verhoogd zijn voordat een bacteriëmie kan worden aangetoond. LBP spiegels zijn gecorreleerd met de aanwezigheid van SIRS maar niet met mortaliteit. Indien de LBP spiegels eenmaal verhoogd zijn, dan kunnen de spiegels dagen tot weken verhoogd blijven. Door een dergelijk beloop van de LBP spiegels is LBP als parameter van acute ziekte minder geschikt. De BPI/ PMN ratio is significant gecorreleerd met de aanwezigheid van SIRS en mortaliteit bij patiënten met een bacteriëmie. Blijkbaar wordt de ernst van inflammatie door BPI spiegels weerspiegeld, en neemt de klinische waarde alleen maar toe als deze spiegels worden beschouwd in relatie tot het PMN aantal. 
In hoofdstuk 6 wordt de veiligheid en de effectiviteit van de PAF (plateletactivating factor) antagonist TCV-309 in de behandeling van SIRS bestudeerd. Het betreft een prospectieve gerandomiseerde dubbel-blinde placebo gecontroleerde klinische studie. Onder andere TNF en IL-8 kunnen het vrijkomen van PAF stimuleren en PAF op zijn beurt is in staat om de synthese van deze cytokinen te induceren.

Er wordt geen verschil gevonden in het aantal noch in de ernst van de bijwerkingen tussen TCV-309 $(n=13)$ en placebo behandelde patiënten $(n=16)$. De mortaliteit op dag 28 en op dag 56 is vergelijkbaar in beide groepen (dag 56: 7/12 TCV309 versus $9 / 16$ placebo, niet significant). Orgaan falen (long en hematologie) verbetert significant bij TCV-309 behandelde patiënten. Er waren bij aanvang van de studie geen verschillen in plasma spiegels van de ontstekingsmediatoren tussen de twee behandelingsgroepen. Ondanks de interventie met TCV-309 is de het beloop van de plasma ontstekingsmediatoren in de twee behandelingsgroepen overeenkomstig. Resultaten van dierexperimenteel onderzoek zijn niet zonder meer te extrapoleren naar interventie studies bij patiënten. Immers, bij een patiënt met SIRS is de onstekingscascade reeds geruime tijd in gang gezet voordat de deze in een studie wordt opgenomen, terwijl in experimentele modellen de interventie meestal vooraf gaat aan of plaats vindt hooguit 1-2 uur na het septisch insult. Om deze reden is het niet eenvoudig om een effect van interventie op het verloop van de plasma concentraties van ontstekingsmediatoren waar te nemen.

Een nosocomiale pneumonie (VAP) is de meest frequent optredende infectie bij beademde patiënten. Het klinisch beeld van VAP varieert van een relatief mild tot een ernstig ziektebeeld met septische shock. In hoofdstuk 7 wordt de invloed van VAP op de inflammatoire respons en overleving in een 'case-control' studie onderzocht.

De ontwikkeling van VAP is niet geassocieerd met een toename van IL-6 noch van IL-8 plasma spiegels. Bij patiënten waarbij VAP samen gaat met het klinisch beeld van een ernstige sepsis of septische shock, zijn IL-6 en IL-8 spiegels hoger in vergelijking met de corresponderende controle patiënten, en de verhoogde IL-6 en IL-8 spiegels zijn geassocieerd met een hogere mortaliteit. Blijkbaar kan het klinisch beeld van VAP worden onderverdeeld in verschillende types, variërend van een ongecompliceerde infectie tot een infectie die gepaard gaat met septische shock, verhoogde IL-6 en IL-8 spiegels en een verhoogde mortaliteit.

In hoofdstuk 8 wordt de ontstekingsreactie gedurende de ontwikkeling van VAP bestudeerd (gemeten aan de hand van BPI, sICAM-1 en sE-selectin plasma spiegels) in relatie tot het klinisch beloop en overleving. De voorspellende waarde van plasma parameters wordt vergeleken met de voorspellende waarde van de 'simplified acute physiology score' (SAPS II).

Gedurende de ontwikkeling van VAP, wordt alleen een toename gezien van SAPS II scores en ontstekingsmediatoren wanneer VAP gepaard gaat met een ernstige sepsis of septische shock. SAPS II waarden, BPI en sE-selectin spiegels, maar niet die van 
sICAM-1, nemen toe vanaf de dag van diagnose bij die patiënten die binnen 10 dagen na diagnose overlijden. Ontstekingsmediatoren voorspelden het beloop niet beter dan de dagelijkse SAPS II scores. Deze resultaten tonen aan dat een relatief eenvoudig score systeem (SAPS II) op zijn minst even bruikbaar is om het beloop van VAP te voorspellen als de plasma concentraties van ontstekingsmediatoren.

In dit proefschrift wordt de betrokkenheid van diverse ontstekingsmediatoren zowel bij ziektes van infectieuze origine als bij hemorrhagische shock aangetoond. Blijkbaar wordt de, soms excessieve, activatie van de ontstekingscascade weerspiegeld in verhoogde plasma concentraties van meerdere ontstekingsmediatoren, die dientengevolge gecorreleerd zijn met mortaliteit (sTNF-R, IL-6, BPI, sICAM-1). Echter, enkele significante beperkingen zijn aangetoond met betrekking tot de klinische bruikbaarheid, b.v. nierfalen op sTNF-R spiegels, PMN leukocyten aantal en de plasma verwerking op BPI spiegels.

Concluderend, zowel plasma spiegels van ontstekingsmediatoren als score systemen kunnen behulpzaam zijn bij het bepalen van de ernst van ziekte. Echter, op het ogenblik is de plaats van zowel ontstekingsmediatoren als score systemen in de medische besluitvorming rondom de individuele patiënt zeer beperkt. 



\section{APPENDIX}

\section{Definitions}

Systemic inflammatory response syndrome (SIRS):

The systemic inflammatory response to a variety of severe clinical insults. The response is manifested by two or more of the following conditions: (1) temperature $>38^{\circ} \mathrm{C}$ or $<36^{\circ} \mathrm{C}$; (2) heart rate $>90$ beats per minute; respiratory rate $>20$ breaths per minute or $\mathrm{PaCO} 2<32 \mathrm{mmHg}$; and (4) white blood cell count $>12.000 / \mathrm{mm}^{3},<4.000 / \mathrm{mm}^{3}$, or $>10 \%$ immature (bands) forms.

\section{Sepsis:}

SIRS as a result of infection.

\section{Severe sepsis:}

Sepsis associated with organ dysfunction, hypoperfusion or hypotension. Hypoperfusion and perfusion abnormalities may include, but are not limited to lactic acidosis, oliguria, or an acute alteration in mental status.

\section{Septic shock:}

Sepsis-induced hypotension despite adequate fluid resuscitation along with the presence of perfusion abnormalities that may include, but are not limited to lactic acidosis, oliguria, or an acute alteration in mental status. Patients who are receiving inotropic or vasopressor agents may not be hypotensive at the time that perfusion abnormalities are measured

\section{Sepsis-induced hypotension:}

A systolic blood pressure $<90 \mathrm{mmHg}$ or a reduction of $\geq 40 \mathrm{mmHg}$ from baseline in the absence of other causes for hypotension.

\section{Muliple organ dysfunction (MODS):}

presence of altered organ function in an acutely ill patient such that homeostasis cannot be maintained without intervention.

Definitions for sepsis and organ failure and guidelines for the use of innovative therapies in sepsis. The ACCP/ SCCM Consensus Conference Committee. American College of Chest Physicians/ Society of Critical Care Medicine. R.C. Bone et al., Chest 1992; 101: 1644-55 


\begin{tabular}{|c|c|c|c|c|c|c|c|c|c|}
\hline PHYSIOLOGIC VARIABLE & +4 & +3 & +2 & +1 & 0 & +1 & +2 & $\cdot 3$ & +4 \\
\hline TEMPERATURE- rectal & 241 & $39-40.9$ & & 385.38 .9 & $36-38.4$ & $34-35.9$ & $32-33.9$ & $30-31.9$ & $\leq 29.9$ \\
\hline MEAN ARTERIAL PRESSURE-muHg & 2160 & $130-159$ & $110-129$ & & $70-109$ & & $50-69$ & & $\leq 49$ \\
\hline HEART RATE (ventricular response) & 2180 & $140-179$ & $110-139$ & & $70-109$ & & $55-69$ & $40-5-1$ & $\$ 39$ \\
\hline RESPIRATORY RATE (non-ventilated or ventilated) & 250 & $35-49$ & & $25-34$ & $12-24$ & $10-11$ & $6-9$ & & $\leq 5$ \\
\hline \multicolumn{10}{|l|}{ OXYGENATION: (A-a)DO2 ot $\mathrm{PaO} 2(\mathrm{mmHg})$} \\
\hline a. $\mathrm{FiO} 2 \geq 0.5$ record $(\mathrm{A}-\mathrm{a}) \mathrm{DOO} 2$ & 2500 & $350-499$ & $200-349$ & & $\leqslant 200$ & & & & \\
\hline b. $\mathrm{FiO} 2<0.5$ record only $\mathrm{PaO} 2$ & & & & & $>70$ & $61-70$ & & $55-60$ & $<55$ \\
\hline ARTERIAL $\mathrm{pH}$ & $\geqslant 7.7$ & $7.6-7.69$ & & $7.5-7.59$ & $7.33-7.49$ & & $7.25 \cdot 7.32$ & $7.15-7.24$ & $\leq 7.15$ \\
\hline SERUM SODIUM (mmol/ L) & 2180 & $160-179$ & $155-159$ & $150-154$ & $130-149$ & & $120-129$ & $111-119$ & $\$ 110$ \\
\hline SERUM POTASIUM (mmol/ L) & $\geq 7$ & $6-6.9$ & & $5.5-5.9$ & $3.5-5.4$ & $3-3,4$ & $2.5-2.9$ & & $\leq 2.5$ \\
\hline $\begin{array}{l}\text { SERUM CREATININE (mg/ } 100 \mathrm{~mL}) \\
\text { double point score for acute renal fallure }\end{array}$ & 2300 & $176-300$ & $126-175$ & & $50-125$ & & $<50$ & & \\
\hline HEMATOCRIT (\%) & 260 & & $50-599$ & $46-49.9$ & $30-15.9$ & & $20-29.9$ & & $\leq 20$ \\
\hline $\begin{array}{l}\text { WHITE BLOOD COUNT (total/ } \mathrm{mm}^{3} \text { ) in } 1.000 \mathrm{~s} \\
\text { GI ASGOW COMA SCORE (GCS): } 15 \text { minus actual GC }\end{array}$ & $\geq 10$ & & 20.39 .9 & $15-19,9$ & $3-149$ & & 1.29 & & $s 1$ \\
\hline
\end{tabular}

GLASCOW COMA SCORE (GCS): 15 minus actual GCS

ACUTE PHYSIOLOGY SCORE (APS): Sum of the 12 indivitubal vanable points

B) AGE POINIS

Assign points to age as follows

\begin{tabular}{lc}
\hline Age (yrs) & Points \\
\hline 544 & 0 \\
$45-54$ & 2 \\
$55-64$ & 3 \\
$65-74$ & 5 \\
275 & 6 \\
\hline
\end{tabular}

\section{C) CHRONIC HEALTH POINTS}

If the patient has a history of severe organ system insufficiency of is immunocompromised assign points as follows:

a. for nonoperative or emergency postoperative patients 5 points or

b. for electric postoperative patients 2 points
DEFINITIONS

Organ insufficiency or immunocompromised state must have evident prior to this hospital admission and conform the following critera:

LIVER: Biopsy proven cirrhosis and documented portall hypertension: episodes of past upper $G I$ bleeding attributed to portal hypertension: or prior episodes of hepatic failure/ encephalopathy/ coma.

CARDIOVASCULAR: New York Heart Association Class IV

RESPIRATORY: Chronic restrictive obstructive. or vascular disease resultng in severe exercise restriction. i.e. unable to climb stairs or perform household duties or dncumented chronic hypoxia. hypercapnia. secondary polycythemia. severe pulmonary hypertension ( $40 \mathrm{~mm}$ $\mathrm{Hig}$. or respiratory dependency

RENAL Receiving chronic dialysis

IMMUNO-COMPROMISED: The patient has received therapy that sippresse resistance to infection. e.g. immunosupprescion. chemotherapy, rediation long term or recent high dose steroits of has a disease that is sufficiently advanced to suppress resistance to infection. $\mathrm{eg}$. leukemia. Jymphoma. AIDS

Knaus WA et a APACHE II: a severity of disease classification system. Crit Care Med 1985,13:818-29
APACHE II SCORE

Sum of $A+B+C$

A) APS points

B) Age points

C) Chronic Health points

Total APACHE 11 


\section{The Grading of Sepsis}

Table I: SCORING OF LOCAL EFFECTS OF TISSUE INFECTION

\begin{tabular}{|c|c|}
\hline Attribute & Score \\
\hline \multicolumn{2}{|l|}{$\begin{array}{l}\text { Wound infection with purulent discharge/ } \\
\text { entrocutaneous fistula }\end{array}$} \\
\hline $\begin{array}{l}\text { Requiring only light dressing changed not } \\
\text { more than once daily }\end{array}$ & 2 \\
\hline $\begin{array}{l}\text { Requiring to be dressed with a pack, dressing } \\
\text { needing to be changed more than once daily, } \\
\text { requiring application of a bag and/ or } \\
\text { requiring suction }\end{array}$ & 4 \\
\hline Peritonitis & 2 \\
\hline Localized & 6 \\
\hline Generalized & \\
\hline \multicolumn{2}{|l|}{ Chest infection } \\
\hline $\begin{array}{l}\text { Clinical or radiolgical signs of chest infection } \\
\text { without productive cough }\end{array}$ & 2 \\
\hline $\begin{array}{l}\text { Clinical or radiolgical signs of chest infection } \\
\text { with a cough producing purulent sputum }\end{array}$ & 4 \\
\hline $\begin{array}{l}\text { Full clinical manifestation of lobular/ } \\
\text { bronchopneumonia }\end{array}$ & 6 \\
\hline $\begin{array}{l}\text { Deep-seated infection (e.g. subfrenic abscess, } \\
\text { pelvic abscess, empyema thoracis, acute or } \\
\text { chronic osteomyelitis) }\end{array}$ & 6 \\
\hline
\end{tabular}

Table II: SCORING OF PYREXIA (ORAL TEMPERATURE)

\begin{tabular}{lc}
\hline Attribute & Score \\
\hline $\begin{array}{l}\text { Maximum daily temperature }\left({ }^{\circ} \mathrm{C}\right) \\
36-37.4\end{array}$ & 0 \\
$37.5-38.4$ & 1 \\
$38.5-39$ & 2 \\
$>39$ & 3 \\
$<36$ & 3 \\
& Add \\
Minimum daily temperature $>37.5^{\circ} \mathrm{C}$ & 1 \\
If 2 or more temperature peaks above $38.4^{\circ} \mathrm{C}$ in & 1 \\
one day & 1 \\
If any rigours occur in a day & \\
\hline Temperature should be recorded at least 4 times in 24 \\
h. The record for the $24 \mathrm{~h}$ period is assessed as above \\
and 'pyrexia score' computed.
\end{tabular}

Elebute EA, Stoner HB. The grading of sepsis. Br J Surg $1983 ; 70: 29-31$
Table III: SCORING OF SECONDARY EFFECTS OF SEPSIS

\begin{tabular}{lc}
\hline Attribute & Score \\
\hline $\begin{array}{l}\text { Obvious jaundice (in the absence of established } \\
\text { hepatobiliary disease) }\end{array}$ & 2 \\
$\begin{array}{l}\text { Metabolic acidosis } \\
\text { Compensated }\end{array}$ & 1 \\
Uncompensated & 2 \\
Renal failure & 3 \\
$\begin{array}{l}\text { Gross disturbance of mental orientation/ level } \\
\text { of conciousness (e.g. delirium, coma) and/ or }\end{array}$ \\
$\begin{array}{l}\text { other focal neurological manifestations of } \\
\text { pyemia/ septicemia (having excluded other } \\
\text { causes) diathesis (from disseminated }\end{array}$ \\
$\begin{array}{ll}\text { Bleeding } \\
\text { intravascular coagulation) }\end{array}$ \\
\hline
\end{tabular}

Table IV: SCORING OF LABORATORY DATA

\begin{tabular}{lc}
\hline Attribute & Score \\
\hline Blood culture & 1 \\
Single positive culture & \\
Two or more positive cultures separated by & 3 \\
24 h & \\
Single positive culture + history of invasive & 3 \\
procedure & \\
Single positive culture + cardiac mumer and/ & 3 \\
or tender enlarged spleen & \\
& \\
Leukocyte count (x10E9/ L) & \\
$12-30$ & 1 \\
$>30$ & 2 \\
$<2.5$ & 3
\end{tabular}

Hemoglobin level in the abscence of obvious bleeding $(\mathrm{g} / \mathrm{dL})$

7-10

$<7$

Platelet count ( $\times 10 \mathrm{E9} / \mathrm{L})$

100-150
Plasma albumin level $(\mathrm{g} / \mathrm{L})$
31-35
$<25$

Plasma total bilirubin level in the abscence of clinically obvious jaundice

$>25 \mu \mathrm{mol} / \mathrm{L}$ 

Increased plasma levels of soluble tumor necrosis factor receptors in sepsis syndrome: correlation with plasma creatinine. A.H.M. Froon, M.H.A. Bemelmans, J.W.M. Greve, C.J. van der Linden, W.A. Buurman. Crit Care Med 1994; 22: 803-9

LPS toxicity regulating proteins in bacteremia. A.H.M. Froon, M.A. Dentener, J.W.M. Greve, G. Ramsay, W.A. Buurman. J Infect Dis 1995; 171: 1250-7

J.F. Leeuwenberg, A.H.M. Froon, L.M. Vaessen, A.J. Hoitsma, D. Abramowicz, J.P. van Hooff, W.A. Buurman. Soluble tumor necrosis factor-receptors are not a useful marker of acute allograft rejection: a study in patients with renal or cardiac allografts. Transpl Int $1995 ; 8: 459-65$

M.A. Dentener, G.J. Francot, F.T. Smit, A.H.M. Froon, H.J. Pennings, E.F. Wouters, W.A. Buurman. Presence of bactericidal/ permeability-increasing protein in disease: detection by ELISA J Infect Dis 1995; 171: 739-43

Increased concentrations of cytokines and adhesion molecules in patients after repair of abdominal aortic aneurysm. A.H.M. Froon, J.W.M. Greve, C.J. van der Linden, W.A. Buurman. Eur J Surg 1996; 162: 287-96

Treatment with the platelet-activating factor antagonist TCV-309 in patients with severe systemic inflammatory response syndrome. A prospective, multi-center, double-blind, randomized phase II trial, A.H.M. Froon, J.W.M. Greve, W.A. Buurman, C.J. van der Linden, H.J.M. Langemeijer, C. Ulrich, M. Bourgeois. Shock 1996; 5: 313-9

ICU admission criteria for patients with self-poisoning; reduction of admissions is possible. J.C. de Graaff, A.H.M. Froon, J.W.M. Greve, G. Ramsay. Clin Intensive Care 1996; $7: 236-41$

The systemic inflammatory response in the development of Ventilator associated pneumonia. M.J.M. Bonten, A.H.M. Froon, C.A. Gaillard, J.W.M. Greve, P.W. de Leeuw, M. Drent, E.E. Stobberingh, W.A. Buurman. Am J Resp Crit Care Med 1996; 156:1105-13

Primary definitive surgery in perforated peptic ulcer: is it necessary? J.W.M. Greve, S.Y.G. Peeters, A.H.M. Froon, P.B. Soeters. Dig Surg 1997; 14:521-6 
Prediction of clinical severity and outcome of ventilator-associated pneumonia. Comparison of simplified acute physiology score with systemic inflammatory mediators. A.H.M. Froon, M.J.M. Bonten, C.A. Gaillard, J.W.M. Greve, M.A. Dentener, P.W. de Leeuw, M. Drent, E.E. Stobberingh, W.A. Buurman. Am J Resp Crit Care Med $1998 ; 158: 1026-31$

D-Lactate as a marker for intestinal ischemia after abdominal aneurysm repair M. Poeze, A.H.M. Froon, J.W.M. Greve, G. Ramsay. Br J Surg 1998; 85:1221-4 
Indertijd ben ik aan dit onderzoek begonnen als 'opstapje' voor de opleiding chirurgie. Dat een en ander gegroeid is tot een boekje is te danken aan het geduld en de inzet van velen.

Mijn promotoren, prof.dr. P.B. Soeters en dr. C.J. van der Linden, wil ik bedanken voor de geboden mogelijkheden om dit proefschrift te verwezenlijken.

Dr. W.A. Buurman, beste Wim, jouw suggesties over de link tussen patiënt en experiment gaven soms meer stof tot nadenken dan me lief was. De afronding van dit werk is in belangrijke mate te danken aan jouw enthousiasme.

Dr. J.W.M. Greve, beste Jan-Willem, jouw motivatie en volharding, zeker tijdens de laatste loodjes, waren onmisbaar. De onwaarschijnlijke nauwkeurigheid die kenmerkend voor je is, is in dit boekje terug te vinden.

Op het lab waar ik regelmatig dreigde te verdrinken in het werk, kon ik altijd rekenen op een helpende hand van Gaby, Ingeborgh, Jet, Marc, Marian, Mieke, Monique, en Trudy. Bedankt hiervoor, ook voor jullie gezelligheid.

De studies zoals beschreven in dit proefschrift waren niet uitvoerbaar zonder de medewerking en inzet van de verpleegkundigen en coördinatoren van de afdeling intensieve zorg D3 en E3. Mijn dank. Met name de TCV-309 trial zal veel van jullie kostbare tijd gevraagd hebben.

De leden van de beoordelingscommissie te weten prof.dr. H.F.P. Hillen (voorzitter), prof.dr. H.J. ten Duis, dr. S. van der Geest, prof.dr. L.G. Thijs, en prof.dr. E.F.M. Wouters dank ik voor hun bereidheid het manuscript te willen beoordelen.

Alle assistenten en stafleden van de afdeling Algemene Heelkunde van zowel het Academisch Ziekenhuis Maastricht als van het Atrium Medisch Centrum te Heerlen dank ik voor hun tolerantie. Mijn betrokkenheid bij de afdeling heeft ongetwijfeld geleden onder mijn wetenschappelijke activiteiten.

Mijn paranimfen, René van der Hulst en Marc Bonten, dank ik alvast voor de steun tijdens de promotie.

René, je stond misschien aan de zijlijn van dit proefschrift, maar je was wel een trouwe supporter.

Marc, je bent me op onnavolgbare wijze voorbij gesneld, het leek wel alsof ik stil stond. Maar toch, ook ik heb de 'eindstreep' gehaald, mede dankzij jouw inzet.

Ten slotte, Solange, het boekje heeft veel energie en tijd gevraagd waardoor we ons veel hebben moeten ontzeggen. Bedankt voor je begrip en je geduld. Vanaf nu hebben we eindelijk weer eens tijd voor 'al het andere'. 

Albert Froon, geboren 12 februari 1963 te Utrecht

1975 - 1981 Atheneum-B, St. Bonifatius College te Utrecht

1981 - 1988 Geneeskunde aan de Rijksuniversiteit Utrecht

1988 - 1990 AGNIO algemene heelkunde, St. Elisabeth Ziekenhuis te Amersfoort

1990 - 1991 AGNIO algemene heelkunde, Academisch Ziekenhuis Maastricht

1991 - 1994 Wetenschappelijk onderzoek bij de vakgroep algemene heelkunde, Academisch Ziekenhuis Maastricht

1994 - 1997 AGIO algemene heelkunde, Academisch Ziekenhuis Maastricht, opleider Prof. Dr. G. Kootstra

1997 - AGIO algemene heelkunde, Atrium Medisch Centrum te Heerlen, opleider Dr. P.R.G. Brink 


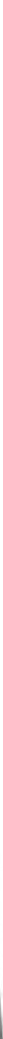

IS8N 90-9012941-3 